\title{
A spatial optimization approach to watershed water quality management: A case of the Opequon Watershed
}

\author{
Wilbert Karigomba \\ West Virginia University
}

Follow this and additional works at: https://researchrepository.wvu.edu/etd

\section{Recommended Citation}

Karigomba, Wilbert, "A spatial optimization approach to watershed water quality management: A case of the Opequon Watershed" (2009). Graduate Theses, Dissertations, and Problem Reports. 4481.

https://researchrepository.wvu.edu/etd/4481

This Dissertation is protected by copyright and/or related rights. It has been brought to you by the The Research Repository @ WVU with permission from the rights-holder(s). You are free to use this Dissertation in any way that is permitted by the copyright and related rights legislation that applies to your use. For other uses you must obtain permission from the rights-holder(s) directly, unless additional rights are indicated by a Creative Commons license in the record and/ or on the work itself. This Dissertation has been accepted for inclusion in WVU Graduate Theses, Dissertations, and Problem Reports collection by an authorized administrator of The Research Repository @ WVU.

For more information, please contact researchrepository@mail.wvu.edu. 


\title{
A SPATIAL OPTIMIZATION APPROACH TO WATERSHED WATER QUALITY MANAGEMENT: A CASE OF THE OPEQUON WATERSHED.
}

\section{Wilbert Karigomba}

\author{
Dissertation submitted to the Davis College of Agriculture, Natural Resources, \\ and Design \\ at West Virginia University \\ in partial fulfillment of the requirements for the degree of \\ Doctor of Philosophy in Natural Resource Economics
}

Agricultural and Resource Economics

\author{
Dissertation Committee: \\ Alan R. Collins, Ph.D., Chair \\ Michael P. Strager, Ph.D., Co-Chair \\ Tatiana Borisova, Ph.D. \\ Gerard D’Souza, Ph.D. \\ Calvin O. Masilela, Ph.D. \\ Morgantown, West Virginia \\ 2009
}

Key Words: Spatial Optimization, GIS, Water Quality, Best Management Practices, Watershed Management, Agriculture 


\section{ABSTRACT}

\section{A SPATIAL OPTIMIZATION APPROACH TO WATERSHED WATER QUALITY MANAGEMENT: A CASE OF THE OPEQUON WATERSHED}

\section{Wilbert Karigomba}

The Opequon Creek watershed is located in northern VA and the eastern panhandle of WV. Currently, the main creeks in the watershed do not meet VA or WV state water quality standards for recreational uses and aquatic life. In both states, the creeks are listed as impaired due to high levels of nutrients, bacteria, benthic and biologic impairment. The Opequon Creek is part of the upper Potomac River watershed, and ultimately impacts water quality in the Chesapeake Bay watershed. The main aim of this study was to develop a methodology that can be used to reduce nutrient loadings entering the bay area and improve water quality in Opequon watershed by implementing four innovative agricultural BMPs. The study develops an integrated approach to nutrient reduction incorporating three models involving water quality modeling, nutrient fate and transportation and an optimization model to recommend a least cost strategy for nutrient reduction.

Four optimization scenarios were evaluated, involving a uniform, holistic, prioritization, and targeted reduction approaches. A uniform reduction approach evaluated each subwatershed to meet a reduction goal. Using specific land use contributions, an annual cost of \$5.9 million would be required to meet $\mathrm{N}$ and $\mathrm{P}$ reduction goals on 14 of the 17 subwatersheds. The holistic approach is a scenario whereby the entire watershed's nutrient reduction strategy is evaluated to meet the nutrient reduction goal at the Opequon watershed mouth. However, no optimal solution was found for this approach using agricultural BMPs. When BMPs were implemented on all acres of crop and pasture land, a total cost of $\$ 19.3$ million was computed with only $43 \%$ of the reduction goal is achieved for $\mathrm{P}$ and $42 \%$ for $\mathrm{N}$. In the third scenario, a prioritization approach targets priority subwatersheds. High priority subwatersheds were identified using the WCMS nutrient levels and public participation prioritization exercise in watershed management. The same three subwatersheds were identified as high priority by both methods: Mill, Tuscarora and Middle Creeks. Using P as the only constraint, the total cost of BMP implementation for these three subwatersheds under the Chesapeake Bay values was approximately $\$ 1.1$ million compared to $\$ 282,000$ using specific land use specific values. This result showed that nutrient reduction costs are much lower under specific land use contributions than using the Chesapeake Bay wide averages. The final scenario involved a targeted approach where reduction goals are to be met for both the Virginia and West Virginia parts of the Opequon watershed. No optimal solution exists for these two points of evaluation. As with the second scenario, when BMPs were implements on all agricultural land, VA had $69 \%$ and $63 \%$ of reduction goals achieved for $\mathrm{N}$ and $\mathrm{P}$ while WV had $36 \%$ and $49 \%$ of reduction goals achieved for $\mathrm{N}$ and $\mathrm{P}$, respectively.

From a perspective of water resource policy, this study showed that: (1) P goals are more attainable at reasonable cost than $\mathrm{N}$ goals so that trading on the Opequon watershed is more likely to be feasible for $\mathrm{P}$ than $\mathrm{N}$; (2) compliance with WV and VA reduction goals across all subwatersheds is more achievable than meeting a holistic reduction goal for the entire watershed; and (3) local knowledge gives comparable information on priority subwatersheds as does watershed modeling. 


\section{ACKNOWLEDGEMENTS}

First of all, I would like to thank my advisor and co-advisor, Professor Alan R. Collins and Dr. Michael P. Strager for their outstanding guidance and invaluable support throughout my Ph.D. program at West Virginia University. Your guidance and help in all my studies, research papers and conference presentations are highly commendable.

Special thanks to my advisory committee members Drs Gerard D'Souza, Tanya Borisova and Calvin Masilela for providing me with useful comments, suggestions, and the stimulating discussions we had. I would like to express my deepest thanks to Dr. Tanya Borisova for her invaluable comments on both theoretical and empirical areas of my research. I am thankful to Drs. Gerard D'Souza and Tanya Borisova for teaching Quantitative Methods and guidance in optimization techniques and model development. My acknowledgements to Professor Calvin O. Masilela, external member of my advisory committee, mentor and colleague, for his counsel, encouragement, undying support and help during all the stages of my Ph.D. study. Thank you so much in believing in me.

Above all, this work would not have been possible without the undying support, sacrifice and encouragement of my wife Abigail. Thank you so much. I am also thankful to my son Anesu and my daughter Bethany for their patience and moral support throughout my study.

My sincere gratitude is expressed towards Tom Basden for providing research funding through the Mid-Atlantic Water Program.

Lastly, I am heavily indebted to all my friends during the Ph.D. program. Thank you for your help, support and encouragement. May God bless you all. 
To my wife Abigail, Anesu and Bethany for your support and trust in me. 


\section{$\underline{\text { Table of Contents }}$}

A Spatial Optimization Approach to Watershed Water Quality Management: A Case

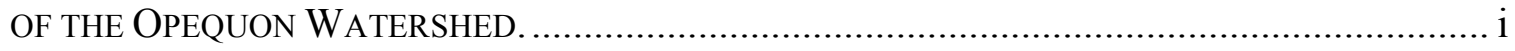

ABSTRACT ....................................................................................................... ii

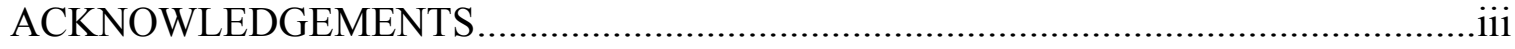

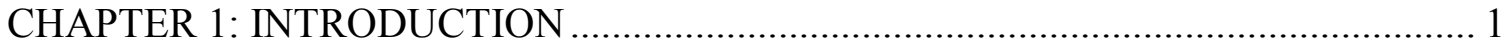

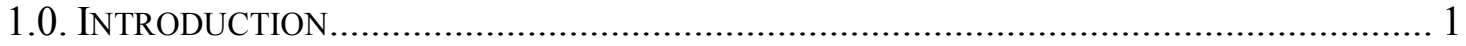

1.1. NutRIENT ISSUES IN THE CHESAPEAKE BAy WATERSHED .................................... 5

1.1. NutRIENT ISSUES IN THE CHESAPEAKE BAy WATERSHED ................................... 6

CHAPTER 2: RESEARCH OBJECTIVES AND CONTRIBUTIONS ......................... 14

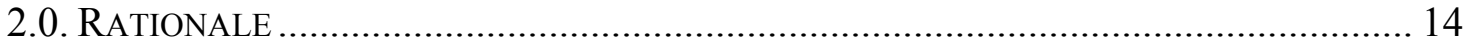

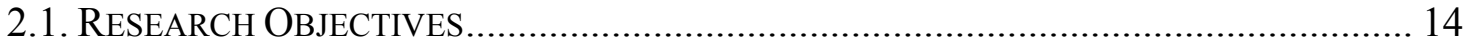

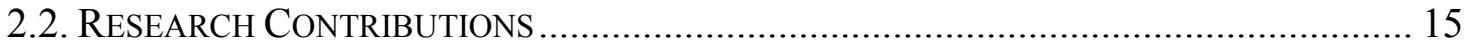

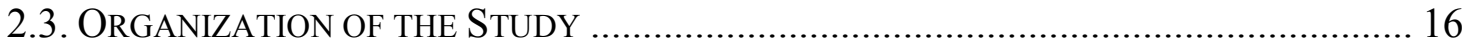

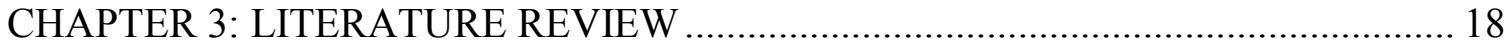

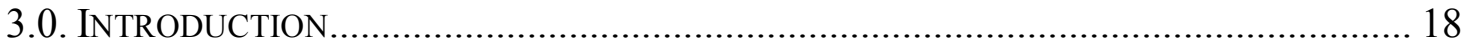

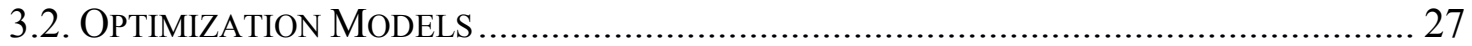

3.2.1. MATH PROGRAMMING ModeLS........................................................................ 29

3.2.1.2. LINEAR AND NON LINEAR OPTIMIZATION MODELS ........................................ 30

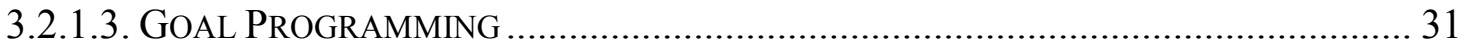

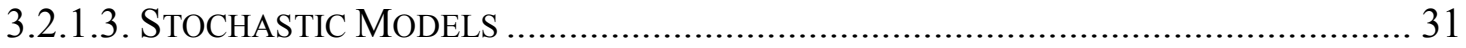

3.2.1.4. SPATIO-TEMPORAL AND DYNAMIC MODELS .................................................. 32

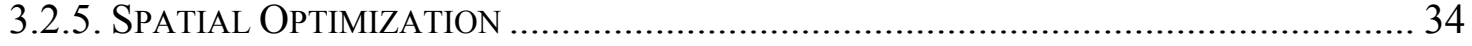

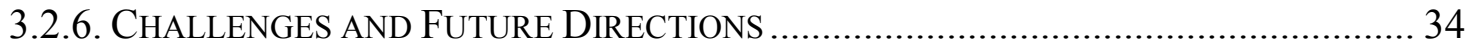

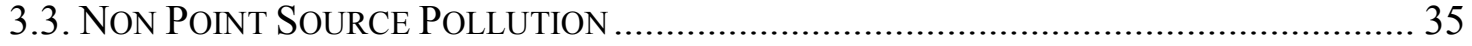

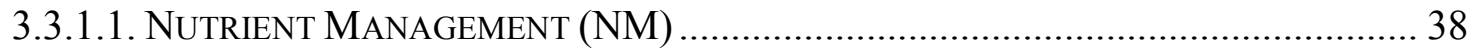

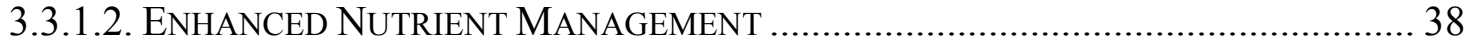

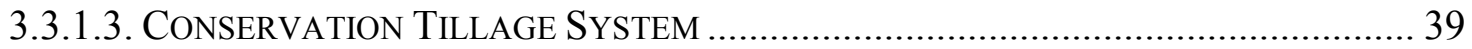

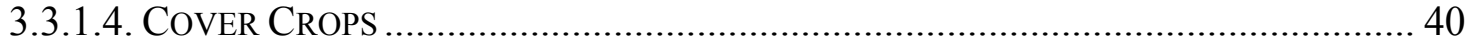

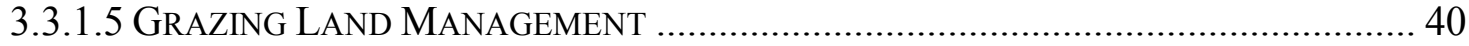

3.3.1.6. EFFECTIVENESS OF BeSt MANAGEMENT PRACTICES ...................................... 41 


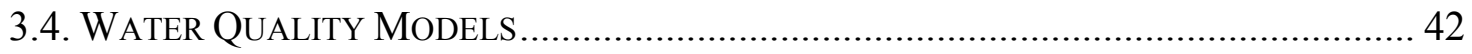

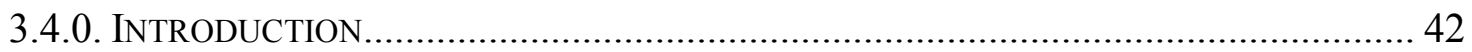

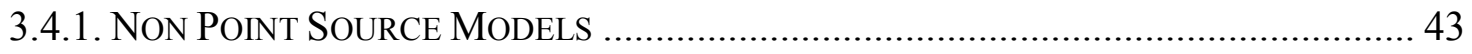

3.4.1.1 Ground Water Loading Effects of Agricultural Management Systems

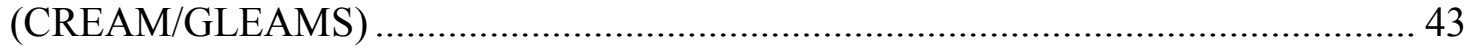

3.4.1.2 Agricultural Non-Point Source (AGNPS) ............................................ 43

3.4.1.3 Hydrological Simulation Program - FORTRAN (HSPF) ......................... 44

3.4.1.4 AREal Non Point Source Watershed EnVIronment Response Simulation

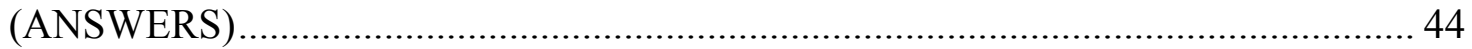

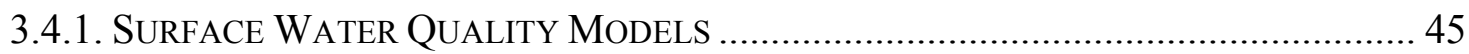

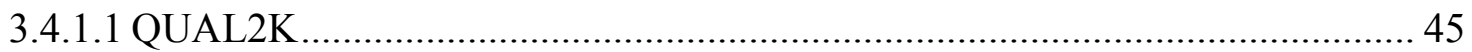

3.4.1.2 WATER QUALity ANALYSiS SimUlation Program (WASP).......................... 45

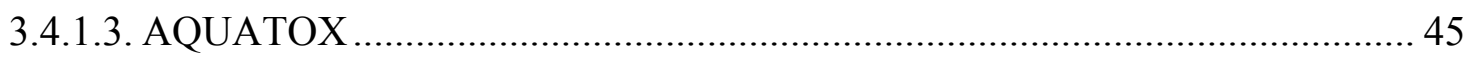

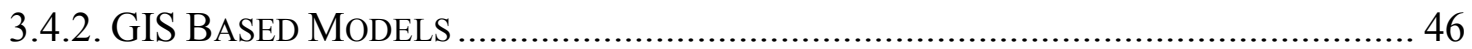

3.4.2.1 SoIL AND WATER ASSESSMENT ToOL (SWAT) ............................................. 47

3.4.2.2. WATERSHED CHARACTERIZATION AND MODELING SOFTWARE (WCMS) ........ 47

3.4.2.3. CORPUS Christi BAy NATIONAL ESTUARY PROGRAM MOdEL ...................... 48

3.4.3. Pollution Reduction Impact Comparison (PreDICT) Model..................... 48

3.5. Water Quality MaNAGEMENT ReSEARCh .......................................................... 49

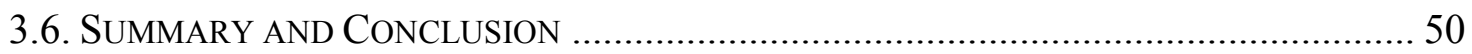

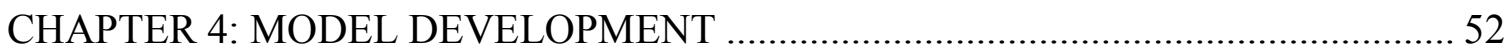

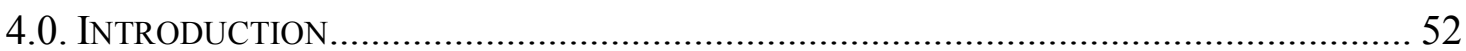

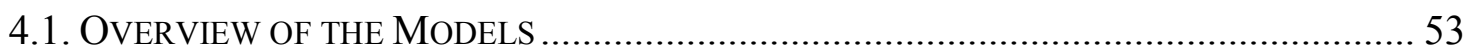

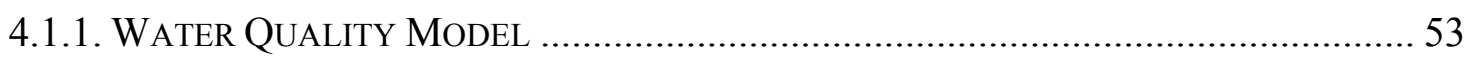

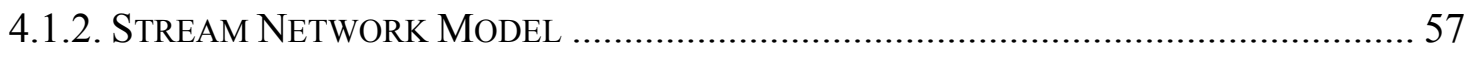

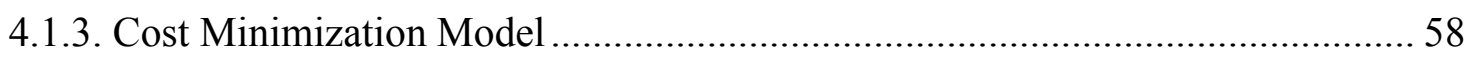

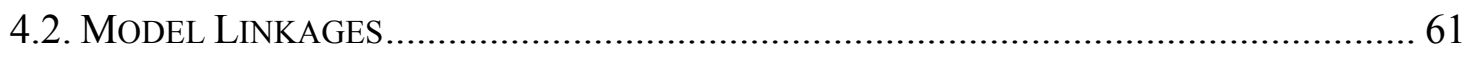

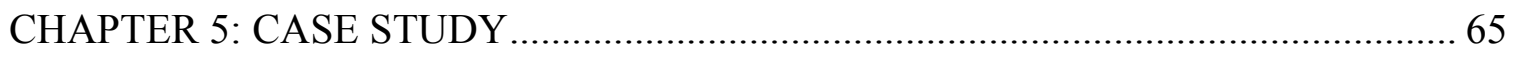

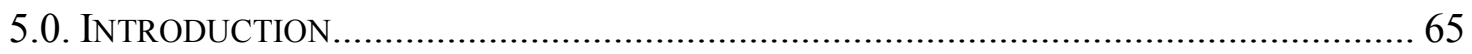

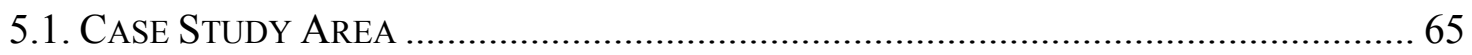

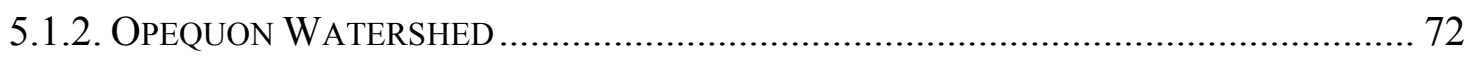

5.1.3. OPEQUON WATERSHEd WATER Quality MANAGEMENT ……............................ 73

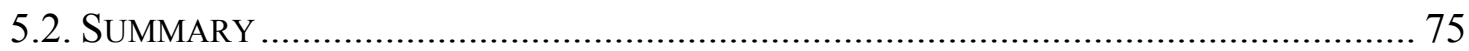

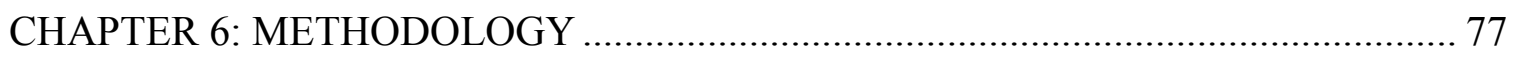

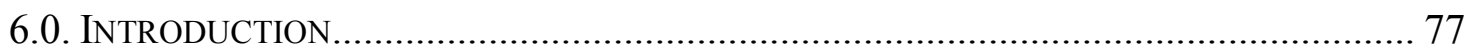


6.1. Watershed Quality Modeling and Optimization ................................................. 77

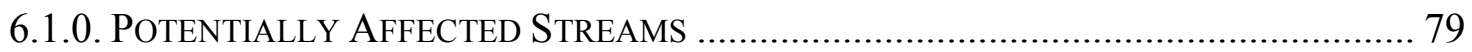

6.1.1. Nitrogen and Phosphorous Nutrient Simulations ………………………........ 82

6.1.2. Network Model and Nutrient Fate AND TRANSPortation ......................... 83

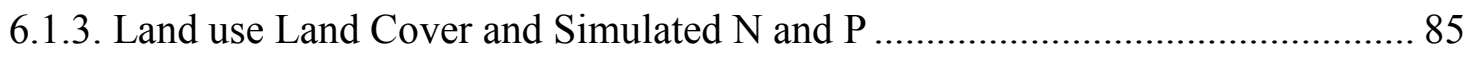

6.1.4. Cost Effective Nutrient Management Strategy …………………………….... 86

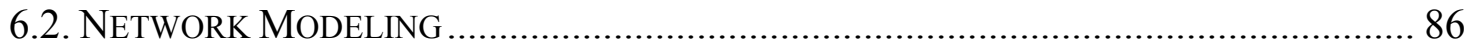

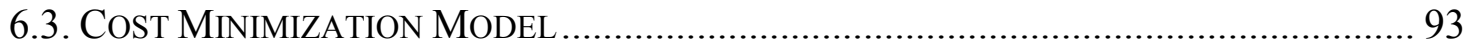

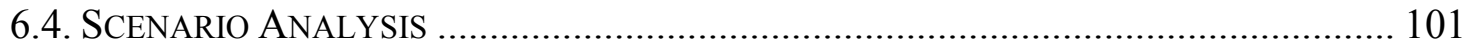

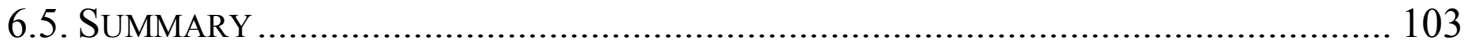

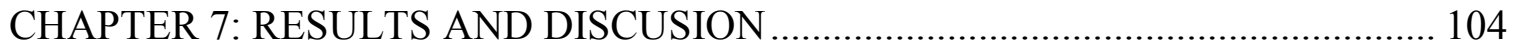

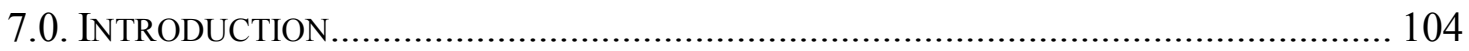

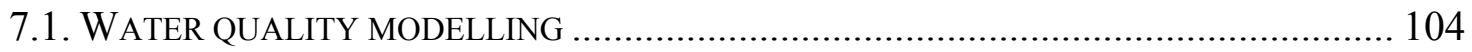

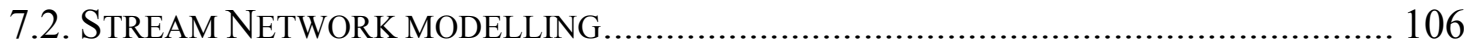

7.3. OptiMizATION AND LEAST Cost STRATEGY ………........................................ 108

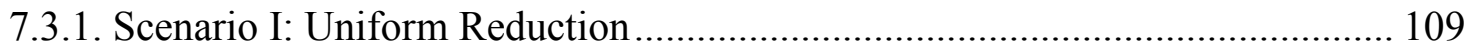

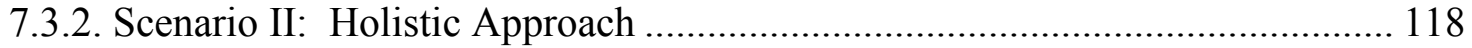

7.3.3. Scenario III: Prioritization Approach........................................................... 120

7.3.4. Scenario IV: Targeted Approach .................................................................. 122

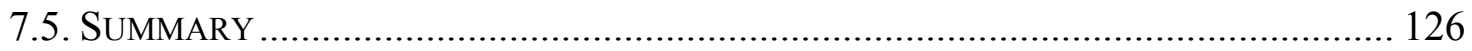

CHAPTER 8: CONCLUSIONS AND FUTURE RESEARCH ……………………..... 127

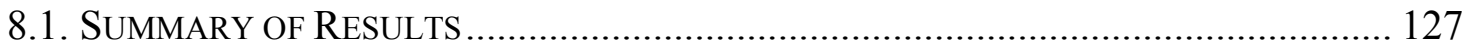

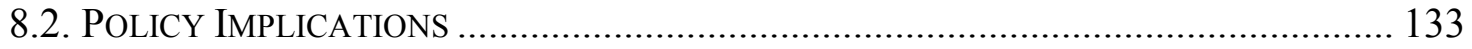

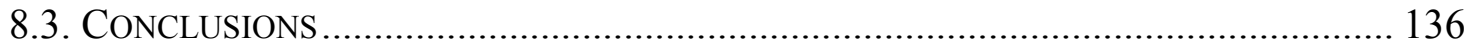

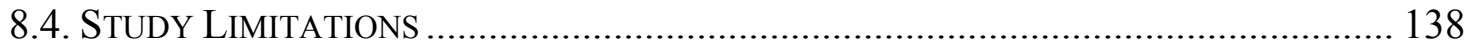

8.5. RECOMMENDATIONS FOR FUTURE RESEARCH ……........................................ 140

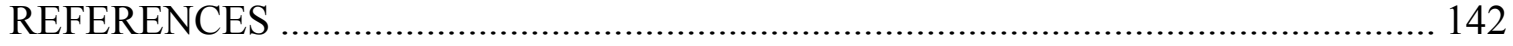

APPENDIX I: Opequon Creek Watershed Land Use and Subwatershed Characteristics 174 APPENDIX II: Agricultural BMP Efficiency Recommendations................................... 175

APPENDIX III: Opequon Watershed Land Use Classification ...................................... 179

APPENDIX IV - Data Required for WCMS …………........................................ 180

APPENDIX V: Results from Cost Minimization Modeling....................................... 182 


\section{List of Figures}

Figure 1: Subwatersheds of Opequon Creek Watershed ………………….............................. 58

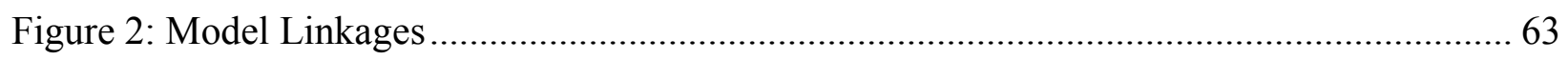

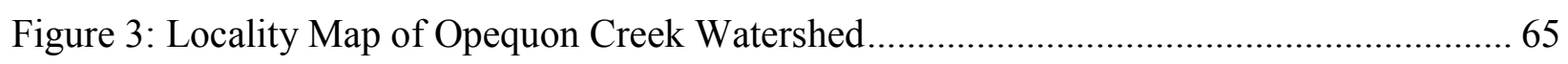

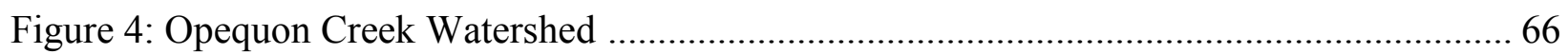

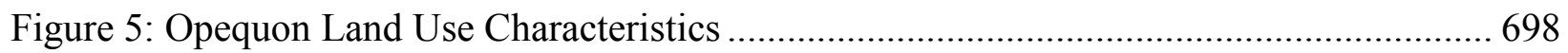

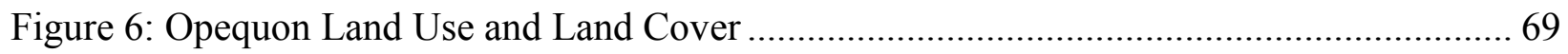

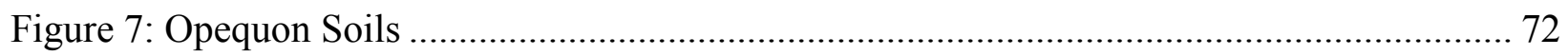

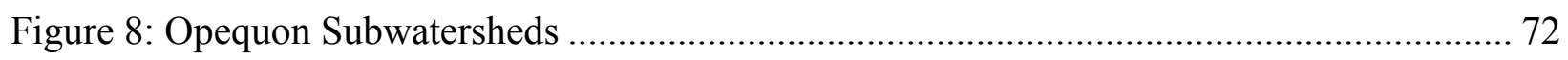

Figure 9a-c: Potentially Affected Streams from Different Land Use ......................................... 82

Figure 10: Modeled Nitrogen and Phosphorous Concentrations .................................................. 84

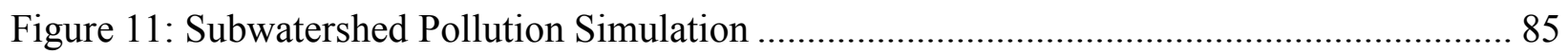

Figure 12: Land Use /Land Cover and Nutrient Concentrations ................................................5 585

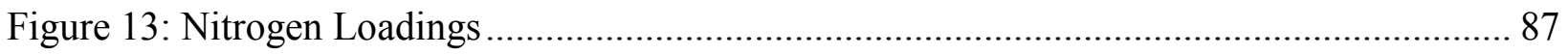

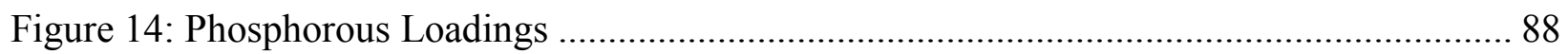

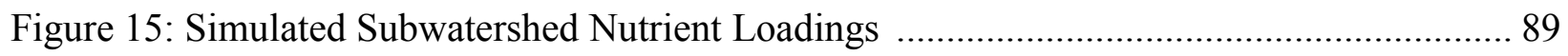

Figure 16: Distribution of Subwatershed Pour Points and Main Stem Sampling Points ............. 92

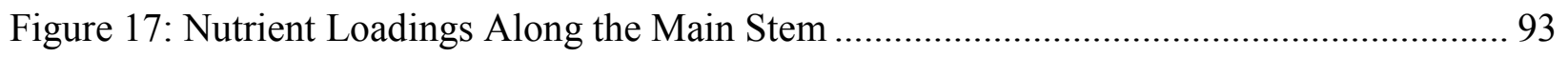

Figure 18: Subwatershed Phosphorous Loadings .................................................................... 105

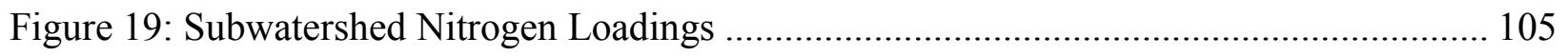

Figure 20: Opequon Creek Main Stem Nitrogen and Phosphorous Loadings............................. 107

Figure 21: Land Use Characteristics of Opequon Creek Watershed ......................................... 111

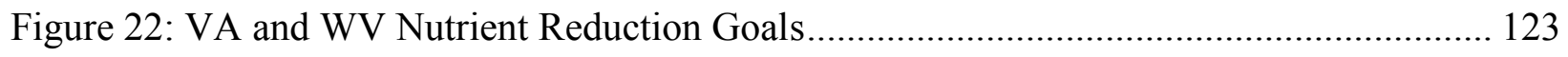




\section{List of Tables}

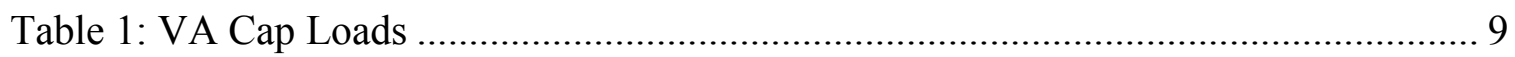

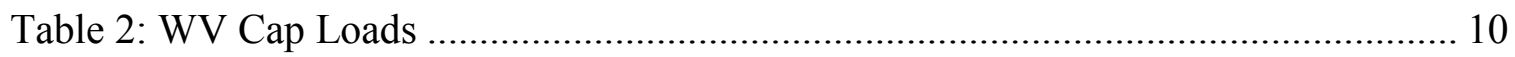

Table 3: WV and VA TN and TP Potomac Basin Cap Load Allocations for 2010 ......... 10

Table 4: Chesapeake Bay Area Average P and N Loads By Land Use........................... 11

Table 5: Nutrient Loads From Land Cover Type …………………………………........ 56

Table 6: Spatial Distribution of Nutrient Loadings and Subwatershed Coeffients .......... 91

Table 7: BMP Cost and Reduction Efficiences ............................................................. 99

Table 8: The Opequon Subwater Prioritization Matrix ................................................... 101

Table 9: VA and WV Chesapeake Bay Targeted Nutrient Reduction Goals ................. 103

Table 10: Chesapeake Bay Average Land Use Contributions......................................... 109

Table 11: Uniform Nutrient Reduction Chesapeake Bay Average Land Use Loadings 110

Table 12: Pasture Land Optimal BMP Implementation ................................................. 112

Table 13: Chesapeake Bay Wide Averages Optimal Solutions Under N and P Constraints

Table 14: Subwatershed Specific Land Use Nutrient Contributions ............................. 115

Table 15: Optimal Costs from Land Use Specific Loadings ......................................... 116

Table 16: Specific Land Use Loadings Optimal Solutions Under Separate N and P Constraints

Table 17: Opequon - Implementing all BMPs on Agricultural Land ........................... 120

Table 18: Top Three Priority Subwatershed BMP Implementation Costs ..................... 121

Table 19: WV - Implementing all BMPs on Agricultural Land ................................... 124

Table 20: VA - Implementing all BMPs on Agricultural Land .................................... 124 


\section{CHAPTER 1: INTRODUCTION}

\subsection{INTRODUCTION}

Water provides the basis of life on Earth and the foundation of all civilizations. Increasing global demand for fresh water supplies coupled with limited availability of clean water and an uneven spatial plus temporal distribution of water supplies often leads social and economic problems. These problems include: struggles over access and use of limited water resources, lack of access to safe drinking water and inadequate sanitation, low economic growth and agricultural productivity, (Shah, 2007; UNDP, 2006; NRC, 2000). Thus, a major management challenge for water resources is maintaining water quality to meet human, plant and animal life (Cosgrove and Rijsberman, 2000).

Increasing human populations and economic activities have continued to degrade existing water quality (Goolsby et al., 1999; Maybeck et al., 1989). Globally, many countries do not have standards to control water pollution and enforce water quality standards, resulting in few countries that have adequately controlled water pollution and managed water quality. The US, for instance, has been dealing with water pollution and water quality issues since the Industrial Revolution (Markham, 1994). The trends continued into the twentieth century resulting in the enactment of the 1972 Clean Water Act (CWA). The enactment of the CWA saw the rejection of practices that resulted in polluted lakes, rivers and coastal waters.

Section 303(d) of the Clean Water Act requires states, territories, and authorized tribes to develop lists of impaired waters that are too polluted or degraded to meet the water quality standards set by states, territories, or authorized tribes. The Clean Water Act requires all states, territories, and authorized tribes to develop lists of impaired waters, develop priority rankings 
and develop Total Maximum Daily Loads (TMDLs) for such waters. TMDLs are fundamentally a watershed based pollution control approach aimed at controlling pollution by setting the maximum amount of any pollutant, contaminant, or impairment that can enter a body of water before the quality of the water is deemed unfit for its designated uses (US EPA, 1991). Basically, it is a threshold, target, or upper limit of allowable pollution. Once a TMDL is developed, least cost strategies such as water quality trading can be implemented. The TMDL process requires that water quality standards be attained and maintained throughout the year.

Despite an increase in the number of waters that are safe for different uses like fishing and swimming (US EPA, 2007; Zhao, 2004; Boyd, 2000; Carpenter et al., 1998; Smith and Ribaudo, 1998), a number of rivers still do not meet water quality goals. A major problem has been attributed to the lack of water quality standards and effective controls and monitoring systems (Leinwand, 1990). Water quality problems have also been compounded by the difficulty in controlling and managing spatially diffuse and varied non point sources of pollution. As a result, a number of challenges and gaps still exist to successfully improve water quality.

One study estimated that drinking water of 50 million people in the US is potentially contaminated by agricultural chemicals (Liu and Hallberg, 2002). In a 1994 national water quality inventory study, about $40 \%$ of surveyed waters in the USA remained polluted for fishing, swimming and other uses (US EPA, 2007). In 2000, 45\% of assessed lakes were classified as impaired for one or more uses including swimming, drinking and aquatic wildlife (US EPA, 2000c). US EPA (2007) summarizes the water resources assessments conducted by the state governments. More than one-third of the river miles, lake acres, and estuary square miles were found to suffer some degree of impairment. The leading causes of impairment are attributed to silt, sewage, fertilizer, oil, grease and disease causing bacteria (US EPA, 2007). A number of 
studies have identified agriculture as a major contributor to pollution of the Nation's surface waters (Ribaudo et al., 1999; US EPA, 1998, 1994).

In order to meet this challenge, environmental protection agencies have placed high priority on water quality management practices and least cost strategies for the protection, improvement and management of streams, watersheds and costal waters' water quality. Such least cost strategies are aimed at improving the overall water quality given some constraints, including among others a desired or targeted water quality and limited resources. US EPA reports $(1990,1993)$ observed that costs of protecting and safeguarding water quality will continued to increase with time. As a result, it is logical that in designing water quality management programs, there is a need to ensure that the usage of available resources achieves the maximum environmental goal (Schleich and White, 1997). A least cost strategy to water quality management is not only important, but also vital in identifying and determining the optimal level of water quality protection to meet a desired level given certain limited resources.

For instance, in a 2004 report, the Chesapeake Bay Commission's had an estimated budget of $\$ 19$ billion earmarked for the Bay restoration efforts (CBC, 2004). The bulk of the budget was devoted to water quality attainment, particularly, efforts to reduce nutrient and sediment loads to the Bay by 2010 . The challenge was a three pronged strategy, vis-à-vis, where to focus available funds to achieve the most efficient use of resources, what control measures and management practices are both cost effective and widely applicable, thereby yielding potentially large nutrient reduction opportunities and lastly, which practices will deliver the largest nutrient and sediment load reductions at a least cost (CBC, 2004). 
Water pollution control programs have focused mainly on a large scale ecosystem restoration approach to water pollution management. Such large scale restoration approach had limited success in reducing water pollution levels (Frissell, 1997; Frissell and Bayles, 1996). These limited successes have triggered increased interest in comprehensive watershed based approaches to water quality protection and management (Potter, 2006; Borisova et al., 2005; Rao and Kumar, 2004; Haith, 2003; Nizeyimana et al., 1997; US EPA, 2001). These studies concur that watershed based analyses would lead to better targeting of limited financial resources and may likely result in significant restoration, maintenance and protection of water resources in the USA (US EPA, 2007).

Watershed based analyses, however, create a need for water quality modeling and optimization techniques that can be used to evaluate the spatial interactions and assess proposed best management practices (BMPs) within a watershed (Potter, 2006; Frissell and Bayles, 1997). BMPs are single or combinations of management, cultural and structural practices, identified by researchers as the most effective and economical way of minimizing environmental damage (Cestti et al., 2003; Alfera and Weismiller, 2002). A number of these BMPs are currently under consideration and evaluation as the most cost effective practices for nutrient reduction within the Chesapeake Bay Region (CBC, 2004). They include among others, conservation tillage, treatment of highly erodible land, stream bank protection, nutrient management planning, winter cover crops, waste management systems, forest and grass buffers (Cestti et al., 2003; Chesapeake Bay Program, 1994).

For such watershed-based management programs to be successful, there is a growing recognition by environmental protection and management agencies that clean water strategies built on this foundation need to be tailored to specific watershed areas and conditions. Clean and 
safe water is a by-product of a healthy well managed watershed. From this perspective, a watershed based approach helps in striking a balance among efforts to control point source pollution and polluted runoff and protect water sources. This approach also helps to identify the most cost-effective pollution control strategies to meet a target water quality level. A number of researchers concur that watershed-based management efforts have resulted in substantial reductions in water pollutants discharged in the last 20 years (US EPA, 2007; Potter, 2006; Borisova et al., 2005; Rao and Kumar, 2004; Haith, 2003; Schleich and White, 1997; US EPA, 1993). Lastly, a watershed approach allows for different stakeholders and watershed communities to participate in the restoration and protection of their water resources and provides a strong foundation to build community based partnerships. Local participation should lead to greater accountability of the community and stakeholders and more progress to meet the target water quality levels (US EPA, 1998).

\subsection{Nutrient ISSUES IN THE CHESAPEAKE BAy WATERShED}

The Chesapeake Bay is the United State's largest and most productive estuary, with a total area of $11000 \mathrm{~km}^{2}$, a watershed of $167000 \mathrm{~km}^{2}$ and a human population of over 15 million (Boesch et al., 2001). The bay area has been regarded as "the immense protein factory" (by H.L Mencken) because of its large fish industry. The Chesapeake Bay watershed has received a significant attention of many watershed based environmental management programs as a result of the declining water quality and aquatic life. A lot of intensive research conducted in the bay area focused mainly on eutrophication and efforts to reduce nutrients entering the watershed. There has been significant progress in controlling point source pollution since the passage of the Clean Water Act by Congress in 1970, owing to the relative ease of identification and control (Boyd, 2000; Carpenter et al., 1998). However, this success story has not been the same with non 
point sources of pollution. Scientific studies have confirmed that eutrophication caused by $\mathrm{N}$ and $\mathrm{P}$ is a common problem in the US lakes, rivers, estuaries and coastal oceans (including the CB watershed) (Boesch et al., 2001; Carpenter et al., 1998; Smith and Ribaudo, 1998).

\subsection{Nutrient IsSues IN THE Chesapeake Bay Watershed}

The Chesapeake Bay is the United States, largest and most productive estuary, with a total area of $11000 \mathrm{~km}^{2}$, a watershed of $167000 \mathrm{~km}^{2}$ and a human population of over 15 million (Boesch et. al., 2001). The bay area has been regarded as "the immense protein factory" (by H.L Mencken) because of its large fish industry. The Chesapeake Bay watershed has received significant attention of many watershed based environmental management programs as a result of the declining water quality and aquatic life.

Intensive research conducted in the bay has focused mainly on eutrophication and efforts to reduce nutrients entering the bay waters (Boesch et al., 2001; Nixon, 1995; Duarte, 1995). There has been significant progress in controlling point source pollution since the passage of the Clean Water Act by Congress in 1970, owing to the relative ease of identification and control (Boyd, 2000; Carpenter et al., 1998). However, this success story has not been the same with non point sources of pollution. Scientific studies have confirmed that eutrophication caused by $\mathrm{N}$ and $\mathrm{P}$ is a common problem in the US lakes, rivers, estuaries and coastal oceans (including the CB watershed) (Boesch et al., 2001; Carpenter et al 1998; Smith and Ribaudo, 1998).

Nutrients in the Chesapeake Bay have been studied extensively as environmental stressors in this ecosystem (Boesch et al., 2001; Nixon, 1995). A number of these studies have examined among others, sources of nutrients, simulations of biological activities, modeling of water quality, oxygen depletion and loss of vegetation (Davidson et al, 1997; Nixon, 1995; 
Malone et al., 1995). The research studies have indicated that both $\mathrm{N}$ and $\mathrm{P}$ entering the Bay come mainly from agriculture (Carpenter et al., 1998; Cooper, 1995; US EPA, 1995).

Consequently, in order to achieve the nutrient reduction goals, major reductions have to be met in nutrient transport from agricultural areas. It has been estimated that between 1990 and 1992, a total of approximately 30 million pounds of $\mathrm{P}$ and 600 million pounds of $\mathrm{N}$ entered Chesapeake Bay from its nine major tributaries of Susquehanna, the Potomac, and the James Rivers. Despite some concerted efforts to reduce nutrients over the past twenty years, annual loads of nutrients from point and non point remain a critical problem affecting the Chesapeake Bay.

Concerted efforts to reduce nutrients in the Bay area can be traced to the formation of the Chesapeake Bay Program (CBP) in 1983. The main goal was to restore the Bay waters from toxic pollutants and nutrients enrichment. Since its inception in 1983, the CBP's highest priority has been the restoration of the Bay's living resources by controlling and reducing excessive nutrient pollutants affecting water and aquatic life. The main goal the 1983 agreement was to reduce $\mathrm{N}$ and $\mathrm{P}$ by $40 \%$ by the year 2000 . In 1987 , the CBP and its tributaries agreed to achieve and maintain a $40 \%$ nutrient reduction goal. Currently, the Bay area has an annual load reduction target of 6.7 million pounds of $\mathrm{P}$ and 103 million pounds of $\mathrm{N}$ in order to meet the water quality standard set for the Chesapeake Bay and its tidal tributaries. The main goal being that by the year 2010, the Chesapeake Bay and its tributaries would be removed from the impaired waters list stipulated under the Clean Water Act. This goal was reinforced by recent mandate by President Obama's Executive Order on Chesapeake Bay Protection and Restoration that calls for a new accountability framework that guides federal, state and local water quality restoration efforts (EPA, 2009). The Executive Order includes components of the Chesapeake Bay Total Maximum Daily Load (TMDL), currently under discussion, that set pollution limits for point sources and 
nonpoint sources contributing nitrogen, phosphorus and sediment to the Bay and its tidal creeks, rivers and embayments (EPA, 2009).

After the 1987 agreement, the signatory states of Maryland (MD), Pennsylvania (PA), Virginia (VA) and the District of Columbia (DC), instituted phosphate detergent bans, that resulted in significant decreases in the amount of phosphorus entering the Bay from wastewater treatment plants. At the same time, wastewater treatment plants employed new technologies, such as nutrient removal technology, aimed at reducing N and P loads. Subsequently, a number of agreements between different states have been aimed at renewing the commitments to reduce all nutrient and sediment-related problems in the Bay. They include the Chesapeake 2000 and 2003 agreements aimed at improving water quality. The member states also agreed to “... correct the nutrient- and sediment-related problems in the Chesapeake Bay and its tidal tributaries sufficiently to remove the Bay and the tidal portions of its tributaries from the list of impaired waters under the Clean Water Act” by 2010 (Chesapeake Bay Agreement, 2000, p 6). These agreements included headwater states of Delaware (DE), VA, PA, MD, DC, New York (NY) and West Virginia (WV) and were aimed at instituting new, aggressive nutrient and sediment reduction goals to restore the Bay's water quality necessary to support the living resources of the Bay. By signing the Chesapeake 2000 Agreement, member states made a commitment to help remove the Chesapeake Bay from the federal Clean Water Act's list of impaired waters by 2010. To this effect, a number of the member states developed new scientifically approved water quality criteria, Nutrient and Sediment Reduction Tributary Strategies and best management practices aimed at reducing nutrients and sediments from non-point sources (Borisova et al., 2005). Successful and effective nutrient reduction strategies have been in the implementation of 
nutrient and animal waste management on agricultural lands, conservation-tillage and the use of fencing to keep livestock out of streams (CBC, 2004; Cestti et al, 2003).

However, challenges still exist to manage non point sources of nutrients especially from agriculture and urban areas. To meet these challenges, a number of states within the Bay area, in cooperation with the US EPA and the CBP have agreed to annual nutrient cap load allocations for different basins to meet the desired and agreed water quality standard. Achieving such basin nutrient cap load allocation will ultimately result in the improvements of water quality throughout the Chesapeake Bay watershed. WV and VA capacity loads or load allocations ${ }^{1}$ reported in the state tributary strategies utilized 1985 as a baseline, 2002 as progress and 2010 as the target year (Table 1).

Table 1: VA Cap Loads

\begin{tabular}{|l|l|l|l|l|}
\hline & $\begin{array}{l}\text { TN(lbs/Yr) } \\
\text { 1985 Baseline }\end{array}$ & 2002 VA Strategy & 2010 VA Strategy & Cap Load Allocation \\
\hline Potomac & $24,243,869$ & $22,844,023$ & $12,904,649$ & $\mathbf{1 2 , 8 3 9 , 7 5 5}$ \\
\hline & TP(lbs/Yr) & TP(lbs/Yr) & TP(lbs/Yr $)$ & TP(lbs/Yr $)$ \\
& 1985 Baseline & 2002 VA Strategy & 2010 VA Strategy & Cap Load Allocation \\
\hline Potomac & $2,312,229$ & $1,951,674$ & $1,120,665$ & $\mathbf{1 , 4 0 1 , 8 1 3}$ \\
\hline
\end{tabular}

\footnotetext{
${ }^{1}$ Load allocations are the portion of the allowable pollutant discharge attributed to existing and future non point sources to attain and maintain a set water quality standard (Novonty, 2002). Because nutrient loadings change due to ecological or meteorological reasons, load allocation are based on allowable discharges based on discharge limits for which TMDLs are established.
} 
Table 2: WV Cap Loads

\begin{tabular}{|l|l|l|l|l|}
\hline & TN(lbs/Yr) & TN(lbs/Yr) & TN(lbs/Yr) & TN(lbs/Yr) \\
& 1985 Baseline & 2002 WV Strategy & 2010 WV Strategy & Cap Load Allocation \\
\hline WV & $7,540,000$ & $7,150,000$ & $4,750,000$ & $\mathbf{4 , 7 5 0 , 0 0 0}$ \\
\hline & TP(lbs/Yr) & TP(lbs/Yr $)$ & TP(lbs/Yr $)$ & TP(lbs/Yr $)$ \\
& 1985 Baseline & 2002 WV Strategy & 2010 WV Strategy & Cap Load Allocation \\
\hline WV & 570,000 & 570,000 & 370,000 & $\mathbf{3 7 0 , 0 0 0}$ \\
\hline
\end{tabular}

Note: TN is Total Nitrogen, TP is Total Phosphorous and Cap Load is the capacity load.

Table 1 show that VA had to meet 5.7\% and a $16.6 \%$ reduction for TN and TP respectively from 1985 to 2002 loads. Table 2 shows that WV, has to only meet a 5.2\% reduction in TN loads for the same period. Table 3 below shows that VA has to meet $47 \%$ and $39 \%$ reduction in total $\mathrm{N}$ and $\mathrm{P}$ respectively, from the 2000 to 2010 . WV has to meet approximately $37 \%$ and $35 \%$ reduction in TN and TP respectively from the 2000 to 2010 loads.

Table 3: WV and VA TN and TP Potomac Basin Cap Load Allocations for 2010

\begin{tabular}{|c|c|c|c|c|}
\hline & \multicolumn{2}{|c|}{ Nitrogen (million lbs/yr) } & \multicolumn{2}{|c|}{$\begin{array}{r}\text { Phosphorus (million } \\
\text { lbs/yr) }\end{array}$} \\
\hline & $\begin{array}{l}2000 \\
\text { Progress }\end{array}$ & 2010 Cap & $\begin{array}{l}2000 \\
\text { Progress }\end{array}$ & 2010 Cap \\
\hline VA & 24.35 & 12.84 & 1.96 & 1.40 \\
\hline WV & 7.46 & 4.71 & 0.54 & 0.36 \\
\hline
\end{tabular}


Understanding these sources of nutrients is important for strategic targeting. Recent studies have called for spatially explicit watershed based models to better understand sources and stream monitoring and modeling of nutrients as well as realistically account for hydrological behavior in nutrient prediction (Potter, 2006; Borisova et al., 2005; Rao and Kumar, 2004; Haith, 2003; Nizeyimana, 1997; NRC, 1994).

The average total phosphorous and total nitrogen loads from different land uses in the CBR on a per unit basis are presented in Table 4 .

Table 4: CBA Average Phosphorous and Nitrogen Loads by Land Use

\begin{tabular}{|l|r|r|}
\hline Land Use & TP (lbs/acre) & TN (lbs/acre) \\
\hline Forest & .1 & 3.8 \\
\hline Pasture & .4 & 7.0 \\
\hline Livestock Operations & 409.5 & 2049.5 \\
\hline Conventional Tillage & 2.3 & 22.4 \\
\hline Conservation Tillage & 1.8 & 18.3 \\
\hline Hay & 1.5 & 9.8 \\
\hline Urban areas Business \& Residential & .8 & 9.9 \\
\hline Atmospheric Loads & .6 & 14.4 \\
\hline
\end{tabular}

(Adopted from: Cestti et al, 2003)

Most nutrients in the Bay area come from human activities (Boesch et al., 2001;

Carpenter et al., 1998; Cooper, 1995; US EPA, 1995). The major sources include surface water runoff, point sources (mainly wastewater treatment plants and industrial facilities) and from air 
pollution deposits. It is believed that the greatest contributors of nutrients are surface runoff from agricultural and urban areas (Boesch et al., 2001). These nutrients come from fertilizers, septic systems, boat discharges, and farm animal manure. However, other nutrients also come from a number of natural sources, including soil, plant material, animal waste and the atmosphere.

\subsubsection{Opequon Water Quality Problem}

The Opequon Creek watershed is located in northern VA and the eastern panhandle of WV. Throughout the watershed, rapid growth and development is being experienced due to growth from the Washington-Baltimore Metropolitan Area causing strains on the environmental resources. The VA portion of the watershed is approximately $22 \%$ urban, $30 \%$ agriculture and $48 \%$ forest while the $\mathrm{WV}$ portion is predominantly forest, with significant agriculture and a growing urban influence. In WV, the karst geology (limestone bedrock) makes it prone to rapid distribution of pollutants into groundwater and subsequently into surface waters from both urban and agricultural sources.

The Opequon watershed in WV currently suffers from water pollution due to high levels of $\mathrm{N}$ and $\mathrm{P}$ (WVDEP, 2005). Although substantial reduction of nutrient levels and the maintenance of water quality standards is a significant challenge, this is critical and necessary for the protection of water bodies. Currently, several creeks in the watershed do not meet VA and WV state water quality standards for recreational uses and aquatic life. In both states, concentrations of total $\mathrm{N}$ and $\mathrm{P}$ have exceeded EPA recommended values in nearly every sample in the past five years (VT CTMDLWS, 2006; WVDEP, 2005). In WV, the WV Tributary Strategy Stakeholders Group (WV PTS, 2005) assigned the highest priority ranking to the Opequon based on the significance of $\mathrm{N}$ and $\mathrm{P}$ impairment, the high level of $\mathrm{N}$ delivery to the 
Bay, watershed group activity and potential impact of pollution on local drinking water systems (WVPTS, 2005).

A number of critical issues are evident about nutrient pollution in the watershed as a whole. Firstly, practices that are known to be effective in reducing nutrient loads to streams are not being practiced and implemented. According to the DEP, the high levels of nitrates and fecal coliform in the Opequon are a result of livestock proximity to streams (WVDEP, 2005). In VA and WV, farmers' resistance to fencing streams is high (WVDEP, 2005). In addition, despite the fact that cover crops have been identified as one of the most cost effective nutrient reduction BMPs, there has been a low level of use by farmers (WVDEP, 2005). Moreover, there are issues pertaining to the growing urban impact on landscapes, stream hydrology and function, and storm water runoff. Increasing development around the Winchester, VA and Martinsburg, WV has resulted in an increasing demand for additional permitted waste load allocation. As a result, the Opequon wastewater treatment plant, operated by the Frederick-Winchester Service Authority (FWSA) is operating close to its design capacity.

The Chesapeake Bay headwaters, including the Opequon Creek watershed, contribute a significant amount of pollution and add to some of the water quality problems facing the Chesapeake Bay watershed. A number of strategies have been considered including comprehensive, watershed-based approaches, aimed at accelerating nutrient pollution reduction from priority watershed by incorporating both innovative and proven BMPs. 


\section{CHAPTER 2: RESEARCH OBJECTIVES AND CONTRIBUTIONS}

\subsection{RATIONALE}

Existing water quality studies in the Chesapeake Bay area have shown that sources of $\mathrm{N}$ and P entering the Bay area come mainly from agriculture (Carpenter et al., 1998; Cooper et al., 1995). As a result, policies and agricultural management practices aimed at reducing nutrient pollution from agricultural land have become the centerpiece for nutrient reduction and management strategies. It is from this perspective that this research is focused on agricultural best management practices that can be implemented in order to achieve the nutrient reduction goals for Opequon watershed. The focus on Opequon is also due to high priority of this watershed. The implementation of agricultural BMPs in the Opequon are especially important due to extensive farming in the watershed. The streams in Opequon watershed eventually empty into the Chesapeake Bay, ultimately affecting aquatic plants and animals and other environmental problems. In the Opequon watershed, a number of streams have been found to be impaired (i.e., not safe for drinking, fishing, or swimming), due to excess nutrients of phosphorus and nitrogen (VT CTMDLWS, 2006). Most nutrients are believed to emanate from agricultural lands, thereby affecting the water quality.

This research study utilizes a watershed-based management strategy as this approach provides a comprehensive strategy to identifying the most cost-effective pollution control strategies geared at meeting the targeted water quality level.

\subsection{RESEARCH OBJECTIVES}

The main objective of this study is to develop an integrated water quality management approach for the Opequon Creek watershed that will help watershed communities and other stakeholders answer water quality and management questions using the least cost strategy. More 
specifically, this approach will develop a water quality management framework that integrates optimization techniques, water quality modeling and GIS in an analysis of water quality management in Opequon watershed. The components of an integrated water quality approach includes a water quality model that simulates fate and transportation of nutrients within the watershed; a network model that simulates nutrient transportation from subwatersheds to the mouth of the Opequon creek and a cost minimization model that recommends the least cost strategy for pollution abatement by evaluating different agricultural best management practices (BMPs). This research is focuses mainly on agriculture land use and agricultural BMPs within the Opequon watershed. Additional research objectives include:

1. To evaluate $\mathrm{N}$ and $\mathrm{P}$ nutrient reduction goals for Opequon watershed using a comprehensive water quality management approach that includes stakeholder participation.

2. Examine and recommend least cost strategy and cost effective agricultural BMPs.

3. Recommend strategies to improve water quality in the Opequon Creek and its tributaries and draw policy implications from the research findings.

\subsection{RESEARCH CONTRIBUTIONS}

The research introduces some new research concepts in water quality modeling and management. The main focus of this study is the identification of cost effective agricultural BMP strategies for nutrient reduction to meet both the VA and WV Opequon Creek watershed water quality targets. The study integrates GIS techniques, water quality modeling and optimization techniques as a decision tool to identify applicable nutrient management strategies. In so doing, this research study contributes a new methodology of managing water pollution. The research advances existing knowledge in quantifying impacts of land use practices and evaluate the utility 
of different agricultural BMPs for water quality management in the Opequon Creek watershed. In this perspective, the research broadens the scope and understanding of scientific and economic issues of watershed water quality management and decision making practices.

Research results will provide science based information to environmental planners and policy analysts in targeting resources where they are needed most in the Opequon watershed, selecting cost effective agricultural BMPs in remediating water pollution to meet the water quality reduction target. This information is critical to environmental policy formulation, recommending BMPs to better protect the watershed, enhancing water quality and to improve the watershed natural environment. More generally, the research methods can be used by environmental planners, land use planners and resource managers to predict the potential sources and consequences of different land use practices and make informed management decisions and implement specific BMPs within any watershed.

\subsection{ORganization OF THE STUdY}

The study is organized into eight chapters. Chapter One set the stage for the study, providing the relevant background information. This Chapter indicates the research objectives and rationale for this study. Chapter Three is a literature review focused upon the theoretical/conceptual framework upon which this study is premised, with the key issues of optimization and water quality management being explored. By reviewing the various optimization techniques and best management practices and water quality modeling, the strengths and shortcomings of different techniques and models are discussed. Chapter Four discusses model development approaches and examines the linkages between the different models. Chapter Five profiles the case study area and water quality issues. Chapter Six is methods and Chapter Seven includes results plus discussion. Finally, Chapter Eight summarizes 
the findings, suggests, and recommends further studies and discusses them in the context of ongoing developments in the study area. This chapter discusses the research contributions, limitations, and future research directions based on the study's observations and findings. Also addressed here are the study's wider relevance and geo-spatial optimization research implication for others as well as its contributions to the existing state of knowledge. 


\section{CHAPTER 3: LITERATURE REVIEW}

\subsection{INTRODUCTION}

This chapter provides a literature review of water quality management, optimization models, non point source pollution, water quality modeling and a general overview of the Chesapeake Bay area nutrient best management strategies. Water quality management is reviewed in terms of tools, techniques and models used for surface water quality analysis. A number of agricultural BMPs used within the Chesapeake Bay are discussed and a reviewed. Lastly, literature review on water quality management optimization models is presented. The mathematical programming models include linear and non-linear approaches, deterministic and stochastic methods, as well as multi-criteria decision analysis techniques that have been utilized in water quality planning and management research. The chapter concludes by discussing water quality management issues and future research directions.

\subsection{WATER QUALITY, WATERSHED MANAGEMENT AND POLICIES}

Water quality management and pollution control are critical issues in watershed planning, management and policy formulation (Sadeghi et al., 2009; Li et al., 2008; Loucks and van Beek, 2005; Loucks et al., 1967). Water quality planning and management require the identification and evaluation of different alternatives in order to satisfying some economic and/or water quality goals. As a result, the effectiveness of any strategy is determined by how well these goals are met. The emphasis in this research is on mathematical models, the applications of GIS and public participation in the management of watershed water quality.

Resource economists view water pollution as an externality or residual generated by human production and consumption processes (Tietenberg, 2006; Freeman III, 2003a; Coase, 
1960). Residuals are an inevitable end product to a number of economic activities and when they are not accounted for in production or consumption decisions, the result is a misallocation of resources. Environmental and resource economists support cost effective policies that are geared towards maximizing society's net economic benefits and minimize costs (Tietenberg, 2006; Just et al., 2004; Freeman III, 2003a; Kolstad, 2000). In watershed management, resource economists would support policies that achieve the water resource objective at lowest cost or maximize societal net benefits at the same costs (US EPA, 1995a; Hanley, 1993)

Recent advances in technology and sophisticated mathematical programming software (e.g. GAMS, MATLAB, and QM for Windows 2) have facilitated the development of dynamic and optimization water quality and economic models (Ward, 2007). Over the years, these models have made it easier to routinely, reliably and consistently estimate how different water pollution cases can be minimized and managed in a cost effective way. Management of water quality programs based on cost effectiveness enables management programs and policies to achieve greater environmental outcomes at lower costs (Greenhalgh et al., 2006).

These aspects of water quality are usually relevant to environmental economists and other environmental scientists. It is estimated that the US spends more than $2 \%$ of GDP on pollution control, which is more than any other country (Greenberg, 1995; Carlin, 1992). It is therefore, imperative to develop policies that control and manage water pollution in a cost effective manner. Recent advances in computer technology have been utilized to develop economical solutions to a variety of water-quality problems (Popper et al., 2005; Kavanaugh et al., 2003; Shortle and Horan, 2001; Sasikumar and Majumdar, 1999, 1998; Shortle et al., 1998; Sasikuma et al., 1999; Lee and Wen, 1997, 1996; Funk, 1993; Schleich et al., 1997, 1996; Lee et al., 1993). 
These studies have examined issues of water pollution from both point and non point sources from different watersheds using a variety of mathematical and water quality models.

The fact that a number of aquatic ecosystems are under threat from nutrient over enrichment from both non point and point sources is well documented. Excessive nutrients in streams, rivers and lakes such as $\mathrm{N}$ and $\mathrm{P}$ are the main causes of water pollution in the United States, leading to significant water quality problems that affect both aquatic and non aquatic plant and animal life (Boesch et al., 2001; US EPA, 1996; Cestti et al., 2003; Carpenter et al., 1998). The sources of nutrient pollution has been attributed to excessive use of fertilizer, animal waste, urban area surface runoff, and discharge from waste treatment plants and overflows from septic systems.

The sources of nonpoint $\mathrm{N}$ and $\mathrm{P}$ pollution have been attributed to primarily agricultural and urban activities (Sharpley et al., 2001, 1997; Carpenter et al., 1998; Novotny and Olem, 1994). Research conducted in the Chesapeake Bay in the 1970s and 1980s also identified agriculture as one of the main culprits responsible for excessive nutrients and decline of the Bay's health (Cesti et al., 2003; Ribaudo et al., 1999; Chesapeake Bay Program, 1997). Scientific literature indicates that agriculture is the predominant source of nonpoint nutrient pollution in the U.S. (Boesch et al., 2001; Ribaudo et al., 1999; NRC, 1999; Chesapeake Bay Program, 1997; US EPA, 1996). If current practices continue, water pollution will continue to increase. However, this is not inevitable, as a number of mitigating strategies, technologies, land use practices and conservation measures are capable of reducing the amount of nutrients in water.

Water quality issues are increasingly being acknowledged as a central factor in water resource management and policy formulation. Information on tradeoffs among watershed water 
quality and quantity are critical in development of effective watershed conservation policies. A sustainable water quality management program involves water resource policy, institutional reform and financial resources. The increase in point and non point source pollution has been met with the introduction of regulatory policies and instruments together with institutional reforms, increased financial resources for water resource management and increased need for land use planning, let alone faster and efficient decision making techniques, all aimed at protecting and safeguarding water quality. As a result, the need for comprehensive water policy must ensure that the usage of available limited resources should achieve the maximum environmental goal.

The pattern and processes in the last two centuries pertaining to rapid population growth, economic expansion and urban development are critical in formulating future water resource policies and laws aimed at safeguarding water quality. Increasing population, urban developmental pressures, the lack of land use planning and increased demand for scarce water resources are not only contributing to the degradation of water resources but also affecting the available quantities of water (Deason et al., 2001; Vink, 1983). However, effective water policy involves a combination of environmental regulations, BMPs, land use planning, utilization of geospatial technologies and adoption of watershed based management strategies that can result in improved water quality (Randir and Tsvetkova, 2008; Deason et al, 2001).

Legislation establishing water quality standards has been the preferred approach. Water quality standards are the foundation of water pollution control programs mandated by the Clean Water Act (US EPA, 2009). These standards are important in that they define the goals for a water body by designating its uses, setting criteria to protect those uses and setting provisions to protect water bodies from pollution (US EPA, 2009). However, not all states have developed 
watershed water quality standards for water quality management, consequently making it difficult to recommend specific water quality management strategies and policies.

Resource economists have recommended market-based approaches such as nutrient pollution credit trading, as mechanisms to help meet water quality standards (US EPA, 2008; Tietenberg, 2006; Just et al., 2004; Freeman III, 2003a; Kolstad, 2000). The development of such a system has received a lot of support from environmental managers and policy makers. Water quality trading is a market based approach for reducing the costs of meeting the environmental goal of controlling pollution (US EPA, 2008; Blunk et al., 2006; Jarvie and Solomon, 1998). A well designed trading program allows for minimization of costs by trading in an open market by creating incentives for polluters to discover cheaper and more efficient methods of pollution abatement (US EPA, 2008; Just et al., 2004; Freeman III, 2003a; Kolstad, 2000). Environmental economists favor this policy in that society will be better off through trading due to reduced costs than if trade was not allowed. Consequently, a functional nutrient credit can result in an effective reduction of nutrient pollution costs regardless of the geographical scale of the area. This policy option provides a less regulatory platform for those capable of reducing nutrients to benefit from further reduction of non point source pollution and improves the cost effectiveness of compliance of watershed set targets.

Another policy option is the development of TMDLs for watersheds and different pollutants. TMDLs specify the amount of a particular pollutant in a water body and allocate allowable pollutant loads among sources, thereby providing a basis for attaining water quality standards (Boyd, 2000). TMDLs are directly linked to water quality trading in that by establishing a pollutant cap on a watershed, the TMDL acts as a driver for creating a market for water quality trading. The objective of TMDL program is the attainment of water quality 
standards through the control of point and non point sources of pollution. Under the TMDL regulations, the EPA requires all states to lists waters that do not meet water quality criteria for designated uses for various watersheds. If a water body exceeds the set TMDL, point sources may be required to reduce further beyond their prescribed permit. This has resulted in unfair penalties to point source polluters, while non point source polluting farmers have shown little interests in undertaking BMPs that can reduce water pollution. Trading would creates the possibility that point may be able to meet their pollution allotments from other point and non point sources as long as the overall amount of pollution in the water body meets the TMDL cap (Blunk et al., 2006).

However, the development and implementation of TMDLs have been fraught with a number of technical and political bottlenecks. Only recently the EPA started implementing the TMDLs requirements. Although meeting TMDL criteria has proved problematic (mainly due to the general paucity of reliable and accurate water quality data and information at the state level to set the water quality standards, determine impaired waters and develop TMDLs), the current TMDL policy has potential to regulate NPS if the aforementioned shortcomings addressed. In addition, the holistic watershed level analysis required by TMDL process will lead to the identification on unregulated pollution sources (Boyd, 2000). Thus TMDLs as a policy option will likely promote significant and desirable changes in water quality management (Boyd, 2000). It should be noted that TMDLs do not prescribe enforcement; rather they are planning tools that can be used to guide enforcement activities. TMDLs rules have rejuvenated the identification, prioritization and repair of polluted waters.

Genskow and Prokopy (2008) argued that in order to reduce environmental impacts of non point source pollution, the planning, implementation and evaluation efforts should focus on 
the most critical areas to improve water quality. However, the successful monitoring and management of non point source pollution must be derived from land use data rather than identifying specific polluters (KYE, 2004; US EPA, 1997, 2003b). The US EPA (1997) considers pollution from all sources to be important contributors to the pollution of nation's water bodies. Urban runoff is another major contributor to the pollution and impairment of rivers and streams. Rapid population growth and urbanization increases the demand for water resources, increases the volume and rate of surface runoff from impervious surfaces as well as the concentration of pollution. Sound land use planning policies including smart growth policies can be instrumental in controlling and managing water pollution. When growth is managed and smart, land use activities can be designed to have less impact on the hydrological systems. Land use planning such as watershed based zoning, smart growth and cluster development can be used in watershed protection that result in the improvement of water quality, while at the same time increasing the value of existing and developable land (Barrios, 2000). Recently, smart growth approaches have received a lot of attention in that they enhance neighborhoods and involve locals in the development process. These tools allow for the investment is open space and watershed protection from surface runoff that will improve water quality in the long run.

Despite significant progress in controlling point sources of pollution, non point source pollution especially from agricultural land has been problematic. It is well documented that agriculture is the single largest user and polluter of fresh water resources (Carpenter et al., 1998; Cooper, 1995; US EPA, 1995; FAO, 1993). There has been increased interest in agricultural proven conservation techniques or best management practices (BMPs) that can minimize water quality impacts as part of watershed based approach to water pollution control and management. 
There are different BMPs and the focus of this study has been on agricultural BMPs. Agricultural BMPs have proved to be effective in reducing nutrient pollution. For instance, the Chesapeake Bay Commission identified six top choice practices that can substantially reduce nutrients at a least cost. They include waste treatment upgrades, diet and feed adjustments, traditional nutrient management, enhanced nutrient management, conservation tillage, and cover crops (CBC, 2004). The Virginia Department of Conservation and Recreation identified nutrient management, forest and riparian buffers, stream bank fencing, cover crops and continuous no till as cost effective practices (VCN, 2009).

The costs of implementing BMPs can be a barrier to adoption. However, state and federal cost-share programs are available to assist farmers meet the BMP implementation costs. Federal grants of up to $60 \%$ of the costs of state management plans have been available to states to fund technical assistance, demonstration projects, implementation and monitoring of BMP initiatives. According to the WVDEP (2005), farmers in VA and WV have been resistant to stream fencing. Above all, despite cover crops being the most cost effective nutrient reduction BMP, there has been a low level of use by farmers (WVDEP, 2005).

BMPs became core policy instruments of the NPS program base on voluntarism and localism. According to Verweij (2000) voluntary or consensual programs are more effective than regulatory or adversarial approaches in watershed protection. Thus watershed based approaches that incorporate community participation in environmental or developmental projects are likely more successful than mere regulatory policies or instruments.

Agricultural BMPs have also been successful in addressing non point sources of pollution. However, the economic and water quality impacts of BMPs at a watershed scale are poorly understood especially in rural farming communities like Opequon watershed where 
farmers have been resistant to practices that are known to be effective in reducing nutrient loads to streams are not being practiced and implemented (Qiu, 2008; WVDEP, 2005). The WV DEP observed that the high levels of nitrates and fecal coliform in the Opequon is a result of livestock proximity to streams (WVDEP, 2005). Despite this, farmers in both VA and WV have been highly resistant to fencing streams and low levels of use of cover crops despite having been identified as one of the most cost effective nutrient reduction BMPs (WVDEP, 2005). Thus an integrated approach is important in understanding the economic and water quality impacts of agricultural BMPs in order to achieve water quality goals in a watershed. The evaluation of different BMPs to achieve a targeted water quality level is essential for watershed management strategy, water resource policy evaluation and formulation.

Equally important, is the significant recognition that successful watershed based programs for controlling and managing water pollution must engage stakeholder and form watershed based partnership. It has been established that for watershed management programs to succeed there is a need to engage communities and stakeholders (Darghouth, 2008; Gunawan et al., 2004; Leach et al., 2002; Duane, 1997). To this effect, watershed-based approaches to watershed protection and management have permeated the water resource policies. It has been observed for instance, that top down regulations of water resources on their own are not sufficient unless they are complemented by bottom approaches and stakeholder participation, together with adaptive management and market based approaches (Leach et al., 2002; GWP, 2000).

Watershed based approaches allows for an integrated systems approach that help decision makers engage in a broader scale analysis, decision making and community integration. The integrated watershed management approach in this study in premised on the concept that water 
quality issues are better understood and addressed at a watershed scale. Focusing on a watershed scale also helps in the identification of possible sources of pollution, evaluate different management practices and identify and recommend least cost strategy for pollution control and management to meet the desired water quality.

\subsection{Optimization Models}

Managing water quality is essential for sustainable water resources. Of critical significance is the fact that human usage of water has increased six-fold, while human population has increased three-fold, during the last century (Gleick, 2003; Cosgrove and Rijsberman, 2000). Unfortunately, such an increase in human population has been accompanied by an increase in water pollution, resulting in the degradation of water quality of many river systems (ERMITE Consortium, 2004; Kavanaugh et al., 2003). In order to sustainably manage water resources, there is a need to reconcile different land use practices with the natural environment. However, many studies have shown that uncertainties of complex environmental systems make it difficult reconcile different environmental demands given the difficulties in identifying all possible sources of pollution, reliably identifying costs and optimally allocate pollution abatement measures within watersheds, let alone make rational, concrete and cost effective decisions (Younger, 2003; Kavanaugh et al., 2003; Shortle and Horan, 2001).

One solution to these complex water quality management issues requires the use of optimization models to account for such conflicting environmental demands in a watershed. The utility of optimization techniques and models as tools for spatial decision analysis is well documented and recognized (Church, 2000, 1999; Malczewski, 1999). A number of optimization techniques and models have been developed for spatial decision making to manage water pollution and water quality management out of which linear programming has been widely used 
owing to its simplicity and applicability to different environmental problems (Sadeghi et al., 2009; Benli and Kodal, 2003; Amir and Fisher, 1999; Chang et al., 1995).

Onal et al (1998) utilized environmental impacts and income distribution goals in economic analysis of watershed management policies in a watershed using conventional programming and a chance constrained programming formulation. This study found out that farm costs increased notably by restricting agricultural pollution. Other researchers have also used advanced optimization models like stochastic optimization models using chance constrained optimization (Burn and McBean, 1985; Lohani and Thanh, 1979), interactive fuzzy interval multi-objective mixed integer programming (Chang et al., 1997) and robust optimization (Maeda et al., 2000; Mulvey et al., 1995). These models have demonstrated that using case study specific criteria, a least cost strategy of reducing water pollution is attainable by analyzing different land use patterns, agricultural activities and waste treatment options.

Randir et al., (2000) employed a watershed land prioritization model for water supply optimization through the integration of GIS, relations between land criteria and effects, as well as run off travel time in a watershed. Their research concluded that focusing on high priority areas in a watershed maximized benefits to water quality and would likely result in lower expenditures. The methodology can also be applied to different land protection and land use decisions by incorporating different criteria and weights. A linear programming watershed optimization model developed by Wang et al., (2004) specified the amount of land for each land use at a sub-watershed level. The study also utilized GIS-based spatial allocation model to recommend specific locations based on land use, slope, distance and conversion preferences (Sadeghi et al., 2009). In the following sections, some of the optimization techniques that have been used in water quality management in river systems are examined. 


\subsubsection{Math Programming Models}

Water quality studies can be traced back to the 1920 s, where water scientists and engineers used mathematical models to simulate fate transportation of pollutants in water systems (Chapra, 1996). Starting in the 1960s and 1970s, mathematical programming was applied to different environmental quality management problems, using linear programming (LP) models to solve dissolved oxygen (DO) problems from wastewater discharge (Sobel, 1965; Loucks, Revelle, and Lynn, 1967; Lohani and Thanh, 1978; Burges and Lettenmaier, 1975). For instance, Lynn et al., (1962) used linear programming models for wastewater treatment plant design.

More recently, other researchers have examined treatment strategies and costs of acid mine drainage (AMD), salinity problems and soil nutrient loading problems (Funk, 1993; Lee, Howitt, and Marino, 1993; Schleich, White, and Stephenson, 1996). A number of these studies used either deterministic or chance-constrained static linear programming models to estimate minimum costs of attaining a desired level of water quality improvement (Agha, 2006; Funk, 1993; Ali, 2002; Sobel, 1965; Loucks, Revelle, and Lynn, 1967; Lohani and Thanh, 1978).

Recent environmental management models that were developed and applied to different environmental management applications have incorporated mathematical programming applied to decision making and planning in order to minimize costs subject to quality standard constraints (Greenberg, 1995; Ahlfeld, 1990; Agha, 2006). However, other studies used the models for policy analysis and the mathematical model for environmental and economic impacts (Greenberg, 1995). There are different mathematical programming models. The following section reviews some of the mathematical programming models used in water quality modeling. 


\subsubsection{LiNEAR AND NON LINEAR OPTIMIZATION MODELS}

One class is of mathematical programming models is a linear programming (LP) model. Using LP, a water quality modeling problem is set up as either maximizing or minimizing a linear function subject to linear constraints. These constraints can be equalities or inequalities (Anderson et al., 2008). Equality constraints are restrictions that limit the value of the objective function to an exact or equal a given value. An inequality constraint is where the decision variables have to be less or equal to or greater than or equal to the given value. In other words, they set up limits on the objective function.

When a LP model has uncertain parameters, it is called a stochastic program, otherwise if it is certain; it is a deterministic program. Some researchers have argued that effective management of water quality should involve a balanced mix of deterministic and stochastic concepts (Ward and Loftis, 1983). Linear optimization methods are often limited in watershed management mainly due to a large number of variables and/or relationships to be optimized. To this effect, most LPs have often been criticized as failing to address stochastic water quality problems and ignore some spatial relations between places. Linking such models to a GIS system would allow for the analysis of spatial variations (Malczewski, 1999; Agha, 2006; Jankowski, 1995).

Another class where there is a restriction on the variables to have integer values is called integer program. If the program in linear and some of the variables have to be integers is called mixed integer program (MIP). Dynamic program (DP) has the added dimension of time and the addition of state variables. DP allows one to break up a large problem in a way that once all the smaller problems have been solved, one is left with an optimal solution to the larger problems 
(Anderson et al, 2008; Greenberg, 1995). It is a way of solving problems where you need to find the best decisions one after another.

\subsubsection{Goal Programming}

Goal programming basically is a modification of conventional LP. Unlike a primal LP model which focuses on optimal allocation of a scarce resource to meet a given set of objectives, goal programming seeks a plan that comes close as possible to attaining specified goals (Loganathan and Bhattacharya, 1990). A number of researchers have applied goal programming in optimal water quality management (Loganathan and Bhattacharya, 1990; Sasikumar and Majumdar, 1998; Lee and Wen, 1996, 1997). For instance, Lee and Wen's (1996) study involved obtaining optimal analysis of assimilative capacity (allowable pollution loading) and treatment cost of wastewater based on models and standards of water quality, as well as an equitable removal of wastewater in a river basin. Loganathan and Bhattacharya (1990) used five goal programming schemes (preemptive goal programming, weighted goal programming, min-max

goal programming and fuzzy goal programming) that minimize deviations from a set of preferred reservoir flow values based on forecasted inflows and precipitation. These formulations involved a number of objectives like minimizing costs, risk, and deviations from targets or goals.

\subsubsection{STOCHASTIC MODELS}

A number of environmental studies have utilized chance constrained programming and first-order uncertainty analysis approaches to incorporate variability into the modeling framework. For instance, Lohani and Thanh (1978) adopted a chance-constrained programming framework to minimize total operating costs of biochemical oxygen demand (BOD) removal by determining the degree of removal required at each treatment facility without violating DO standards. Others like Liebman and Lynn (1966) have used a discrete inter-temporal dynamic 
programming approach, introduced by Bellman (1957) and Aris (1961), to determine the amount of BOD removal for each waste discharger such that DO concentration standards would be met at minimum total cost of waste treatment. However, others have used deterministic mixed integer linear programming. For instance, Funk (1993) used a deterministic mixed integer linear programming (MIP) model to analyze acidity problems in the Middle Fork River watershed in West Virginia. The focus of his study was to find a least-cost solution to neutralize acidity within a spatial water quality model, using a spatial dynamic model.

\subsubsection{SPATIO-TEMPORAL AND DYNAMIC MODELS}

Similarly, other water quality studies have advanced spatial dynamic modeling to incorporate inter-temporal variables (Ali, 2002; Markris, 2001; Greiner and Cacho, 2001; Funk, 1993; Opaluch, 1982; Liebman and Lynn, 1966). For instance, Funk (1993) analyzed acidity problems in the streams of Middle Fork River watershed in West Virginia using a deterministic mixed-integer linear programming (MIP) model. The main aim of the study was to find a leastcost solution to reduce stream acidity. The study utilized four data points to estimate the minimum treatment cost. Ali (2002) adopted Funk's model and developed a stochastic cost minimization MIP model to solve for the location and maximum capacity of treatment plants to be built throughout the watershed that will provide the optimal level of treatment throughout the year for the AMD treatment plants in the Paint Creek watershed in West Virginia. Ali used water quality constraints, mass-balance conditions on the state of water quality transition equations, treatment technology capacity constraints, technology selection constraints, and non-negativity conditions on the choice variables. To minimize costs, the model utilized a spatial network of streams in the watershed. The model also incorporates inter-temporal variations in stream 
conditions into the management process through the statistical distributions of pollution loadings. Thus, Ali's model was both a spatial and dynamic optimization model.

Liebman and Lynn (1966) used discrete dynamic programming approach, introduced by Bellman (1957) and Aris (1961), to investigate DO problems. The main focus of their study was to determine the level of BOD removal for each waste discharger such that DO concentration standards would be met at minimum total cost of waste treatment. Opaluch (1982) used a dynamic framework to find the optimal method of achieving water quantity and quality standards to the Upper Santa Ana Watershed, located in Southern California. The study examined the supply of pollution-disposal services by minimizing the cost of achieving the standards with various quantities of pollution generated. Greiner and Cacho (2001) employed an optimal control approach which utilized a dynamic catchment optimization model for water salinity control and management. The results of their model indicate that it was economically efficient to restrict soil salinization to only a fraction of the area at risk. The dynamic catchment optimization model can be used in catchment management plans for determining land use patterns and associated rates salinity and in the identification of areas within the catchment where land use changes could be most efficiently implemented to control salinity concentration levels.

It should be pointed out that, although some of the above mentioned studies are not directly relevant to the nutrient pollutant reduction problem investigated in this study, they deserve special attention as they contribute significantly to the body of scientific knowledge pertaining to water quality management through the application of different mathematical programming and optimization models. 


\subsubsection{SPATIAL OPTIMIZATION}

There are a number of research studies that have emphasized spatial issues and multiple criteria decision analysis when dealing with water quality management issues (Hof and Bevers, 2000; Malczewski, 1999; Prato, T., 1999; Munda, Nijkamp and Rietveld, 1994; Munda, 1993). Hof and Bevers (1998) defined spatial optimization as a methodology used to maximize or minimize a management objective, given the limited area, finite resources, and spatial relationships in an ecosystem. When spatial objectives are included in an optimization, the objective function is no longer a linear combination of decision variables. In this case, one can use IP and MIP to solve for such problems, although such problems are very complex in reality (Murray and Church, 1995; Bettinger et al., 1999). The major weakness in this area of study is that although most applications of optimization approaches are location based, most of the optimization approaches are not spatially explicit and consequently do not address spatial relations and interactions (Church et al., 2000; Randhir et al., 2000, Seppelt and Voinov, 2002; Nevo and Garcia, 1996). Spatially explicit approaches consider spatial location, distribution and interrelationships and dynamics in geographical space.

\subsubsection{Challenges and Future Directions}

Research has shown that a number water quality studies tend to ignore the spatial relationships. Available literature has shown that a number of studies have used optimization and spatial analysis techniques to different application areas. Hof and Bevers (2000) have argued that adaptive management processes that utilize spatial relationships and optimization methodology are likely to be effective in learning about ecological systems and their management.

Although the integration of analytical and optimization models into GIS has emerged as a promising research area attracting planners and other resource managers, a number of challenges 
still exists. Traditionally, GIS can only perform four basic functions on spatial data; vis-à-vis data input, storage, analysis and output (Burrough and McDonnell, 1998; Goodchild et al., 1992; Burrough, 1990). The analytical components of GIS have not been fully explored in most GIS software packages. Moreover, traditional optimization problems are non-spatial in nature. In addition, a big gap still exist in spatial analysis and modeling pertaining socio-economic data, temporal and three dimensional data (Clement and Thas, 2007; Steinberg and Steinberg, 2006; Goodchild, 2004; Raper, 2000). Most data stored in GIS are static, yet the real world is dynamic. The ability of GIS systems to model data in real time is still a technical challenge.

Raper (2000) argues that GIS could be made multi-dimensional, based on modeling limitations of current two-dimensional GIS and suggests the extension of GIS to incorporate the third dimension, 3D GIS, and spatio-temporal GIS. Steinberg and Steinberg (2006) also pointed out that until socioeconomic data is incorporated in most GIS analysis, most research will be missing a number of important variables in their analysis. Thus advancing the research agenda for the integration of optimization techniques and spatio-temporal GIS may dominate GIS research applications in the near future. This research does not account for spatio-temporal variations.

\subsection{Non Point Source Pollution}

Non-point source pollution (NPS) has been identified as the major contributor to pollution of water resources in the US. NPS pollution from agricultural activities contributed to $72 \%$ of the impaired stream miles in 48 states reporting sources (Yagow, 1999). Despite numerous efforts to combat and reduce agricultural NPS pollution, a challenge still remains (Ma and Bartholic, 2003; Yagow, 1999). Instead of instituting restrictive legislation or regulatory policies, the use of BMPs has proved to be more effective in reducing NPS (Cestti et al., 2003; CBC, 2004). BMPs 
are a practice or combination of practices that are determined to be the most effective economically practical means of controlling or mitigate point and non-point pollutant levels compatible with environmental quality goals (Cestti et al., 2003; CBC, 2004; Gale et al., 1993; US EPA, 1993). BMPs are basically pollution prevention practices.

Agricultural BMPs are voluntary although in some states they are mandatory. An innovative aspect of many agricultural BMPs is that they address non point sources of pollution, such as runoff from agricultural lands. In addition, BMPs are site specific and therefore vary from place to place according to the nature and source of pollution. A number of BMPs have been in use as they are considered both environmentally and economically sustainable (Cestti et al., 2003; CBC, 2004). An integration of regulatory policies and BMPs can also be applied to nutrient management.

Water pollution can be cost effectively minimized and managed from non point sources of pollution by adopting and applying land use specific non point source BMPs to meet a specified or targeted water quality standard (Veith et al., 2003; Wossink and Osmond, 2002; Stanley, 2000; Novotny and Olem, 1994). Agricultural BMPs ensure that agricultural practices are carried out in a way that protects water quality from non point source pollution. The experiences in the CBW of applying BMPs for controlling non point source pollution are particularly relevant for this study. The following section describes the agricultural water pollution management BMPs that were considered in this research as they relate to and recommended for the Chesapeake Bay area.

According to the Chesapeake Bay Agreement of 2000, the Bay states and the District of Columbia will implement BMPs in order to minimize water pollution from nutrients and 
sediments. A number of BMPs have been implemented in the CBW. The list of BMP types ranges from planting new riparian forest buffers, upgrading sewage treatment plants, farm nutrients management to storm water runoff management (CBP, 1994). Although farmers have the option of using structural or management practices, good farm management is key to successful nutrient reduction. For the purpose of this study, the following BMPs are examined, nutrient management (NM), enhanced nutrient management (ENM), conservation tillage (CT), cover crops (CC) and Grazing Land Management (GLM)

\subsubsection{CBA Best Management Practices}

States and federal agencies in the Bay area agreed in 1987 to work together with the local farmers to develop and implement site specific "total resource management plans" composed of BMPs aimed at reducing nutrients, sediments and pesticides from polluting the water quality in the watershed (Cestti et al., 2003). In 1982 tributary strategies were adopted for meeting specific levels of $\mathrm{N}$ and $\mathrm{P}$ in the Bay area. Of importance to this study is the adoption of relevant BMP combinations to address agricultural non point pollution.

BMPs vary tremendously in their effectiveness, costs and longevity. There are a number of BMPs that resource managers can choose from in order to achieve the desired goals and targets. The selection of BMPs represents a classical investment problem where one evaluates different alternatives with varying costs and characteristics. The following sections describe the different agricultural BMPs that can be adopted for nutrient reduction and management. 


\subsubsection{NUTRIENT MANAGEMENT (NM)}

Nutrient management involves the use of BMPs that permit a land use activity while controlling non point source water pollutants. According to the USDA, nutrient management is "managing the amount, source, placement, form, and timing of the application of nutrients and soil amendments to ensure adequate soil fertility for plant production and to minimize the potential for environmental degradation, particularly water quality impairment" (Ribaudo et al., 1999). In short, it is a system of management measures, which provides recommendations on optimum rates, times, and application methods of nutrients based on soil and manure analysis results and expected crop yields (Cestti et al., 2003; CBC, 2004).

Common structural NM practices include waste storage structures, diversions, and fencing for livestock exclusion. Other nutrient management practices are nonstructural. Examples of these practices are planned grazing systems and spreading waste on agricultural fields. Nutrient management plans (NMPs) are the most widespread management practice currently in use in the Chesapeake Bay watershed for the control of N and P. This BMP prescribes the use and timing of nutrients in manure or commercial fertilizer to reduce or eliminate excess application while assuring no loss of yield (Ribaudo et al., 1999).

\subsubsection{ENHANCED NUTRIENT MANAGEMENT}

Enhanced Nutrient Management (ENM), also referred to as "yield reserve," provides no less than $15 \%$ further reduction in $\mathrm{N}$ applied to cropland beyond traditional NM, thereby maximizing the efficiency of $\mathrm{N}$ use (CBC, 2004; Cestti et al., 2003). A number of studies indicate diminishing crop response to increasing rates of nitrogen application, while others have reported exponentially increasing rates of nutrient loss as nutrient application rates increase. In 
short, agricultural yield reserve programs are intended to provide incentives to farmers who apply $\mathrm{N}$ and $\mathrm{P}$ at levels below their recommended rates. This BMP is not recommended in areas where manure and land applied sewage sludge nutrients exceed utilization capacity of the land at rates appropriate for NM planning as this results in excess nutrients. Research has revealed that implementing ENM on all row crops and hay acreage would significantly reduce nitrogen runoff better than traditional NMPs (CBC, 2004; Alfera and Weismiller, 2002; Ribaudo et al., 1999). According to the $\mathrm{CBC}$ (2004), an astounding 23.7 million more pounds of nitrogen, or over $20 \%$ of the CBR total nitrogen reduction goal, could be captured through this single management practice. Despite its reduction efficiencies, currently no state is set up to operate an ENM program. However, the practice is being investigated on a pilot scale and incorporated in a number of the emerging state tributary strategies.

\subsubsection{CONSERVATION TILlage SySTEM}

Conservation tillage covers any tillage system that leaves at least $30 \%$ of the soil surface covered with crop residue after planting (Cestti et al., 2003; CBC, 2004). More specifically, it refers to planting crops with minimal cultivation of the soil and retaining cover crops and crop residues that cover a minimum of $30 \%$ of the field. While this provides some nitrogen reduction benefits, more important, it is the single most beneficial agricultural management practice for phosphorus and sediment control, providing $38 \%$ phosphorus reduction and $100 \%$ of the sediment reduction (CBC, 2004; CTIC, 1998). Methods include no-till ${ }^{2}$, in which no plowing of the soil takes place and crop seeds are planted through perennial residue cover and strip-till, in which narrow planting strips are tilled, leaving the majority of the field untilled and under

\footnotetext{
${ }^{2}$ No till is a conservation tillage type without any soil preparation. Seeds, fertilizer, and herbicides are inserted through the residue from the last crop into the soil in a single planting operation
} 
residue cover. Others include ridge-till ${ }^{3}$, used in cold, wet areas in which tilled ridges are built up and planted with residue cover between the rows; variations of minimum tillage with degrees of permanent cover and continuous no-till (CBC, 2004).

\subsubsection{COVER Crops}

Cover crops ${ }^{4}$ are small grain crops planted in the fall for the purpose of consuming any excess nutrients remaining in the field after harvesting row crops (Cestti et al., 2003). The primary purpose of cover crops is to capture nitrogen, though they also provide phosphorus reduction and help to anchor the soil thereby reducing erosion soil. There are two basic types, those geared towards reducing soil erosion and those that provide nitrogen to succeeding crops (legumes) (Mutch and Martin, 1998). This practice is similar to crop rotation and has been used extensively in the Bay area (CBC, 2004).

\subsubsection{GRAZING LAND MANAGEMENT}

Stream water pollution from animal waste is a growing environmental concern (Evans et al., 2003; Guan and Holley, 2003; WV DEP, 2005; Millard et al. 1994). Grazing land management (GLM) involves all practices and operations aimed at managing the amount and type of livestock forage. The practice entails rotational grazing, managing animal stocking rates, forage species selection, and irrigation (Evans et al., 2003; CBC, 2004; Daly, 1990).

GLM also includes dividing pasture areas into grazing paddocks that are intensively grazed for a given short period, and then allowed to rest and recover before being grazed again (Hubbard et al., 2003; Daly, 1990). The grazing and resting time of each paddock is determined

\footnotetext{
${ }^{3}$ This is a conservation tillage type whereby the crop is planted in ridges following the contour of the land and in which nutrients and pesticides are only applied to the ridge.

${ }^{4}$ A cover crop is one that is grown to benefit the top soil and or other crops and usually not harvested.
} 
by the seasonal variations, quality of the forage and the growth stage of the forage. This practice has the advantage of protecting the soil surface from soil erosion than conventionally produced crops (Hubbard et al., 2003).

\subsubsection{Effectiveness of Best Management Practices}

There is no quick answer to what is the most cost effective BMP. Existing literature defines cost effectiveness of BMPs as a performance to cost comparison (Lai et al., 2006; Cestti et al., 2003; Landphair, 2001; Scheich and White, 1997). However, it is difficult to spatially apply such an approach due to variation in location and geographic conditions. In addition, because the use of one BMP is rarely sufficient to control agricultural non point pollution, BMPs are usually not implemented in isolation but in conjunction one or more complementary BMPs (Cestti et al., 2003; Alfera and Weismiller, 2002; US EPA, 1993). Consequently, although one may be tempted to use per unit costs as a measure of cost effectiveness, external factors and spatial variations makes it difficult to do so. There are spatial variation in topography, climate, agricultural systems, site selection, installation and maintenance costs. Moreover, some BMPs are used in conjunction with others. Consequently, BMP effectiveness varies from site to site and the BMP types and combinations.

The Agricultural BMP pollutant removal efficiencies recommended by the Chesapeake Bay Tributary Strategy Work group (2007) for the CBW are shown in the Appendix II. These efficiencies were based on regional research on the BMP and the judgment of research and scientific professionals (Chesapeake Bay Program Tributary Strategy Workgroup, 2007). Research experience in the Chesapeake Bay has show that BMP combinations are often the most cost effective propositions (Cestti et al., 2003; CBP, 1994; Shuyler, 1993). It should be noted 
however, that the selection of best combination of BMPs needs an integrated resource management systems analysis approach. Integrated resource management systems analysis is an integrative approach of developing watershed based water quality social and economic goals and objectives, involving the collaboration of all stakeholders and agencies in the sustainable management of water resources.

\subsection{WATER QUALITY MODELS}

\subsubsection{INTRODUCTION}

Water quality models are tools used by research scientists to simulate changes in ecosystems due to land use or land cover changes, population changes or changes in environmental management strategy (Tong and Chen, 2002; US EPA, 1998; Srinivasan and Arnold, 1994). A number of point and non point source water pollution models have been developed to support the improvement and effectiveness of water quality control and influence water quality management policies. Most of these models simulate and estimate water pollution from different spatial locations and land use practices.

Research scientists have used water quality models to predict likely environmental impacts; positive or negative changes that may impact an ecosystem (Fisher et al., 2000; USEPA, 2000; Beasley et al., 1980; Bolstad and Swank, 1997). There are a staggering number of water quality models with different acronyms. In the following sections, models addressing surface water quality are reviewed as they relate well to the issue of surface water quality addressed in this research. The major variations in these models are on the algorithms used to represent physical phenomena and specific purpose, otherwise the fundamental concept on which they are based on remains the same. 


\subsubsection{Non POINT Source Models}

\subsubsection{Ground Water Loading Effects of Agricultural Management Systems (CREAM/GLEAMS)}

GLEAMS is an extension of the Chemicals, Runoff and Erosion from Agricultural Management Systems (CREAMS) model developed to evaluates potential pesticide leaching within, through and below the root zone, estimate pesticide movement with surface runoff and sediment losses from a field (Novotny, 1995, Knisel, 1980; Leonard et al., 1987). GLEAM is a continuous simulation, field scale model that assumes a homogeneous land use, soils, and precipitation. Although GLEAMS is a powerful model for assessing the effect of farm level management decisions on water quality, it does not provide an absolute prediction of pollutant loading (Novotny, 1995).

\subsubsection{Agricultural Non-Point Source (AGNPS)}

AGNPS, an improvement of CREAMS, was developed jointly by the Agricultural Research Service (ARS), the Minnesota Pollution Control Agency and the Natural Resource Conservation Service (NRCS) in the 1980's (Young et al., 1989; Young et al., 1995). The objective was to analyze and provide estimates of runoff water quality from agricultural watersheds up to 20,000 hectares. The model is easy to use, flexible and relatively accurate and has been used to investigate a number of water quality problems. The main disadvantage is that it is a single event model. Later developments include the expansion of the capabilities of AGNPS to more advanced and continuous simulation model called AnnAGNPS. The main advantage of this model is that it can be coupled to a GIS and can be used to analyze existing conditions and examine the effects of implementing different management practices within the watershed over time. 


\subsubsection{Hydrological Simulation Program - FORTRAN (HSPF)}

HSPF was developed by the US EPA to simulate watershed hydrology and water quality for conventional and toxic organic pollutants on both pervious and impervious surfaces (Singh et al., 2005; Bicknell et al., 1997; Donigian and Huber, 1990). The main advantage of this model is its ability to predict and analyze possible environmental problems in a watershed. Recent developments have seen HSPF being couple with other software like Watershed Modeling System (WMS) to provide a more user friendly interface and provide graphical interpretation of the HSPF data and automation of some of its functionalities. The main advantage with HSPF is its ability to handle large amounts of data and simulations. It also considered as the only comprehensive model that allows for the integration of land and soil contamination runoff processes with stream and sediment-chemical interactions (Deliman et al., 1999).

\subsubsection{Areal Non Point Source Watershed EnVironment ReSPONSE Simulation (ANSWERS)}

ANSWERS was developed by Beasley and Huggins in effort to supply agencies and individuals with information concerning the effects that land use, management and conservation practices or structures might have on the quality and quantity of water from both agricultural and non agricultural watersheds (Beasley and Huggins, 1980). ANSWERS is useful as a planning tool. The model uses GIS raster data concept to simulate various hydrological processes, sediment transportation, and routing of drainage network. 


\subsubsection{Surface Water Quality MODELS}

\subsubsection{QUAL2K}

QUAL2K is an advanced version of QUAL2E model (Brown and Barnwell, 1987). The model is comprehensive, versatile, and can simulate any combination of up to fifteen water quality parameters. Users have the option of running a steady-state or as a dynamic model, which makes this model very useful in water quality planning and management, like the development of TMDLs. This model has been widely used and applied in assessing the impact of changes in point-source discharges on water quality.

\subsubsection{Water QUality ANalysis Simulation Program (WASP)}

WASP is a dynamic compartment-modeling program for any type of water body (Wool et al., 2004; Ambrose et al, 1988; Connolly and Winfield, 1984; Di Toro et al., 1983). This model is powerful and complex in that it allows users to explore different dimensional systems and a mix of pollutant types (US EPA, 2006). However, its major drawback is that it requires a lot of data and expertise to run the model. Due to its powerfulness, this model has been extensively used in water quality assessments in rivers and streams, the development of TMDLs and waste load allocations (Ambrose et al., 1988).

\subsubsection{AQUATOX}

AQUATOX was developed by the EPA to simulate different effects of chemicals introduced in aquatic ecosystems (US EPA, 2000; Tetra Tech Inc, 2003). The model predicts the fate and transportation of various pollutants, like nutrients and organic chemicals and the likely impacts on the ecosystem. This model is valuable to ecologists, biologists, water quality modelers, and for any ecological risk assessments of aquatic ecosystems (US EPA, 2000). The 
main disadvantage is that the model is complex and requires many input physical and chemical variables which may be challenging for first time users.

\subsubsection{GIS BASED MODELS}

A number of water quality models focus on the in-stream processes of pollutant simulation. However, the spatial linkages of polluting sources, hydrological processes and their impacts downstream have been lacking (Debele et al., 2009; Baird et al., 1996; Benaman, 1996). A geographical information system (GIS) provides a powerful platform of linking spatially based pollution characterization, causes and effects with water quality modeling. A GIS is a computer based system that spatially represents geographic data and links it to other related data. GIS has become a powerful technology in environmental modeling providing ease and accuracy in elevation models and feature representation, watershed delineation, non-point source pollutant loading calculations and other related hydrological and environmental processes (Maidment et al., 2002; Saunders and Maidment, 1996; Newell et al., 1992). Consequently, GIS has emerged as a powerful environmental management and decision making tool for environmental planners, city planners, engineers, political administrators and acting as powerful communication tool to communities and stakeholders. A number of studies have since utilized GIS for non-point source loading assessments, surface and underground water modeling and water balance forecasting (Maidment et al., 1996; Mizgalewicz, 1996; Saunders and Maidment, 1996; Newell et al., 1992). Others have utilized GIS as a spatial decision making tool in watershed planning and management (Sternberg, 1996; Chen et al., 1995; Furst et al., 1993).

A number of water quality models have been linked to GIS in order to make data manipulation and results presentation easier as well as improve the pre and post-processing of water quality model data (Brown et al., 1996; Rindahl, 1996). The following section reviews 
some of the GIS-based water quality models, mainly Soil and Water Assessment Tool (SWAT), Watershed Characterization and Modeling Software (WCMS), the Corpus Christi Bay National Estuary Program Model and PreDICT.

\subsubsection{SOIL AND WATER ASSESSMENT TOOL (SWAT)}

SWAT, an outgrowth of the Simulator for Water Resources in Rural Basins (SWRRB) model, is a basin-scale model developed by the USDA-ARS. The model is a continuous time and distributed parameter hydrological and water quality model (Debele et al., 2006). The objective in SWAT development was to predict the impact of land management practices on water, sediment and agricultural chemical yields in complex watersheds with varying soils, land use and management conditions over long periods of time (Arnold and Fohrer, 2005). SWAT was developed to assist water resource managers in assessing the impact of management on water supplies and nonpoint source pollution in watersheds and large river basins (Arnold et al., 1998) The SWAT model has been used effectively as a tool for assessing water resources, non point pollution problems, TMDL analyses and assessing effectiveness of conservation practices (Borah et al., 2006).

\subsubsection{WATERSHED ChaRACTERIZATION AND MODELING SOFTWARE (WCMS)}

WCMS is a GIS modeling system for desktop mapping and watershed analysis developed by West Virginia University Natural Resources Center (NRAC) to bring spatial data and water quality modeling to the desktop of West Virginia Department of Environmental Protection (WVDEP) personnel (Strager et al., 2009; NRAC, 2007). Requiring a Spatial Analyst (ESRI, 2004, 1999) extension, the model combines a wide variety of spatial data layers with hydrological and water quality modeling concepts for decision making and management of water 
resources. The model is based on a hydrologically corrected digital elevation model for stream flow modeling, calculating drainage area, estimating cumulative flow of pollution, fate and transportation of pollution, expected mean concentration (EMCs), and distance calculation. WCMS is being used by WV state agencies to perform watershed analysis for any region throughout the state. The model also allows flow path analyses, stream and watersheds delineation and does not require separate calibration of data inputs for modeling purposes (NRAC, 2007).

\subsubsection{CORPUS Christi BAy NATIONAL Estuary Program MODEL}

The Corpus Christi Bay model analyzes point, non point and atmospheric pollution loads in a water body (Baird et al, 1996). Like WCMS, the model is based on a hydrologically corrected DEM to calculate stream flow and average concentrations in runoff or EMCs. The model has been applied in the quantification of atmospheric, point and non point sources of pollution and in the estimation of nutrient and metal loads to the bay (Quenzer et al., 1998).

\subsubsection{Pollution Reduction Impact Comparison (Predict) Model}

PRedICT is a companion software tool for use with AVGWLF developed for evaluating the implementation of both agricultural and non-agricultural pollution reduction strategies at the watershed scale (Evans et al., 2002; Evans et al., 2003a). It is part of a comprehensive GIS-based modeling approach developed to accurately predict nutrient loads in watersheds in Pennsylvania. The advantage of using PRedICT is that it allows users to create what if scenarios that can be evaluated with future conditions reflecting different BMP strategies for pollution reduction. The tool has in built pollutant reduction coefficients for $\mathrm{N}, \mathrm{P}$ sediment and unit cost information for a variety of BMP strategies. Most importantly, users can also use optimization routines in order to 
identify the least cost and most efficient reduction strategy of pollution reduction (Evans et al., 2002).

\subsection{WATER QuAlity MANAGEMENT RESEARCH}

Watershed water quality management is a coordinated effort involving a number of stakeholders in a watershed-based management effort to conserve, maintain, protect or restore habitat and water quality (NRCS, 2000; Pullar and Springer, 2000). A variety of models have been developed and applied in the prioritization of pollution reduction strategies and predicting possible sources and likely impacts of water pollution (Baird et al., 1996; Debele et al., 2006; Evans et al., 2002, NRAC, 2007). In general, when the sources of pollution are known, prediction of impacts can be carried out fairly easy and accurately. In cases of non-point sources of pollution, modeling and the level of data requirements can be huge and complex. Depending on complexity and depth of the problem, the level of information and the number of pollution parameters varies across different case studies.

Research literature has also shown that with appropriate and accurate data, water quality models can predict good results (Maidment and Djokic, 2000; Evans et al., 2002). The disadvantage is that sufficient data to validate models are hard to obtain. In such cases, GIS technology has been utilized to bridge such a gap through its ability to compile, organize, manipulate and analyze spatially referenced water quality model input and output data. A number of studies have used GIS to support different water quality modeling efforts (Evans et al., 2002; Maidment and Djokic, 2000). It is likely that in future, GIS-based water quality modeling will become the standard modeling approach, making it imperative for appropriate GIS datasets to be used in modeling efforts (Evans et al., 2002). 
Despite these advances, a number of studies have pointed that efficient and effective water pollution reduction and management need to account for inherent uncertainties of complex environmental systems that make it difficult to reliably identify major sources of pollution (Younger et al., 2002; Wood et al, 1999). Consequently, it will be difficult to accurately identify and recommend BMPs and least cost strategies aimed at reducing water pollution in watersheds without accounting for such uncertainties (Kavanaugh et al., 2003; Constanza et al., 2002; Shortle et al., 1998; McSweeney and Shortle, 1990).

\subsection{SUMMARY AND CONCLUSION}

A thorough understanding and evaluation of how different spatial processes in a watershed affect water quality are a continuing challenge for water resource scientists and analysts. The development and application of mathematical models and hydrological models has enhanced our understanding of some of the processes, help us in the identification of problems and enhance our decision making. Most watersheds do not have long-term watershed monitoring data as this can be costly. This can be overcome by using hydrological simulations involving water quality modeling.

This section has reviewed some of the currently used watershed-based hydrological and water quality models. The reviewed list is not comprehensive but provides a framework of understanding the complexities, challenges and capabilities some of these models address when dealing with water pollution problems. Each model has its own strengths and weaknesses. Most water quality models are basically mathematical formulations designed to help decision makers generate cost effective pollution control strategies (ReVelle and Mcgarity, 1997; Williams et al., 2004). However, data problems still pose a challenge in water quality modeling, consequently creating uncertainties in model results. Despite these drawbacks, water quality models are still an 
invaluable tool for resource managers and economists in planning and management of watersheds. Water quality models help water resource planners and managers better understand water quality and management process because water quality models are capable of exploring interactions of various sources of pollution, effects of pollution on water quality and costs of options for pollution reduction. Moreover, they provide both qualitative and quantitative information that can be used to support environmental decision making (Wu and Chen, 2009; Wurbs, 1993). It should be noted, however, that water quality models are not a panacea to difficult water quality decisions and management problems, but they simply provide additional information to consider in the decision making process. In other words they strengthen the knowledge base to support decision making. Supportive water resource policy and a strategic framework is needed for watershed management (Darghouth et al., 2008). A number of policies are required for an integrated approach to watershed water quality management. The policies will need to allow for environmental agencies to collaborate with watershed communities and stakeholders in the management of water resources. By engaging the communities in the decision making process, the communities will be empowered to take a leading role and thus become part of the solution and decision making process (Darghout et al., 2008; Craig et al., 2002; Harris and Weiner, 1998). 


\section{CHAPTER 4: MODEL DEVELOPMENT}

\subsection{INTRODUCTION}

This chapter examines the conceptual and empirical model development used in this study. The conceptual model is important as it is an abstraction of the water quality model and maps the actual testing and implementation of the final empirical Opequon watershed water quality model. Water quality and hydrological models often consist of mathematical models representing a particular geographical area and the stream hydrological network system (Debele et al., 2006; US EPA, 2006; Tong and Chen, 2002; Bicknell, 1997; Novotny, 1995; Young et al., 1995; Srinivasan and Arnold, 1994). A majority of such studies tend to focus on sources, fate and transportation of pollution. However, the extent of the geographical area of analysis, the level of detail of the model, and the complexity of the mathematics vary according to the purpose of the water quality model. Most water quality models require a lot of data collection, preparation and management. Examples include WCMS (Strager et al., 2010; NRAC, 2007) and SWAT (Bingner, and Theurer, 2009; Debele et al., 2006). Some water quality studies involve a number of calculating modules and a data flow between these models, (see AQUATOX (US EPA, 2000) or WASP (Di Toro et al., 1983) HSPF (Bicknell et al., 1997; Donigian and Huber, 1990) and AGNPS (Young et al., 1995). In short, water quality models represent a simplification of different environmental patterns and processes under study. The modeling results are useful in exploring different what if scenarios and objectives at different spatial and temporal scales.

In the following section, an overview of the models used in this study is presented, and then their overall linkages, actual tasks and tools involved are discussed. 


\subsection{OVERVIEW OF THE MODELS}

The study uses three models; a water quality model, a GIS based stream network model, and an optimization model. The water quality model simulates fate and transport of nutrients in the watershed. The network model simulates pollutant flow within the watershed and the cost minimization model recommends least cost strategies of nutrient management with input of watershed community and stakeholders in the identification and prioritization of areas needing priority clean up.

The water quality model simulates nutrient concentrations within a watershed. Nutrient concentration levels are analyzed from a subwatershed level to determine loadings from different subwatersheds, fate and transportation of nutrients from one subwatershed to another and ultimately at the mouth of the watershed. The results of the network model are critical in determining the level of nutrient reduction needed to meet a desired water quality in the watershed. Using a cost minimization model, agricultural BMPs are evaluated for recommending a least cost strategy for nutrient reduction. A more detailed discussion of these models will be examined and discussed in detail in the following sections.

\subsubsection{WATER QUALITY MODEL}

Most water quality models are developed to simulate the movement of water through a river network to a final receiving water body. Both the network and water quality models are built on a GIS framework. GIS provides a representation and analytical framework for watershed spatial data. A river system represents a network flow system of streams from each subwatershed to the mouth of the river. It is the stream network model that forms the base of the spatial simulation and analytical framework of pollution in the watershed. In this study, stream network model utilizes the map and stream topology information of the Opequon watershed to generate a 
spatially explicit network of streams and subwatersheds. Water and nutrients are transported along the stream network to the watershed outlet. This routing process accounts for fate and transportation of nutrients within the watershed.

The GIS based water quality modeling approach utilized for this study is the Watershed Characterization and Modeling System (WCMS) (NRAC, 2007).WCMS is designed on the basic principal of overland flow from land cover in an attempt to examine pollutant concentrations and watershed water quality problems. The main water quality parameters in WCMS for characterizing watershed problems are in-stream concentrations and loadings of nitrogen $(\mathrm{N})$ and phosphorous (P). An ArcGIS extension, WCMS developed by NRAC (2007) integrates both the water quality and stream network modeling. WCMS was built on existing GIS software functionality and capabilities for the development of a spatially explicit overland flow landscape model for water quality analysis, and stream-flow estimation modeling (NRAC, 2007). WCMS runs on a hydrologically corrected digital elevation model, which allows for the creation of raster hydrological functions for calculating flow direction and flow accumulation with better accuracy (NRAC, 2007; Olivera et al., 1996).

Other capabilities of WMCS include calculating expected mean concentrations for $\mathrm{N}$ and P from standard land use land cover classes like urban area, open/brush, agriculture, woodland, barren, and wetland areas. Within WCMS, each standard land cover class has a unique loading coefficient for $\mathrm{N}$ and $\mathrm{P}$ based on published regional literature values (NRAC, 2007). Other pollutant loadings such as total suspended sediments (TSS) and biochemical oxygen demand (BOD) can also be analyzed. However, they are beyond the scope of this study. Using loading values, one can estimate nutrient pollution concentration, stream flow modeling and seasonal loading variations. 
WCMS has some limitations. The WCMS approach makes a number of assumptions including that all streams have the same width, depth, slope and roughness. This approach, also, does not consider other hydrological factor affecting pollutant concentration and transport such as infiltration, interflow, ground water flow additions, or any atmospheric conditions such as temperature or evapotranspiration (NRAC, 2007). Despite these disadvantages, it provides a foundation of and integrative approach to analyzing water quality management.

Three water quality analytical functions are used in this research:

(i) Potentially affected streams - This function tracks surface runoff from potential land uses in the watershed. The research assumption is that agriculture is the major contributor of nutrient pollution during a precipitation event. The main goal is to track all streams and subwatersheds that are likely to be affected by high nutrient concentration levels from the different land uses.

(ii) Expected mean concentration (EMC) modeling from land cover - estimates total $\mathrm{N}$ and $\mathrm{P}$ as concentrations and loadings in the stream based on six aggregated land use and land cover classification. These classes are associated related to the expected loadings based on the acreage size of the class. These loadings are annual averages and when used with the modeled stream flow gives concentrations and loadings for the stream (NRAC, 2007). The cover classes and associated EMC levels used in the model are shown below. 
Table 5: Nutrient Loads from Land Cover Type.

\begin{tabular}{|r|l|r|r|}
\hline Value & Land Use & $\mathbf{N}(\mathbf{m g} / \mathbf{L})$ & $\mathbf{P}(\mathbf{m g} / \mathbf{L})$ \\
\hline 1 & Urban & 1890 & 9 \\
\hline 2 & Open/Brush & 2190 & 130 \\
\hline 3 & Agriculture & 3410 & 240 \\
\hline 4 & Woodland & 790 & 6 \\
\hline 5 & Barren & 3900 & 100 \\
\hline
\end{tabular}

(Source: NRAC, 2007)

Table 5 shows that barren land produces the highest EMC of $\mathrm{N}$ annually, followed by agriculture, open brush, urban and woodlands have the least contributions. In terms of EMC of P, agriculture has the highest annual impact, followed by open brush, barren, urban and least is woodland.

It should be noted that the results obtained from EMC modeling can be thought at worst case scenario as a other factors can cause variation in the EMCs including among others, soil type, geology, changes in precipitation, land use practices etc (NRAC, 2007).

(iii) Fate and transportation of N and P from each subwatershed mouth with simulated or collected water quality data. The advantage with method is that it can be used to calibrate concentrations and loadings downstream of the sampled points. 


\subsubsection{STREAM NETWORK MODEL}

In order to analyze the interrelationships between various subwatersheds, a watershed is represented as a network. The network flow is a collection of nodes and arcs, whereby each arc (stream) carries the nutrients from each node (stream junction).

The subwatersheds and the hydrological network model of the Opequon Creek and its subwatersheds are shown diagrammatically on Figure 1. Each subwatershed has a mouth represented by a node/point, and these nodes are connected by arcs to form a stream network. Nutrient loadings from each subwatershed are simulated at the mouth of the watershed. Fate and transport of nutrients are also examined along the main stem of the Opequon. The loading reductions for identifying a least cost strategy for nutrient reduction in the optimization model are evaluated at the mouth of each subwatershed as well as at the mouth of the entire Opequon watershed. 


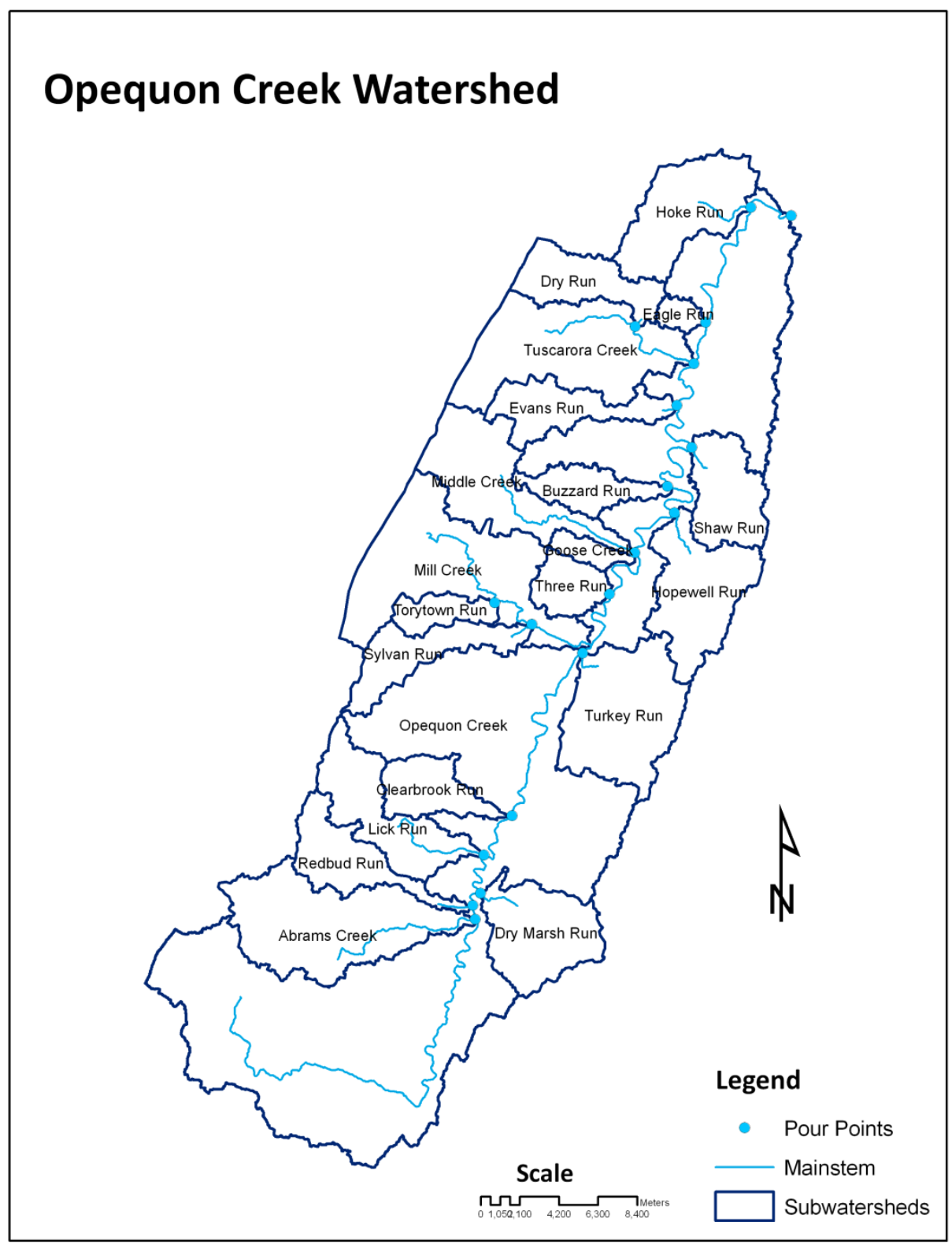

Figure 1: Subwatersheds of Opequon Creek Watershed

\subsubsection{Cost Minimization Model}

The cost minimization model is composed of a total cost function of pollution reduction given constraints on loading reductions to be achieved. The cost function is comprised of per 
unit cost of each BMP implementation per subwatershed. The cost minimization model is assumed to be a linear function of $\mathrm{N}$ and $\mathrm{P}$ loadings in the watershed.

The general cost minimization model for the nutrient reduction problem uses the following notation;

$C_{i}=$ cost per acre to put $B M P_{i}$ in place on subwatershed $i$.

$B M P=$ acres of $B M P$

$B M P_{c}=$ acres of the $\mathrm{c}^{\text {th }}$ BMP on crop land

$B M P_{p}=$ acres of the $\mathrm{p}^{\text {th }} \mathrm{BMP}$ on crop land

$i=$ subwatershed.

$a_{i m}=$ loadings ${ }^{5}$ transfer coefficient from subwatershed to the mouth of the watershed.

$R_{c i}=$ lbs per acre reduction by $B M P$ on crop land for either $N$ or $P$.

$R_{p i}=$ lbs per acre reduction by $B M P$ on pasture land for either $N$ or $P$.

The model basically seeks to find an allocation of BMPs across all subwatersheds that provides the least cost strategy of BMP implementation to meet the targeted loading reductions.

\footnotetext{
${ }^{5}$ Loadings are defined as the total amount of a pollution from a specific area or land use received by a water resource in a given fixed time period. They are expressed as the amount of pollutant per unit of land area per unit of time, usually measured in tons (or pounds) per acre per year, or metric tons (or kilograms) per hectare per year if using metric units. Loading are different from concentrations in that they provide information about the land area where the pollutant is coming from, the time over which the pollutant enters the water resource and the total amount of pollutant delivered (MD DNR, 2004).
} 
In the model, $T C$ represents the total cost of reducing $\mathrm{N}$ and $\mathrm{P}$ discharges at the mouth of watershed. Thus the objective is simply to minimize the total cost of the BMP implementation (TC) across all subwatersheds, subject to achieving the target loading reductions for either $N$ or $P$ at the mouth of the watershed. The targeted loading reductions used in the study are derived from the Potomac Basin reduction goals of 1985. Mathematically, the conceptual model is:

$$
\begin{gathered}
\text { Min TC }=\operatorname{Min} \sum_{i} \sum_{c} C_{i} B M P_{i c}+\sum_{i} \sum_{p} C_{i} B M P_{i p} \\
\text { subject to } \\
\text { Loading Reduction } \leq \sum_{i} \sum_{c} R_{c} B M P_{c i} * a_{i m}+\sum_{p} \sum_{i} R_{p i} B M P_{p i} * a_{i m} \\
\sum_{i}^{n} B M P_{i} \leq \text { Crop }{ }_{i} \\
\sum_{i}^{n} B M P_{i} \leq \text { Pasture }_{i} \\
B M P_{i c} \geq 0 \\
i=\text { subwatersheds }
\end{gathered}
$$

The BMPs that are reviewed in this study were drawn from the most cost effective measures recommended for the CBR. Only the top choice BMPs based on reliability of the practice, sensitivity to different conditions, consistency of success in nutrient reduction, political reality and the possibility of funding over time are considered for the CBR (CBC, 2004). Despite the fact that the experience in the Chesapeake Bay Region on the use of BMPs to control nonpoint sources of pollution are applicable to the research study area, modeled data and case 
study characteristics were used to generate more representative BMPs and their associated costs of implementation and respective nutrient reduction efficiencies. This study focuses only agricultural based BMPs, as agriculture is major source of nutrients entering the Chesapeake Bay watershed.

\subsection{Model LiNKAGES}

The following section discusses the linkages between the three models used in this study. The objective is to outline how the models relate to each other. The models are water quality, network model, and cost minimization. A brief description and overview of each model and data requirements will be examined, followed by how the models are linked together.

The water quality model is built on the watershed network flow model. This model allows for the examination of the main sources of pollution, projects stream flow levels to estimate pollutant loadings, identifies the most affected streams, and finally targets watersheds that should be of highest priority for treatment and best management practices can be used to address the problems. Thus, the water quality model analyzes pollutants loads, while the network model simulates the fate and transport of nutrients among subwatersheds and within the watershed as a whole.

The stream network model forms the core of the simulation framework that spatially integrates the contributions from point and nonpoint sources in the watershed. The model uses the spatial and stream topology information in a watershed to generate a spatially explicit network of stream reaches (NRAC, 2007). Water is routed through the stream network to the watershed outlet. The routing process accounts for fate and transportation of nutrients within the watershed. The network model developed in ArcGIS hydrological data analysis which 
incorporates stream flow, flow direction, flow accumulation, digital elevation model and land use. This data also forms the basis of WCMS water quality modeling and analysis.

The cost minimization model seeks to find the least cost strategy for nutrient reduction in the watershed by recommending $\mathrm{BMPs}^{6}$. Understanding nutrient fate and transportation is critical in designing and implementing BMPs that can cost efficiently reduce nutrient concentrations. The BMP choices are constrained by the desire to minimize costs and land use and the targeted water quality level.

Community and stakeholder input are critical for sustainable watershed management programs. Participation of the local communities and stakeholders can be through meetings, workshops, interviews, GIS mapping and statistical data analysis. Through their participation and inputs, a number of watershed management strategies can be identified and evaluated for a least cost strategy of nutrient reduction as well as management of the watershed. Local knowledge can also be combined with scientific knowledge for more informed decision making. This study utilized data by the Opequon Creek Project Team (Bartley, 2006) that involved the stakeholders' inputs in the watershed prioritization of the Opequon Creek. The prioritization involved different criteria for comparing and distinguishing subwatersheds. The subwatersheds were then ranked and evaluated to identify the most critical watersheds that would require priority attention in terms of BMP implementation to reduce nutrient pollution. The results of the

\footnotetext{
${ }^{6}$ BMPs are basically pollution prevention practices. They are defined as economically sound, voluntary practices that are capable of minimizing nutrient and sediment contamination of surface and groundwater. They are individual or combinations of management, cultural and structural practices that researchers have identified as the most cost effective and economical way of reducing water pollution (Gale et al., 1993; US EPA, 1993).
} 
community prioritization exercise are used to develop a scenario where the cost minimization model can be applied to evaluate different BMPs in the priority watershed as identified by the community and stakeholders. The linkages of the three models are shown diagrammatically below;

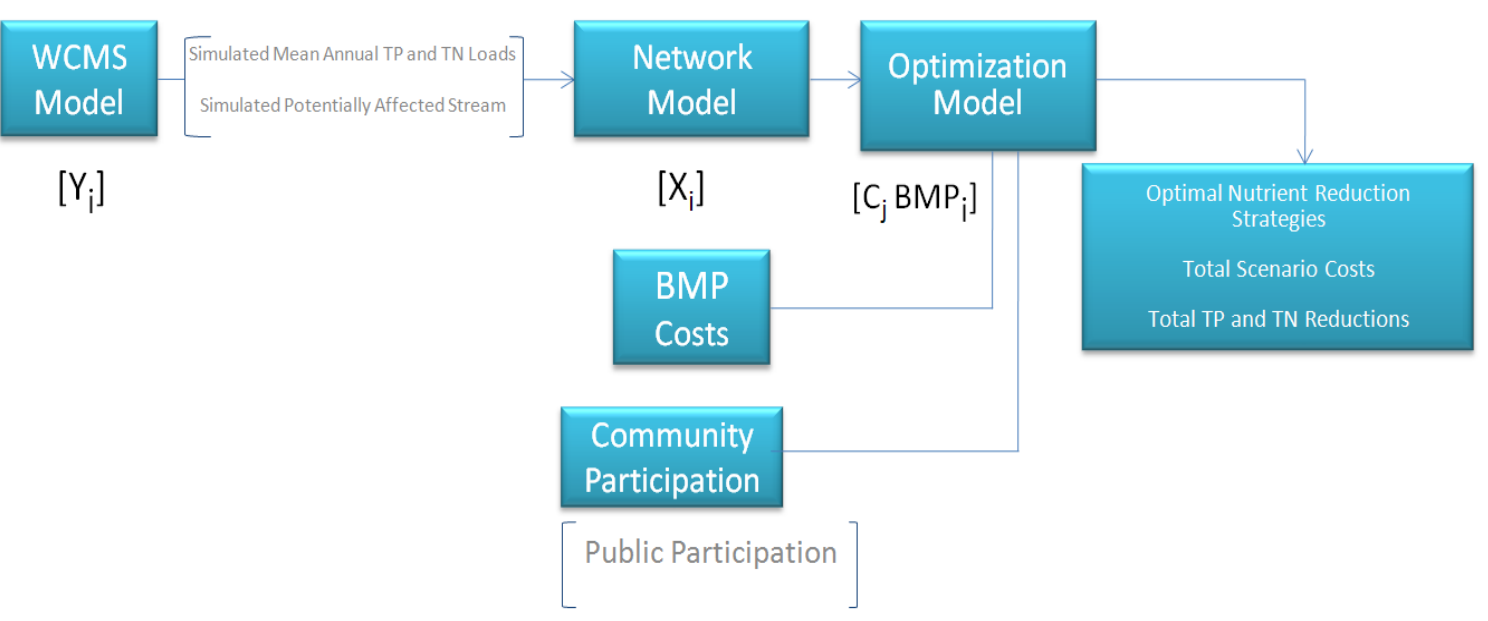

Figure 2: Model Linkages

whereby $Y_{i}$ are the loadings simulated for the entire watershed simulated by WCMS, $X_{i}$ is the nutrient loading measured at the mouth of each subwatershed and $C_{i} B M P_{i}$ are the total costs of BMP implementation.

Integrated models are used for decision analysis for watershed management action plans. Watershed management plans involve watershed planning and watershed management strategies towards meeting the targeted environmental quality. The process involves problem identification, stakeholder input and evaluation of alternative by examining challenges and opportunities and recommendation of a plan of action that will be followed in order to address the environmental 
problem. Like in any project management cycle, the last stages involve implementation, monitoring and evaluation of the afore-mentioned management efforts. 


\section{CHAPTER 5: CASE STUDY}

\subsection{INTRODUCTION}

Watershed based water quality studies have become increasingly common in engineering and hydrological sciences in the past three decades (Prowse, 1984; Randir et. al., 2000; Rao and Kumar, 2004). This is because large scale catchment studies have proved very difficult due to complex relationships and interrelated spatial variations (Prowse, 1984; Randir et. al., 2000). The aim of this chapter is to present a case study description of the Opequon watershed where a comprehensive integrated water quality management approach will be applied.

\subsection{Case Study Area}

The Opequon Creek watershed of Virginia (VA) and West Virginia (WV) is a fourth-order tributary of the Potomac. The Opequon watershed is located in northern VA and the eastern panhandle of WV (Figure 3).

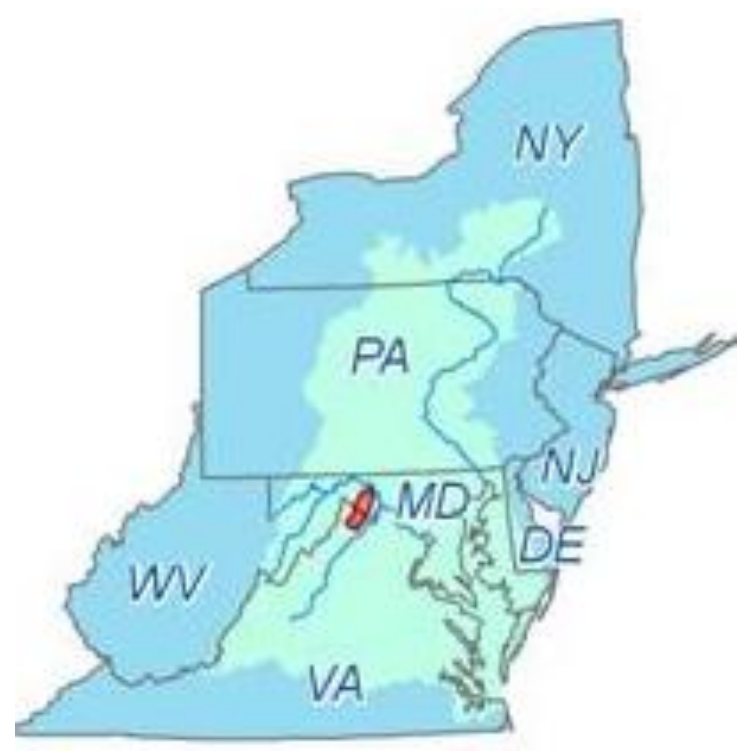

Figure 3: Locality Map of Opequon Creek Watershed (Source: OCPT) 
In VA, it starts near the town of Opequon in Frederick County and then flows through the counties of Frederick and Clarke, bends and flows north into West Virginia towards the Potomac River. In WV, the Opequon watershed flows through Jefferson and Berkeley counties. The Opequon Creek watershed is about 124,000 acres in size and drains $894 \mathrm{~km}^{2}$ (approximately 554 miles $^{2}$ ) of the northern Shenandoah Valley, before it influxes into the Potomac River (see Figure 2). Thus the Opequon is part of the Upper Potomac River Watershed, northern Shenandoah Valley and the greater Chesapeake Bay watershed. About $56 \%$ of the Opequon Creek watershed is in WV and 44\% in VA. The locality map of Opequon watershed is shown on Figure 4 below.

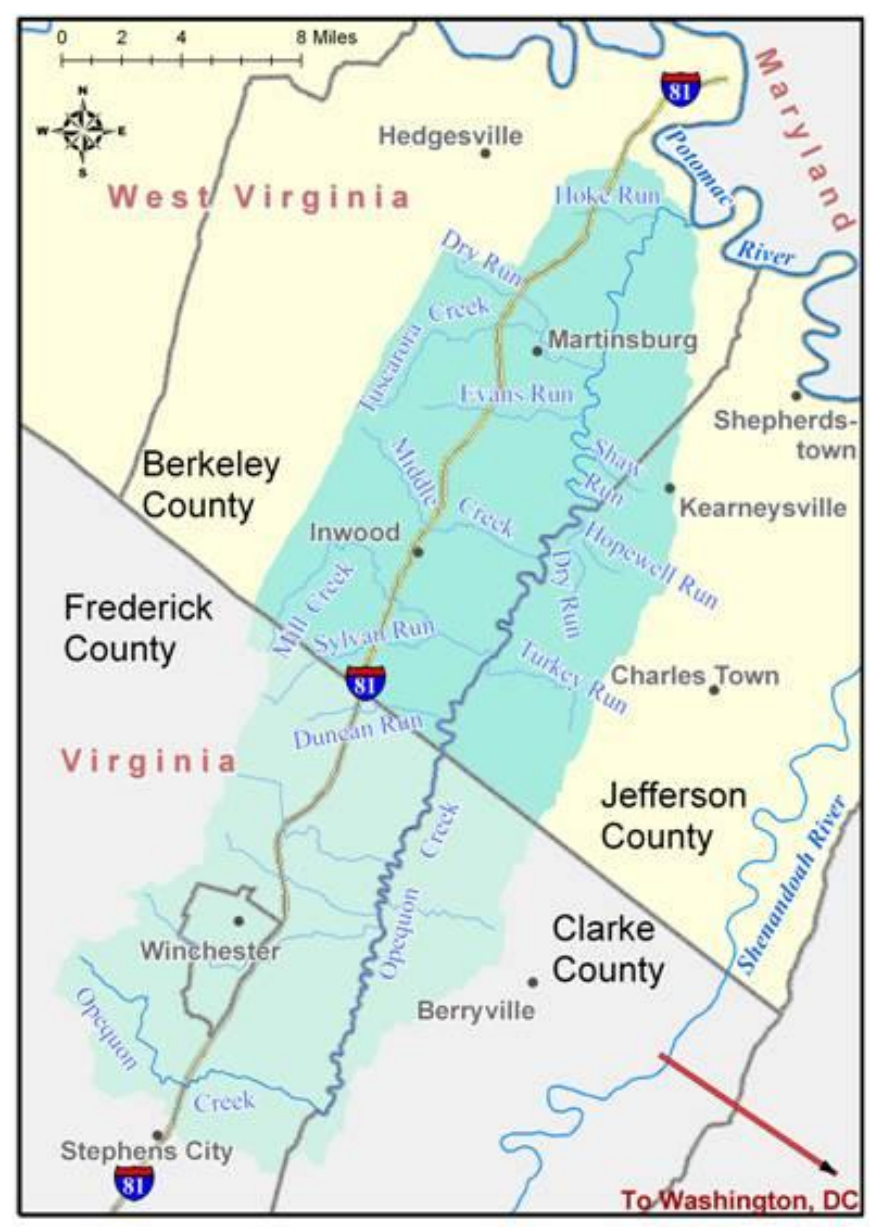

Figure 4: Opequon Creek Watershed

(Source: OCPT) 
Throughout the Potomac Basin, rapid growth and development is occurring, especially the Washington-Baltimore Metropolitan Area and along the I-81 corridor. The Potomac Basin's population is expected to increase $20 \%$ from 2000 to 2020 , with highest projected growth from areas within commuting distance of Washington D.C. area, which includes Opequon watershed area. In WV, Berkeley County is the fastest growing county in the state experiencing about $28 \%$ growth in the last decade (WV DEP, 2005). The watershed's rural areas and cities of Winchester, Virginia, and Martinsburg, West Virginia have had similar rapid population growth over the last two decades. Projected growth in predominantly rural counties is expected to continue growing, as the DC commuter corridor expands, creating a huge demand on the region's land, biological and water resources (Evaldi and Paybins, 2006; WV DEP, 2005). Consequently, there are regional and local resource management concerns about the vulnerability and sustainability of water resources to meet future growth.

In terms of land use, the VA portion of the watershed is approximately $22 \%$ urban, $30 \%$ agriculture and $48 \%$ forest while the WV portion is predominantly forest (51.4\%), with significant agriculture (35.3\%) and a growing urban influence (9.5\%). In short, the watershed consists of mixed land uses: urban areas, agriculture lands and a significant forest cover (see Figures 5 and 6). Throughout the watershed, rapid growth and development is occurring causing serious strains on water quality.

The subwatershed land use characteristics are shown in Figure 5. Forest is the dominant land use (36\%) followed by open brush (35\%), agriculture (16\%) and urban land (11\%). Forests are important for protecting the soil and improving water quality by capturing, filtering and retaining water. The reduction in forest due to rapid urbanization (11\%) in the Opequon will ultimately affect water quality. Another leading cause of impaired water quality in the 
Chesapeake Bay from nutrients is from grazing land. About $35 \%$ of land in the Opequon subwatersheds is grazing land.

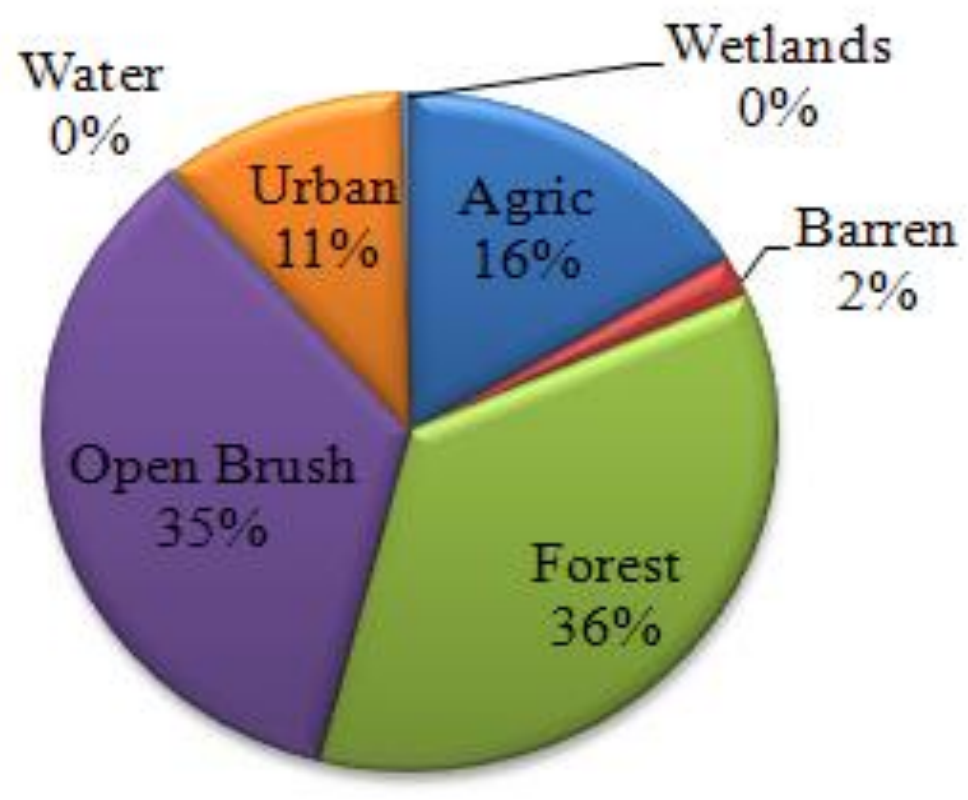

Figure 5: Opequon Land use Characteristics

The Opequon land use land cover data was derived from the Chesapeake Bay program's 2000 multi-temporal Landsat imagery. The data was classified using the Environmental Protection Agency (EPA) Multi-Resolution Land Characteristics Consortium (MRLC) classes. They include urban, open/brush, agriculture, woodland, barren, wetland and open water bodies (Appendix III). The land use land cover classification for Opequon is shown on Figure 6. 


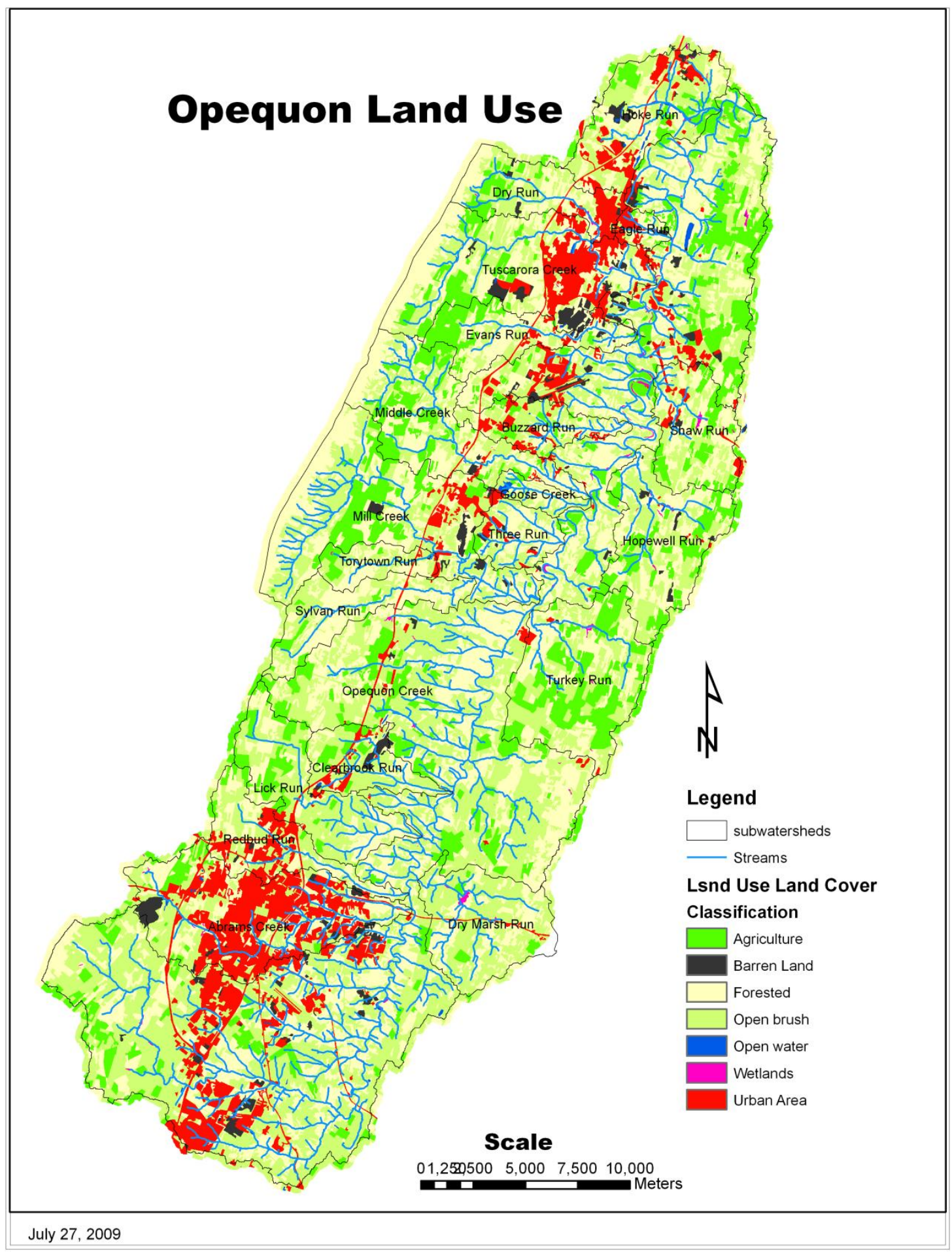

Figure 6: Opequon Land Use and Land Cover 
As shown on the map, the main land use coverage in the Opequon Creek watershed is mainly forest and open brush land and about $16 \%$ agriculture. However, with new residential construction and other urbanization developments, both forest land and farm land are rapidly converting into more urban environments (WVDEP, 2005).

Land use land cover provides information on land characteristics and the spatial distribution of potential nutrient pollution sources, such as agriculture and urban areas. Land use patterns are important in that the more homogeneous the land use, the less complex that area is in terms of identifying possible sources of pollution and recommending BMPs (Flynn, 1999; Wu and Ahlert, 1979).

Also of significance are the soil characteristics of the study region. The most important factor is that underlying soil patterns affects the hydrological system. In WV, the karst geology (limestone bedrock) makes it prone to rapid distribution of pollutants into groundwater and subsequently into surface waters from both urban and agricultural sources. 


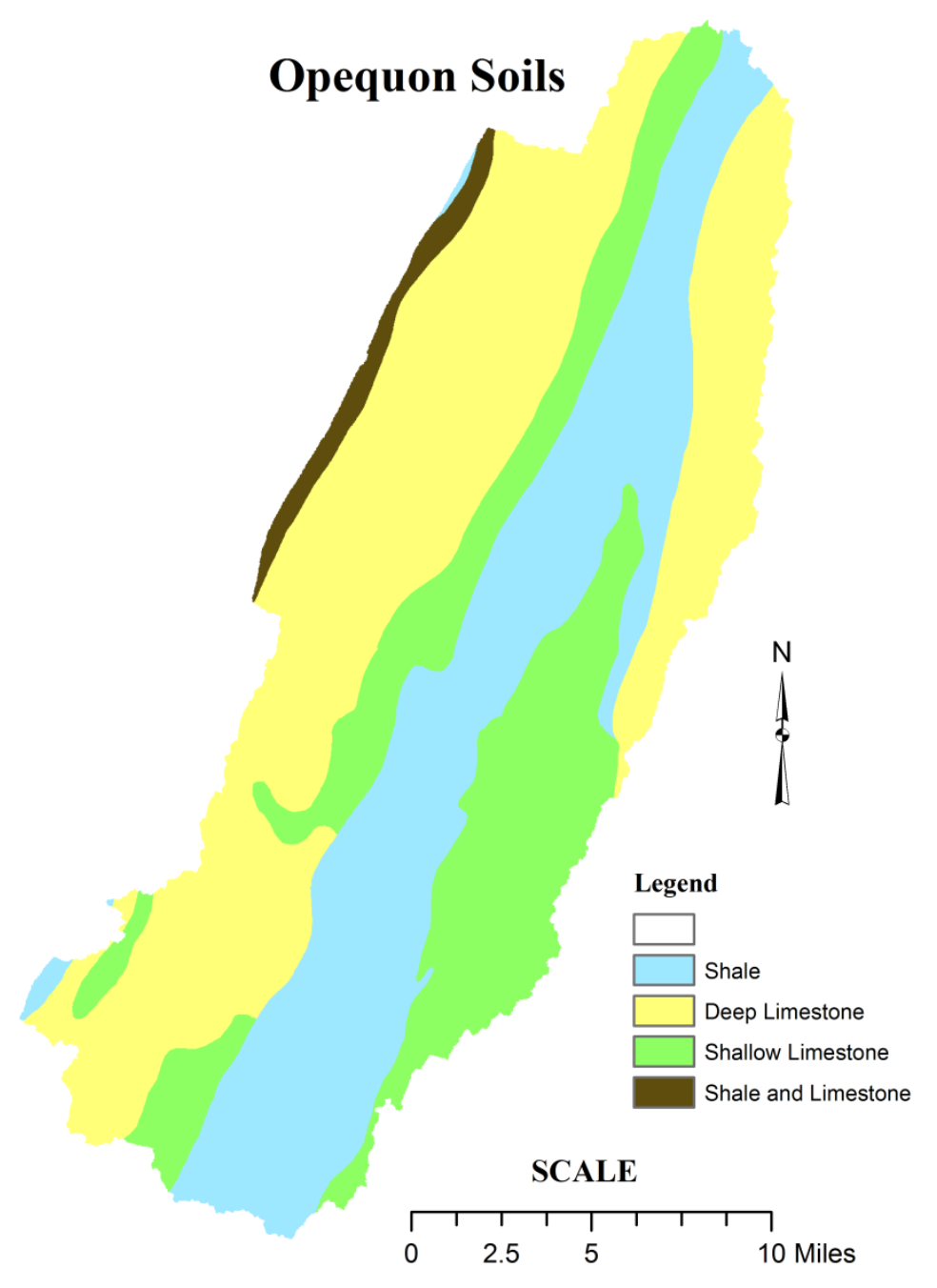

Figure 7: Opequon Soils

A large percentage of the Opequon Creek watershed is karst topography (Figure 7). Karst topography is a relatively flat or rolling landform underlain by limestone, characterized by water sinkholes and springs, as well as caves and caverns (WV DEP, 2005). In general, karstic upland soils are relatively dry. In this study area, the limestone is highly fractured, which causes nutrients and pollutants applied to the landscape to readily seep into underground watercourses and pollute surface waters. 


\subsubsection{OPEQUON WATERSHED}

This research is focused on the entire watershed, with twenty subwatersheds: Hoke Run, Eagle Run, Tuscarora Creek, Dry Run, Dry Marsh Run, Evans Run, Shaw Run, Evans Run, Buzzard Run, Goose Creek, Hopewell Run, Middle Creek, Mill Creek, Sylvan Run, Torytown Run, Turkey Run, Abrams creek, Redbud creek, Lick run and Clearbrook Run (Figure 8 below).

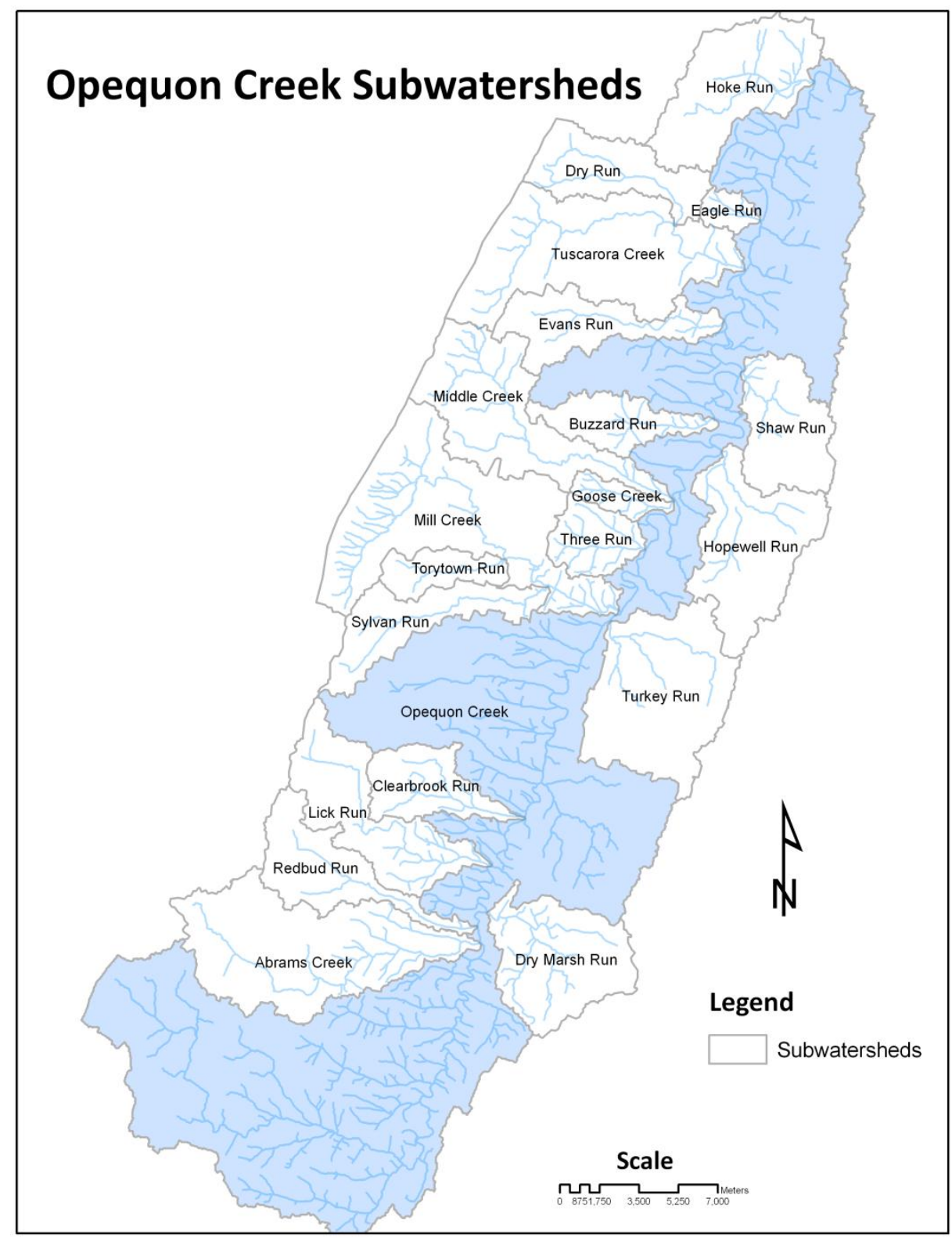

Figure 8: Opequon Subwatersheds 
The Opequon Creek subwatersheds acreage is shown in Appendix I. The Opequon Creek watershed is part of the Chesapeake Bay Targeted watershed program which looks at innovative, sustainable and cost effective ways for reducing nutrient pollution in the Chesapeake Bay (WVPTS, 2005). For instance, in 2006, the Opequon Creek Project Team (OCPT) and the Canaan Valley Institute worked on a subwatershed prioritization process to determine where to most effectively target resources for pollution reduction, decision making and restoration strategies (OCPT, 2006). The prioritization process involved watershed communities and stakeholders in the identification of subwatersheds that needed attention for restoration and protection as well as cost effectively focus the limited available resources for water pollution reduction and management.

\subsubsection{OPEQUON WATERShed WaTER QUality MANagement}

The high nutrient levels in the Opequon watershed are of critical significance to the Chesapeake Bay cleanup efforts. According to the $\mathrm{N}$ and $\mathrm{P}$ impairment indices developed by Potomac Tributary Stakeholder Team (2004), the Opequon Creek had the highest values in the West Virginia Potomac sub-watershed. Sources of these pollutants are from both point sources and nonpoint sources. In addition, residential development in West Virginia is intense in the eastern panhandle. For instance, in 2004, Berkeley and Jefferson Counties had the largest percentages of building permits issued in West Virginia with 34\% and 10\% respectively (OCPT, 2007).

Currently, the main creeks in the watershed (Opequon and Abrams) do not meet VA or WV state water quality standards for recreational uses and aquatic life (WVPTS, 2005; WVDEP, 2005). In both states, the creeks are listed as impaired due to high levels of bacteria, benthic and biologic impairment (WVDEP, 2005). Due to these impairments, a Total Maximum Daily Load 
(TMDL) plan has been developed and is in the process of being implemented on the VA portion of the Opequon watershed and WV recently completed its TMDL plan in January, 2008.

About 26 out of the 29 waterbodies and impairments identified on the WV's 2006 Section 303(d) list have had TMDLs developed for the Potomac Direct Drains Watershed by the WV DEP (WV DEP, 2005). The TMDLs were developed for fecal coliform bacteria and/or biological impairments and the TMDL plan for the Opequon Creek watershed were completed in January 2008(Armstead, 2008). Currently, there are ongoing efforts to develop nutrient water quality standards. On the other side, VA developed TMDLs for three of the stream segments of the Opequon watershed (Abrams, Upper Opequon, and Lower Opequon) in 2003, which were approved by the US EPA in 2004 (VT CTMDLWS, 2006). During the 2004, two more segments, Redbud Run and Lick Run were added to the impaired list. However, no TMDLs have been developed and completed for Redbud Run and Lick Run. The VA TMDLs for Opequon Creek were developed by characterizing the sources of bacteria and sediment in each subwatershed and determining the reduction required from each of those sources to meet the applicable water quality standards through the Hydrologic Simulation Program - Fortran (HSPF) water quality model (Armstead, 2008; VT CTMDLWS, 2006).

By 2006, VA has developed a TMDL implementation plan (IP) that includes practices that address those impairments. Specifically, the IP describes implementation actions to achieve the water quality goals in the Opequon Creek watershed (VT CTMDLWS, 2006). The US EPA approved VA's water quality standards in 2007 and with amendments in August, 2009.

The Opequon Creek watershed TMDL is being implemented under the Potomac Direct Drains watershed, a component of the Potomac River watershed. TMDLs are operational in 
Virginia under the EPA's Department of Environmental Quality. Monitoring of pollutants is carried out annually and waters which do not meet the standards are reported to the EPA. A number of strategies have been implemented to attain certain reduction targets including amongst others, implementation of BMPs, nutrient trading, installation of control technology and watershed tributary strategies. Tributary strategies under CBW agreements lead to reduction goals.

The TMDL plans encourage the adoption and implementation of BMPs to reduce water pollution on priority watersheds. A watershed is a geographic delineation of an entire water body system and the land that drains into it. The advantage of a watershed management approach is that it focuses on water resource protection and restoration through integrated efforts within a defined hydrological region (Armstead, 2008; WVDEP, 2005).

Consequently a comprehensive, watershed-based approach is needed to accelerate nutrient pollution reduction from priority watershed by incorporating both innovative and proven BMPs. A number of BMP strategies which have been under consideration include establishment of forested riparian buffer zones, pasture management repair/replace fertilizer septic systems, infiltration basin/trench (rain garden bioretention) and loafing lot management. In Opequon, agricultural BMPs will be examined as potential sources of $\mathrm{N}$ and $\mathrm{P}$.

\subsection{SUMMARY}

The Opequon provides an interesting case study in that the character of the watershed is representative of widespread land use in the Chesapeake Bay area and will serve as a model to many watersheds by addressing non point sources of water pollution from different land use and land cover patterns using an integrated approach that incorporates stakeholders, GIS, water 
quality modeling and economic optimization techniques for informed decision making to improve and managing water quality. 


\section{CHAPTER 6: METHODOLOGY}

\subsection{INTRODUCTION}

This chapter describes the methods and techniques used for water quality simulation, calibration, modeling and analysis as well as the economic optimization. The first part of the chapter examines the WCMS water simulations and modeling analysis, followed by a description of the analytical and optimization methods and a summary of analysis results.

\subsection{Watershed Quality Modeling and Optimization}

There are two scales of analysis used in this study, the watershed scale and the subwatershed level. The subwatershed scale examines the different water quality management options at the watershed level without accounting for the spatial variations in pollution sources. The watershed level takes into consideration spatial distribution of pollution and its downstream impacts. The methodology used in this study is divided into three main tasks namely:

(1) Watershed water quality modeling.

This involved creating GIS data for water quality modeling (see Appendix IV). The results from the water quality modeling exercise include the identification of potentially affected streams, estimation of expected mean concentrations, and simulation of downstream impacts of point and non point sources of pollution.

\section{(2) Stream Network model}

The stream network model which utilizes a hydrologically corrected Digital Elevation Model (DEM) simulates fate and transport of nutrients in the watershed. It forms the basis of the spatial analysis framework for both point and non point source pollution from different land uses. The 
model uses grid data to represent spatial variations in pollution concentrations and loadings in the Opequon watershed.

It should be noted that both stream network and water quality modeling tasks are undertaken in WCMS extension of ArcGIS (NRAC, 2007). The watershed water quality modeling is grid based comprising of stream network, flow direction, flow accumulation, runoff, cumulative runoff, water length, digital elevation models and land use / land cover grids, and a database of expected mean concentrations (EMC) values per land use. EMC values are measurements of pollutant annual average levels that occur during precipitation events. The assumption used in WCMS water quality modeling is that EMCs of $\mathrm{N}$ and $\mathrm{P}$ are directly related to land uses in the watershed as shown in Table 5 in Chapter 4.

(3) Cost effective nutrient reduction and management The evaluation of a least cost strategy for nutrient reduction to meet the desired reduction goal for $\mathrm{N}$ and $\mathrm{P}$ for the Opequon is carried out using linear programming. The linear programming model utilizes per unit costs of different agricultural BMPs and their reduction efficiencies, land use data (specifically acreage under agriculture (crop and animal pasture)) and subwatershed nutrient transfer coefficients to determine a least cost strategy for nutrient reduction for Opequon Creek watershed.

The three models are integrated together with stakeholder and local communities' input to form a comprehensive and integrative approach to water pollution reduction and management. The goal is to recommend a least cost strategy for reducing pollution to meet a desired reduction goal. Local community participation is essential for the success and sustainable management of the watershed water resources. 


\subsubsection{Potentially Affected Streams}

Potentially affected streams are water pollution simulations based on non point sources of pollution from different land use/ land cover. Potentially affected streams are WCMS estimates of the probability of increased nutrient loads from land cover composition. The simulation of potentially affected streams identifies possible stream pollution from different land uses by tracking the overland flow from the different land use to the streams. In this study, six categories of potential sources of non point sources of pollution used are agriculture, barren land, forests, open brush, open water, wetlands and urban areas (Appendix III).

Different scenarios were simulated with variations on where the potential sources of pollution are assumed to be coming from. The following are simulations examples $(8 \mathrm{a}-8 \mathrm{~d})$ based on different potential sources of pollution. WCMS requires spatial data layers of land slope (DEM), land use grid and EMCs (see Table 5) to be integrated in a GIS as model inputs to estimate the potential impacts of different land uses. 


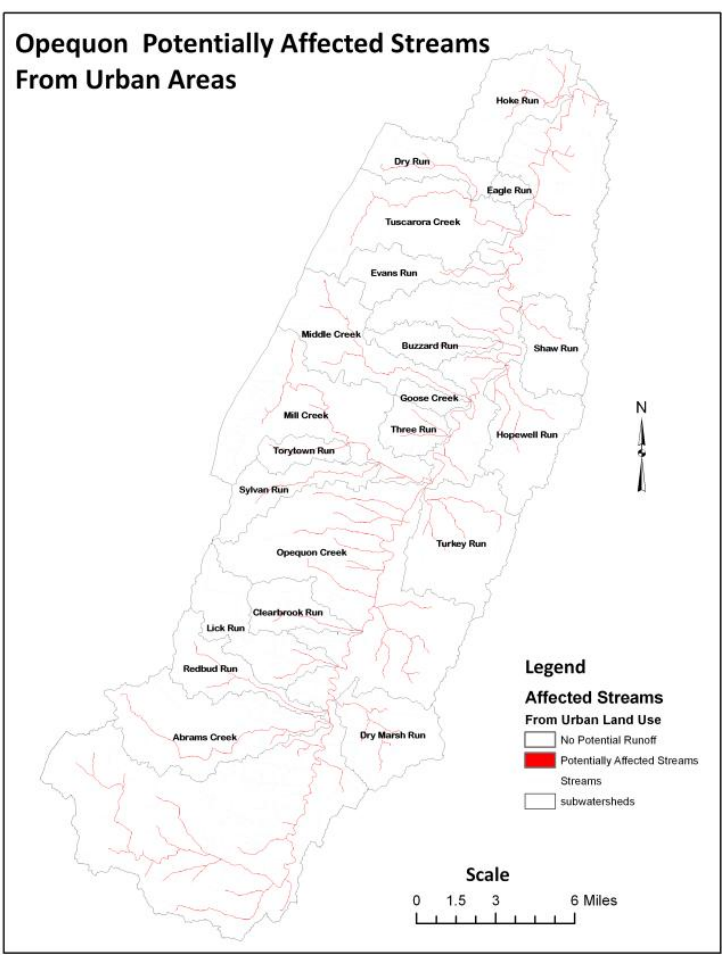

Figure 9a: Urban land use

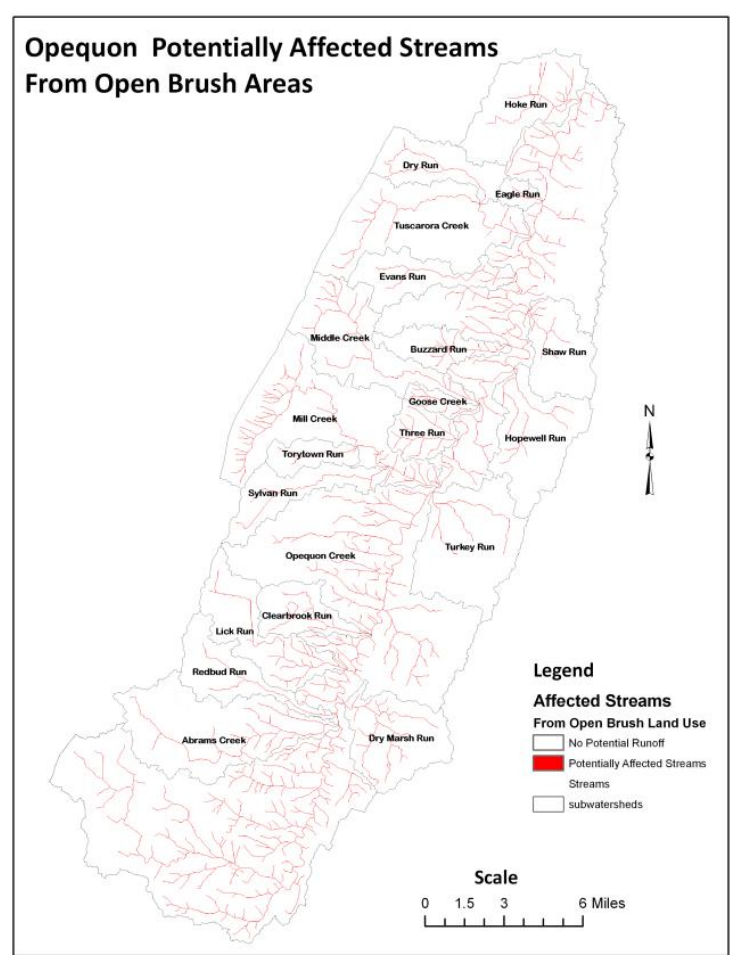

Figure 9b: Open Brush

Figure 9a shows the WCMS simulation of the potential impact of urban land use on streams and Figure $9 \mathrm{~b}$ shows the potential impact of open brush land. Figure $9 \mathrm{c}$ and $9 \mathrm{~d}$ below shows the potential impact from agricultural land and forest land respectively. 


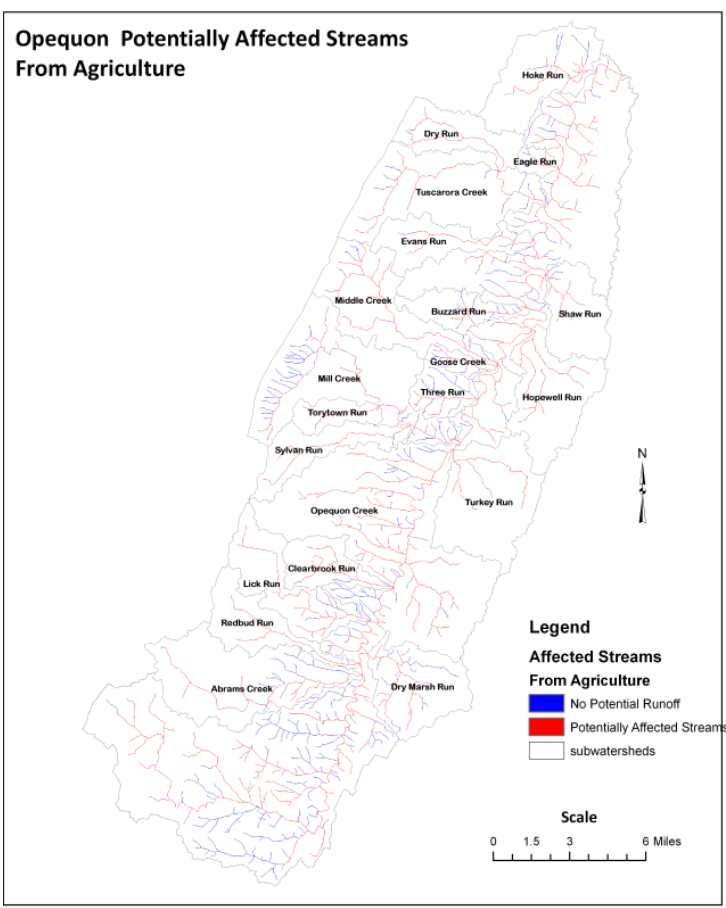

Figure 9c: Agricultural land

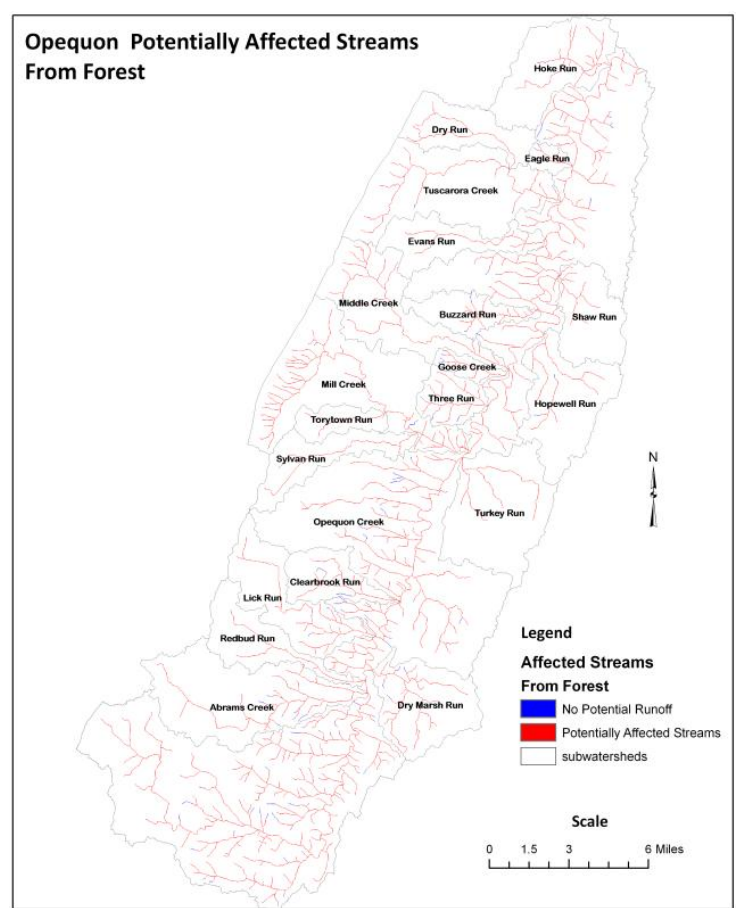

Figure 9d: Forest land

Figure 9a - c: Potentially Affected Streams from Different Land Use

As shown from these simulations, different land uses have different impacts on the stream water quality. Forest and open brush have greater impact than agriculture and urban land uses. The results are based on the assumption that the respective land uses are the primary sources of nutrients. Given that forest and open brush have greater acreages than urban and agriculture, there is greater potential stream impact than in agriculture and urban land uses. These simulations were then applied to the optimization and cost minimization model for BMPs selection process and implementation for a least cost strategy for effective nutrient reduction at a subwatershed and watershed scales. 


\subsubsection{Nitrogen and Phosphorous Nutrient Simulations}

Water quality modeling in WCMS utilizes a weighted mass balance approach using stream flow and sampled locations or land use data to associate the point location or land use information and stream condition (NRAC, 2007). The resultant modeled nutrient values can be reported either as nutrient values in $\mathrm{Mg} / \mathrm{L}$ for concentration or as $\mathrm{Kg} / \mathrm{Yr}$ for loading. The advantage with this is that the user can specify the units of measurement and thus reduces time to convert from one unit to another. Figure 10 shows simulated $\mathrm{N}$ and $\mathrm{P}$ concentrations in the Opequon Creek watershed.
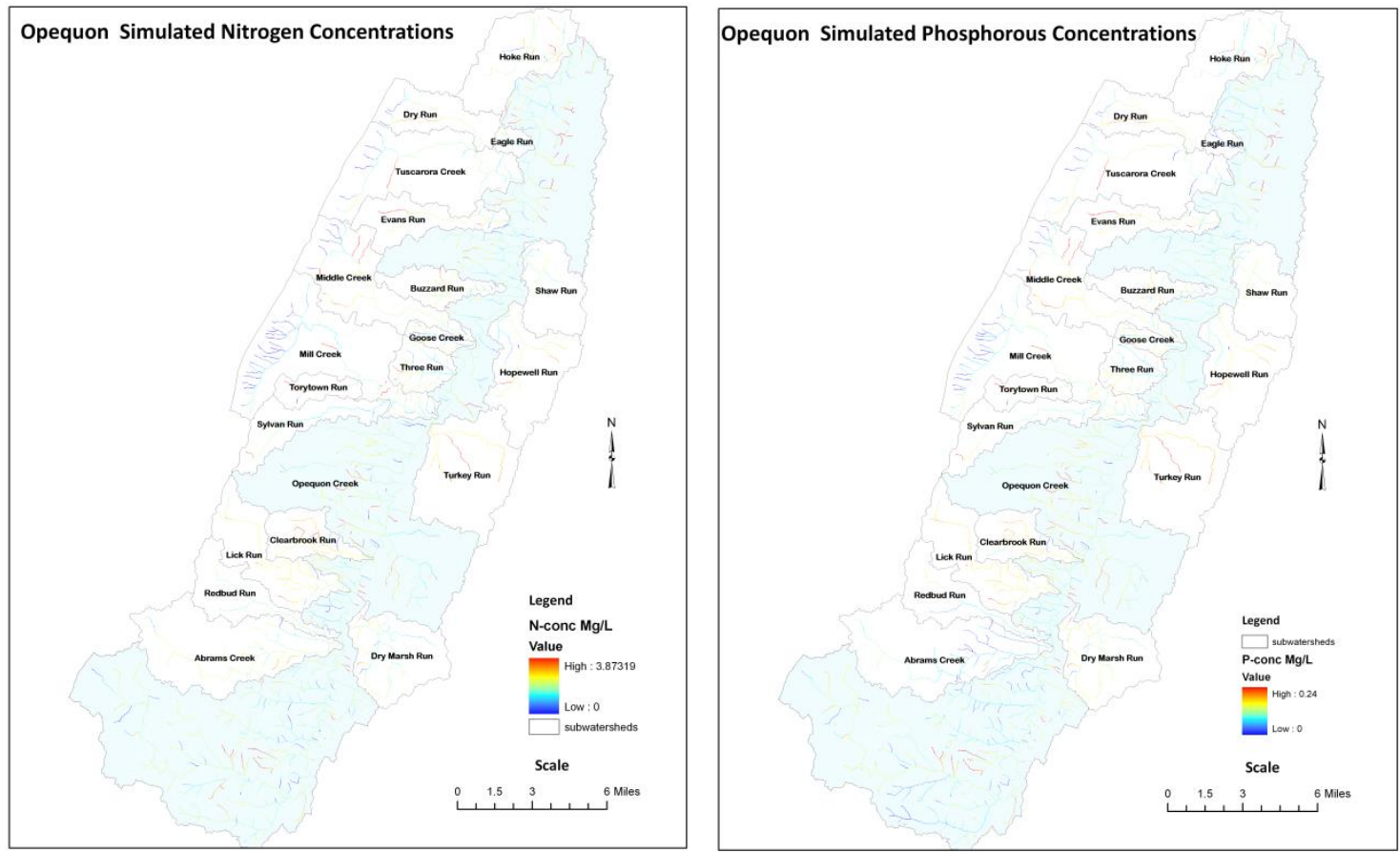

Figure 10: Modeled Nitrogen and Phosphorous Concentrations

Simulated nutrient concentrations are shown from red to blue; with red being the highest impact, moderate impact is shown as yellow and light blues, and the dark blue indicates the lowest impact. An overlay analysis of land use cover and simulated nutrient concentrations show 
that most of the simulated highly polluted streams were in agricultural land (see Figures 9a, and $9 b)$.

\subsubsection{NETWORK MODEL AND NUTRIENT FATE AND TRANSPORTATION}

Non point source pollution is spatially disparate and diffuse and is only indicative of relative or potential sources of pollution. In order to address water pollution problems, specific sources of water pollution are critical in order to come up with mitigation measures and strategies. Such specific pollutant concentrations or loadings can be derived either from field sampling of particular locations or by water quality model simulations of sources of pollution from different spatial locations. This study used each subwatershed's mouth or pour point to as sources of nutrient loadings emanating from that subwatershed. Figure 11 shows different sampling points considered in this study. The points located at the mouth of each subwatershed are used to simulate nutrient loading from that subwatershed. 


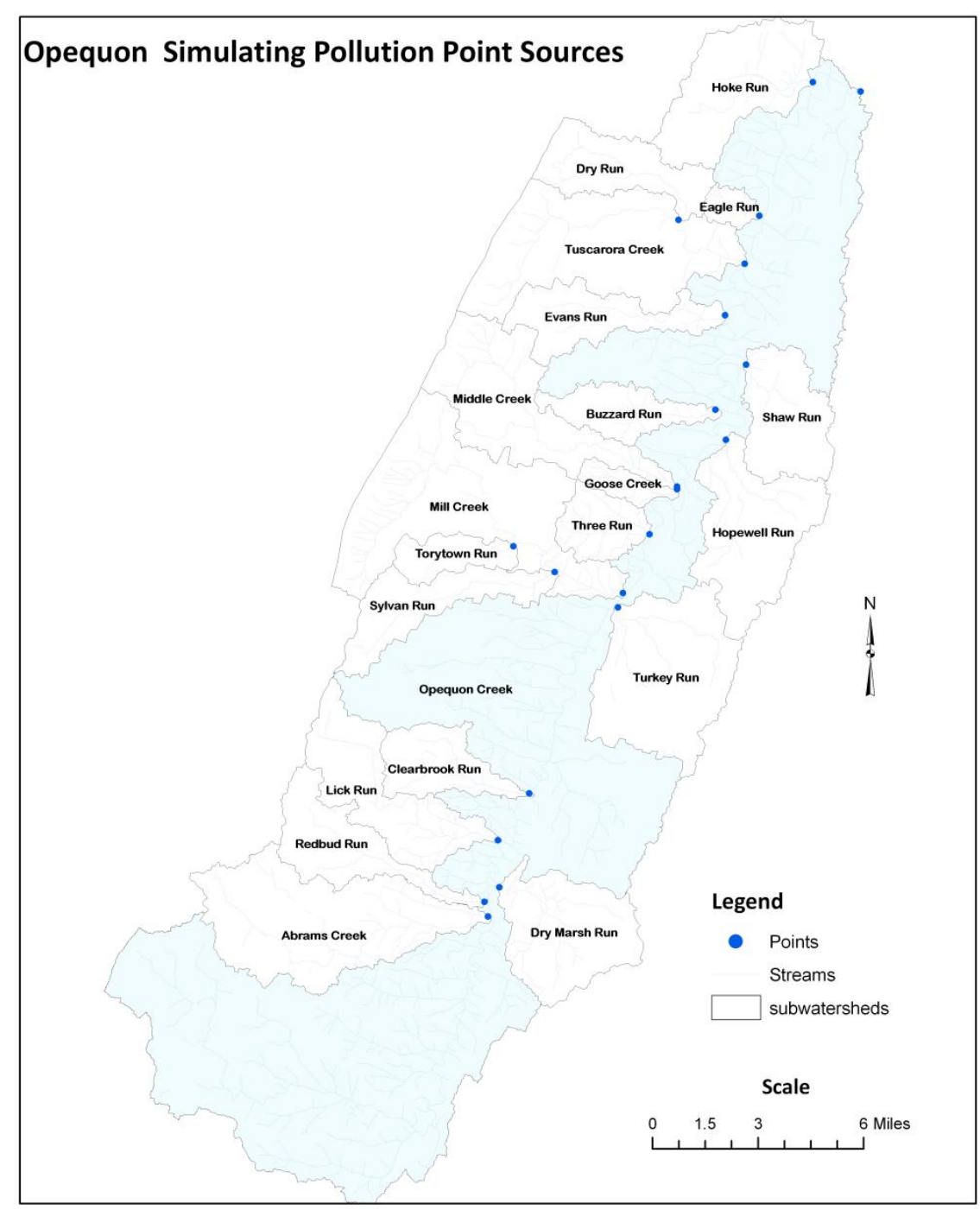

Figure 11: Subwatershed Pollution Simulation

It is from these points that loadings from each subwatershed are simulated. WCMS uses EMCs for land cover types and estimates the concentrations and loadings of pollutants in the affected streams. 


\subsubsection{Land use Land Cover and Simulated $\mathbf{N}$ and $P$}

Figure 12 shows the relationship between land use / land cover and the simulated $\mathrm{N}$ and $\mathrm{P}$ nutrient concentrations.
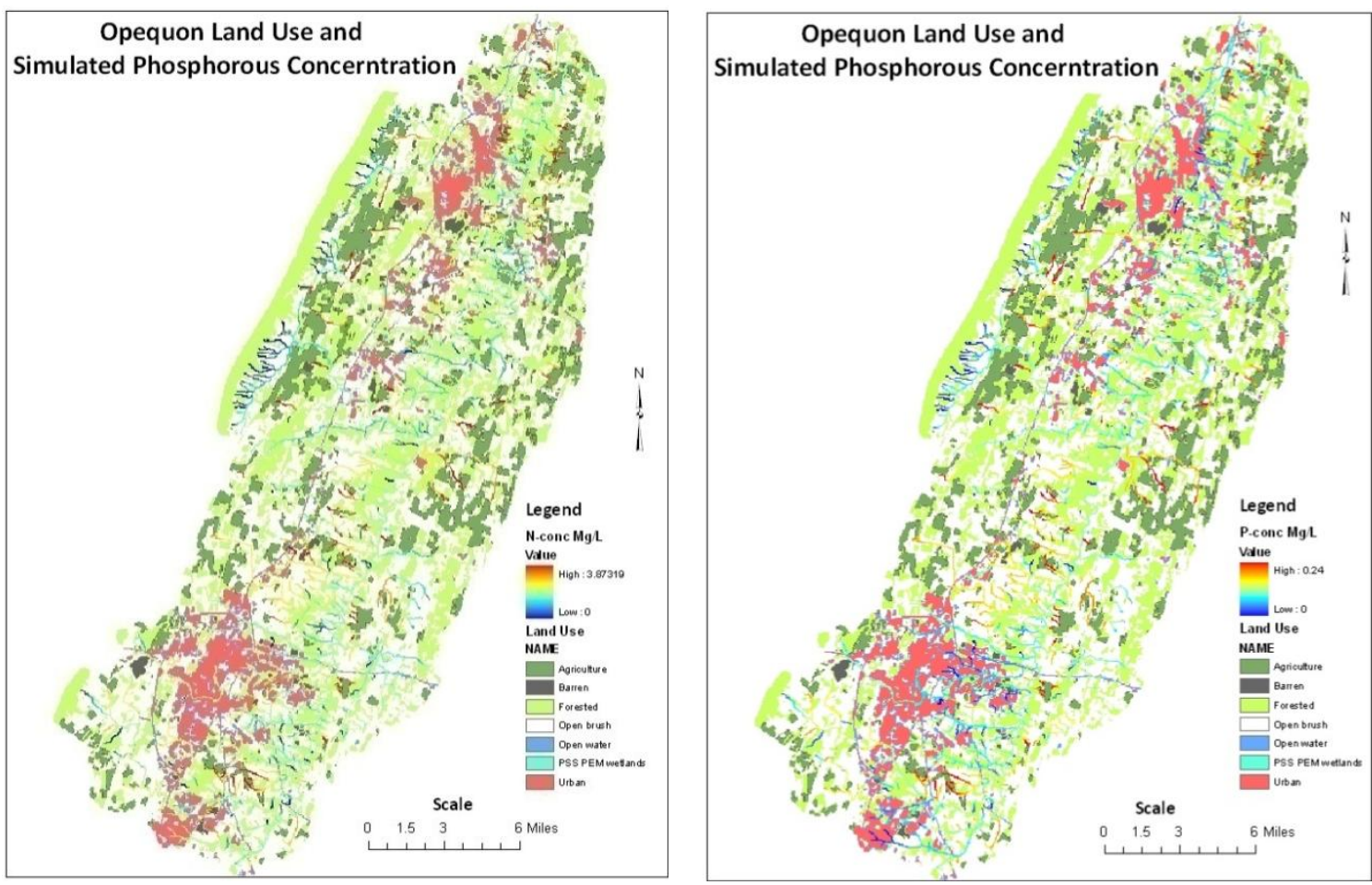

Figure 12: Land Use /Land Cover and Nutrient Concentrations

From the WCMS water quality modeling, EMCs are derived for each subwatershed in the Opequon creek. These concentrations are used to simulate fate and transportation of nutrients in the watershed via the network model. The network model calculates the loadings of nutrients as they are transported from one subwatershed to another. 
As note in previous section, nutrient levels can be reported as either concentrations or loadings. These loadings are the key input in the economic optimization model, which evaluates different BMPs for nutrient reduction from each subwatershed to meet the desired water quality at the mouth of the Opequon Creek at least cost.

\subsubsection{Cost Effective Nutrient Management Strategy}

The final step is to evaluate nutrient-reduction performance and cost effectiveness of innovative BMPs. Four agricultural innovative management alternatives are used to assess costeffectiveness in reducing nutrient loads. The CBR choice of agricultural BMPs (nutrient management, enhanced nutrient management, conservation tillage and cover crops) was based on their potential significance in reducing nutrient loads in the Bay area, applicability to agricultural land, and their feasibility on different land uses. For this study, modeled data and case study characteristics were used in PRediCT (Evans et. al., 2003), to identify more appropriate and representative BMPs and their associated costs. The agricultural BMPs used are conservation tillage/cover crops, cropland protection, nutrient management and grazing land management. The BMPs are evaluated per subwatershed and an overall watershed nutrient management strategy is recommended.

\subsection{NETWORK MODELING}

The network model seeks to simulate fate and transportation of nutrients from each subwatershed to the mouth of the Opequon Creek. This water quality modeling function is embedded in ArcGIS 9.3 and integrated with WCMS extension to simulate nutrient concentrations/loadings; fate and transport of nutrients based on digital elevation model, stream 
flow, direction and accumulation, precipitation land use/land cover patterns in the watershed. Utilizing the above mentioned GIS data layers, the results of WCMS simulated loadings from each subwatershed are shown in Figure 13 and 14.

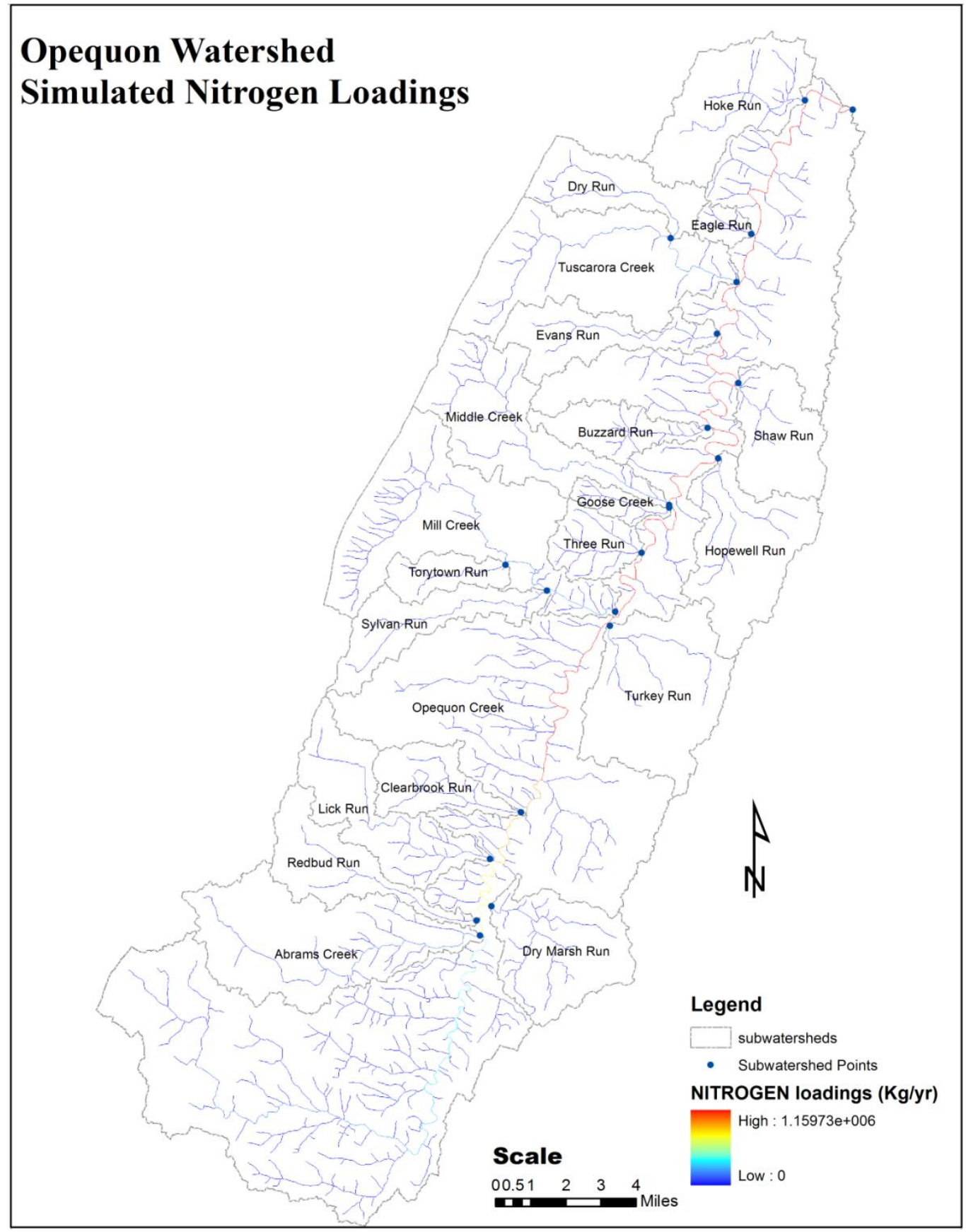

Figure 13: Nitrogen Loadings 


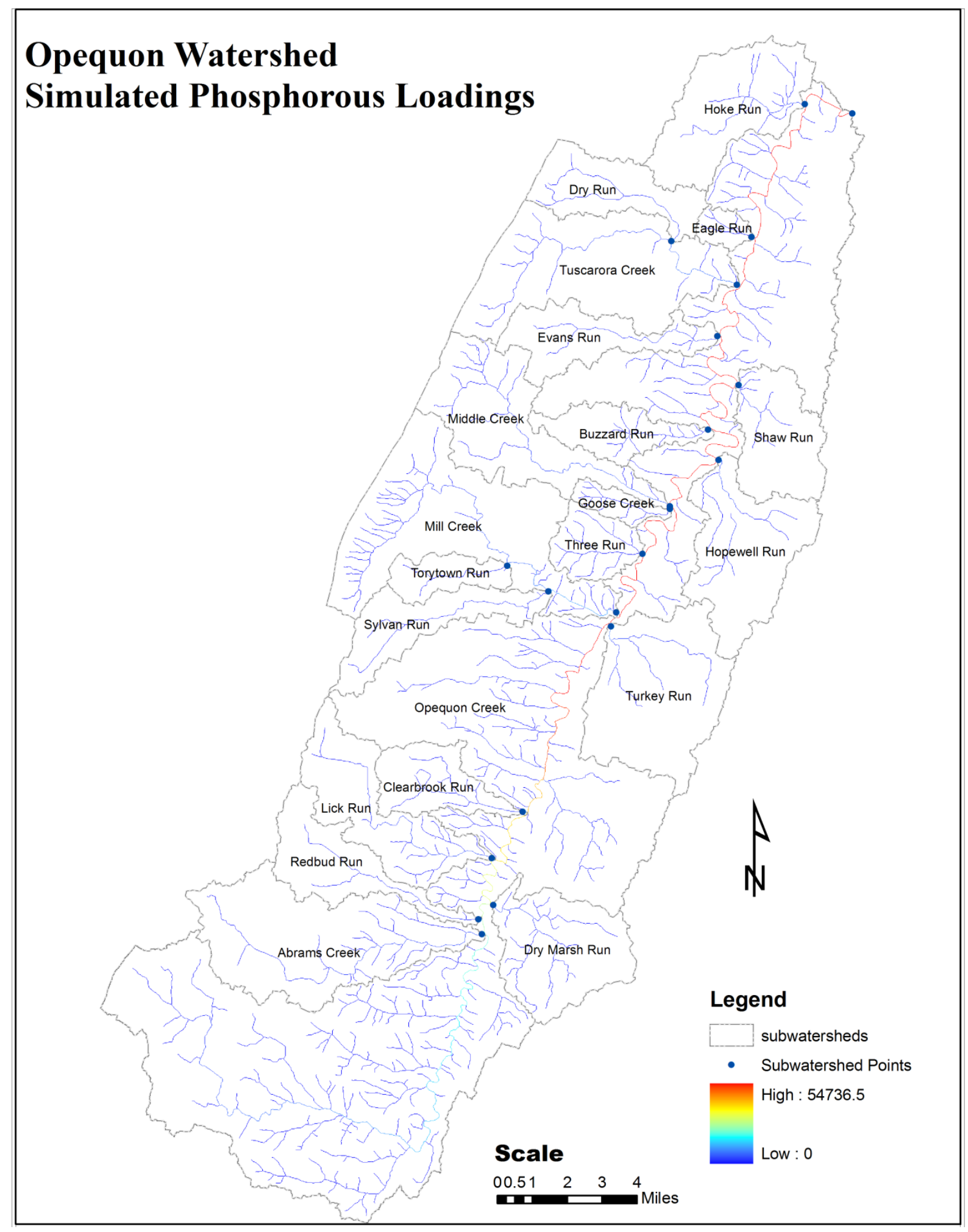

Figure 14: Phosphorous Loadings 


\section{Loadings $(\mathrm{Kg} / \mathrm{Yr})$}

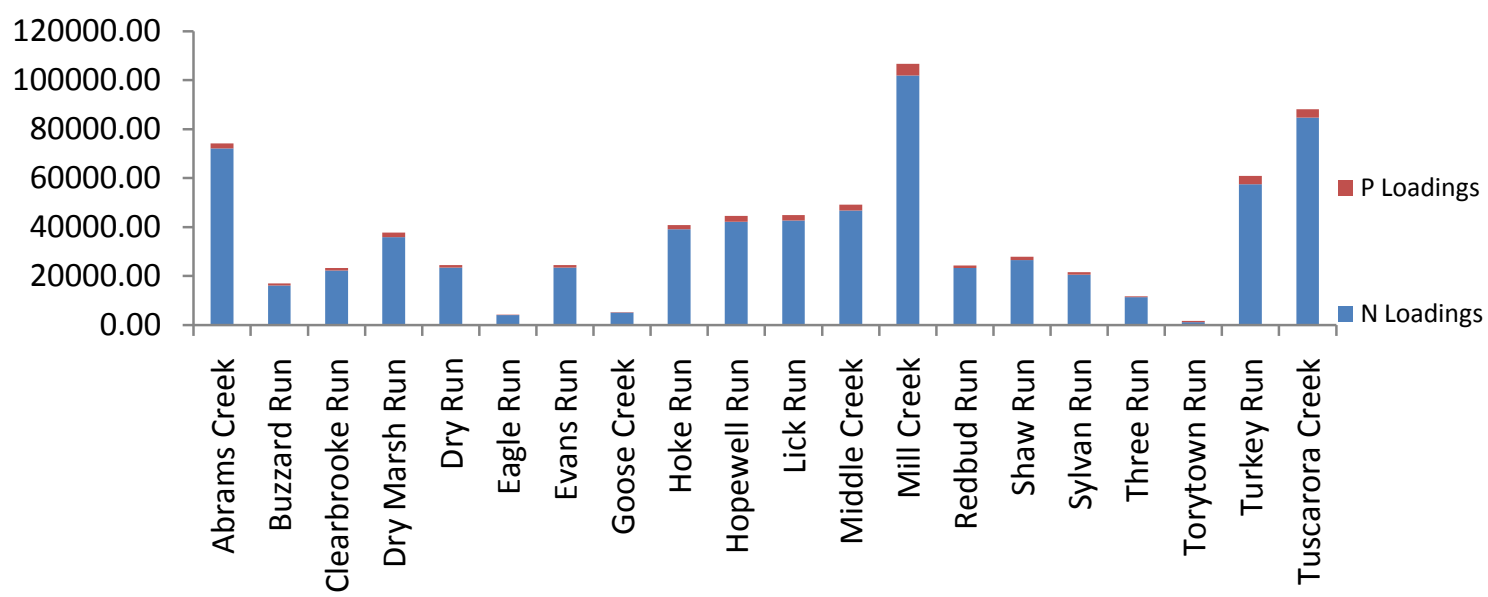

Subwatersheds

\section{Figure 15: Simulated Subwatershed Nutrient Loadings}

As shown on Figure 15, the highest nutrient contributions are from Mill, Tuscarora and Abrams Creeks. There is a strong correlation between the loadings from each subwatershed and its size. Larger subwatersheds have higher nutrient loadings than smaller subwatersheds.

The study also aimed at examining fate and transportation of nutrients to the next subwatershed, finally reaching the mouth of the watershed. A weighted transfer coefficient $a_{i m}$ was used to represent each subwatershed's impact on the main stem. The assumption is that, all things equal, the subwatershed closer to the mouth of the watershed will affect a lesser part of the main stem compared to the one that is further, but will have a greater impact on nutrients exiting the mouth of the Opequon (Bartley, 2006; Haggard et al., 2005; Beaulac and Reckhow, 1982).

The subwatershed coefficient for subwatershed $i$ is given by;

$$
a_{m i}=1-\left[\frac{L_{o}-L_{s}-L_{w}}{L_{0}}\right]
$$


Note that $\frac{L_{o}-L_{s}-L_{w}}{L_{0}}$ is a ratio, whereby $L_{o}$ is the loading the watershed's mouth or main outlet, $L_{s i}$ is the loadings on the main stem midway before the next subwatershed joins the main stem and $L_{w i}$ is the loadings from a subwatershed $i$. By subtracting the ratio of loadings between these points from 1, the loading the watershed's mouth, we have coefficients which indicate the relative contribution of a given subwatershed discharge on the Opequon Creek. In other words, a subwatershed located higher in the watershed will have a lower coefficient because nutrient concentrations or loadings tend to dissipate and diluted along the greater length of the main stem, whereas a subwatershed that enters the main stem of Opequon close to its mouth will have greater impact on concentrations or loadings exiting the Opequon Creek watershed due to less dissipation and dilution of nutrient loadings before they exit the watershed.

These coefficients indicate the weight or impact the loadings from each subwatershed will have on the main stem. In this Abrams subwatershed for instance will have a lower coefficient as it is the furthest from the mouth compared to Hoke Run which is closer to the mouth of the watershed. Subwatershed, main stem loadings and subwatershed coefficients are shown in Table 6. 
Table 6: Spatial distribution of Nutrient Loadings and subwatershed coefficients

\begin{tabular}{|c|c|c|c|c|c|c|}
\hline \multirow{2}{*}{\multicolumn{3}{|c|}{ Subwatershed Nutrient Loadings }} & \multicolumn{2}{|c|}{$\begin{array}{l}\text { Main Stem Nutrient } \\
\text { Loadings }\end{array}$} & \multirow{2}{*}{\multicolumn{2}{|c|}{$\begin{array}{c}\text { Subwatershed Transfer } \\
\text { Coefficients }\end{array}$}} \\
\hline & & & $N(l b s / Y r)$ & $P(l b s / Y r)$ & & \\
\hline Subwatershed & $N(l b s / Y r)$ & $P(l b s / Y r)$ & 435636.8 & 13307.7 & Nitrogen & Phosphorous \\
\hline Abrams Creek & 158990.2 & 4382.9 & 435636.8 & 19780.6 & 0.23 & 0.20 \\
\hline Redbud Run & 51509.7 & 1965.5 & 597420.3 & 24304.2 & 0.25 & 0.22 \\
\hline Dry Marsh Run & 79268.3 & 4091.3 & 650324.8 & 26334.6 & 0.29 & 0.25 \\
\hline Lick Run & 94000.6 & 5117.3 & 741828.3 & 30960.8 & $\mathbf{0 . 3 3}$ & $\mathbf{0 . 3 0}$ \\
\hline Clearbrooke Run & 48963.3 & 2417.6 & 848752.3 & 36755.9 & 0.35 & 0.32 \\
\hline Turkey Run & 126857.0 & 7468.2 & 1156930.8 & 52887.3 & $\mathbf{0 . 5 0}$ & $\mathbf{0 . 5 0}$ \\
\hline Mill Creek & 224611.0 & 10688.5 & 1335947.6 & 62827.4 & 0.61 & 0.61 \\
\hline Three Run & 24989.2 & 964.7 & 1584231.5 & 74804.6 & 0.63 & 0.63 \\
\hline Goose Creek & 11223.2 & 511.1 & 1616091.0 & 76099.8 & 0.64 & 0.63 \\
\hline Middle Creek & 102991.4 & 5351.2 & 1628641.1 & 76730.9 & 0.68 & 0.68 \\
\hline Hopewell Run & 93078.5 & 5036.1 & 1757227.5 & 83284.9 & 0.72 & 0.73 \\
\hline Buzzard Run & 35669.6 & 1593.7 & 1858019.7 & 88629.9 & 0.74 & 0.75 \\
\hline Shaw Run & 58597.9 & 2928.4 & 1910663.7 & 90947.3 & 0.77 & 0.78 \\
\hline Evans Run & 51580.7 & 2544.6 & 2019313.6 & 95949.6 & 0.81 & 0.82 \\
\hline Tuscarora Creek & 186657.8 & 7484.4 & 2094031.7 & 99469.1 & 0.89 & 0.89 \\
\hline Eagle Run & 8911.8 & 250.4 & 2314223.5 & 108588.4 & 0.91 & 0.90 \\
\hline Hoke Run & 86347.7 & 3786.0 & 2417315.2 & 113711.7 & 0.98 & 0.97 \\
\hline \multirow{2}{*}{\multicolumn{3}{|c|}{ Opequon Mouth }} & 2517755.2 & 118331.9 & & \\
\hline & & & 2551410.7 & 120420.2 & & \\
\hline
\end{tabular}

Abrams Creek which is upstream has smaller coefficients for nutrient effects downstream than say Hoke Run which is located near the mouth of the Opequon. The sampled points are located in between subwatershed mouths as shown on Figure 16. 


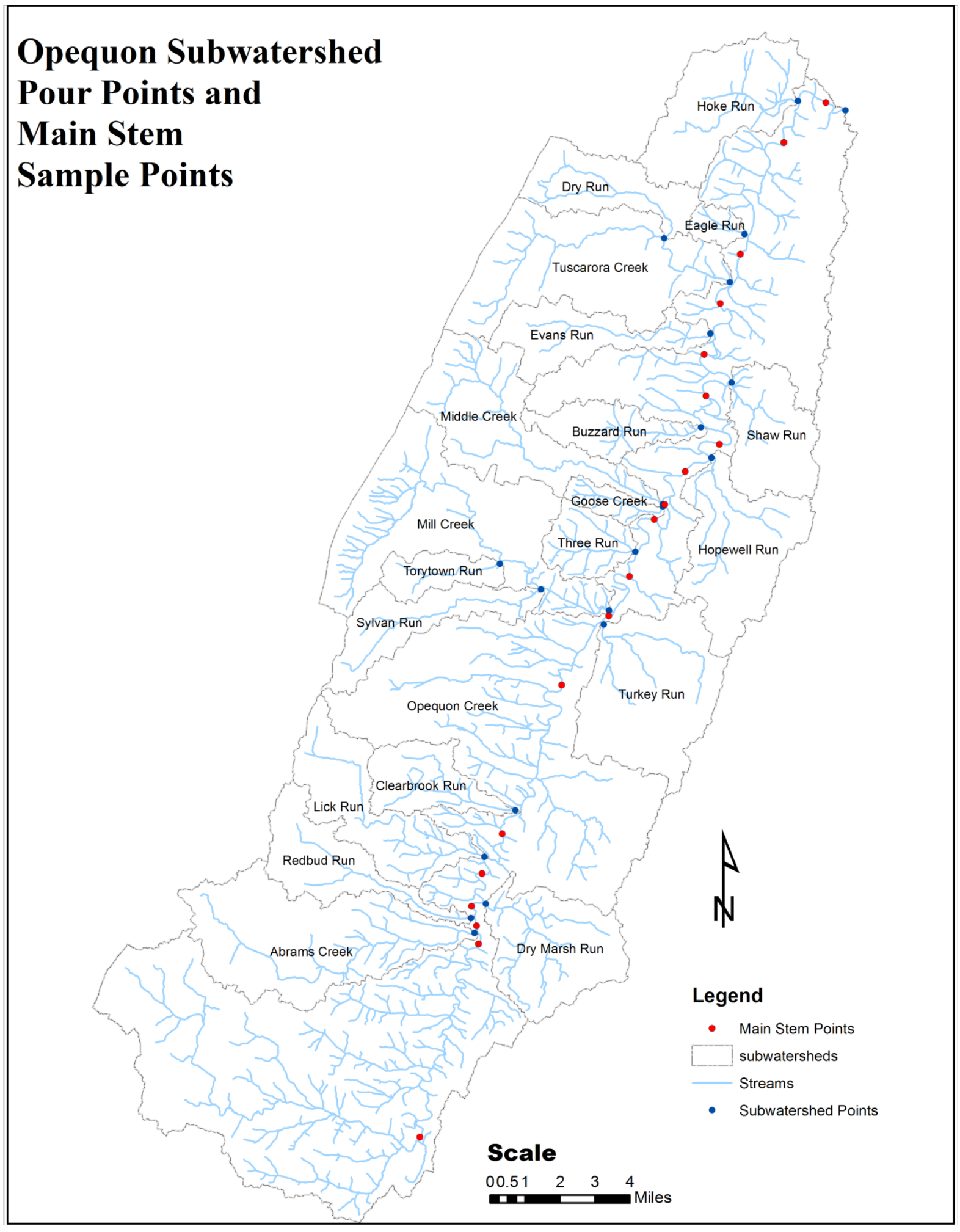

Figure 16: Distribution of Subwatershed Pour Points and Main Stem Sampling Points 
The loadings accumulate along the main stem as shown in the diagram below.

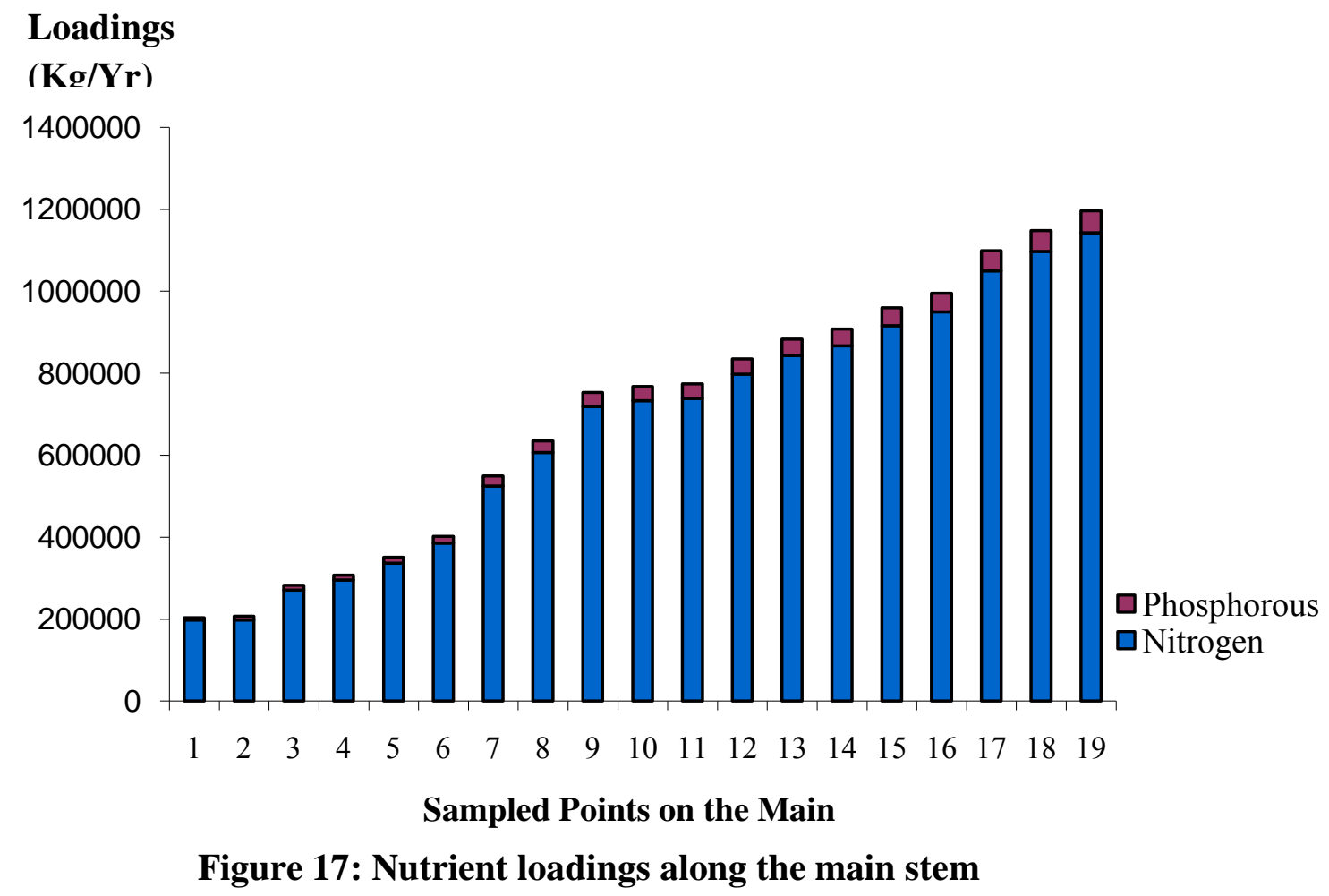

The diagram above shows loadings along the main stem of the Opequon, starting with the furthest point (1) to the mouth of the Opequon Creek (19). As can be seen from Figure 17, the concentration of nutrients accumulates along the main stem. Consequently, subwatersheds near the mouth of the main stem will have a greater impact on nutrient contribution at the mouth of the Opequon than those further upstream. Thus coefficients are incorporated in the optimization model to account for this downstream impact of nutrient transfer.

\subsection{Cost Minimization Model}

Constrained optimization problems are common in economics and operations research whereby the main objective is either maximizing output or profits from a given budget or sales; 
or minimizing cost of a set of production output. This study utilizes a linear cost minimization model. It should be noted that a linear programming problem, such as the one used in this study, assumes a linear objective function and linear inequality constraints. Linearity assumes constant prices for outputs (like in a perfect competition market), constant returns to scale and nonnegative constraints. Unlike in a maximizing problem, the resource constraints appear in the objective function in a cost minimization problem. Mathematically, the cost minimization problem for this study is given by;

$$
\begin{aligned}
& \text { Min } \quad T C=\operatorname{Min} \sum_{i} \sum_{c} C_{i} B M P_{i}+\sum_{i} \sum_{p} C_{i} B M P_{i} \\
& \text { subject to: } \\
& \text { Loading Reduction } \leq \sum_{i} \sum_{c} R_{c} B M P_{c i} * a_{i m}+\sum_{p} \sum_{i} R_{p i} B M P_{p i} * a_{i m} \\
& \sum_{i}^{n} B M P_{i} \leq \operatorname{Crop}_{i} \\
& \sum_{i}^{n} B M P_{i} \leq \text { Pasture }_{i} \\
& B M P_{i c} \geq 0 \\
& i=\text { subwatersheds }
\end{aligned}
$$

The total cost function ( $T C$ ) is total costs of implementing agricultural BMPs on agricultural land. It is composed of per unit cost of BMP implementation $\left(C_{i}\right)$ and the number of acres ( $B M P)$ on which the BMP will be implemented. Each BMP has nutrient reduction 
efficiencies $\left(R_{c}\right)$ depending on the type of nutrient it is aimed to reduce. These reduction efficiencies and per unit costs vary for both $\mathrm{N}$ and $\mathrm{P}$ reductions. Most agricultural BMPs can reduce both $\mathrm{N}$ and $\mathrm{P}$. Research experiences from the Chesapeake Bay have pointed to some of the cost effective BMPs within the Bay area. The Chesapeake Bay recommended agricultural BMPs, potential annual reduction at the maximum feasible level of implementation and their respective per unit costs.

Two methods were used to compute the nutrient loadings needed for $R_{c}$. In the first method, Chesapeake Bay wide averages were used for $\mathrm{N}$ and $\mathrm{P}$ loadings (Table 4). Reductions were computed by converting Conventional Tillage estimates (lbs/ha) from Table 4 to loadings per acre (lbs/acre) for Conservation Tillage and Crop Protection BMPs. The same computations were applied to Nutrient Management and Grazing Land Management $\mathrm{N}$ and $\mathrm{P}$ using the pasture loading estimates. To compute nutrient reductions, these loadings were multiplied by the agricultural BMP N and P reduction efficiencies (Table 7).

The second method utilized $\mathrm{N}$ and $\mathrm{P}$ loadings per acre computed at a subwatershed level. The total loadings per subwatershed were computed from WCMS. Then, these loadings were allocated out to each land use (forest/woodland, pasture/open brush, crop/agriculture, barren land and urban areas) in a subwatershed based upon relative contributions of Table 4 nutrient loading values for the Chesapeake Bay area. Subwatershed total loadings are a product of the pounds (lbs) per acre and the total number of acres per subwatershed land use category. The contributions of each land use are weighted against agriculture/crop land to obtain the $\mathrm{N}$ and $\mathrm{P}$ loading in pounds per acre for agriculture and pasture lands that would result in the WCMS total 
subwatershed contribution estimate. Nutrient reductions in pounds per acre were then computed using the same $\mathrm{N}$ and $\mathrm{P}$ reduction efficiencies from Table 7 as in method one.

In addition nutrients from one subwatershed find their way into the main stem and transferred from one subwatershed to another and eventually leave the watershed at the mouth or pour point. The impact a subwatershed on the main stem is denoted by $a_{i m}$. This is a transfer coefficient representing the assimilative capacity of water as loadings from one subwatershed are transferred along the main stem to the mouth of the watershed. Subwatershed that are far away from the mouth of the watershed have a lower transfer coefficient as the nutrients get diluted and assimilated by the water along the main stem than the subwatershed that are closer to the mouth of the watershed. Different BMPs if implemented can reduce nutrient loadings in the watershed. Therefore the overall objective is to evaluate nutrient reduction performance and cost effectiveness of different BMPs and recommend a nutrient reduction strategy for the Opequon watershed.

For this study the BMP types, costs and reduction efficiencies were derived from Pollution Reduction Impact Comparison Tool (PRedICT) (CPSU, Evans et al, 2002). PRedICT is a decision-support tool that allows simple and quick analyses of load reductions for various BMP implementation strategies on a watershed scale. The model allows for the evaluation of loadings of nitrogen, phosphorus, and sediment from agricultural, industrial, and urban sources.

The analysis is based on user-defined watershed characteristics, such as land use spatial characteristics, nutrient loadings from various sources, existing BMP levels, and BMP pollution reduction efficiencies and costs. The model output generates pollutant loadings given existing 
and proposed BMP levels, estimated load reductions, and the costs for the proposed BMP scenario (Borisova et al, 2005).

The model simulates mean annual loadings of N, P, Sediment, Pathogens under various BMP implementation scenarios for nutrient reduction. The advantage of PredICT is that it aggregates several agricultural BMPs into BMP systems/combinations. The logic being that, as recognized by the Chesapeake Bay Program, BMPs are typically used in combinations rather than individually to mitigate on-farm loss of soil and nutrients. Specifically, the following PredICT BMP combinations are used in this study, conservation tillage/cover crops, cropland protection, nutrient management and grazing land management.

Other BMPs that are modeled in PRedICT but not incorporated in this study include vegetated buffer strips, fencing, bank stabilization, constructed wetlands / wet ponds / bioretention, wastewater treatment plant up-grades / reduction of people on septic systems, upgrades for animal systems and erosion and sediment control on un-paved roads.

The following data are required to apply PRedICT:

- Watershed area, area of row crops vs. hay/pasture, agriculture land on sloped land, streams in agriculture / urban areas, total stream length, area of high / low density urban, and unpaved road length

- Current extent of BMP application (as percent of area / stream length)

- Pollution reduction efficiencies for BMP.

- Unit costs for BMP

A number of scenarios can be evaluated using different current and future BMP applications, wastewater treatment upgrades, reductions of people on septic systems, erosion and sediment 
control for unpaved roads, and changes to animal systems. However, this study was limited only to agricultural/rural BMPs. In terms of outputs, the model produces estimated scenario loading / runoff from upland (by land use), streambank erosion, groundwater / subsurface, point source discharge, septic systems, etc; percent reductions in loading in comparison with the current state and total scenario costs. This study only utilized the reduction efficiencies and total costs per BMP implementation as input data for the cost minimization model.

PRedICT also has an option to perform spatial optimization (i.e., to achieve maximum reduction for a given budget, or to minimize costs of achieving targeted reductions). However, this option is not yet implemented in the current PRedICT version 7.1.3, 2008 edition. The following agriculture BMP per unit costs and nutrient reduction efficiencies derived from PRedICT model were used in this study (Evans et al., 2003). These costs are average annual costs of BMP implementation, derived from the Conservation Catalog prepared by the Pennsylvania Conservation Partnership (2000) and the BMP guidance document by the U.S. EPA (1990) (Evans et al., 2003). 
Table 7: BMP Costs and Reduction Efficiencies

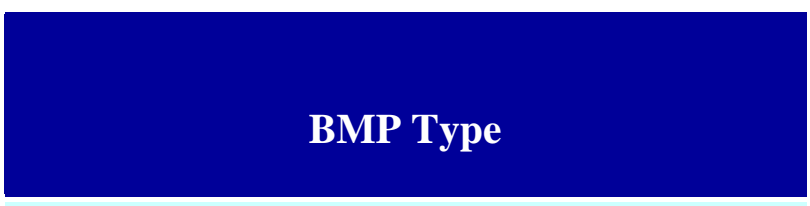

BMP 1 - Conservation Tillage, Cover Crops

BMP 2 - Cropland Protection

BMP 3 - Nutrient management

BMP 4 - Grazing Land Management

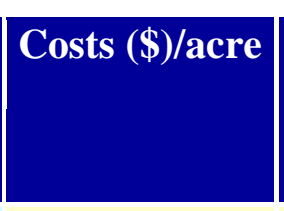

$\$ 30.00$

$\$ 25.00$

$\$ 110.00$

$\$ 360.00$
N Reduction

Efficiency (\%)

.25

36
P Reduction

Efficiency $(\%)$
.23

.70

.28

.43

\subsubsection{Public Participation and Optimization Modeling}

The incorporation and involvement of watershed stakeholders and communities is important for the successful management of the watershed. The level of involvement and participation varies and it is usually difficult to not only accurately characterize, but also get the communities and stakeholders to participate voluntarily.

Given research time limitations, this study utilized data and results from a study conducted by the Opequon Creek Project Team (OCPT, 2006) that involved the stakeholders' inputs in the watershed prioritization of the Opequon Creek. In order to prioritize subwatersheds, different criteria were selected for comparing and distinguishing subwatersheds.

The Opequon Creek Project Team selected and ranked critical elements as follows: 
1. Level of Tributary Impairment (including nutrients, sediment, fecal bacteria and habitat). This was further subdivided into Nitrogen, Phosphorus, and Habitat components.

2. Impact of Tributary on Main Stem

3. Level of Stakeholder Involvement

4. Homogeneity of Land Use (higher is better)

a. This is intended to indicate subwatershed complexity.

b. Relates to probability of success of implemented projects.

5. Amount of existing credible info/data available for that subwatershed

6. Change in impervious surface over time (as a proxy for landscape change - where work is probably most needed).

Once the criterions were selected, the prioritization criteria were ranked, from most to least important (OCPT, 2006). From these rankings, a normalized rank was developed that gave the higher ranked criteria proportionally more weight in a prioritization matrix shown in Table 8 . 


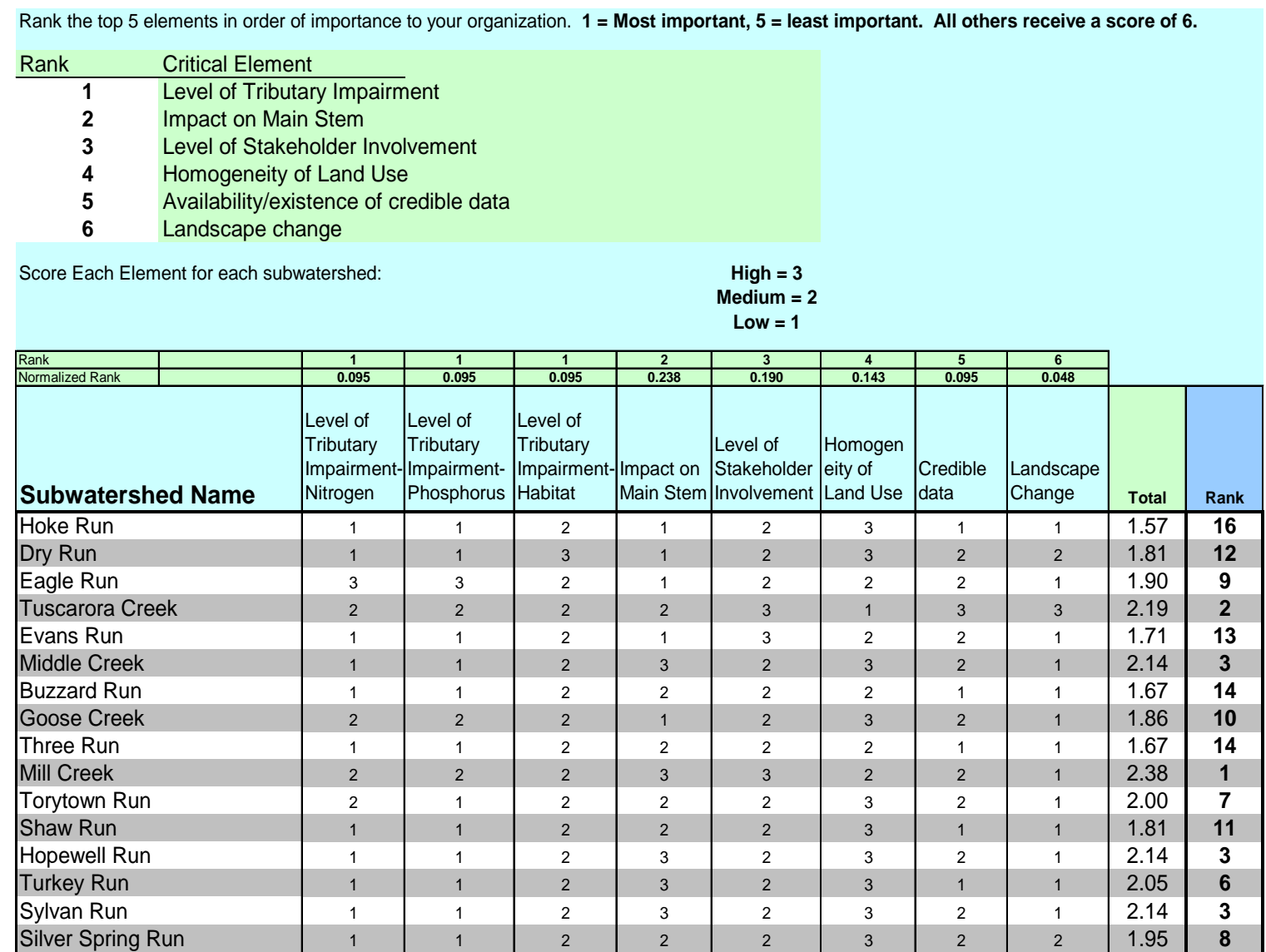

\section{Table 8: The Opequon Subwatershed Prioritization Matrix}

(Source: Bartley, 2006)

As shown above, the results of the study showed that the highest priority subwatershed, according to the criteria selected and the scores assigned within the prioritization matrix by the OCPT, was Mill Creek with a weighted average of 2.38; followed by Tuscarora Creek with a weighted average of 2.19; Middle Creek; Hopewell Run and Sylvan Run subwatersheds tie for third at 2.14 (Bartley, 2006).

\subsection{SCENARIO ANALYSIS}

There are four scenarios of analysis used in this study. The first scenario is a "uniform allocation" which requires that every sub watershed make the same amount of pollution 
reduction of $37 \%$ and $35 \%$ for $\mathrm{N}$ and $\mathrm{P}$ respectively. The reduction levels are derived from the WV watershed reduction goals for the Potomac Basin using 1985 as a base year to 2010. Thus in this scenario, every subwatershed must meet these reduction goal. This scenario utilizes two sources of data for the model namely, the Chesapeake Bay land use nutrient contribution averages and WCMS specific land use contributions.

The second scenario is holistic approach whereby the entire watershed's nutrient reduction strategy is to meet the nutrient reduction level without considering specific watersheds for nutrient reductions. The main objective is to meet the reduction level of nutrients at the mouth of the watershed. This approach incorporates the spatial distribution of pollution sources into the cost minimization model and focuses on reducing loadings to meet the targeted reduction level at the mouth of the watershed.

The third scenario is a prioritization approach to pollution reduction, which examines BMP evaluation and implementation in highest polluting subwatersheds. High polluting subwatersheds can be identified by either utilizing WCMS water quality simulation of nutrient loadings in respective subwatersheds or utilizing local community input through public participation to identify, rank and prioritize subwatersheds that need immediate attention to reduce nutrient loadings. For this approach secondary data from the OCPT is utilized where the Opequon Creek community identified, ranked and prioritized subwatersheds for nutrient reduction. These priority subwatersheds are then evaluated for a least cost strategy to reduce nutrient levels using different BMP options.

The fourth scenario, a targeted approach, involves meeting reduction goals in Virginia and West Virginia parts of the Opequon watershed. Thus two points are analyzed along the main 
stem, one at the border between WV and VA, and the other point at the mouth of the Opequon in WV. The VA reduction goals for $\mathrm{N}$ and $\mathrm{P}$ are $47 \%$ and $39 \%$ respectively, while $\mathrm{WV}$ has to meet a $37 \%$ and $35 \%$ for $\mathrm{N}$ and $\mathrm{P}$ respectively as shown on the Table 9 below.

Table 9: VA and WV Chesapeake Bay Targeted Nutrient Reduction Goals

\begin{tabular}{|c|c|c|c|c|c|}
\hline State & \multicolumn{4}{|c|}{$l b s / Y r$} & \multirow[b]{2}{*}{$\%$ Reduction } \\
\hline VA & 1985 & 2002 & 2010 & Cap Load & \\
\hline TN & 24243869 & 22844023 & 12904649 & 12839755 & 47.0 \\
\hline \multirow[t]{2}{*}{ TP } & 2312229 & 1951674 & 1120665 & 1401813 & 39.4 \\
\hline & \multicolumn{4}{|c|}{$l b s / Y r$} & \\
\hline $\mathbf{W V}$ & 1985 & 2002 & 2010 & Cap Load & $\%$ Reduction \\
\hline TN & 7540000 & 7150000 & 4750000 & 4750000 & 37.0 \\
\hline TP & 570000 & 570000 & 370000 & 370000 & 35.1 \\
\hline
\end{tabular}

(Source: Potomac Basin Nutrient Reductions)

Using these different scenarios, different nutrient strategies are evaluated and compared for the Opequon. The advantage with this approach is that it allows for the evaluations of all possible strategies to reduce nutrients given the available management options and their effectiveness to meet the desired goal at least cost. It also allows for multiple view analysis by integrating different management options for more informed decision making.

\subsection{SUMMARY}

This chapter examined the methods and techniques for evaluating the different BMPs for nutrient reduction. Four scenarios are considered, a uniform reduction strategy across all subwatersheds, a holistic approach involving the entire watershed, a targeted or priority watershed approach, and specific reduction points along the main stem. The goal is to recommend the least cost strategy given the available choice of BMPs, per unit costs of BMP implementation, reduction efficiency levels and the acreage of land use for implementation. 


\section{CHAPTER 7: RESULTS AND DISCUSION}

\subsection{INTRODUCTION}

Chapter 6 described the methods and techniques used for water quality simulation, calibration, modeling and analysis as well as the economic optimization. This chapter analyses and interprets the empirical results. Firstly, the results of the water quality modeling are presented, followed by stream network modeling and lastly, the optimization modeling.

\subsection{WATER QUALITY MODELLING}

Water quality modelling simulations shown previously in Figure 17 were nutrient loadings along the Opequon main stem. These loading simulations are based on watershed land use characteristics of 2007. Seven general classes were used as loading values for the nutrients analyzed in this study were only available for afore mentioned classes. These classes are shown in Appendix IV. The land use classification is associated with expected concentrations/loadings based on the acreage of the land use class. The derived loadings are annual averages and when used with the modeled stream flow can give concentration $(\mathrm{Mg} / \mathrm{L})$ as well as loadings $(\mathrm{Kg} / \mathrm{Yr})$ results for the stream (NRAC, 2007).

Figures 18 and 19 show WCMS simulated N and P loadings by subwatershed. Mill Creek has the highest loadings of $\mathrm{N}$ and $\mathrm{P}$, followed by Tuscarora. Abrams, Turkey Run and Middle Creeks also indicate high nutrient loadings. The results are consistent with large areas under crop production and grazing lands. 


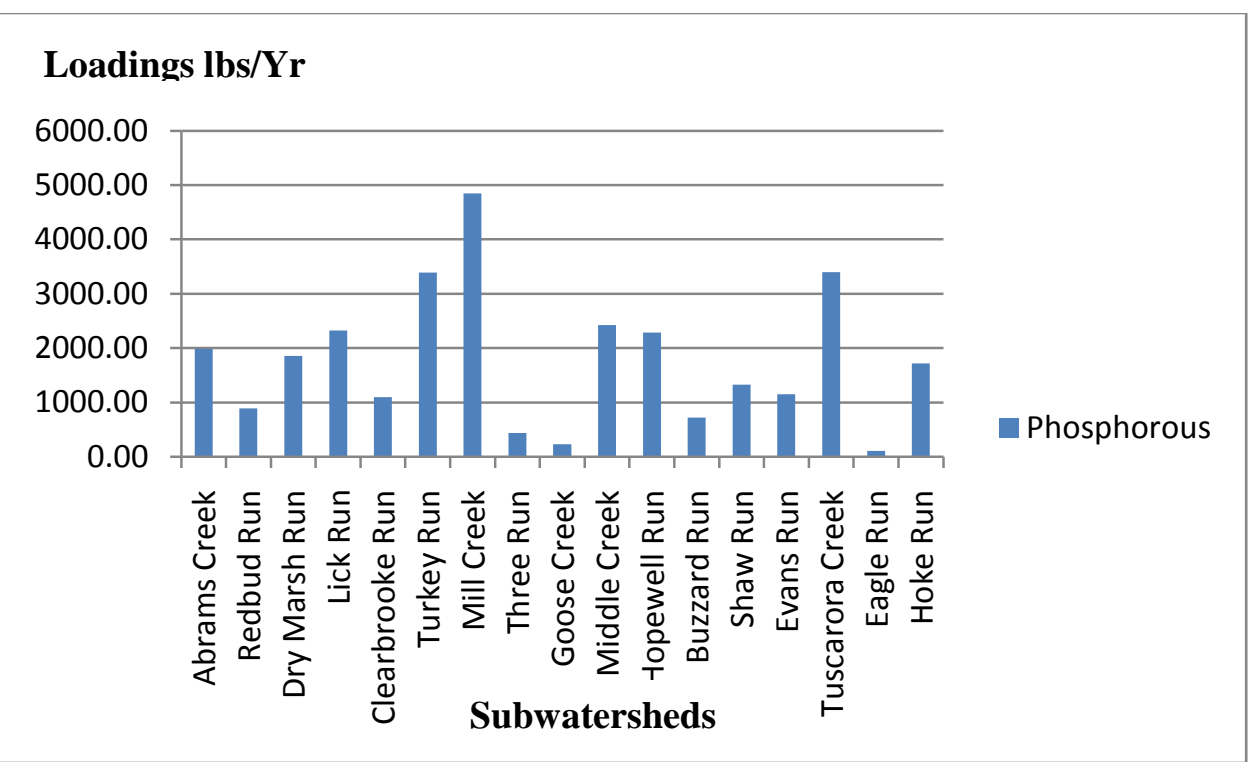

Figure 18: Subwatershed Phosphorous Loadings

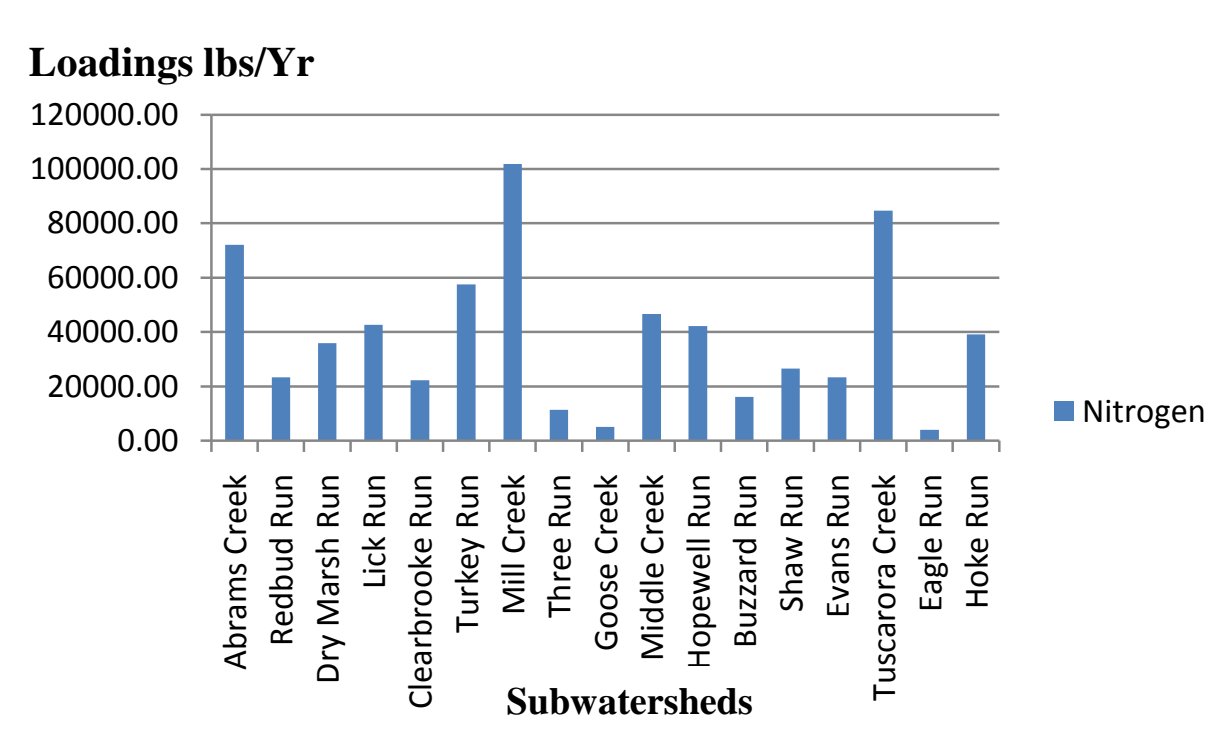

Figure 19: Subwatershed Nitrogen Loadings 
It can be inferred from the results that agriculture plays a significant role in nutrient contribution to the Opequon Creek. The results are consistent with research findings in the Chesapeake Bay and other studies that observed that agriculture is the number one polluter of nutrients (Chesapeake Bay Program, 1998; US EPA, 2007; US EPA, 1992; US Geological Survey, 1999). The subwatersheds showing significant nutrient contributions (Mill, Abrams and Tuscarora creeks) can be targeted as priority subwatersheds for nutrient reduction. The prioritized watershed can then be further evaluated for a least cost strategy of BMP recommendation and implementation.

\subsection{STREAM NETWORK MODELLING}

Stream water quality modelling was conducted on the main stem of the Opequon Creek to establish fate and transportation of nutrients. The nutrient loadings were determined for 20 systematically sampled points along the main stem (Figure 19). These points are midway between subwatersheds' mouths to establish nutrient transfer between subwatersheds. 


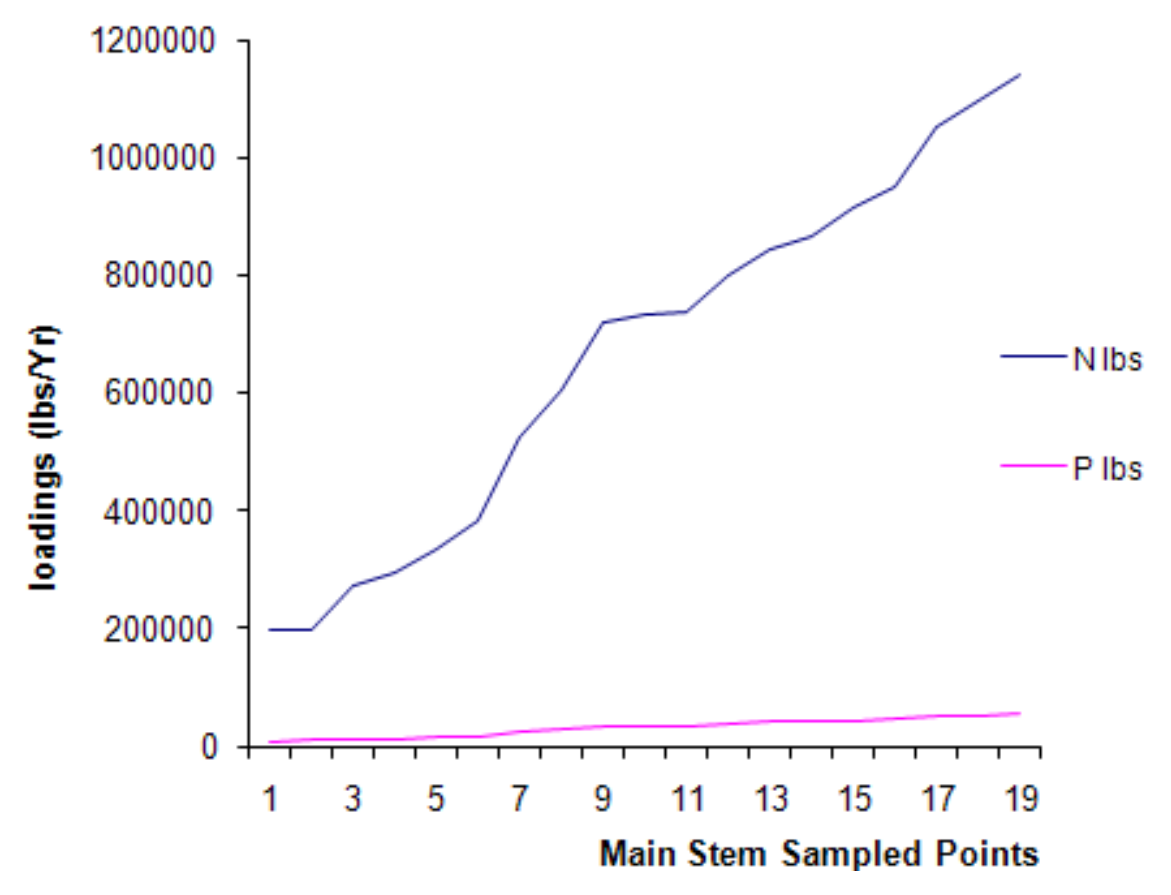

Figure 20: Opequon Creek Main Stem $N$ and P loadings

The results show that the Opequon watershed has substantially higher levels of $\mathrm{N}$ than $\mathrm{P}$. According to US EPA (2005), the major sources of excess nitrogen in predominantly agricultural watersheds are fertilizer and animal waste. As shown on the land use map for the Opequon (Figure 5), agriculture and open brush land are the predominant land uses in Opequon watershed. One can infer that high levels of $\mathrm{N}$ are agricultural related. This is because research studies have shown that high concentrations of nutrients in agricultural streams are correlated with nitrogen inputs from fertilizers and manure used for crops and livestock wastes (Ribaudo, 2001; US Geological Survey, 1999; US EPA, 1998). In addition, excessive use of agricultural fertilizer and manure production also causes $\mathrm{N}$ and $\mathrm{P}$ surplus to accumulate in soil, resulting in some of it leaching into the soil and transported to creeks and streams. Since the source of pollution is non 
point source, there is a need to implement agricultural BMPs that can help in the reduction of nutrients in the Opequon to meet a reduction goal.

The model results also show an increase of nutrients towards the mouth of the Opequon Creek. The results are consistent with fate, transportation and accumulation of nutrients as they move downstream. The importance of these results is that they can be used in prioritizing where to implement that can optimally reduce nutrients.

\subsection{OPtimization ANd Least COST STRATEgY}

Watershed management policies aimed at achieving water quality goals have to consider and evaluate different management options so that a least cost strategy that meets the objectives with minimal inputs can be explored and implemented. In order to recommend a least cost strategy for water pollution control, it is important to identify the different management strategies and available BMP choices, establish their effectiveness in reducing water pollution, and relate the costs of pollution control practice and the resulting improvement in water quality.

BMP per unit costs and reduction efficiencies were derived from PreDICT model. Water pollution levels were simulated in WCMS, an ArcGIS extension developed by NRAC at West Virginia University. In examining the cost minimization model, this research utilized the WV Potomac Basin reduction goals of 1985 as the constraints, whereby N and P are reduced by $37 \%$ and $35.1 \%$ respectively by 2010 to meet the set cap load using 1985 as a baseline year.

A number of scenarios are explored. The first scenario is a "uniform allocation" which requires that every sub watershed make the same amount of pollution reduction of $37 \%$ and $35.1 \%$ for $\mathrm{N}$ and $\mathrm{P}$ respectively. The second scenario is holistic approach for the entire watershed nutrient reduction, whereby the goal is to meet the above mentioned reduction target. The third 
scenario is a targeted approach to pollution reduction, which requires BMP evaluation and implementation in highest priority subwatersheds as identified through public participation or water quality modeling in WCMS. The fourth scenario is to prioritize on specific points along the watershed where BMPs can be implemented to meet the nutrient reduction level. These scenarios are examined and evaluated for a least cost strategy for nutrient reduction.

\subsubsection{Scenario I: Uniform Reduction}

Using QM for Windows (Weiss, 2006), under the two options are considered. The first option is to use the Chesapeake Bay wide average nutrient levels per land use and apply a subwatershed uniform nutrient reduction strategy. The Chesapeake Bay Wide average land use contributions are summarized below:

Table 10: Chesapeake Bay Wide Average Land use Contributions

\begin{tabular}{|lrrrr|}
\hline Nutrient & $\begin{array}{r}\text { Conservation } \\
\text { Tillage }\end{array}$ & $\begin{array}{r}\text { Crop } \\
\text { Protection }\end{array}$ & $\begin{array}{r}\text { Grazing Land } \\
\text { Management }\end{array}$ & $\begin{array}{r}\text { Nut } \\
\text { Management }\end{array}$ \\
\hline Nitrogen & 5.60 & 5.20 & 3.00 & 4.90 \\
\hline Phosphorous & 0.80 & 0.90 & 0.10 & 0.10 \\
\hline
\end{tabular}

The Chesapeake Bay averages were applied to each subwatershed optimization model. The results in acres per BMP and the associated total costs are shown in Table 11. 
Table 11: Uniform Nutrient Reduction Using Chesapeake Bay Average Land use Loadings

\begin{tabular}{|c|c|c|c|c|c|}
\hline \multirow[b]{2}{*}{ Subwatershed } & \multicolumn{4}{|c|}{ BMP Implementations (Acres) } & \multirow[b]{2}{*}{$\begin{array}{l}\text { Optimal BMP } \\
\text { Costs }(\$ 1,000)\end{array}$} \\
\hline & $\begin{array}{c}\text { Conservation } \\
\text { Tillage }\end{array}$ & $\begin{array}{c}\text { Crop } \\
\text { Protection }\end{array}$ & $\begin{array}{l}\text { Grazing Land } \\
\text { Management }\end{array}$ & $\begin{array}{c}\text { Nutrient } \\
\text { Management }\end{array}$ & \\
\hline Abrams Creek & & & & & Infeasible \\
\hline Buzzard Run & 320.2 & 320.2 & $1,102.2$ & $1,102.2$ & 558 \\
\hline Clearbrooke & 469.1 & 469.1 & $1,352.3$ & $1,827.7$ & 714 \\
\hline Dry Marsh & & & & & Infeasible \\
\hline Eagle Run & & & & & Infeasible \\
\hline Evans Run & 1134 & 1134 & 549.3 & 1051.6 & 378 \\
\hline Goose Creek & & & & & Infeasible \\
\hline Hoke Run & & & & & Infeasible \\
\hline Hopewell & $1,696.9$ & $1,696.9$ & 669.8 & $2,863.5$ & 649 \\
\hline Lick Run & 1,175 & 1,175 & 1,701 & 3,452 & 1,056 \\
\hline Middle Creek & 1,955 & 1,955 & 1,525 & 2,518 & 933 \\
\hline Mill Creek & & & & & Infeasible \\
\hline Redbud run & & & & & Infeasible \\
\hline Shaw Run & 980.7 & 980.7 & 988.6 & $1,648.7$ & 591 \\
\hline Three Run & & & & & Infeasible \\
\hline Turkey Run & $3,506.3$ & $3,506.3$ & - & $1,830.8$ & 394 \\
\hline Tuscarora & & & & & Infeasible \\
\hline Totals & 11,237 & 11,237 & 7,887 & 16,295 & $\$ 5,253 *$ \\
\hline
\end{tabular}

*Infeasible solutions are not accounted for in this total.

The model assumes that each BMP is evaluated independently with other BMPs in the subwatershed per land use. For instance, agricultural land under Crop Protection can also be under Conservation Tillage at the same time. The same applies to pasture/open brush lands which can implement BMP combinations of Grazing Land Management and Nutrient Management. The costs of achieving nutrient reduction goals per subwatershed are summarized in Table 11. The results are consistent with the amount of nutrients discharged per subwatershed. The WCMS water quality modeling results showed that the top five polluting subwatersheds were Mill Creek, Tuscarora, Abrams, Turkey and Middle Creek. The above results, however, show that costs are a function of the BMP under consideration and its reduction efficiency let alone the acreage over which the BMPs will be implemented. For instance, the WCMS simulations showed that Turkey Run discharged more nutrients than Lick Run, but the least cost 
strategy shows that Lick Run has a higher optimal cost for nutrient reduction than Turkey Run due to the optimal BMP combinations recommended for each subwatershed to optimally reduce the nutrients to reach the desired reduction level. In addition, subwatersheds such as Goose Creek, Hoke Run, Eagle, Three Run and Abrams Creek which have proportionally smaller acreages under agriculture/crop compared to other land uses within the subwatershed (see Figure 21 below), were infeasible because the targeted reduction is greater than the amount of nutrients that could be reduced from implementing BMPs on agricultural land only in the subwatershed.

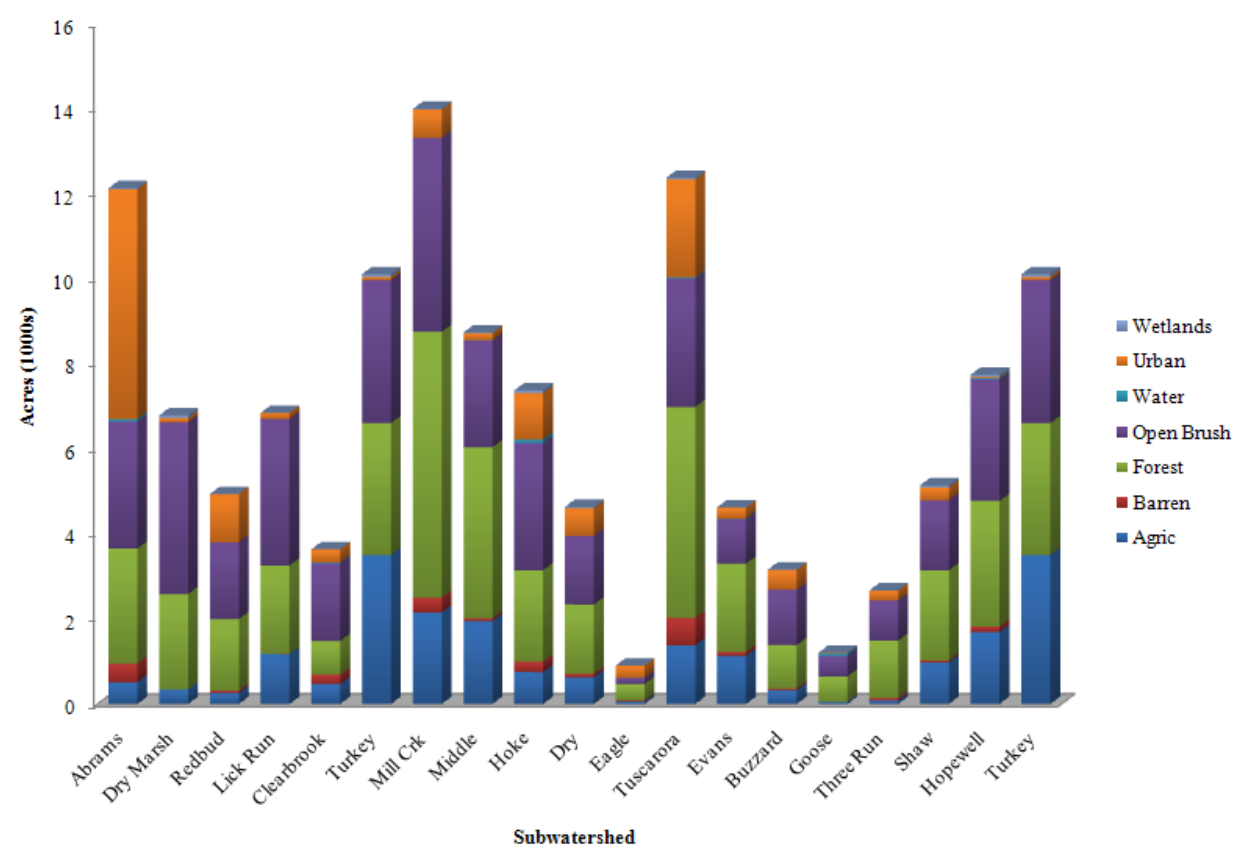

Figure 21: Land use Characteristics of Opequon Creek Watershed.

The results also show that in order to achieve feasibility in a subwatershed, the optimization model places all available agricultural land under BMP combinations of Conservation Tillage and Crop Protection. All agricultural land is placed under BMP combination of Conservation Tillage and Crop Protection due to the high N levels (Figure 18), which are mainly from agricultural land. Agricultural land is utilized mainly due to the fact that the costs per $\mathrm{lb}$ of reduction for $\mathrm{N}$ and $\mathrm{P}$ on agricultural land are lower than on pasture land. The 
optimization model constraint right hand sides for the feasible subwatersheds were positive, indicating that the $\mathrm{N}$ constraints were binding in order to reach an optimal solution. For pasture land, however, the percentage of BMP implementation varies by subwatershed (Table 12).

Table 12: Pasture Land Optimal BMP Implementations

\begin{tabular}{|l|r|r|r|}
\hline Subwatershed & \multicolumn{1}{|c|}{$\begin{array}{c}\text { Grazing } \\
\text { Land } \\
\text { Management }\end{array}$} & $\begin{array}{c}\text { Nutrient } \\
\text { Management }\end{array}$ & $\begin{array}{c}\text { \% Grazing } \\
\text { Land } \\
\text { Management }\end{array}$ \\
\hline Buzzard & 1,102 & 1,102 & 100 \\
\hline Clearbrooke & 1,352 & 1,828 & 74 \\
\hline Evans Run & 548 & 1,051 & 52 \\
\hline Hopewell & 669 & 2,863 & 23 \\
\hline Lick Run & 1,701 & 3,451 & 49 \\
\hline Middle Creek & 1,525 & 2,518 & 61 \\
\hline Shaw Run & 988 & 1,648 & 60 \\
\hline
\end{tabular}

For instance, Middle Creek requires approximately $61 \%$ of its pasture land under Grazing Land Management as well as all the pasture land to implement Nutrient Management BMP. Similar BMP implementation patterns are found in Clearbrooke, Evans Run, Hopewell Run, Lick Run, and Shaw Run subwatersheds that recommend implementing different proportions of pasture land under Grazing Land Management and all their pasture land under Nutrient Management in each respective subwatershed. However, Buzzard Run requires all pasture land under both Grazing Land Management and Nutrient Management. Only Turkey Run requires Nutrient Management BMP only for its pasture land. Although implementing all BMPs is considered optimal in the model, in practice this is not realistic. All BMPs may be recommends in the model because each BMP is evaluated separately on the same land use.

To determine reasons for infeasibility in Abrams, Dry Marsh, Eagle Run, Goose Creek, Hoke Run, Mill Creek, Redbud, Three Run and Tuscarora, separate nutrient constraints together 
with the acreage constraints were considered in the optimization model per subwatershed. Using the Chesapeake Bay wide averages, Table 13 below summarizes optimal solutions when each nutrient is considered separately in the optimization model.

Table 13: Chesapeake Bay Wide Averages Optimal Solutions under Separate $\mathbf{N}$ and $P$ Constraints

\begin{tabular}{|c|c|c|c|c|c|}
\hline \multirow[b]{2}{*}{$\begin{array}{l}\text { Subwatershed (N } \\
\text { or P Constraint) }\end{array}$} & \multicolumn{4}{|c|}{ BMP Implementations (Acres) } & \multirow[b]{2}{*}{$\begin{array}{l}\text { Optimal BMP } \\
\text { Costs }(\$ 1,000)\end{array}$} \\
\hline & $\begin{array}{l}\text { Conservation } \\
\text { Tillage }\end{array}$ & $\begin{array}{c}\text { Crop } \\
\text { Protection }\end{array}$ & $\begin{array}{c}\text { Grazing } \\
\text { Land } \\
\text { Management }\end{array}$ & $\begin{array}{c}\text { Nutrient } \\
\text { Management }\end{array}$ & \\
\hline Abrams (P) & & & & & Infeasible \\
\hline Abrams $(\mathrm{N})$ & & & & & Infeasible \\
\hline Dry Marsh $(\mathrm{N})$ & 346 & 346 & $1,906.8$ & 4,043 & 1,150 \\
\hline Eagle Run $(\mathrm{P})$ & 41.3 & 60 & & & 3 \\
\hline Goose Creek $(\mathrm{N})$ & 46 & 46 & 420.3 & 487 & 207 \\
\hline Hoke Run $(\mathrm{P})$ & 751 & 751 & - & 453 & 91 \\
\hline Mill Creek (P) & 2,156 & 2,156 & & 678 & 193 \\
\hline Redbud run $(\mathrm{P})$ & 255 & 255 & 726 & 1,0809 & 474 \\
\hline Three Run(P) & & & & & Infeasible \\
\hline Three Run $(\mathrm{N})$ & & & & & Infeasible \\
\hline Tuscarora (P) & 1,386 & 1,386 & - & 2,578 & 360 \\
\hline
\end{tabular}

The results indicate which nutrient is constraining an optimal solution in each subwatershed and what happens when you remove this constraint. For instance, in Dry Marsh and Goose Creek, by removing the $\mathrm{P}$ constraint, an optimal solution for $\mathrm{N}$ reduction is achieved, whereas in Eagle Run, Hoke Run, Mill Creek, Redbud and Tuscarora, optimal P reductions are achieved by removing the $\mathrm{N}$ constraints. The results indicate that the $\mathrm{P}$ goal is easier to achieve than the $\mathrm{N}$ goal in most subwatersheds.

In summary, in this scenario, nine subwatersheds out of the seventeen had infeasible optimal solutions. Infeasibility was caused by limited agricultural acres in the subwatersheds, which means that the reduction goal could not be achieved with only four BMPs on crop and pasture land. These subwatersheds had proportionally smaller acreages on crop land, despite comparable acreages on pasture or open brush land. Consequently nutrient contributions thus fall 
below the targeted reduction resulting in an infeasible solution. Infeasible solutions were recorded for Abrams, Dry Marsh, Eagle, Goose Creek, Hoke Run, Mill Creek, Redbud Run, Three Run and Tuscarora Creek. Optimal solutions with separate constraints of either N or P as the nutrient load remained infeasible for Abrams and Three Run. Using $\mathrm{N}$ as the separate constraint, it will cost Dry Marsh $\$ 1.1 \mathrm{~m}$ and Goose Creek $\$ 207$ thousand to optimally reduce N. Using P as a separate constraint, Redbud had the highest optimal cost of $\$ 474$ thousand, followed by Tuscarora, Mill Creek and Eagle Run with $\$ 360, \$ 193$ and $\$ 3$ thousand respectively.

The uniform reduction scenario was also evaluated using each subwatershed specific land use nutrient contributions shown in Table 14 below. 
Table 14: Subwatershed Specific Land Use Nutrient Contributions

\begin{tabular}{|c|c|c|c|c|c|}
\hline Subwatershed & $\begin{array}{l}\text { Conservation } \\
\text { Tillage }\end{array}$ & $\begin{array}{l}\text { Crop } \\
\text { Protection }\end{array}$ & $\begin{array}{l}\text { Grazing Land } \\
\text { Management }\end{array}$ & $\begin{array}{l}\text { Nutrient } \\
\text { Management }\end{array}$ & Nutrient \\
\hline \multirow[t]{2}{*}{ Abrams Creek } & 8.83 & 8.12 & 4.77 & 7.76 & $\mathbf{N}$ \\
\hline & 0.50 & 0.56 & 0.07 & 0.06 & $\mathbf{P}$ \\
\hline \multirow[t]{2}{*}{ Redbud } & 7.85 & 7.22 & 4.24 & 6.90 & $\mathbf{N}$ \\
\hline & 0.69 & 0.77 & 0.10 & 0.09 & $\mathbf{P}$ \\
\hline \multirow[t]{2}{*}{ Dry Marsh } & 9.67 & 8.90 & 5.22 & 8.51 & $\mathbf{N}$ \\
\hline & 1.34 & 1.49 & 0.20 & 0.16 & $\mathbf{P}$ \\
\hline \multirow[t]{2}{*}{ Lick Run } & 8.74 & 8.04 & 4.72 & 7.69 & $\mathbf{N}$ \\
\hline & 1.00 & 1.11 & 0.15 & 0.12 & $\mathbf{P}$ \\
\hline \multirow[t]{2}{*}{ Clearbrooke } & 8.64 & 7.94 & 4.66 & 7.59 & $\mathbf{N}$ \\
\hline & 0.89 & 0.99 & 0.13 & 0.11 & $\mathbf{P}$ \\
\hline \multirow[t]{2}{*}{ Turkey Run } & 6.17 & 5.67 & 3.33 & 5.42 & $\mathbf{N}$ \\
\hline & 0.64 & 0.71 & 0.10 & 0.08 & $\mathbf{P}$ \\
\hline \multirow[t]{2}{*}{ Mill Creek } & 10.96 & 10.09 & 5.92 & 9.64 & $\mathbf{N}$ \\
\hline & 1.11 & 1.24 & 0.17 & 0.14 & $\mathbf{P}$ \\
\hline \multirow[t]{2}{*}{ Three Run } & 8.46 & 7.78 & 4.57 & 7.44 & $\mathbf{N}$ \\
\hline & 7.08 & 7.87 & 1.06 & 0.87 & $\mathbf{P}$ \\
\hline \multirow{2}{*}{ Goose Run } & 9.04 & 8.32 & 4.88 & 7.95 & $\mathbf{N}$ \\
\hline & 1.22 & 1.35 & 0.18 & 0.15 & $\mathbf{P}$ \\
\hline \multirow[t]{2}{*}{ Middle Creek } & 7.18 & 6.61 & 3.88 & 6.32 & $\mathbf{N}$ \\
\hline & 0.74 & 0.83 & 0.11 & 0.09 & $\mathbf{P}$ \\
\hline \multirow[t]{2}{*}{ Hopewell Run } & 7.32 & 6.74 & 3.96 & 6.44 & $\mathbf{N}$ \\
\hline & 0.78 & 0.87 & 0.12 & 0.10 & $\mathbf{P}$ \\
\hline \multirow[t]{2}{*}{ Buzzard Run } & 7.88 & 7.25 & 4.26 & 6.93 & $\mathbf{N}$ \\
\hline & 0.77 & 0.86 & 0.12 & 0.10 & $\mathbf{P}$ \\
\hline \multirow[t]{2}{*}{ Shaw Run } & 7.26 & 6.68 & 3.92 & 6.38 & $\mathbf{N}$ \\
\hline & 0.73 & 0.81 & 0.11 & 0.09 & $\mathbf{P}$ \\
\hline \multirow[t]{2}{*}{ Evans Run } & 6.51 & 5.99 & 3.52 & 5.73 & $\mathbf{N}$ \\
\hline & 0.61 & 0.68 & 0.09 & 0.07 & $\mathbf{P}$ \\
\hline \multirow[t]{2}{*}{ Tuscarora Creek } & 10.37 & 9.54 & 5.60 & 9.12 & $\mathbf{N}$ \\
\hline & 0.87 & 0.97 & 0.13 & 0.11 & $\mathbf{P}$ \\
\hline \multirow[t]{2}{*}{ Eagle Run } & 7.16 & 6.59 & 3.87 & 6.30 & $\mathbf{N}$ \\
\hline & 0.43 & 0.48 & 0.06 & 0.05 & $\mathbf{P}$ \\
\hline \multirow[t]{2}{*}{ Hoke Run } & 8.13 & 7.48 & 4.39 & 7.15 & $\mathbf{N}$ \\
\hline & 0.77 & 0.85 & 0.11 & 0.09 & $\mathbf{P}$ \\
\hline
\end{tabular}


The specific land use contributions were applied to the optimization model. The results are summarized in Table 15. Only three subwatersheds (Abrams, Eagle Run, and Goose Creek) remain infeasible when land use specific loadings were applied in the optimization model.

\section{Table 15: Optimal Costs from Land Use Specific Loadings}

\begin{tabular}{|c|c|c|c|c|c|}
\hline \multirow[b]{2}{*}{ Subwatershed } & \multicolumn{4}{|c|}{ BMP Implementations (Acres) } & \multirow[b]{2}{*}{$\begin{array}{c}\text { Optimal } \\
\text { BMP } \\
\text { Costs }(\$ 1,000) \\
\end{array}$} \\
\hline & $\begin{array}{l}\text { Conservation } \\
\text { Tillage }\end{array}$ & Crop Protection & $\begin{array}{l}\text { Grazing Land } \\
\text { Management }\end{array}$ & $\begin{array}{c}\text { Nutrient } \\
\text { Management }\end{array}$ & \\
\hline Abrams Creek & & & & & Infeasible \\
\hline Buzzard Run & 320 & 320 & & 1,201 & 150 \\
\hline Clearbrooke & 469 & 469 & & $1,357.4$ & 175 \\
\hline Dry Marsh & 345 & 345 & - & 2829 & 330 \\
\hline Eagle Run & - & & - & - & Infeasible \\
\hline Evans Run & 1,134 & 1,034 & - & 849.9 & 156 \\
\hline Goose Creek & & & & & Infeasible \\
\hline Hoke Run & 751.3 & 751.3 & 0 & $2,819.4$ & 351 \\
\hline Hopewell & 1,697 & 1,697 & - & $1,631.5$ & 272 \\
\hline Lick Run & 1,175 & 1,175 & - & $1,949.4$ & 279 \\
\hline Middle Creek & 1,955 & 1,955 & & 1751 & 300 \\
\hline Mill Creek & 2,156 & 2,156 & & 3,895 & 547 \\
\hline Redbud run & 255 & 255 & 1,508 & 1,809 & 756 \\
\hline Shaw Run & 981 & 981 & - & $1,247.7$ & 191 \\
\hline Three run & 80.2 & 80.2 & 555.6 & 946 & 308 \\
\hline Turkey Run & 3,506 & 3,506 & - & 983 & 301 \\
\hline Tuscarora & 1,386 & 1,386 & 2,451 & 3,026 & 1,291 \\
\hline Totals & 16,211 & 16,211 & 4,515 & 26,593 & $\$ 5,868$ \\
\hline
\end{tabular}

The results also show that Tuscarora is the most costly subwatershed to reduce nutrients, followed by Redbud, Mill Creek and Hoke Run. However, Abrams Creek, Eagle Run and Goose Creek remain infeasible under both the Chesapeake Bay wide averages and specific land use contributions.

The subwatershed BMP implementation total costs under the Chesapeake Bay wide averages were nearly $\$ 300$ thousand more than the specific land use loadings. Under the Chesapeake Bay wide average loadings, the total watershed optimal coasts for nutrient 
reductions was approximately $\$ 5.2$ million, with nine infeasible solutions and total BMP implementation costs under the specific land use loading values was approximately $\$ 5.9$ million, with only three infeasible subwatersheds. The land use specific loadings approach are judged to be more representative of the local Opequon land use activities and impacts, whereas the Chesapeake Bay wide averages are not reflective of the Opequon watershed in particular. Consequently, such average values are likely to inflate the costs of nutrient reduction.

Infeasible subwatersheds were further evaluated under separate $\mathrm{N}$ and $\mathrm{P}$ constraints. The results are shown below.

Table 16: Specific Land Use Loadings Optimal Solutions under Separate $N$ and $P$ Constraints

\begin{tabular}{|c|c|c|c|c|c|}
\hline \multirow[b]{2}{*}{$\begin{array}{l}\text { Subwatershed } \\
(\mathrm{N} \text { or } \mathrm{P})\end{array}$} & \multicolumn{4}{|c|}{ BMP Implementations (Acres) } & \multirow[b]{2}{*}{$\begin{array}{l}\text { Optimal BMP } \\
\text { Costs }(\$ 1,000)\end{array}$} \\
\hline & $\begin{array}{c}\text { Conservation } \\
\text { Tillage }\end{array}$ & $\begin{array}{c}\text { Crop } \\
\text { Protection }\end{array}$ & $\begin{array}{c}\text { Grazing Land } \\
\text { Management }\end{array}$ & $\begin{array}{c}\text { Nutrient } \\
\text { Management }\end{array}$ & \\
\hline Eagle $(\mathrm{N})$ & & & & & Infeasible \\
\hline Eagle (P) & & & & & Infeasible \\
\hline Abrams (N) & & & & & Infeasible \\
\hline Abrams (P) & & & & & Infeasible \\
\hline Goose Creek $(\mathrm{P})$ & 60 & 60 & 16.1 & 146 & 25 \\
\hline
\end{tabular}

The results show that Abrams and Eagle Run remain infeasible using either $\mathrm{N}$ or P only as a nutrient constraint. However, Goose had an optimal solution of $\$ 25$ thousand using P as the constraint. This implies that low $\mathrm{N}$ levels from this subwatershed are the causes of infeasibility as the model' P constraint' Right Hand side was positive, indicating that $\mathrm{N}$ constraint was binding for the optimal solution. For Abrams and Eagle Runs, the results show that $\mathrm{N}$ and $\mathrm{P}$ contributions from agricultural and pasture land are not large enough so that BMP reductions cannot meet the targeted reduction level. 
The results of the optimization models are shown in Appendix V. A dual price for a right hand side (RHS) resource limit is the amount the objective function will improve per unit increase in the RHS value of the constraint. In this case of a minimizing problem, the shadow prices are negative for $\mathrm{N}$ and $\mathrm{P}$ constraints. This result indicates a lowering of costs in a minimization objective function when the $\mathrm{N}$ or $\mathrm{P}$ constraint is lowered by one unit.

Except Turkey Run which had dual values of -22.4 for $\mathrm{N}$ and 0 for $\mathrm{P}$, Abrams, Clearbrooke, Evans, Hopewell, Lick, Middle and Shaw Run under scenario 1 using the Chesapeake Bay wide averages all had dual values of -120 for $\mathrm{N}$ and 0 for $\mathrm{P}$. This means that a unit increase in the $\mathrm{N}$ constraint increases the objective function by $\$ 120$. Under subwatershed land use specific values, the duals vary by subwatershed characteristics and range from -11.4 to 64.2. A few exception of Dry Marsh, Redbud and Three Run which had dual values of -667.5, 3.6 and -339 for $\mathrm{P}$ and all 0 s for $\mathrm{N}$ respectively. The results show that the dual values under the Chesapeake Bay wide averages are greater than under specific land use contributions, which implies greater costs per unit increase in the constraint.

\subsubsection{Scenario II: Holistic Approach}

The holistic approach builds on Scenario I, whereby nutrient reduction is evaluated across the entire Opequon watershed. The optimization model for this approach evaluates every subwatershed for a least cost strategy for nutrient reduction based on the four agricultural BMPs constrained by $\mathrm{N}$ and $\mathrm{P}$ targeted loading reductions at the mouth of the Opequon. Each subwatershed's nutrient contribution is weighted by a transfer coefficient, which represents the spatial effects of each subwatershed in terms of nutrient loadings on the main stem. Given that

the transfer coefficients are spatially weighted values, it was appropriate to use land use specific loadings as they relate to the characteristics of the watershed. 
However, the results of the holistic model showed an infeasible solution for the entire Opequon Creek watershed. This means that no optimal allocation of agricultural and pasture BMPS exists so that nutrient reduction goals for the entire Opequon Creek watershed are obtained. The infeasibility of the holistic model resulted from the subwatersheds' agricultural land use nutrient contributions, weighed by transfer coefficients for the mouth of the Opequon, being too low such that there were not enough agricultural land and pasture acreages to achieve the reduction goals needed for the entire watershed (constraints). The model results showed that there are low nutrient contributions from agriculture and crop land. As shown in the Table 17, total reductions achieved from all agriculture and pasture land placed in BMPs were below the targeted reduction goal.

Infeasibility is very commonly associated with complex and big models (Ibrahim and Chinneck, 2008; Tamiz et. al., 1996). However, the models used in this study are neither big nor complex, meaning that other factors other than size and complexity are the problem of infeasibility. Another possible issue is that the BMP reduction efficiencies were too low to reduce the required levels of nutrients. Consequently, total nutrient reductions are lower than the targeted reduction goal of $\mathrm{N}$ and $\mathrm{P}$.

Thus the model is infeasible because total agricultural nutrient contributions are lower than total reduction target. Given an infeasible optimal solution for the entire Opequon watershed, cost computations were made assuming that all agricultural land is put under agricultural BMPs using both the holistic and specific locations approaches.

The holistic approach considers placing BMPs on all subwatersheds (Appendix V). By implementing agricultural BMPs on all subwatersheds in the Opequon watershed, the total costs 
of implementation are approximately $\$ 19$ million. The costs are a product of implementing BMPs on approximately 16,826 acres under crop/agriculture and 39,056 acres under pasture land. Agricultural land acres constitute about $43 \%$ of total pasture land acres in the subwatersheds (Table 17).

Table 17: Opequon - Implementing all BMPs on Agricultural Land

\begin{tabular}{|l|r|r|}
\hline Agriculture (Acres) & Pasture (Acres) & Total Costs \\
\hline 16,826 & 39,056 & $\mathbf{\$ 1 9 , 2 8 1 , 6 2 8}$ \\
\hline & & $\begin{array}{r}\text { Targeted Total } \\
\text { Reductions (lbs) }\end{array}$ \\
\hline & $\begin{array}{r}\text { Reductions } \\
\text { Achieved (lbs) }\end{array}$ & $\mathbf{9 4 4 , 0 2 2}$ \\
\hline Nitrogen & 428,332 & $\mathbf{4 2 , 1 4 7}$ \\
\hline Phosphorous & 24,013 & \\
\hline
\end{tabular}

The computed results show that implementing BMPs on all agricultural and pasture lands in every subwatershed reduces loadings by $428,332 \mathrm{lbs}$ of $\mathrm{N}$ and $24,013 \mathrm{lbs}$ of $\mathrm{P}$. $\mathrm{N}$ and $\mathrm{P}$ reductions are well below the target goal reductions of $944,022 \mathrm{lbs}$ and $42,147 \mathrm{lbs}$ for $\mathrm{N}$ and $\mathrm{P}$ respectively. Total $\mathrm{N}$ and $\mathrm{P}$ reductions from the Opequon are only $45 \%$ and $57 \%$ respectively of the targeted reduction goal. This indicates that agricultural $\mathrm{N}$ and $\mathrm{P}$ contributions are lower than the reduction goal. The results imply that that agricultural land is partially contributing to the high levels of $\mathrm{N}$ and $\mathrm{P}$. Thus other land uses need to be considered for evaluation.

\subsubsection{Scenario III: Prioritization Approach}

The prioritization approach utilizes the results from the uniform approach whereby the subwatersheds identified as priority, either through public participation or WCMS water quality modeling, are evaluated for least cost strategy for nutrient reduction. 
In scenario I, under the Chesapeake Bay, $100 \%$ of cropland is placed under both Crop Protection and Conservation Tillage, while only $60 \%$ of the pasture land is placed under Grazing Land Management, and all pasture land to implement Nutrient Management. However, under the land use specific values, the optimal solution is to place all cropland under Crop Protection and Conservation Tillage and do nothing on pasture land.

The top three priority subwatersheds identified through public participation were Mill Creek, Tuscarora and Middle Creek (Bartley, 2006). Using WCMS water quality modeling, the top three priority subwatersheds (subwatershed with the highest levels of nutrient contributions in the Opequon) were Mill Creek, Tuscarora, followed by Turkey and Middle Creek in the third place. Top three subwatersheds analyzed in this scenario are Tuscarora, Mill Creek and Middle Creek. The total costs of BMP implementation for the three priority subwatersheds under the Chesapeake Bay averages and the specific land use contributions are summarized in Table 18.

Table 18: Top Three Priority Subwatershed BMP Implementation Costs

\begin{tabular}{|c|c|c|c|c|}
\hline \multirow[t]{2}{*}{ Subwatershed } & \multicolumn{4}{|c|}{ Total Costs for Reduction $(\$ 1,000)$} \\
\hline & $\begin{array}{l}\text { Chesapeake Bay } \\
\text { Averages (CBA) }\end{array}$ & $\begin{array}{l}\text { CBA P } \\
\text { Constraint }\end{array}$ & $\begin{array}{l}\text { Specific Land use } \\
\text { Values (SLV) }\end{array}$ & $\begin{array}{l}\text { SLV P } \\
\text { Constraint }\end{array}$ \\
\hline Middle Creek & 933 & 53 & 300 & 59 \\
\hline Tuscarora & - & 860 & 1,291 & 140 \\
\hline Mill Creek & - & 193 & 547 & 83 \\
\hline Total Costs & & 1,106 & & 282 \\
\hline
\end{tabular}


Table 18 shows that in the optimization models in Scenario I, both Mill Creek and Tuscarora had infeasible solutions under the Chesapeake Bay wide average land use nutrient contribution, but had an optimal solution for nutrient reduction under the specific land use nutrient values of approximately $\$ 1.3$ million and \$547 thousand respectively. Using P constraint only, Tuscarora and Mill Creek had optimal values of \$860 thousand and \$193 thousand respectively under the Chesapeake Bay values. On the other hand, Middle Creek had an optimal solution of $\$ 933$ thousand under the Chesapeake Bay wide values and $\$ 300$ thousand under the land use specific values. Using the land use specific values, Middle Creek had an optimal solution of $\$ 59$ thousand with P constraint only. The total costs of BMP implementations under the Chesapeake Bay values and land use specific values for the top three priority subwatershed with $\mathrm{P}$ as the only constraint were $\$ 1.1$ million and $\$ 282$ thousand respectively. This means that the land use specific reduction levels had a lower BMP implementation costs than the Chesapeake Bay averages in meeting the reduction goals.

\subsubsection{Scenario IV: Targeted Approach}

This scenario considers nutrient reduction on two points along the main stem. The two points considered are: one point located on the border of WV and VA, and the second point at the mouth of the Opequon. The nutrient reduction goal for VA are $47 \%$ for $\mathrm{N}$ and $39 \%$, while WV reduction goals are $37 \%$ and $35.1 \%$ respectively as set for each respective state. The reduction goals are shown graphically in Figure 22 below. 


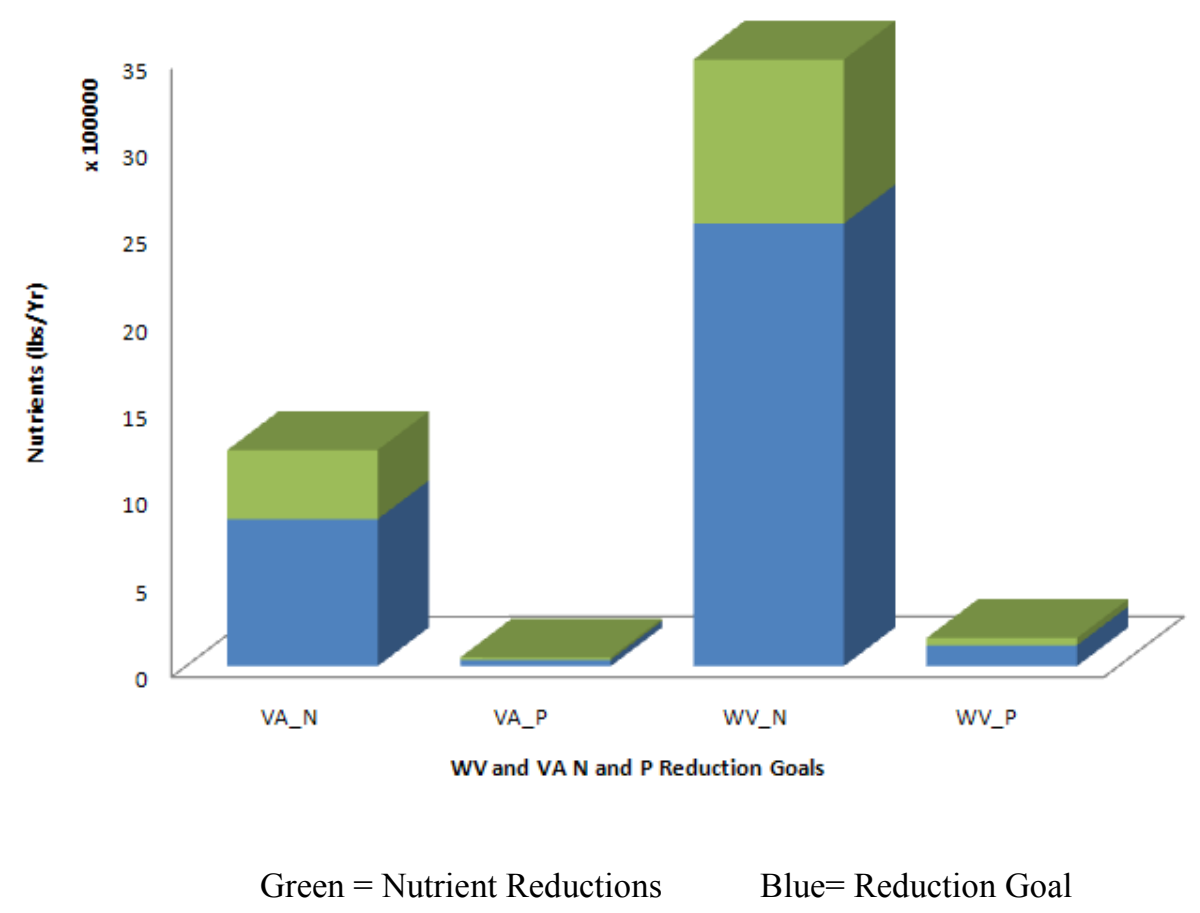

Figure 22: VA and WV Nutrient Reduction Goals

The VA side consisted of Abrams, Dry Marsh, Redbud, Lick Run and Clearbrooke subwatersheds. Each subwatershed's transfer coefficients were estimated for the VA side and evaluated using a uniform reduction goal of $47 \%$ for $\mathrm{N}$ and $39 \%$ for $\mathrm{P}$ at the border of WV and VA. The WV side consisted of Turkey Run, Mill Creek, Goose Creek, Hopewell Run, Buzzard Run, Shaw Run, Evans Run, Tuscarora Creek, Eagle Run and Hoke Run. The reduction goal for the WV side was $37 \%$ for $\mathrm{N}$ and $35.1 \%$ for $\mathrm{P}$ evaluated at the mouth of the Opequon Creek watershed.

The results of the optimization models for both VA and WV however, also reported infeasible solutions under both the Chesapeake Bay wide average land use nutrient values and land use specific values, indicating that more BMPs other than agriculture are required for the model and also that the reduction targets are greater than simulated agricultural land nutrient 
reductions. Since no optimal solution was found in both WV and VA, costs of BMP implementations were evaluated by implementing BMPs on all agricultural land. Table 19 and 20 summarize the results of putting all agriculture land under BMPs in WV and VA.

Table 19: WV - Implementing all BMPs on Agricultural Land

\begin{tabular}{|l|r|r|}
\hline Agriculture(Acres) & Pasture (Acres) & Total Costs \\
\hline 14,072 & 24,928 & $\mathbf{\$ 1 2 , 4 8 9 , 8 8 5}$ \\
\hline & & $\begin{array}{r}\text { Targeted Total } \\
\text { Reductions (lbs) }\end{array}$ \\
\hline Nitrogen & $\begin{array}{r}\text { Reductions } \\
\text { Achieved (lbs) }\end{array}$ & $\mathbf{9 4 4 , 0 2 2}$ \\
\hline Phosphorous & 362,540 & $\mathbf{4 2 , 1 4 7}$ \\
\hline
\end{tabular}

Table 20: VA - Implementing all BMPs on Agricultural Land

\begin{tabular}{|r|r|r|}
\hline Agriculture(Acres) & Pasture (Acres) & Total Costs \\
\hline $2,753.5$ & $14,128.3$ & $\mathbf{\$ 6 , 7 9 1 , 7 4 4}$ \\
\hline & $\begin{array}{r}\text { Reductions } \\
\text { Achieved (lbs) }\end{array}$ & $\begin{array}{r}\text { Targeted Total } \\
\text { Reductions (lbs) }\end{array}$ \\
\hline Nitrogen & 144,599 & $\mathbf{2 1 0 , 9 8 3}$ \\
\hline Phosphorous & 5,513 & $\mathbf{8 , 7 2 6}$ \\
\hline
\end{tabular}

The results show that WV has almost twice the cost for agricultural BMP implementation than VA. The reasons for this are twofold. First, although WV is only contributing $38 \%$ of $\mathrm{N}$ and $47 \%$ of $\mathrm{P}$, compared to VA's $61 \% \mathrm{~N}$ and $40 \% \mathrm{P}$, WV has almost twice as much land under pasture (approximately 10,800 acres more) and about 11,319 acres more under agriculture than VA. Second, per unit costs of implementing BMPs in pasture land are greater than under BMPs for crop land. Consequently, implementing all BMPs in WV with a greater amount of pasture land area than VA will increase costs of BMP implementation. As shown Tables 19 and 20, nutrient reductions from agricultural land in both $\mathrm{WV}$ and VA are below the total nutrient 
reduction levels established for both VA and WV. VA had 69\% and 63\% reductions achieved for $\mathrm{N}$ and $\mathrm{P}$ respectively and $\mathrm{WV}$ had $36 \%$ and $49 \%$ reductions achieved for $\mathrm{N}$ and $\mathrm{P}$ respectively.

The results also show that by putting BMPs on all agriculture, the total costs of BMP implementation is a function of acres of land under crop land and pasture. Consequently, total costs under this scenario will not yield varied total costs results whether you are targeting specific locations or treating the entire watershed. The variations will be on nutrient contributions per area of consideration, such as the VA side and the WV side. The total costs of implementing BMPs on all agricultural VA side and WV side is equal to the costs of implementing BMPs in the entire watershed. The results will be different if land uses were making significant contributions that need reduction, or BMP reduction efficiencies were high enough to meet the reduction goal, and then an optimal solution can be identified.

In practice, optimal solution infeasibility may be difficult to determine especially in this case where some subwatersheds are feasible and others are not. The model could be accurate but at the same time the BMP strategies evaluated don't allow the model to be feasible. For instance, the number of agriculture and pasture acreage may not be large enough to produce nutrients that warrant reduction. The other possibility is that the BMP reduction efficiencies are not good enough to meet the targeted reduction. A case in point is that this study only focuses on nutrient reduction using agricultural BMPs only, when other land uses practice also make significant nutrient contributions at the same time. Thus we are technically trying to meet some goals with insufficient options, resulting in infeasibility. 


\subsection{SUMMARY}

In summary, this chapter looked at the results of the water quality modeling using WCMS, an ArcGIS extension. Top three subwatersheds were Mill Creek, Tuscarora and Turkey Run. These subwatersheds were also identified as priority subwatershed by watershed community and stakeholders. The optimization approach adopted four approaches for evaluating least cost strategies for nutrient reduction in the Opequon watershed. In the uniform allocation reduction strategy, all subwatersheds have to reduce $\mathrm{N}$ and $\mathrm{P}$ by $37 \%$ and $35.1 \%$ respectively using both the Chesapeake Bay wide land use nutrient contribution averages and land use specific averages. Eight of the seventeen subwatersheds had optimal solutions. The remaining subwatersheds had infeasible solutions implying that either the reduction goal could not be achieved or other non agricultural BMPs were required for evaluation in the model. Infeasibility was also encountered in the holistic approach and the specific locations approach, where every subwatershed is evaluated for nutrient reduction goal set at the mouth of the Opequon watershed as well as meet the reduction goals set by VA and WV states. The results also indicate that more BMPs are needed to account for nutrient contribution from non agricultural land. The targeted approach show feasible solutions on in Mill Creek and Middle Creek using the Chesapeake Bay wide land use values but infeasible under the land use specific values. This implies that under the specific land use contributions, agricultural land nutrients were below the reduction goal. 


\section{CHAPTER 8: CONCLUSIONS AND FUTURE RESEARCH}

\subsection{INTRODUCTION}

Water quality issues in the Chesapeake Bay region in general and the Opequon Creek in particular are of significance not only to the aquatic health in the Chesapeake Bay but also to the sustainable management of water resources. This research study focused on agricultural land as the primary source of nutrients in the Opequon Creek watershed. Water quality modelling and optimization techniques were used to evaluate different agricultural BMP choices.

\subsection{Summary OF ReSUlts}

The aim of this study was to develop a methodology for nutrient pollution management for the Opequon Creek watershed using proven and innovative best management practices to accelerate nutrient reduction in the Opequon Creek watershed. The focus of this study was on agricultural land, consequently only agricultural BMPs were considered. The choice of BMPs was based on the proven and recommended BMPs in the Chesapeake Bay area that included nutrient management, cover crops, conservation tillage and grazing land management. The watershed physical characteristics were modeled in PRedICTC optimization software to determine the costs of implementing each BMP and the reduction efficiencies for both $\mathrm{N}$ and $\mathrm{P}$. The recommended agricultural BMPs were Conservation Tillage/Cover Crops costing \$30/acre and reduction efficiencies of $25 \%$ and $36 \%$ for $\mathrm{N}$ and $\mathrm{P}$ respectively, Crop Protection costing $\$ 25 /$ acre and reduction efficiencies of $23 \%$ and $40 \%$ for $\mathrm{N}$ and $\mathrm{P}$ respectively, Nutrient Management costing \$110/acre and reduction efficiencies of $70 \%$ and $28 \%$ for $\mathrm{N}$ and $\mathrm{P}$ respectively, and Grazing Land Management costing \$360/acre and reduction efficiencies of 
$43 \%$ and $34 \%$ for $\mathrm{N}$ and P respectively. These costs and reduction efficiencies formed the basis of the decision variables in the optimization model.

Subwatershed nutrient contributions were modeled using WCMS, an ArcGIS extension developed by NRAC, West Virginia University (Strager et al., 2010). Nutrient contributions were established for each subwatershed and along the main stem. The results of the water quality and stream network modeling show that larger subwatersheds and subwatersheds with a significant acreage of cropland had higher nutrient contributions (Appendix I). The results of the water quality modeling were important in determining potential reduction levels that would be required to meet reduction goals. The reduction goals used for this evaluation were for VA 47\% and $35 \%$ for $\mathrm{N}$ and $\mathrm{P}$ respectively and $\mathrm{WV}$ had reduction goals at $37 \%$ and $35 \%$ for $\mathrm{N}$ and $\mathrm{P}$ respectively.

Four scenarios were evaluated. The first involved a uniform reduction approach, whereby every subwatershed is evaluated to meet a reduction level set for $\mathrm{WV}$ as the final monitoring point of the watershed. In this approach a subwatershed may or may not have an optimal solution depending on the nutrient contribution and land use characteristics. Where no optimal solution was identified, this result implied that there is a need to incorporate non agricultural BMPs to achieve reductions from other possible sources of pollution.

It is well established that NPS nutrient pollution sources are spatially diffuse (e.g. agriculture, pasture and urban land use) and are directly related to and impacted by precipitation events, such as surface runoff from rain or snowmelt, natural landscape conditions and spatial and temporal variations. This research study only focused on agriculture as the primary source of nutrient pollution, thereby ignoring other potential sources of pollution from other watershed 
land uses. The land use characteristics of the Opequon Creek subwatersheds (Figure 5) show a mix of land uses in the watershed, with $36 \%$ forests, $35 \%$ open brush, $11 \%$ urban and $16 \%$ agriculture, $2 \%$ barren land and the remainder is under water and wetlands. These land uses also contribute nutrients in the Opequon Creek. Thus other BMPs apart from agriculture, such as stream channel and storm water management BMPs could also be incorporated for evaluation for nutrient pollution reduction.

The second scenario is holistic approach to the evaluation of BMP choices at a watershed scale. This approach is whereby all subwatersheds are evaluated together in a single optimization model to determine the amount of reduction needed in each subwatershed in order to meet the reduction goal at the mouth of the Opequon at $37 \%$ and $35 \%$ for $\mathrm{N}$ and $\mathrm{P}$ respectively. The results of the watershed scale approach, however, show infeasibility in the model. When all four BMPs were implemented on all possible agricultural and pasture land, about $43 \%$ of the reduction goal is achieved for $\mathrm{P}$ and $42 \%$ for $\mathrm{N}$. This does not imply that an optimal solution does not exist for the watershed. Instead, it indicates that BMPs had too low reduction efficiencies to meet the required goal, simply more BMP choices may be required for other watershed land uses, or simply that the reduction level is cannot be achieved under the current land use conditions.

The total costs of placing BMPs on 16,826 acres of crop land and 39,056 acres of pasture land was approximately $\$ 19.2 \mathrm{~m}$. It should be noted that this evaluation was based on placing all agricultural and pasture land into BMPs. In practice, it is highly unlikely that this scenario could be implemented. Using BMP cost-share and educational programs over a decade long period, Meals (1996) reports that 60 to $80 \%$ of watershed cropland and 68 to $75 \%$ of livestock were 
covered under participating farms in two watersheds in Vermont. These participation rates were judged to be high compared to other agricultural nonpoint source projects.

The third scenario involved a prioritization approach, whereby instead of evaluating the different BMP choices in the entire watershed, only specific or high priority subwatersheds are evaluated for BMP implementation. The specific high priority subwatersheds were identified using the WCMS nutrient levels and public participation prioritization exercise in watershed management. The WCMS results correspond to what the community identified as priority watershed that needed urgent clean up. The three subwatersheds identified as priority subwatersheds by both methods were Mill, Tuscarora and Middle Creeks. These subwatersheds were evaluated for BMP implementation to meet the WV reduction goals. Mill Creek and Tuscarora Creek had infeasible solutions under the Chesapeake Bay wide average land use contributions, but optimal solutions under land use specific contributions. When only a P constraint is used in the optimization model, Tuscarora and Mill Creek had optimal values of $\$ 860$ thousand and $\$ 193$ thousand respectively under the Chesapeake Bay values. Middle Creek had an optimal solution of $\$ 933$ thousand under the Chesapeake Bay wide values and $\$ 300$ thousand under the land use specific values. Using the land use specific values, Middle Creek had an optimal solution of $\$ 59$ thousand with P constraint only. Using P as the only constraint for the three priority subwatershed, the total cost of BMP implementations under the Chesapeake Bay values was approximately $\$ 1.1$ million and $\$ 282$ thousand using specific land use specific values. The results show that much lower costs are achieved using specific land use values than the Chesapeake Bay averages.

The last scenario considered in this study is a targeted approach, which evaluates specific locations in the watershed in VA and WV given the different state reduction goals. Two points 
were considered: (1) along the main stem of the Opequon Creek at the border of WV and VA with reduction goals of $47 \%$ and $39 \%$ for $\mathrm{N}$ and $\mathrm{P}$ respectively, (2) the mouth of the Opequon in WV with reduction goals of $37 \%$ and $35 \%$ for $\mathrm{N}$ and $\mathrm{P}$ respectively. The optimization results show infeasibility in both optimization models. When all agricultural and pasture lands are placed into BMPs, WV achieves $36 \%$ of the reduction goal for $\mathrm{N}$ and $49 \%$ for $\mathrm{P}$ while VA achieves $69 \%$ of the reduction goal for $\mathrm{N}$ and $63 \%$ reduction for $\mathrm{P}$. Total costs are $\$ 12.5$ million for WV and \$6.7 million for VA. These results indicate that either higher reduction efficiency BMPs are needed for agriculture or other land use BMPs need to be included in the optimization model. Thus there is a need to incorporate and evaluate other non agricultural BMPs in order to reach the reduction goal at least cost.

Key issues can be inferred from this study. Given that potential sources of nutrient pollution are varied, other land use activities have to be considered in the optimization modeling analysis. For instance, the Opequon Creek and its subwatersheds are known to receive effluent from a number of both public and private permitted waste water treatment plants (WVDEP, 2005). This aspect and other non agricultural land use nutrient contribution were not considered in this study. In addition, although agriculture is considered the number one nutrient contributor from leaching of excess fertilizer and manure into the water, the subwatersheds have only $16 \%$ of the land under agriculture (crop land) and 35\% under open brush/pasture land, giving a total of 51\% under agricultural use. The other significant land uses are urban and forest land with $11 \%$, and $36 \%$ respectively. Thus approximately $51 \%$ of the land use in this study area was evaluated for nutrient reduction, ignoring 49\% of other land uses. In Opequon, rapid urban residential and business construction has contributed to a significant increase in storm water runoff from roofs and paved surfaces (Bartley, 2006; WV DEP, 2005). Such urban storm water 
management and riparian forest BMPs are important in reducing nutrients in the watershed. A number of BMPs that can be considered for the Opequon watershed include urban storm water management BMPs, stream fencing where cattle use the creeks as a source of drinking water, creating or enhancing wetlands and waste treatment plants. Such BMPs can result is a substantial reduction of nutrients from different land uses, thereby reducing annual $\mathrm{N}$ and $\mathrm{P}$ pollution to Opequon Creek to meet the desired reduction goal.

Additionally, Opequon watershed has a large amount of fractured limestones (Figure 6), which allow surface pollutants to rapidly percolate and infiltrate into underground water and into watershed. The impact of these soil characteristics were not accounted for in this study. Of equal significance is the impact of human activities like recreational fishing and small boating on water pollution. These factors and other non agricultural land use activities contribute to the complexity of nonpoint sources of pollution the watershed.

The results of the study also demonstrate that community input is critical in watershed management. Scenario III analysis showed that the WCMS results were validated by community input from the prioritization exercise. Both methods identified the same top three subwatersheds in terms of priority. This result indicates that local knowledge can contribute similar information as watershed modeling to decision analysis.

Reduction of nutrients in the Opequon will greatly improve water quality not only in the Opequon watershed but also contribute to improvement in the Chesapeake Bay. The resulting benefits from water quality improvement are water use and intrinsic benefits. Water use benefits result from using the water for activities such as public water supplies, recreation, irrigation, etc. The other non-use benefits (intrinsic) benefits such as improvement in the aesthetics of the 
watershed. Benson (2006) used willingness to pay (WTP) as a measure to estimate the benefits of improved water quality in the Opequon. The median WTP per household annually for a five year period on WV side of the Opequon was $\$ 44$ and on the VA side was $\$ 64$. Aggregated over the entire watershed, the present value of total monetary benefits for water quality improvement were between $\$ 4$ and $\$ 5$ million. Benson's results are lower than to the estimated $\$ 5.9$ million annual costs for nutrient reductions on 14 of 17 subwatersheds in the Opequon under scenario I for land use specific computations.

On a larger watershed scale, Bockstael et al., (1989) estimated the annual aggregate WTP for a moderate improvement in the Chesapeake Bay's water quality to be in the range of $\$ 10$ to \$100 million in 1984 dollars. However, Lipton (2001) used WTP and contingent valuation (CV) to study the value of water quality improvements to recreational boaters in the Chesapeake Bay. His results showed a present value of the WTP for a relatively permanent water quality improvement, at a 5\% discount rate, was approximately \$146 million. The study also found annual compensation variation of reduced access to the boating ranging from $\$ 353$ to $\$ 424$. While the Opequon contributes only a relatively small portion of the total nutrients flowing to the Chesapeake Bay, these studies demonstrate ways of estimating benefits of improved water quality at both the local and larger regional levels. They indicate to the scale of benefits that might be achieved if the nutrient reduction goals were met.

\subsection{POLICY IMPLICATIONS}

Watershed level water quality management can be effectively carried out with supportive policy and legal framework. A number of policies are needed if an integrated approach to watershed level water quality management is to be adopted, especially policies that facilitate community and stakeholder participation, let alone institutional arrangements that allow 
environmental agencies, stakeholders and watershed communities to collaborate. This research study integrated GIS, water quality modeling, public participation and optimization for watershed water quality management. Adopting a watershed based approach empowers communities to take a leading role in the management of water resources.

NPS pollution has not been effectively controlled by traditional forms of pollution regulation. The approach used in this study can be used as an effective and efficient method to identify possible priority pollution sources. Consequently, there are a number of reasons why the results of this study are important for water policy on the Opequon Creek watershed and any other watershed facing water quality problems. First, watershed level water quality modeling and simulation of nutrients results can be used in the monitoring of watershed water pollution, especially for watersheds which do not have nutrient pollution monitoring sites. Water quality modeling can be used to generate the data and information for managing water pollution where current monitoring does not exist. Second, simulated nutrient loadings can aid policy makers and water resource managers in the development of TMDLs and nutrient reduction standards for the Opequon Creek watershed. Lastly, the results of this study highlight the significance of public participation in watershed management and decision making. The results indicate that community inputs and local knowledge are equally important as scientific data. As demonstrated in this study, WCMS water quality modeling results corresponded to community evaluations of priority subwatersheds. Consequently, public input should not be ignored in any watershed management program or development projects.

Environmental economists have recommended a number of policy options that aim at improving the management water resources. It is now established that command and control policies for non point source pollution are difficult to implement due to the spatially diffuse 
nature of the pollution sources, complexity in defining causes and effects, and the nature of remedial action if the sources are unknown. Thus, incentive based policies are likely to be more cost effective in watershed management than regulatory policies. Examples that can be considered in water pollution management are cost sharing, tax incentives, stakeholders' education about water pollution, and technical support programs that reward those who voluntarily adopt BMPs aimed at reducing nutrient pollution.

Another option that has been considered is water quality trading. Water quality trading has recently received considerable attention from resource economists and environmental managers (Carpenter et al, 1998; Greenhalgh et al., 2009). Trading has been advocated for point sources of pollution that are required to reduce their nutrient discharge levels. These point sources can trade with diffuse sources of pollution that have a lower cost of achieving reductions. Water quality trading is a viable option that can be considered as an alternative for nutrient reductions in the Opequon watershed. This research demonstrated that $\mathrm{P}$ is more feasible to control than N. Consequently, it is most likely more feasible to create a trading program for $\mathrm{P}$ rather than $\mathrm{N}$. The results also demonstrated that compliance of nutrient reduction goals for $\mathrm{WV}$ and VA are likely to happen at the subwatershed level rather than the watershed scale. Thus trading may only be feasible at the subwatershed level.

Lastly, land use planning can lead to reduced water pollution and improved watersheds. It has been observed that different land use practices (e.g. forestry, agriculture and urban area) pollute and affect affects water quality. For instance, agricultural land contributes significant amounts of nutrients in streams mainly from farm animal wastes and application of commercial fertilizers. Converting agricultural land to residential or commercial use (urbanization) can lead to reduced nutrient contribution to streams. However, urbanization increases surface runoff and 
water pollution from different types of pollutants, such as oil and gasoline products. Nutrient pollution can be minimized through comprehensive watershed land use planning. Planners must aim at minimizing land uses that affect the hydrological functions and water quality of watersheds. Thus, land use developments plans must be accompanied by a comprehensive environmental impact assessment statement that details how the proposed development will impact existing hydrological systems and what measures will be put in place to mitigate such impacts.

Environmental land use planning also builds on collaborative decision making of different stakeholders in watershed management. This study also showed that the Opequon water pollution problems transcend institutional boundaries that require states of VA and WV to take a coordinated watershed management approach to reduce pollution. Improved collaboration leads to better environmental management of water resources. In addition, the use of technologies like GIS and water quality models can provide the relevant land use and water quality data that can be analyzed to enhance our understanding and analysis of watershed systems for more informed decisions on management options.

\subsection{Conclusions}

The Opequon currently faces nonpoint source pollution from a combination of agricultural and non agricultural land uses. As a result, combinations of different land use specific BMPs need to be implemented to reduce water pollution. The watershed also faces growing urban impact on landscapes that has affected stream water quality. As a result, an optimal approach to Opequon watershed water quality managements warrants consideration of other non agricultural BMPs to be considered in Opequon Creek Watershed. These include urban storm water management BMPs, creating or enhancing wetlands and stream bank fencing from 
cattle. Combinations of such BMPs will reduce the annual nutrient loadings in the Opequon Creek watershed.

This study found both feasible and unfeasible solutions under the different scenarios of a uniform reduction, targeted subwatersheds, a subwatershed prioritization approach and reducing nutrients in specific spatial locations. The reasons for infeasibility included that other non agricultural BMPs are required to reduce nutrients especially in subwatersheds where other land uses like urban areas (Tuscarora) or forests (Mill Creek, Tuscarora and Middle Creek), and barren land are significant. As shown in Table 4, such land uses also contribute significant amounts of nutrient pollution. Another problem could be failure to account for other land use activities like livestock operations which are the major nutrient pollution contributors.

This study showed that for the Opequon watershed:

(i) $\mathrm{P}$ goals are more attainable at reasonable cost than $\mathrm{N}$ goals. Thus trading is more feasible for $\mathrm{P}$ than $\mathrm{N}$.

(ii) Uniform reduction across all subwatersheds is more achievable than holistic reduction approach.

(iii) Compliance with WV and VA reduction goals is more feasible at a subwatershed level rather than at a watershed scale. Nutrient trading is thus more feasible at a subwatershed level rather than at a watershed scale, however, this severely limits the number of possible trading between point and non point sources.

(iv) Although scenarios II and IV evaluated BMP implementation on all agriculture and pasture land at just under $\$ 20$ million annually. In practice, it is highly unlikely to that all agriculture and pasture land implement BMPs. 
(v) The use of subwatershed specific values rather than Chesapeake Bay wide yields much lower optimal costs.

(vi) Local knowledge can be used to validate scientific data and incorporated in watershed decision analysis.

(vii) Prioritization of watershed pollution reduction offers the least cost strategy for nutrient reduction for Opequon watershed.

\subsection{STUdY LiMitations}

There are many limitations in this study. First, WCMS model assumes that all streams have the same width, depth, slope and roughness. In reality, this is not the case as stream channels, width and slopes vary across the watershed and across different geological conditions. WCMS does not also consider other hydrological factor affecting pollutant concentration and transport such as infiltration, interflow, ground water flow additions, or any atmospheric conditions such as temperature or evapotranspiration (NRAC, 2007). Despite these disadvantages, it provides a foundation of and integrative approach to analyzing water quality management.

The other limitation of this study is that it focuses primarily on agricultural land as the main contributor of nutrient pollution in watershed. However, as this study showed (see Figure 9), there are other land use activities that contribute significant amounts of nutrients within the Opequon watershed. Since the scope of analysis was limited to agricultural land, additional analyses of other land use activities as well as evaluation of non agricultural BMPs in nutrient management would provide more informed recommendations for a least cost strategy on the Opequon watershed. 
The study also assumes that BMPs become effective upon implementation. Practically, it takes time for BMPs to become effective and efficient in reducing nutrients (Borisova et al., 2005; Gitau et al., 2004). Moreover, the economic optimization model assumed that BMPs are implemented independent of each other. In reality, BMP combinations are usually implemented to reduce nutrient pollution. Thus, possible BMP combinations as well as single BMPs evaluations could have been incorporated in the analysis for an optimal solution.

The study did not account for other factors that can affect water pollution, such as variations in soil types, population size and distribution, rate of urbanization and specific agricultural activities such as swine or poultry farms that have greater impact on the nutrient contributions in the watershed. For instance, different soil properties affect the rate and amount of nutrient transfer through the soil. Opequon watershed is in a limestone region that allows nutrients to quickly seep into the ground and pollute surface waters. Consequently, there are different nutrient management strategies for different soil types. In addition, there are spatial variation in topography, climate, agricultural systems, site selection, installation and maintenance costs. Consequently, BMP effectiveness varies from site to site and the BMP types and combinations.

PredICT also has some limitations. The software was developed primarily for use in Pennsylvania. As a result some of the BMP systems modeled may not be applicable for the conditions in Virginia or West Virginia (Borosova et al., 2005). The main assumptions made in the current analysis are:

- Estimation of BMP systems' efficiencies based on PredICT default values.

- Application of PredICT default values and secondary data sources to estimate costs of BMPs, which may not reflect the specific conditions in the Opequon Creek watershed 
- Classification of all agricultural land as land on the slope greater than $3 \%$.

However, the general algorithm used in PredICT can be easily adapted to incorporate other BMP systems, if the information about these systems is available (Borisova et al, 2005).

Lastly, the transfer coefficients used in this study assume a constant and explicit knowledge of biochemical reaction of nutrients. In reality stream nutrient fate and transportation from subwatersheds to the mouth are considered to be dynamic and stochastic. Thus a dynamic method of generating coefficients is required that can incorporate the spatial and temporal variations and relationships.

\subsection{RECOMMENDATIONS FOR FUTURE RESEARCH}

This study was limited to agricultural BMPs; as a result other scenarios analyzed in this study could not reach an optimal solution based on the limited number of agricultural BMPs. A number of land use activities (such as urban development, barren lands and wetlands) that contribute nutrients in the watershed were not considered. In addition, other variables like soil characteristics and its spatial variation were not considered in the modeling of nutrient contributions. Future research could incorporate a number of additional BMPs and incorporate watershed characteristics such as soil in the analysis and evaluation of BMPs. SWAT model allows for the economic evaluation and effectiveness of BMPs in reducing nutrient loadings and improve water quality. Land use changes can be analyzed to determine if any particular land use change affects nutrient levels, if so by how much.

An integrated model composed of water quality modeling and optimization would be recommended for further research. For instance, PRedICT would have been ideal for this research, however, only the BMP evaluation module is currently functional and the optimization 
tool is still under development. The advantage of using SWAT is that, like WCMS, it also comes as an ArcGIS extension, allowing for both economic and geospatial analysis.

It is also important for future research to incorporate socio-economic data such as population data and urban development. The Opequon is a region that is undergoing urban development and consequently such land use developments affect the water quality in the streams. 


\section{REFERENCES}

Agha, S. R. 2006. "Use of Goal Programming and Integer Programming for Water Quality Management - A Case Study of Gaza Strip”. European Journal of Operational Research, 174(3): 1991-1998.

Ahlfeld, D.P. 1990. “Two-Stage Ground-Water Remediation Design”. ASCE Journal of Water Resources Planning and Management, 116(4): 517-529.

Alfera, L. K. and Weismiller, 2002. "Best Management Practices to Control Non-point pollution from Agricultural Lands within the Black Sea Basin”. Symposium Proceedings, World Bank Conference of Agricultural Non-point Pollution in the Black Sea and Baltic Sea Basins. Przysiek, Poland

Ali, Md. Kamar. 2002. “Stream Water Quality Management: A Stochastic Mixed-integer Programming Model”. Unpublished Ph.D. Dissertation, West Virginia University, WV.

Ambrose, R.B., T.A. Wool, J.P. Connolly and R.W. Schanz. 1988. "WASP4, A Hydrodynamic and Water Quality Model. Model Theory”. User's Manual, and Programmer's Guide. US EPA, Athens, GA. EPA/600/3-87-039.

Amir, I. and F.M. Fisher. 1999. "Analyzing Agricultural Demand for Water with an Optimizing Model”. Agricultural Systems 61: 45 - 56.

Anderson, D., D. Sweeney and T. Williams. 2008. "An Introduction to Management Science: Quantitative Approaches to Decision Making”. $12^{\text {th }}$ edition. Thompson South Western.

Aris, R. 1961. Discrete Dynamic Programming. Academic Press, New York. 
Armstead, J. 2008. "Decision Rationale Total Maximum Daily Loads for Selected Streams in the Potomac Direct Drains Watershed, West Virginia”. US EPA Region III, Water Protection Division.

Arnold, J. G. and N. Fohrer. 2005. "SWAT2000: Current Capabilities and Research Opportunities in Applied Watershed Modelling”. Hydrological Processes 19(3): 563-572.

Arnold, J. G., R. Srinivasan, R. S. Muttiah, and J. R. Williams. 1998. "Large Area Hydrologic Modeling and Assessment Part I: Model Development”. Journal of the American Water Resources Association, 34(1), 73-89.

Baird C., M. Jennings, D. Ockerman and T. Dybala. 1996. "Characterization of Nonpoint Sources and Loadings to the Corpus Christi Bay National Estuary Program Study Area”. Corpus Christi Bay National Estuary Program CCBNEP-05, Texas Natural Resources Conservation Commission (TNRCC), Austin, Texas.

Barrios, A. 2000. "Urbanization and Water Quality”. Center for Agriculture in the Environment Working Paper Series, WP00-1. American Farmland Trust's Center for Agriculture in the Environment, DeKalb, Illinois.

Bartley, J. 2006. “Opequon Subwatershed Prioritization Final Report”. Prepared for the Opequon Project Team. Canaan Valley Institute.

Beasley, D.B., L.F. Huggins, and E.J. Monke. 1980. “ANSWERS: A Model for Watershed Planning". Transactions of the American Society of Agricultural Engineers 23 (4), 938-944

Bellman, R. 1957. Dynamic Programming. Princeton University Press, Princeton. 
Benaman, J. 1996. "Modeling of Dissolved Oxygen in the Houston Ship Channel Using WASP5 and Geographic Information Systems”. Unpublished MA Thesis, Austin, TX: University of Texas at Austin.

Benli, B., and S. Kodal. 2003. A Non-linear Model for Farm Optimization with Adequate and Limited Water Supplies. Application to the South-east Anatolian Project (GAP) Region. Agricultural Water Management 62: 187-203.

Benson, M. 2006. “An Economic Valuation of Improved Water Quality in Opequon Watershed”. MS thesis, West Virginia University.

Bettinger, P., K. Boston and J. Sessions. 1999. “Combinatorial Optimization of Elk Habitat Effectiveness and Timber Harvest Volume”. Environmental Modeling and Assessment 4: $143-153$.

Bevers, M and J. Hof. 1999. "Spatially Optimizing Wildlife Habitat Edge Effects in Forest Management Linear and Mixed Integer Programs”. Forestry Science. 45(2): 249 -258.

Bicknell, B.R., J.C. Imhoff, J.L. Kittle, Jr., T.H. Jobes, and A.S. Donigian, Jr. 1997. “Hydrological Simulation Program--Fortran, User's Manual for version 11”. U.S. Environmental Protection Agency, National Exposure Research Laboratory, Athens, Ga., EPA/600/R-97/080.

Bicknell, B.R., J.C. Imhoff, J.L. Kittle, Jr., T.H. Jobes, and A.S. Donigian, Jr. 2001. "Hydrologic Simulation Program - FORTRAN (HSPF), User's Manual for version 12.0”: US EPA, Athens, GA, 30605.

Bingner R.L., Theurer F.D., Yongping Y. 2007. AnnAGNPS Technical Processes Documentation, Version 4.0. USDA-ARS, National Sedimentation Laboratory: Oxford, MS. 
Bingner, R. L. and F.D. Theurer. 2009. AGricultural Non-Point Source Pollution Model. URL: http://www.ars.usda.gov/Research/docs.htm?docid=5199 . Accessed 10/10/09

Bockstael, N.E., K.E. McConnell and I.E. Strand. 1989. "Measuring the Benefits of Improvements in Water Quality: The Chesapeake Bay”. Marine Resource Economics 6(1): 1 - 18.

Boesch, D.F., R.B. Brinsfield, and R.E. Magnien. 2001. “Chesapeake Bay Eutrophication: Scientific Understanding, Ecosystem Restoration and Challenges for Agriculture”. Journal Environmental Quality 30: 303 - 320.

Bolstad, P.V., and W.T. Swank. 1997. “Cumulative Impacts of Land use on Water Quality in a Southern Appalachian Watershed". Journal of the American Water Resources Association 33(3): 519-533.

Borah D. K., G. Yagow, A. Saleh, P. L. Barnes, W. Rosenthal, E. C. Krug, L. and M. Hauck. 2006. “Sediment and Nutrient Modeling for TMDL Development and Implementation”. Transactions of the American Society of Agricultural and Biological Engineers 49(4): 967-98.

Borisova, T., G. D’Souza, N. Khandelwal, B. Benham, and M.L. Wolfe. 2005. “Analysis of Sediment Reduction Strategies for Abrams Creek Benthic TMDL Using PredICT Software”. West Virginia University, Division of Resource Management Working Paper RESMWP 0506. Report prepared for CSREES Mid-Atlantic Water Quality Program, within the mini-grant "Public participation in watershed management and the TMDL Process: Evaluation and Improvement. 
Boyd, J. 2000. "The New Face of the Clean Water Act: A Critical Review of the EPA's Proposed TMDL Rules”. Resources for the Future, Discussion Paper 00-12. Washington DC.

Brown, L. C. and T. O. Barnwell. 1987. "The Enhanced Stream Water Quality Models QUAL2E and QUAL2E-UNCAS”. Documentation and User Manual. Environment Research Laboratory. US EPA, EPA /600/3-87/007, Athens, GA.

Brown, M.C., D.H. Davis, R.M. Greenwald, P. Srinivassan, and D.S. Ward. 1996. "ModelGIS, An Interface for the USGS Three Dimensional Finite Difference Model MODFLOW”. Conference proceedings of the 1996 ESRI's User Conference, Redlands, California

Burges, S.J. and D.P. Lettenmaier. 1975. "Probabilistic Methods in Stream Quality Management". Water Resources Bulletin. 11(1): 115-130.

Burke, L., Sugg Z. 2006. "Hydrologic Modeling of Watersheds Discharging Adjacent to the Mesoamerican Reef'. World Resource Institute, Washington, USA, 65p.

Burn, D.H. and E.A. McBean, 1985. "Optimization Modeling of Water Quality in an Uncertain Environment". Water Resources Research, 21(7), 934 - 940.

Burrough, P.A. and R.A. McDonnell, 1998. Principles of Geographic Information Systems. Oxford University Press

Burrough, P.A. 1990. "Methods of Spatial Analysis in GIS”. International Journal of Geographical Information Systems 4(3) 221-223.

Carlin, A. 1992. "The United States Experience with Economic Incentives for Environmental Pollution Control”. Report EPA-R-92-001, U.S. Environmental Protection Agency, Washington, D.C. 
Carpenter S.R., N.F. Caraco, D.L. Correll, R.W. Howarth, A.N. Sharpley, and V.H. Smith. 1998. "Nonpoint Pollution of Surface Waters with Phosphorus and Nitrogen. Ecological Applications 8:559-568.

Cestti R., J. Srivastava and S. Jung. 2003. “Agriculture Non-Point Source Pollution Control: Good Management Practices_-The Chesapeake Bay Experience”. World Bank Working Paper No. 7.

Chang N.B., C.G. Wen, S.L. Wu. 1995. “Optimal Management of Environmental and Land Resources in a Reservoir Watershed by Multiobjective Programming”. Journal of Environmental Management 44: 145-161.

Chang, N.B., Y.L. Chen and S.F. Wang. 1997. “A Fuzzy Interval Multiobjective Mixed Integer Programming Approach for the Optimal Planning of Solid Waste Management Systems”. Fuzzy Sets and Systems, 89: 35-59.

Chapra, S.C. 1996. Applied Numerical Methods with MATLAB for Engineers and Scientist. McGraw Hill.

Chen, C.L, L.E. Gomez, C.W. Chen, C.M. Wu, J.J. Lin, and I.L. Cheng. 1995. “An Integrated Watershed Management Model with GIS and Windows Application”. Proceedings of The International Symposium on Water Quality Modeling, Orlando, Florida.

Chesapeake Bay Agreement. 2000. “Chesapeake 2000”. URL:

http://dnrweb.dnr.state.md.us/bay/res_protect/c2k/index.asp 
Chesapeake Bay Commission (CBC). 2004. "Cost Effective Strategies for the Bay: Smart

Investments for Nutrient and Sediment Reduction". Chesapeake Bay Commission. Policy for the Bay.

Chesapeake Bay Program (CBP). 1994. "The State of the Chesapeake Bay". Rep. CBT/TRS 222/108, Annapolis, Md. URL:http://www.chesapeakebay.net/pubs/sob/index.html

Chesapeake Bay Program Tributary Strategy Workgroup. 2007. “Chesapeake Bay Program Best Management Practices". URL:

http://www.dep.state.pa.us/river/Nutrient\%20Trading\%20Documents/Additions\%206_27_06 /BMP_Descriptions.pdf. Accessed 10-22-09.

Chesapeake Bay Program. 1997. "Chesapeake Bay Nutrient Reduction Progress and Future Directions: Nutrient Reduction Reevaluation Summary Report”. EPA 903-R-97-030. US EPA, Annapolis, MD.

Chesapeake Bay Program. 1998. Nutrient Reduction Progress and Future Directions. Summary Report CBP/TRS 189/97.

Church, R. L. 2002. "Geographical Information Systems and Location Science”. Computers and Operations Research, 29(6): $541-562$.

Church, R.L. 1999. "Location Modelling and GIS”. In Geographical Information Systems $2^{\text {nd }}$ edition, Longley P. et al., John Wiley and Sons, New York.

Clement, L. and O. Thas, 2007. "Estimating and Modeling Spatio-Temporal Correlation Structures for River Monitoring Networks”. Journal of Agricultural, Biological and Environmental Statistics 12(2): $161-176$. 
Coase, R. 1960. "The Problems of Social Cost”. Journal of Law and Economics 3: 1-44.

Connolly, J.P. and Winfield, R. 1984. “A User's Guide for WASTOX: A Framework for Modeling the Fate of Toxic Chemicals in Aquatic Environments. Part 1: Exposure Concentration”. US EPA, Gulf Breeze, FL. EPA-600/3-84-077.

Conservation Technology Information Center (CTIC). 1998. "Crop Residue Management”. Purdue University, West Lafayette, URL: http://www.ctic.purdue.edu.

Constanza, R., A. Voinov, R. Boumans, T. Maxwell, F. Villa, L. Wainger and H. Voinov. 2002. "Integrated Ecological Economic Modeling of the Patuxent River Watershed, Maryland". Ecological Monographs 72(2): 203 - 231.

Cooper, S.R. 1995. “Chesapeake Bay Watershed Historical Land Use: Impact on Water Quality and Diatom Communities”. Ecological Applications 5:703-723.

Cosgrove, W.J. and F.R. Rijsberman. 2000. “World Water Vision: Making. Water Everybody's Business". London: Earthscan Publications.

Craig, W., T. Harris and D. Weiner. 2002. Community Participation and Geographic Information Systems. Taylor and Francis.

Darghouth, S, C. Ward, G. Gambarelli, E. Styger and J. Roux. 2008. Watershed Management Approaches, Policies and Operations: Lessons for Scaling Up. Water Sector Board Paper Series No. 11. The World Bank, Washington DC.

Deason, J.P., T.M. Schad, and G.W. Sherk. 2001. "Water Policy in United States: A Perspective". Water Policy 3: 175 - 192. 
Debele, B., R. Srinivasan and J. Y Parlange. 2009. "Hourly Analyses of Hydrological and Water Quality Simulations using the SWAT Model. Journal of Hydrology 23:303-324.

Deliman, P. N., W. J. Pack, and E. J. Nelson. 1999. "Integration of the Hydrologic Simulation Program-FORTRAN (HSPF) Watershed Water Quality Model into the Watershed Modeling System (WMS)”. Technical Report W-99-2, U.S. Engineer Research and Development Center, Vicksburg, MS.

Di Toro D.M., J.J. Fitzpatrick and R.V. Thomann. 1983. "Water Quality Analysis Simulation Program (WASP) and Model Verification Program (MVP) Documentation”. Hydroscience Inc., Westwood, NY.

Donigian, A.S. and W.C. Huber. 1990. "Modeling of Non-point Source Water Quality and in Urban and Non-urban Areas". EPA 68-03-3515, Environmental Research Laboratory, USEPA Athens, GA.

Duane, T. P. 1997. “Community Participation in Ecosystem Management”. Ecology Law Quarterly 24: $771-796$.

ERMITE Consortium, 2004. "Mining Impacts on the Fresh Water Environment: Technical and Managerial Guidelines for Catchment Focused Remediation". In Younger, P.L., Wolkersdorfer, C. (Eds.), Mine Water and the Environment. Springer, Berlin, p80 Supplementary Issue 1.

Environment Systems Research Institute (ESRI). 1999. "ArcView Spatial Analyst for ArcGIS”. Environmental System Research Institute, Redlands, CA.

ESRI. 2004. “ArcGIS 9.1”. Environmental Systems Research Institute, Redlands, CA. 
Evaldi, R.D. and K.S. Paybins. 2006. "Channel Gains and Losses in the Opequon Creek Watershed of West Virginia, July 25-28”. U.S. Geological Survey Data Series 179.

Evans, B. M. , D. W. Lehning, K. J. Corradini , G. W. Petersen, E. Nizeyimana , J. M. Hamlett, P. D. Robillard, and R. L. Day . 2002. "A Comprehensive GIS-based Modelling Approach for Predicting Nutrient Loads in Watersheds". Journal of Spatial Hydrology 2(2): 1 - 18.

Evans, B.M., D. W. Lehning, T. Borisova, K. J. Corradini, and S. A. Sheeder. 2003a. "PredICT. User's Guide for the Pollutant Reduction and Impact Comparison Tool”. Penn State Institute of the Environment, The Pennsylvania State University. University Park, PA.

Evans, B.M, D. W. Lehning, T. Borisova, K. J. Corradini, and S. A. Sheeder. 2003b. “A Generic Tool for Evaluating the Utility of Selected Pollution Mitigation Strategies within a Watershed. Proc. $7^{\text {th }}$ International Conference on Diffuse Pollution and Basin Management, Dublin, Ireland, 2(4): $10.7-10.12$.

Food and Agricultural Organization (FAO), 1993. "An Overview of Pollution of Water by Agriculture". Sagardoy, J.A. in Prevention of Water Pollution by Agriculture and Related Activities, Proceedings of the FAO Expert Consultation, Santiago, Chile, 20 - 23 October, 1992. Water Report 1, Food and Agriculture Organization, Rome, $19-26$.

Feng, H, M. Jha, and P. Gassman. 2008. "The Allocation of Nutrient Load Reduction across a Watershed: Assessing Delivery Coefficients as an Implementation Tool”. Review of Agricultural Economics 31(1): 183 - 204. 
Fisher, D. S., J. L. Steiner, D. M. Endale, J. A. Stuedemann, H. H. Schomberg, A. J. Franzluebbers, and S. R. Wilkinson. 2000. "The Relationship of Land Use Practices to Surface Water Quality in the Upper Oconee Watershed of Georgia”. Forest Ecology. 128:39-48.

Flynn, K. 1999. “Overview of Public Health and Urban Agriculture: Water, Soil and Crop Contamination and Emerging Urban Zoonoses". International Development Research Centre (IDRC), Ottawa, ON, CA.

Freeman III, A. M. 2003. The Measurement of Environmental and Resource Values: Theory and Methods. Resources for the Future Press: Washington DC.

Freeman III, A.M., 2003. “Economics, Incentives, and Environmental Policy”. In Vig, N.J. and M.E. Kraft (Eds.). Environmental Policy: New Directions for the Twenty-first Century. Congressional Quarterly Press: Washington DC.

Frissell C.A. and D. Bayles. 1996. "Ecosystem Management and the Conservation of Aquatic Biodiversity and Ecological Integrity”. Water Resources Bulletin 32: 229-240.

Frissell C.A. 1997. "Ecological Principles”. In Watershed Restoration: Principles and Practices, Williams J.E, M. P. Dombeck, and C.A. Wood (eds). The American Fisheries Society: Bethesda, MD; 96-115.

Funk, R. E, III. 1993. "Identifying a Cost-effective Solution for Treating Acid Mine Drainage in the Middle Fork River Watershed”. Unpublished M.S. Thesis, West Virginia University, WV.

Furst, J., G. Girstmair, and H.P. Nachtnebel. 1993. “Application of GIS in Decision Support Systems for Groundwater Management". Conference proceedings of the HydroGIS 93: Application of Geographic Information Systems and Water Resources, IAHS, Vienna, Austria. 
Gale, J.A., D.E. Line, D.L. Osmond, S.W. Coffey, J. Spooner, J.A. Arnold, T.J. Hoban, and R.C. Wimberley. 1993. "Evaluation of the Experimental Rural Clean Water Program". U.S. Environmental Protection Agency, EPA-841- R-93-005.

Genskow, K. and L. Prokopy (eds.). 2008. The Social Indicator Planning and Evaluation System (SIPES) for Nonpoint Source Pollution Management: A Handbook for Projects in USEPA Region 5. Great Lakes Regional Water Program. Publication Number: GLRWP-08-SI01.

Gitau M. W., T. L. Veith and W.J. Gburek. 2004. "Farm-level Optimization of BMP Placement for Cost-effective Pollution Reduction". Transactions of the American Society of Agricultural Engineers 47(6): 1923-1931.

Gleick, P.H. 2003. "Global Freshwater Resources: Soft-Path Solutions for the $21^{\text {st }}$ Century”. Science 302(28): $1524-1528$.

Global Water Partnership (GWP). 2000. "Integrated Water Resources Management”. GWP Technical Advisory Committee Technical Advisory Committee Background Paper No. 4. Stockholm.

Goodchild, M. and R. Haining. 2004. "GIS and Spatial Data Analysis: Converging Perspectives". Papers in Regional Science, 83(1): 363-385.

Goodchild, M. F., R. Haining and S. Wise. 1992. "Integrating GIS and Spatial Data Analysis: Problems and Possibilities". International Journal of Geographical Information Systems, 6(5): 407-424.

Goolsby, D.A., W.A. Battaglin, G.B. Lawrence, G.B., R.S. Artz, B.T. Aulenbach, R.P. Hooper, D.R. Keeney, and G.J. Stensland. 1999. "Flux and Sources of Nutrients in the Mississippi- 
Atchafalaya River Basin". National Science and Technology Council Committee on

Environment and Natural Resources Hypoxia Work Group, Topic 3 Report, Washington, D.C.

Greenberg, 1995. "Mathematical Programming Models for Environmental Quality Control". Operations Research 43(4): 578-622.

Greenhalgh, S., M. Selman and J. Guiling. 2009. "Water Quality Trading Programs: An International Overview”. World Resource Institute Policy Notes 1: 1 - 16.

Greenhalgh, S., M. Selman and J. Guiling. 2006. "Paying for the Environment: Investing in Farmers and the Environment". World Resource Institute Policy Notes 1: 1 - 4.

Greiner, R and O. Cacho. 2001. "On the Efficient Use of a Catchment's Land and Water Resources: Dryland Salinization in Australia”. Ecological Economics. 38(3): 441- 458.

Gunawan, B., K. Takeuchi, O.S. Abdoellah. 2004. "Challenges to Community Participation in Watershed Management: An Analysis of Fish Farming Activities at Saguling Reservoir, West Java- Indonesia”. Water Policy. 6(4): 319 - 333.

Haith, D. A. 2003. "Systems Analysis, TMDLs and Watershed Approach". Journal of Water Resources Planning and Management, 129 (4): 257-260.

Hanley, N and C.L. Splash. 1993. Cost Benefit Analysis and the Environment. Edward Elgar Publishing, Inc. UK, USA.

Harris, T and D. Weiner, 1998. "Empowerment, Marginalization and Community-integrated GIS". Cartography and Geographic Information Systems, 25(2): 67 - 76. 
Hof, J and M. Bevers. 1998. "Spatial Optimization for Managed Ecosystems". Columbia University Press, New York.

Hof, J. and M. Bevers. 2002. "Spatial Optimization in Ecological Applications". Columbia University Press, New York.

Hubbard, R. K., G. L. Newton and G. M. Hill. 2004. "Water Quality and the Grazing Animal”. Journal of Animal Science 82:E255-263.

Ibrahim, W. and J.W. Chinneck. 2008. "Improving Solver Success in Reaching Feasibility for Sets of Nonlinear Constraints". Computers and Operations Research 35: 1394-1411.

Blunk, K. S., T. Borisova, C. Abdalla and D. Parker. 2006. "A Primer for Water Quality Credit Trading in the Mid Atlantic Region". Penn State University Information and Communication Technologies in the College of Agricultural Sciences.

Jankowski, P. 1995. “Integrating GIS and Multiple Criteria Decision Making Methods”. International Journal of Geographical Information Systems, 9(3):252-273.

Jarvie, M and B. Solomon. 1998. "Point-Non Point Effluent Trading in Watersheds: A Review and Critique". Journal of Environmental Impact Assessment Review 18: 135 - 157.

Just, R.E., D.L. Hueth and A. Schimtz. 2004. The Welfare Economics of Public Policy: A Practical Approach to Project and Policy Evaluation. Edward Elgar. UK, USA.

Kavanaugh, M.C., Rao, P.S.C.K., Abriola, L., Cherry, J., Destouni, G., Falta, R., Major, D., Mercer, J., Newell, C., Sale, T., Shoemacher, S., Siegrist, R., Teutsch, G., Udell, K. 2003. “The DNAPL Remediation Challenge: Is There a Case of Source Depletion?” Expert Panel Report EPA/600/R-03/143. Environmental Protection Agency (EPA), USA. 
Knisel, W.G. (ed). 1980. “CREAMS: A Field-Scale Model for Chemical, Runoff, and Erosion from Agricultural Management Systems”. Conservation Research Report 26, U.S. Department of Agriculture, Washington, D.C.

Know Your Environment (KYE). 2004. "Nutrient Trading: Commerce as a Tool to Control Water Pollution". Environmental Associates of the Academy of Natural Sciences. URL: www.waterchat.com/Features/Archive/040826 Nutrient\%Trading.htm. Accessed 8-15-09.

Kolstad, C.D. 2000. Environmental Economics. Oxford University Press. New York, Oxford.

Landphair, 2001. "Cost to Performance Analysis of Selected Storm water Quality Best Management Practices”. University College Davis, Road Ecology Center, John Muir Institute of the Environment.

Leach, W.D., N.W. Pelkey, and P.A. Sabatier. 2002. "Stakeholder Partnership as Collaborative Policymaking: Evaluation Criteria Applied to Watershed Management in California and Washington”. Journal of Policy Analysis and Management 21(4): 645 - 670.

Lee, C.S. and C.G. Wen. 1996. “Application of Multiobjective Programming to Water-Quality Management in a River Basin”. Journal of Environmental Management 47, 11-27.

Lee, C.S. and C.G. Wen. 1997. "Fuzzy Goal Programming Approach for Water-quality Management in a River Basin. Fuzzy Sets and Systems 89, 181-192.

Lee, D., J. R. Howitt and M. A. Marino. 1993. "A Stochastic Model of River Water Quality: Application to Salinity in the Colorado River". Water Resources Research 29(12): 39173923.

Leinwand, Gerald. 1990. The Environment: American Issues. New York: Facts on File. 
Leonard, R.A., W.G. Knisel, and D.A. Still. 1987. "GLEAMS: Groundwater Loading Effects of Agricultural Management Systems". Transactions of ASAE, 30(5):1403-1418.

Li, S., Z. Xu, X. Cheng and Q. Zhang, 2008. "Dissolved Trace Elements and Heavy Metals in the Danjiangkou Reservoir, China. Environmental Geology 55 (5): 977-983.

Liebman, J. C and W. R. Lynn. 1966. "The Optimal Allocation of Stream Dissolved Oxygen”. Water Resources Research 2(3): 581 - 596.

Lipton, D.W. 2004. "The Value of Improved Water Quality to Chesapeake Bay Boaters". Marine Resource Economics 19: 265 - 270.

Liu, Z.J. and G.R. Hallberg. 2002. "Spatial Relations between Row Crops and Nitrate Contamination in Groundwater". Water, Air, and Soil Pollution 134:369-387.

Loganathan, G and D. Bhattacharya. 1990. "Goal-programming Techniques for Optimal Reservoir Operations”. Journal of Water Resources Planning and Management 116(6): 820: 838.

Lohani and Thanh, 1979. "Probabilistic Water Quality Control Policies". Journal of the Environmental Engineering Division, ASCE 104(4): 713-725.

Lohani, B. N and N. C. Thanh. 1978. "Stochastic Programming Model for Water Quality Management in a River". Journal of Water Pollution Control Federation. 50(9): 2175- 2182.

Loucks, D., C. Revelle and W. R. Lynn. 1967. "Linear Programming Models for Water Pollution Control”. Management Science. 14(4): 166 - 181.

Loucks, D.P. and E. van Beek 2005. Water Resources Systems Planning and Management: An Introduction to Methods, Models \& Applications. UNESCO Publications France, Paris. 
Lynn W.R., J.A. Logan and A. Charnes. 1962. "System Analysis for Planning Wastewater Treatment Plants”. Journal of Water Pollution Control Federation 34: 565-581.

Ma and Bartholic, 2003. "GIS based AGNPS Assessment Model in a Small Watershed”. National Science 1(1): 50-56.

Maeda, M., B, Zhao, Y. Ozaki, T. Yoneyama. 2000. "Nitrate leaching in an Andisol Treated with Different Types of Fertilizers". Environmental Pollution 121: 477-487.

Maidment DR, ed. 2002. Arc Hydro: GIS for water resources. ESRI Press, Redlands, CA.

Maidment, D and D. Djokic. 2000. Hydrologic and Hydraulic Modeling Support with Geographic Information Systems. ESRI Press, Redlands, CA.

Malczewski, J. 1999. Introduction to GIS: GIS and Multicriteria Decision Analysis. John Wiley \& Sons.

Markham, A. 1994. A Brief History of Pollution. New York: St. Martin’s Press

Markris, M. 2001. “Necessary Conditions for Infinite-Horizon Discounted Two-Stage Optimal Control Problems”. Journal of Economic Dynamics and Control. 25(12): 1935 - 1950.

Maryland DNR. 2004. "Nutrient Loading” URL:

http://www.dnr.state.md.us/coastalbays/water_quality/nutrient_load.html. Accessed $\underline{10 / 21 / 09 .}$

Maybeck M, D. Chapman and R. Helma. 1989. Global Fresh Water Quality: A First Assessment. Blackwell, London. 
McSweeny W. T. and J.S. Shortle. 1990. "Probabilistic Cost Effectiveness in Agricultural Non-point Pollution Control”. Southern Journal of Agricultural Economics 22(1): 95-104.

Meals, D.W. 1996. “Watershed-Scale Response to Agricultural Diffuse Pollution Control Programs in Vermont USA". Water Science Technology 33(4-5): 197-204.

Millard, P. S., K. F. Gensheimer, D. G. Addiss, D. M. Sosin, G. A. Beckett, A. Houckjankoski, and A. Hudson. 1994. “An Outbreak of Cryptosporidiosis from Fresh-pressed Apple Cider". Journal of American Medical Association 272:1592-1596.

Mizgalewicz, P. 1996. “Agrichemical Transport in the Midwest Rivers: A GIS Approach”. Ph.D. Dissertation, University of Texas at Austin, Department of Civil Engineering. Austin, Texas.

Mujumdar, P. P. 2002. "Uncertainty Concepts in Stream Water Quality Management Models". In Rama Prasad and S. Vedula (Eds), Research Perspectives in Hydraulics and Water Resources Engineering: 169-192. World Scientific, Singapore.

Mujumdar, P.P. and K. Sasikumar, 2002. “A Fuzzy Risk Approach for Seasonal Water Quality Management of a River System”. Water Resources Research, 38 (1): 5-9

Mulvey, J.M., R. J. Vanderbei and S. A. Zenios. 1995. "Robust Optimization of Large-Scale Systems". Operations Research 43(2): $264-281$.

Munda, 1993. "Multiple-criteria Decision Aid: Some Epistemological Considerations". Journal of Multi-Criteria Decision Analysis 2: 41 - 55.

Munda, G., P. Nijkamp, and P. Rietveld. 1995. "Qualitative Multicriteria Methods for Fuzzy Evaluation Problems: An Illustration of Economic-ecologic Evaluation”. European Journal of Operational Research 82: 79 - 97. 
Murray and Church. 1995. "Heuristic Solution Approaches to Operational Forest Planning Problems". Operations Research Spektrum 17: 193-203

Mutch, D. R., and T. E. Martin. 1998. “Cover Crops”. In Michigan Field Crop Ecology, Bulletin E264644-53. Michigan State University, East Lansing.

National Research Council (NRC). 1999. New Strategies for America's Watersheds. National Academic Press, Washington, D. C.

National Research Council (NRC). 2000. Assessing the TMDL Approach to Water Quality Management. National Academic Press, Washington, D. C.

Natural Resources Conservation Service (NRCS). 1994. National Handbook of Conservation Practices. Natural Resources Conservation Service. U.S. Department of Agriculture, Washington, DC.

Nevo, A and L. Garcia. 1996. "Spatial Optimization of Wildlife Habitat". Ecological Modeling 91(1): 271- 281.

Newell, C.J., H.S. Rifai, and P.B. Bedient. 1992. Characterization of Non-Point Sources and Loadings to Galveston Bay. Publication GBNEP-15, Galveston Bay National Estuary. Program, Webster, Texas.

Nixon, S.W. 1995. “Coastal Marine Eutrophication: A Definition, Social Causes, and Future Concerns". Ophelia 41:199-219. 
Nizeyimana, E., B. Evans, M. C. Anderson, G.W. Peterson, D. R. DeWalle, W. E. Sharpe, J. M. Hamlett, and B. R. Swistock. 1997. "Quantification of NPS pollution loads within Pennsylvania Watersheds”. Rep. ER9708, Pennsylvania State University, University Park.

Novonty, V. 2002. Water Quality: Diffuse Pollution and Watershed Management. $2^{\text {nd }}$ Edition. John Wiley and Sons, New York.

Novotny and Olem, 1994. Water Quality: Prevention, Identification, and Management of Diffuse Pollution. Van Nostrand Reinhold, Kentucky.

Novotny, V., 1995 (Editor). Nonpoint Pollution and Urban Storm water Management. Water Quality Management Library 9. Technomic Publishing Company, Inc., Pennsylvania. Natural Resource Analysis Center (NRAC). 2007. "Watershed Characterization Modeling System for ArcGIS 9.2”. Release 1.0. Natural Resource Analysis Center, West Virginia University, Morgantown, WV.

Natural Resources Conservation Service (NRCS). 1995. Animal Manure Management. Natural Resources Conservation Service; US Department of Agriculture; NRCS/RCA Issue Brief 7; December. URL: http://www.nhq.nrcs.usda.gov/BCS/nutri/rca7.html.

NRCS. 1998. Buffer Strips: Common Sense Conservation. National Conservation Buffer Initiative. Natural Resources Conservation Service; US Department of Agriculture. URL: http://www.nhq.nrcs.usda.gov/CCS/Buffers.html.

Opequon Creek Project Team (OCPT). 2006. “Opequon Creek Project Team”. URL: http://www.opequoncreek.org/ 
Olivera, F and D. R. Maidment 1999. "Geographic Information Systems (GIS)-based Spatially Distributed Model for Runoff Routing”. Water Resources Research, 35(4): 1155-1164.

Olivera, F., R. J. Chareneau and D. R. Maidment. 1996. "Spatially Distributed Modeling of Storm Runoff and Non-Point Source Pollution Using GIS”. Report 96-4, Center for Watershed Research, University of Texas, Austin, TX

Onal, H., Algozin, K.A., Isık, M., Hornbaker, R.H., 1998. “Economically Efficient Watershed Management with Environmental Impact and Income Distribution Goals. Journal of Environmental Management 53: 241-253.

Opaluch, J. J, 1982. "River Basin Management: The Optimal Control of Water Quantity and Quality". American Journal of Agricultural Economics 64 (5).

Opequon Creek Project Team (OCPT). 2006. “Opequon Creek Project Team: Community Dedication to Protect and Enhance Watershed's Natural Resources". URL: http://www.opequoncreek.org/Publications/Brochure-07.pdf

Popper, S.W., R.J. Lempert and S.C. Bankes. 2005. "Shaping the Future”. Scientific American: 48 53.

Potter, K. W. 2006. "Small-scale, Spatially Distributed Water Management Practices: Implications for Research in the Hydrologic Sciences". Water Resources Research 42(3): W03S08.

Prato, T. 1999. "Multiple Attribute Decision Analysis for Ecosystem Management". Ecological Economics 30(2): 207 - 222.

Prowse, C.W. 1984. "Spatial Variations in Water Quality in an Urbanizing Catchment". Transactions, Institute of British Geographers 9, $494-506$. 
Pullar, D and D. Springer. 2000. "Towards Integrating GIS and Catchment Models". Environmental Modeling and Software 15(5): 451-459.

Qiu, Z. 2008. "Understanding Economics and Water Quality Impacts of Agricultural BMPs in a Suburban Watershed in New Jersey" Paper presented at the annual meeting of the Soil and Water Conservation Society, July 26, 2008, Tucson, Arizona.

Quenzer A. M., D. R. Maidment, F. L. Hellweger, N.J. Eid, G. W. Ward and N. E. Armstrong. 1998. "Total Loads and Water Quality in the Corpus Christi Bay System". CCBNEP-27 Texas Natural Resource Conservation Commission, Austin, Texas.

Randhir, T. O. and O. Tsvetkova. 2008. "Watershed-scale Tradeoffs in Water Quantity and Quality Attributes for Conservation Policy". Journal of Water, Air and Soil Pollution 201(1-4): 347 363.

Randhir, T. O., J. G. Lee, and B. Engel. 2000. "Multiple Criteria Dynamic Spatial Optimization to Manage Water Quality at a Watershed Scale”. Transactions of the American Society of Agricultural Engineers 43(2): 291-299.

Rao, K.H.V.D., and D.S. Kumar. 2004. “Spatial Decision Support System for Watershed Management". Water Resources Management. 18(55): 407 - 423.

Raper, J. 2000. Multidimensional Geographic Information Science. Taylor and Francis, CRC Press

ReVelle C. and A. E. McGarity (Eds). 1997. Design and Operation of Civil and Environmental Engineering Systems. Wiley Publishers, New York.

Ribaudo, M. O., R. D. Horan, and M. E. Smith. 1999. "Economics of Water Quality Protection from Nonpoint Sources: Theory and Practice". Agriculture Economics Report 782, U.S. 
Department of Agriculture, Washington D. C. (URL:

http://www.ers.usda.gov/publications/aer782/).

Ribaudo, M. O., R. Heimlich, R. Claasssen and M. Peters. 2001. "Least-cost Management of Nonpoint Source Pollution: Source Reduction Versus Interception Strategies for Controlling Nitrogen Loss in Mississippi Basin”. Ecological Economics 37: 183 - 197.

Rindahl, B. 1996. "Groundwater Modeling and Analysis: Using the USGS MODFLOW Program and ArcView". Conference proceedings of the 1996 ESRI User's Conference, Redlands, California

Sadeghi, S.H.R., Kh. Jalili and D. Nikkami. 2009. "Land Use Optimization in Watershed Scale". Land Use Policy 26(2): 186 - 193.

Sasikumar, K and P. P. Majumdar. 1998. "Fuzzy Optimization Model for Water Quality Management of a River System". Journal of Water Resources Planning and Management 124 (2): $79-88$.

Sasikumar, K., P. P. Mujumdar, A. Kumar and V. K. Minocha. 1999. "Fuzzy Optimization Model for Water-quality Management of a River system". Journal of Water Resources Planning and Management 125: 179-187.

Saunders, W. K. and D. R. Maidment. 1996. "A GIS Assessment of Nonpoint Pollution in the San Antonio-Nueces Coastal Basin". Center for Research in Water Resources Online Report 961, University of Texas, Austin, TX. 
Schleich, J. and D. White, 1997. "Cost Minimization of Nutrient Reduction in Watershed management Using Linear Programming”. Journal of American Water Association 33 (1): $135-142$.

Schleich, J., White, D. and Stephenson, K. 1996. "Cost Implications in Achieving Alternative Water Quality Targets. Water Resources Research 32 (9): 2879-84.

Seppelt, R and A.Voinov, 2002. "Optimization Methodology for Land Use Patterns Using Spatial Explicit Landscape Models”. Ecological Modeling, 151(2-3): 125-142.

Shah, A. 2007. "Water and Development. Global Issues: Social, Political, Economic and Environmental Issues That Affect Us All”. URL: http://www.globalissues.org/article/601/water-and-development.

Sharpley, A.N. and S. Rekolainen. 1997. "Phosphorus in Agriculture and its Environmental Implications". In: H. Tunney, O.T. Brookes, and A.E. Johnston (eds). Phosphorus Loss from Soil to Water: 1-53. New York, NY: Center for Agriculture and Biosciences International.

Sharpley, A.N., R.W McDowell, J. L.Weld, and P.J.A. Kleinman. 2001. “Assessing Site Vulnerability to Phosphorus Loss in an Agricultural Watershed". Journal of Environmental Quality 30(6):2026-2036.

Shortle, J. S. and R. D. Horan. 2001. "The Economics of Non-point Pollution Control”. Journal Economic Survey 15(3): 255-289.

Shortle, J., R. Horan, and D. Abler. 1998. "Research Issues in Nonpoint Pollution Control". Environmental and Resource Economics 11:571-585. 
Shuyler L.R. 1993. "Nonpoint Source Programs and Progress in the Chesapeake Bay". Agriculture, Ecosystems and Environment 46: 217 - 222.

Singh, J., V. Knapp, J.G. Arnold and M. Demissie. 2005. "Hydrological Modeling of the Iroquois River Watershed Using HSPF and SWAT". Journal of the American Water Resources Association 41(2): 343-360.

Smith, M.E and M. O. Ribaudo. 1998. "The New Safe Drinking Water Act: Implications for Agriculture," Choices (3):26-30.

Sobel, M.J. 1965. "Water Quality Improvement Programming Problems”. Water Resources Research. 1(4): 477-487.

Srinivasan, R., and J.G. Arnold. 1994. "Integration of a Basin-scale Water Quality Model with GIS". Water Resources Bulletin 30:453-462.

Stanley, D. L. 2000. "The Economics of the Adoption of BMPs: The Case of Mariculture Water Management". Ecological Economics 35: 145-155.

Steinberg S. J. and S. L. Steinberg. 2006. Geographic Information Systems for Social Sciences: Investigating Space and Place. Sage Publication.

Strager, M. P., J. J. Fletcher, J.M. Strager, C.B. Yuill, J.T. Petty, R. N. Eli andS. Lamont. 2010. "Watershed Analysis with GIS: The Watershed Characterization and Modeling System." Computers and Geoscience. Accepted awaiting proof for review.

Tamiz, M., S.J. Mardle and D.F.Jones. 1996. Detecting IIS Infeasible Linear Programmes Using Techniques from Goal Programming. Computers and Operations Research 23(2): 113 - 119. 
Tetra Tech, Inc. 2003. "Peer Review of AAQUATOX (Release 2 Beta Version)". Report prepared for: U. S. Environmental Protection Agency, Office of Water, Washington DC.URL: http://www.epa.gov/waterscience/models/aquatox/technical/peer-execsumm-200303.pdf. Accessed 9/01/09.

Tietenberg, T.H. 2006. Environmental and Natural Resource Economics. $7^{\text {th }}$ edition. Pearson/Addison Wesley.

Tong S.T.Y and W. Chen. 2002. "Modeling the Relationship between Land Use and Surface Water Quality". Journal of Environmental Management, 66(3): 377-393.

United Nations Development Program. 2006. "Human Development Report. 2006. Beyond Scarcity: Power, Poverty and the Global Water Crisis". United Nations Development Program. NY. URL: http://hdr.undp.org/en/media/hdr06-complete.pdf. Accessed 05-02-09.

United States Environmental Protection Agency (US EPA). 1991. Guidance for Water Quality-based Decisions: The TMDL Process. EPA 440/4-91-001. Office of Water, Washington, D.C.

US EPA, 1998a. "Clean Water Action Plan: Restoring and Protecting America's Waters. US Government Printing Office, Washington, DC.

US EPA. 2000.”Nutrient Criteria Technical Guidance Manual: Rivers and Streams”. EPA, Washington, D.C., EPA-822-B00-002.

US EPA. 2007.Water Quality Standards Handbook. EPA Publications, Washington DC.

US EPA. 1990. "Rural Clean Water Program" EPA 44/4-90-012. September. Office of Water

US EPA. 1993. "Proceedings of Watershed '93: A National Conference on Watershed Management". Washington DC, March 21 - 24. EPA Document 840-R-94. 
US EPA. 1995a. Ecological Restoration - EPA 841-F-95-007. November.

US EPA. 1995. National Water Quality Inventory: 1994 Report to Congress. EPA 841-R-95- 005. December. Office of Water.

US EPA. 1996. "Environmental Indicators of Water Quality in the United States". EPA 841-R-96002.

US EPA. 1997. "State Source Water Assessment and Protection Programs Guidance". EPA 816- R97-009. August. Office of Water.

US EPA. 1998. "Clean Water Action Plan: Restoring and Protecting America's Waters". United States Government Printing Office, Washington, DC.

US EPA. 1998. "National Water Quality Inventory: 1996 Report to Congress”. Environmental Protection Agency, EPA 841-R-97-008. Office of Water, Washington, DC.

US EPA. 2000a. "AQUATOX: A Simulation Model for Aquatic Ecosystems Release 2.0". Office of Water, US EPA. URL: http://www.epa.gov/waterscience/models/aquatox/

US EPA. 2000b. "National Water Quality Assessment" EPA (305-B report). 841-R-02-001. Office of Water, Washington, DC.

US EPA. 2000c. "National Water Quality Inventory: 1998 Report to Congress". EPA841-R-00-001. Office of Water. Washington, D.C.

US EPA. 2001. "Better Assessment Science Integrating Point and Nonpoint Sources (BASINS) Version 3.0". EPA Report, Office of Water, EPA-823-B-01-001. 
US EPA. 2003. "National Management Measures for the Control of Non-point Pollution from Agriculture". EPA Office of Water, EPA-841-B-03-004.

US EPA. 2006. “Integrated Water Quality Monitoring and Assessment Report”. URL: http://www.epa.gov/OWOW/tmdl/2006IRG/

US EPA. 2007. Water Quality Standards Handbook. EPA Publications, Washington DC.

US EPA. 2009. "EPA Needs to Accelerate Adoption of Numeric Nutrient Water Quality Standards". Report No. 09-P-0223 August 26.

US EPA, 2009a. "U.S. EPA Sets Expectations for Chesapeake Bay States and D.C. to Reduce Water Pollution". News Release. Url: http://www.epa.gov/reg3wapd/tmdl/ChesapeakeBay/pr110409.pdf. Accessed 11/27/09.

US Geological Survey. 1999. “The Quality of Our Nation's Waters: Nutrients and Pesticides”. Circular 1225, Reston, Virginia.

Veith, T. L., M. L. Wolfe, and C. D. Heatwole. 2003. "Optimization Procedure for Cost Effective BMP Placement at a Watershed Scale". Journal of the American Water Resources Association. 39(6): 1331-1343

Verweij, M. 2000. "Why is the River Rhine Cleaner than the Great Lakes (Despite Looser Regulation)?" Land and Society Review, 34(4): 1007-1054.

Vink, A.P.A., 1983. Landscape Ecology and Land Use. Longman Inc., New York.

Virginia Conservation Network (VCN). 2009. “Agricultural BMPs”. Virginia Department of Conservation and Recreation URL: 
www.vcnva.org/anx/index.cfm/1,258,418,0htm1/Agricultural-Best-Management-PracticesAg-BMPs. Accessed 8-16-09

VT CTMDLWS, 2006. "Opequon Creek Watershed TMDL Implementation Plan”. Virginia Tech Center for TMDL and Watershed Studies. URL: http://www.tmdl.bse.vt.edu/uploads/File/pub db files/Opequon\%20Creek\%20TMDL\%20IP \%2007-12-06.pdf. Accessed on 11-10-09.

Wang Y., Xia H., Fu J., Sheng G. 2004. "Water Quality Change in Reservoirs of Shenzhen, China: Detection using LANDSAT/TM data". Science of the Total Environment 328: 195-206.

Ward, F. A. 2007. "Decision Support for Water Policy: A Review of Economic Concepts and Tools". Water Policy 9(1): 1 - 31.

Ward, R. C. and J. C. Loftis. 1983. "Incorporating the Stochastic Nature of Water Quality into Management". Journal of Water Pollution Control Federation. 55(4): 408 - 414.

Weiss, H.J. 2006. POM-QM v 3 for Windows. Prentice Hall

West Virginia Department of Environmental Planning (WV DEP). 2005. “An Ecological Assessment of the Potomac River Direct Drain Watershed”. Report \# 02027004, Watershed Assessment Section, Charleston, WV, Department of Environmental Protection.

West Virginia Potomac Tributary Strategy Group (WVPTS) 2005. "West Virginia’s Potomac Tributary Strategy". Report submitted to the Chesapeake Bay Program, November 7. URL: http://www.wvnet.org/downloads/posted\%20nov142005\%20WVTS/WV_Potomac_Tributar y_Strategy_FINAL.pdf. 
Williams J., C.S. ReVelle and S.A. Levin. 2004. “Using Mathematical Optimization Models to Design Nature Reserves". Frontiers in Ecology and the Environment 2: 98-105.

Wood, S.C., P.L. Younger, and N.S. Robins. 1999. "Long-term Changes in the Quality of Polluted Minewater Discharges from Abandoned Underground Coal Workings in Scotland". Quarterly Journal of Engineering Geology 32:69-79.

Wool, T.A., R.B. Ambrose, J.L. Martin, and E.A. Comer. 2004. "Water Quality Analysis Simulation Program, WASP version 6.0. Draft: User's Manual”. US EPA, Region IV, Atlanta, GA.

Wossink, G.A.A. and D.L. Osmond. 2002. "Cost Analysis of Mandated Agricultural Best Management Practices to Control Nitrogen Losses in the Neuse River Basin, North Carolina". Journal of Soil and Water Conservation 57 (4), 213-220.

Wu, Y.P. and J. Chen, 2009. "Simulation of Nitrogen and Phosphorus Loads in the Dongjiang River Basin in South China using SWAT”. Frontiers of Earth Science in China. Springer and Higher Education Press.

Wu. J. S. and R. C. Ahlert. 1979. “Applications of a Steady State, One Dimensional Water Quality Model". Journal of the American Water Resources Association 15(3): 660-670.

Wurbs, R.A. 1993. "Reservoir System Simulation and Optimization Models". Journal of Water Resources Planning and Management, American Society of Civil Engineers, 119(4): 455 472.

Yagow, G. 1999. "Procedures for Indexing Monthly NPS Pollution Loads from Agricultural and Urban Fringe Watersheds". Environmental Protection Agency, URL: http://www.epa.gov/owow/watershed/Proceed/yagow.htm 
Young R.A, C.A. Onstead, D.D. Bosch, and W.P. Anderson. 1989. “AGNPS: A Nonpoint Source Pollution Model for Evaluating Agricultural Watersheds". Journal of Soil Water Conservation 44(2): 168-173.

Young, R.A., Onstad, C.A., Bosch, D.D., and Anderson, W.P., 1995. “AGNPS: An Agricultural Nonpoint Source Model”. In Singh V.P. (ed.), Computer Models of Watershed Hydrology: Highlands Ranch, Colorado, Water Resources Publications, pp. 1011-1020.

Younger, P.L.; A. Jayaweera; A. Elliot; R. Wood; P. Amos; A.J. Daugherty; A. Martin; L.I. Bowden; A.C. Aplin; D.B. Johnson.2002. "Passive Treatment of Acidic Mine Waters in Subsurface-flow Systems: Exploring RAPS and Permeable Reactive Barriers". Mine Water Treatment: A Decade of Progress. Newcastle Upon Tyne: HERO, 41-50.

Zhao, R.J., Zhang, Y.L., Fang, L.R., Liu, X.R., Zhang, Q.S. 1980. “The Xinanjiang Model”. Hydrological Forecasting 129: 351-356

Zhao, W.Z. 2004. "The Development and Application of Water Quality Automatic Monitoring in Huanghe River". China Water Resources 7, 27-29. 
APPENDICES 


\section{APPENDIX I: Opequon Creek Watershed Land Use and Subwatershed Characteristics}

\begin{tabular}{|c|c|c|c|c|c|c|c|c|c|}
\hline $\begin{array}{c}\text { Watershed } \\
\text { Name }\end{array}$ & $\begin{array}{r}\text { Area } \\
\text { (Acres) }\end{array}$ & Agric & $\begin{array}{r}\text { Op. } \\
\text { Brush }\end{array}$ & $\begin{array}{r}\% \\
\text { Agric }\end{array}$ & $\begin{array}{l}\text { \% Op. } \\
\text { Brush }\end{array}$ & $\begin{array}{r}\text { Nitrogen } \\
\text { (lbs) }\end{array}$ & $\begin{array}{r}\text { Phosphorous } \\
\text { (lbs) }\end{array}$ & $\begin{array}{l}\text { Nitrogen } \\
\text { Coefficient }\end{array}$ & $\begin{array}{l}\text { Phosphorous } \\
\text { Coefficient }\end{array}$ \\
\hline Abrams Creek & 12153 & 5.1 & 30.0 & 4.2 & 24.7 & 72117.48 & 1988.07 & 0.23 & 0.20 \\
\hline Buzzard & 3166 & 3.2 & 13.1 & 10.1 & 41.3 & 16179.61 & 722.92 & 0.74 & 0.75 \\
\hline Clearbrook & 3643 & 4.7 & 18.3 & 12.9 & 50.2 & 22209.60 & 1096.61 & 0.35 & 0.32 \\
\hline Dry Marsh & 6979 & 3.5 & 40.4 & 5.0 & 57.9 & 35955.85 & 1855.82 & 0.35 & 0.32 \\
\hline Dry Run & 4643 & 6.3 & 16.2 & 13.6 & 34.9 & & - & & \\
\hline Eagle Run & 905 & 0.6 & 1.5 & 6.6 & 16.1 & 4042.35 & 113.59 & 0.91 & 0.90 \\
\hline Evans Run & 4632 & 11.3 & 10.5 & 24.5 & 22.7 & 23396.86 & 1154.21 & 0.81 & 0.82 \\
\hline Goose Creek & 1207 & 0.5 & 4.9 & 3.8 & 40.4 & 5090.80 & 231.82 & 0.64 & 0.63 \\
\hline Hoke Run & 7389 & 7.5 & 30.0 & 10.2 & 40.6 & 39167.07 & 1717.34 & 0.98 & 0.97 \\
\hline Hopewell Run & 7760 & 17.0 & 28.6 & 21.9 & 36.9 & 42220.11 & 2284.36 & 0.72 & 0.73 \\
\hline Lick Run & 6859 & 11.7 & 34.3 & 17.1 & 50.3 & 42638.39 & 2321.19 & 0.33 & 0.30 \\
\hline Middle Creek & 8752 & 19.5 & 25.2 & 22.3 & 28.8 & 46716.60 & 2427.31 & 0.68 & 0.63 \\
\hline Mill Creek & 14020 & 21.6 & 45.7 & 15.4 & 32.6 & 101882.89 & 4848.28 & 0.61 & 0.61 \\
\hline Redbud & 4947 & 2.6 & 18.1 & 5.2 & 36.6 & 23364.63 & 891.54 & 0.25 & 0.22 \\
\hline Shaw Run & 5149 & 9.8 & 16.5 & 13.0 & 32.0 & 26579.83 & 1328.30 & 0.77 & 0.78 \\
\hline Sylvan Run & 4699 & 3.0 & 17.9 & 6.3 & 33.2 & 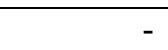 & - & - & \\
\hline Three Run & 2674 & 0.8 & 9.5 & 3.0 & 35.4 & 11335.03 & 437.58 & 0.63 & 0.63 \\
\hline Torytown Run & 2364 & 3.0 & 8.6 & 13.7 & 39.5 & 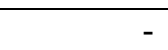 & - & - & - \\
\hline Turkey Run & 10126 & 35.1 & 33.7 & 34.6 & 33.2 & 57541.97 & 3387.56 & 0.50 & 0.50 \\
\hline Tuscarora & 12399 & 13.9 & 30.3 & 11.2 & 24.4 & 84667.45 & 3394.89 & 0.89 & 0.89 \\
\hline $\begin{array}{l}\text { Opequon } \\
\text { Creek }\end{array}$ & 95795 & 111.4 & 403.9 & 11.6 & 42.2 & - & - & - & \\
\hline
\end{tabular}




\section{APPENDIX II: Agricultural BMP Efficiency Recommendations}

$\mathrm{n}$ represents the number of studies

$\mathrm{TN}-$ total nitrogen

TP - total phosphorous

TSS - total suspended solids

As a general rule during the BMP efficiency development process, for all TP efficiencies where specific data is not available on phosphorous the TP load reductions are calculated to be $75 \%$ of the sediment reductions to account for soluble phosphorous losses. In the Chesapeake Bay watershed dissolved reactive phosphorous is assumed to be $25 \%$ and sediment bound phosphorous is $75 \%$ of the total phosphorous load (Sharpley et al, 1993). Thus $75 \%$ of the TSS load reduction is an estimate of the sediment bound phosphorous reductions. Dissolved reactive phosphorous will not be reduced with a sediment reduction.

\section{Conservation Plans:}

These efficiency estimates were reviewed and refined in 2003 with more recent data. As we are not aware of any new studies since 2003, UMD-MAWQ did not recommend a change.

\begin{tabular}{|r|l|l|l|}
\hline BMP & TN & TP & TSS \\
\hline Current efficiency & & & \\
\hline Conventional tillage & $8 \%$ & $5 \%$ & $25 \%$ \\
\hline Conservation tillage & $3 \%$ & $5 \%$ & $8 \%$ \\
\hline Hayland & $3 \%$ & $10 \%$ & $8 \%$ \\
\hline $\begin{array}{l}\text { UMD- Pastureland } \\
\text { rec'd efficiency }\end{array}$ & $5 \%$ & $14 \%$ \\
\hline Conventional tillage & $8 \%$ & $15 \%$ & $25 \%$ \\
\hline Conservation tillage & $3 \%$ & $5 \%$ & $8 \%$ \\
\hline Hayland & $3 \%$ & $5 \%$ & $8 \%$ \\
\hline Pastureland & $5 \%$ & $10 \%$ & $14 \%$ \\
\hline
\end{tabular}




\section{Conservation Tillage:}

Data on the effectiveness of conservation tillage was not found. There is data, however, on the increase in nitrate leaching from conservation tillage. Based on these studies nitrogen efficiencies for surface flow and subsurface flow are derived.

\begin{tabular}{|c|c|c|c|}
\hline BMP & TN & $\mathrm{TP}$ & TSS \\
\hline Current efficiency & $18 \%$ & $30 \%$ & $30 \%$ \\
\hline \multirow[t]{2}{*}{ Developer rec'd efficiency } & $\begin{array}{l}\text { Surface flow } \\
18 \% * ; \text { Subsurface } \\
\text { flow } 0 \% *\end{array}$ & $30 \%$ & $30 \%$ \\
\hline & $8 \%$ & $30 \%$ & $30 \%$ \\
\hline \multirow[t]{2}{*}{$\begin{array}{l}\text { UMD/MAWQP/TSWG/AgNRWG/NSC } \\
\text { rec'd efficiency }\end{array}$} & $8 \%$ & $22 \%$ & $30 \%$ \\
\hline & $8 \%$ & $22 \%$ & $30 \%$ \\
\hline Avg & 0 & 30 & 30 \\
\hline Min & -10 & 20 & 20 \\
\hline Max & 10 & 40 & 40 \\
\hline $\mathrm{n}$ (UMD/MAWQP project review) & 15 & 16 & 16 \\
\hline $\mathrm{n}$ (current efficiency) & $\begin{array}{l}0 \text { (best } \\
\text { professional } \\
\text { judgment) }\end{array}$ & $\begin{array}{l}0 \text { (best } \\
\text { professional } \\
\text { judgment) }\end{array}$ & $\begin{array}{l}0 \text { (best } \\
\text { professional } \\
\text { judgment) }\end{array}$ \\
\hline
\end{tabular}

*The estimated TN efficiencies are based on the ability of the watershed model to separate surface and subsurface flow. If it cannot separate the two flow paths then $8 \%$ reduction efficiency for total nitrogen is assigned to the practice

\section{Forest and Grass Buffer:}

UMD/MAWQP/FWG recommends assigning efficiencies based on geomorphic region, because groundwater flow through buffer systems will have a strong influence on effectiveness and hydrogeomorphic regions help identify different groundwater flow patterns. TN values are capped at $65 \%$ and TP is capped at $45 \%$. The general rule for TP and TSS apply to both grass and forest buffers and TP and TSS for grass and forest buffers stay the same. For grass buffers, $\mathrm{TN}$ reduction efficiencies are relatively $70 \%$ of forest buffer nitrogen efficiencies. 
Forest Buffer:

\begin{tabular}{|l|l|l|l|}
\hline BMP & TN & TP & TSS \\
\hline $\begin{array}{l}\text { n (UMD/MAWQP } \\
\text { project review) }\end{array}$ & $\begin{array}{l}\text { 8 (plus FWG literature } \\
\text { review) }\end{array}$ & $\begin{array}{l}\text { 9 (plus FWG literature } \\
\text { review) }\end{array}$ & $\begin{array}{l}9 \text { (plus FWG literature } \\
\text { review) }\end{array}$ \\
\hline n (current efficiency) & 6 & 6 & 6 \\
\hline
\end{tabular}

\section{Grass Buffer:}

\begin{tabular}{|l|l|l|l|}
\hline BMP & TN & TP & TSS \\
\hline $\begin{array}{l}\text { n (UMD/MAWQP } \\
\text { project review) }\end{array}$ & 4 & 5 & 5 \\
\hline n (current efficiency) & 2 & 2 & 2 \\
\hline
\end{tabular}

\section{Current Riparian Forest Buffer Efficiencies}

\begin{tabular}{|l|r|r|r|}
\hline Current Efficiency: Forest Buffers & \multicolumn{1}{l|}{ TN } & \multicolumn{1}{l|}{ TP } & TSS \\
\hline Coastal Plain Lowlands & 25 & 75 & 75 \\
\hline Coastal Plain Dissected Uplands & 40 & 75 & 75 \\
\hline Coastal Plain Uplands & 83 & 69 & 69 \\
\hline Piedmont Crystalline & 60 & 60 & 60 \\
\hline Blue Ridge & 45 & 50 & 50 \\
\hline Mesozoic Lowlands & 70 & 70 & 70 \\
\hline Piedmont Carbonate & 45 & 50 & 50 \\
\hline Valley and Ridge Carbonate & 45 & 50 & 50 \\
\hline Valley and Ridge Siliciclastic & 55 & 65 & 65 \\
\hline Appalachian Plateau Siliciclastic & 60 & 60 & 60 \\
\hline
\end{tabular}




\section{Current Riparian Grass Buffer Efficiencies}

\begin{tabular}{|l|r|r|r|}
\hline Current Efficiency: Grass Buffers & TN & TP & TSS \\
\hline Coastal Plain Lowlands & 17 & 75 & 75 \\
\hline Coastal Plain Dissected Uplands & 27 & 75 & 75 \\
\hline Coastal Plain Uplands & 57 & 69 & 69 \\
\hline Piedmont Crystalline & 41 & 60 & 60 \\
\hline Blue Ridge & 31 & 50 & 50 \\
\hline Mesozoic Lowlands & 48 & 70 & 70 \\
\hline Piedmont Carbonate & 31 & 50 & 50 \\
\hline Valley and Ridge Carbonate & 31 & 50 & 50 \\
\hline Valley and Ridge Siliciclastic & 37 & 65 & 65 \\
\hline Appalachian Plateau Siliciclastic & 41 & 60 & 60 \\
\hline
\end{tabular}

Source: Chesapeake Bay Program Tributary Strategy Workgroup Meeting August 6, 2007 


\section{APPENDIX III: Opequon Watershed Land Use Classification}

The land use classes used in this study are based on the EPA Multi-Resolution Land

Characteristics Consortium (MRLC) classes. They include:

- Urban (low intensity developed, high intensity developed, residential)

- Open/Brush (hay, pasture grass, mixed pasture, other grasses)

- Agriculture (row crops)

- Woodland (conifer forest, mixed forest, deciduous forest)

- Barren (quarry areas, barren transitional areas)

- Wetland (emergent and woody wetlands)

- Water - open water bodies

Urban - Areas that appeared to have a high level of impermeable soils, parking lots, urban centers, suburban areas to some degree, interstates.

Open/Brush - Areas that appear to be dominated by open grasslands, lawns, pasture, hayfields, and parks.

Agriculture- areas that appear to be under row crop operations. Additionally I included areas that appear to be either plantation pine or Tobacco. The main determining factor was "lines" or striation in the field.

Forest/Woodland- Areas that are forested including "Shrubby" areas and areas that appear to have been cut without signs of development

Barren Land- Areas that are bare exposed soil. Wetland - those areas that are inundated or saturated by surface or groundwater.

Open Water- Large bodies of water, might be classified as a river or lake 


\section{APPENDIX IV - Data Required for WCMS}

The following is a list of the WCMS datasets required for operation of the WCMS

functions. Although WCMS comes with a default dataset, one has to generate the GIS data for specific case study area. It should noted however, that many of the calculations in WCMS are specifically calibrated for grids with a cell size of $20 \mathrm{~m}$.

Datasets required for operation of WCMS functions

\begin{tabular}{|c|c|c|c|}
\hline Dataset Name & Default dataset name & Description & Use in WCMS \\
\hline $\begin{array}{l}\text { Raster stream } \\
\text { network }\end{array}$ & Opqn_Watergrid & $\begin{array}{l}\text { Gridded stream network, } \\
\text { based on hydrologically } \\
\text { corrected NHD stream dataset, } \\
1: 24,000 \text { scale ( } 20 \mathrm{~m} \text { cell size). }\end{array}$ & $\begin{array}{l}\text { All water quality } \\
\text { functions. }\end{array}$ \\
\hline $\begin{array}{l}\text { Flow direction } \\
\text { grid }\end{array}$ & Opqn_Newfdr & $\begin{array}{l}\text { Flow direction grid (direction } \\
\text { of downhill flow from cell) } \\
\text { based on NED elevation data. } \\
\text { Resampled to } 20 \text { m cell size. }\end{array}$ & $\begin{array}{l}\text { All water quality } \\
\text { functions. }\end{array}$ \\
\hline $\begin{array}{l}\text { Flow } \\
\text { accumulation } \\
\text { grid }\end{array}$ & Opqn_Newfac & $\begin{array}{l}\text { Flow accumulation grid } \\
\text { (number of cells flowing to } \\
\text { cell) based on NED elevation } \\
\text { data. Resampled to } 20 \mathrm{~m} \text { cell } \\
\text { size. }\end{array}$ & $\begin{array}{l}\text { All water quality } \\
\text { functions. }\end{array}$ \\
\hline Runoff grid & Opqn_Runoff & $\begin{array}{l}\text { Estimated using relationship } \\
\text { between precipitation and } \\
\text { observed stream flow at USGS } \\
\text { gauges. }\end{array}$ & \\
\hline
\end{tabular}




\section{APPENDIX V: Results from Cost Minimization Modeling}

\section{Scenario I - Uniform Reduction Cost Minimization Model Results}

\section{Chesapeake Bay Wide Averages}

Abrams Creek

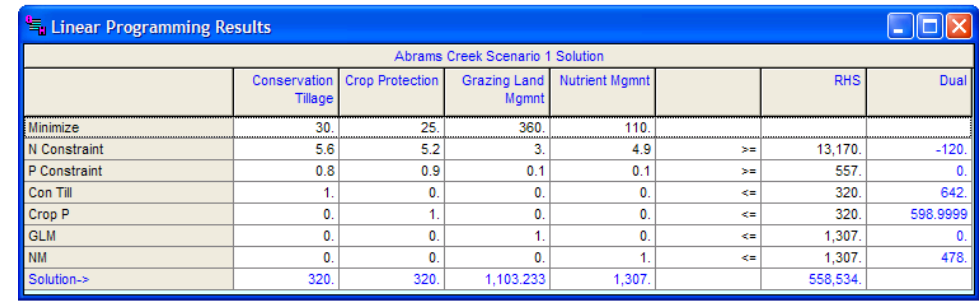

Clearbrooke

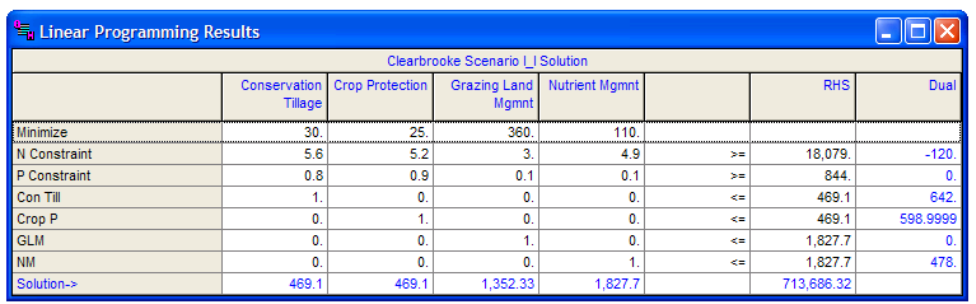

Evans Run

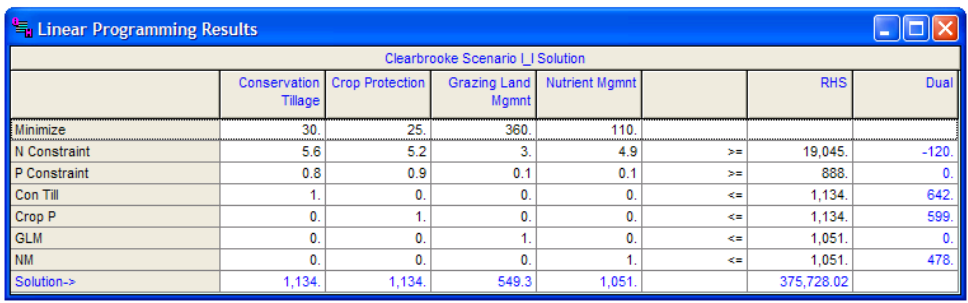

Hopewell

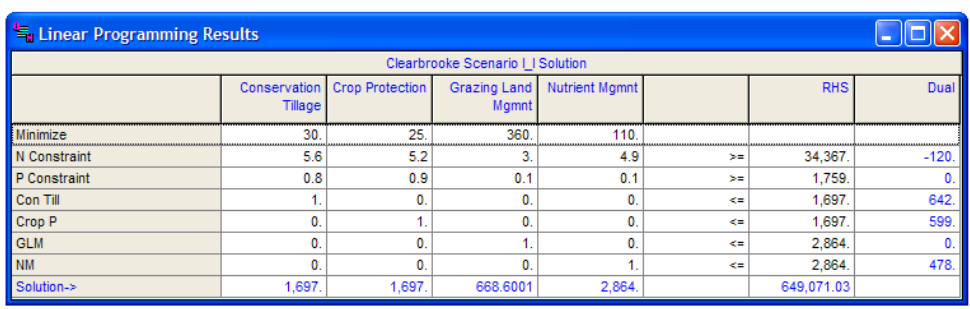




\section{Lick Run}

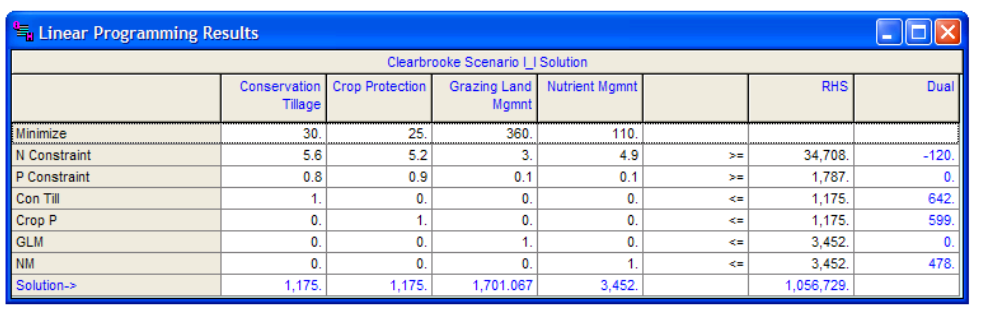

\section{Middle Creek}

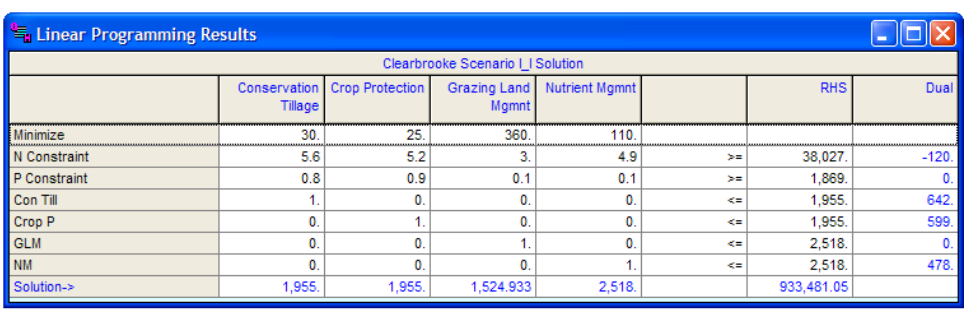

Shaw Run

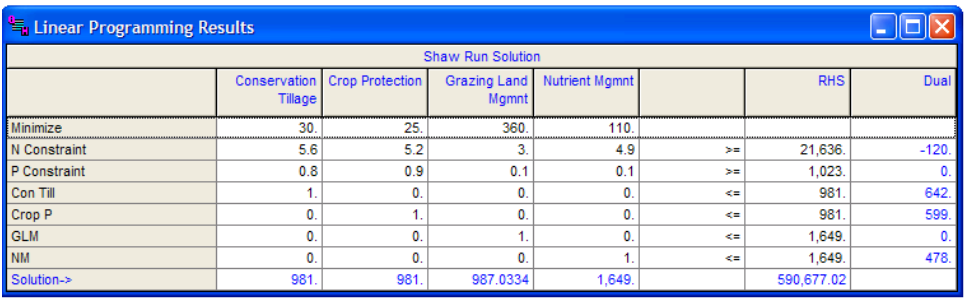

\section{Turkey}

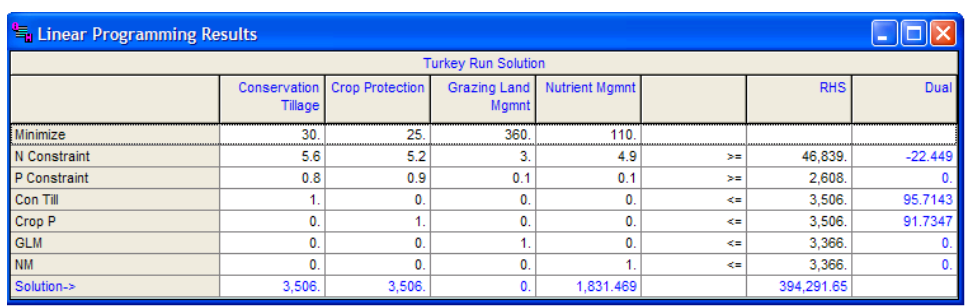




\section{Chesapeake Bay Wide Averages with N Constraint Only}

Dry Marsh

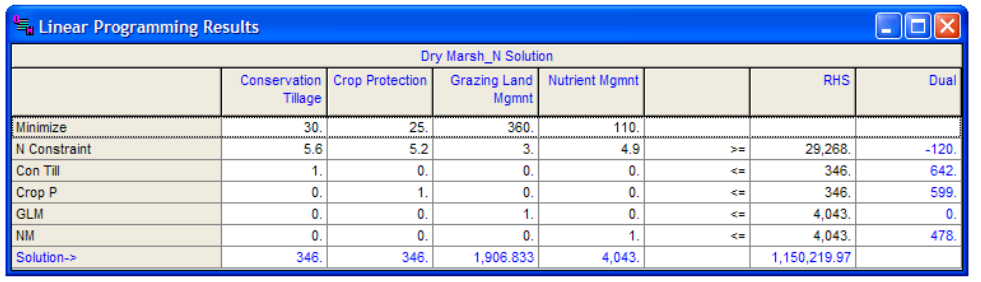

Goose Creek

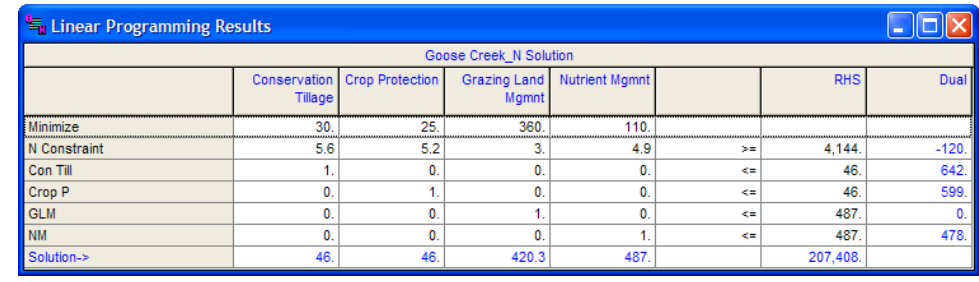

\section{Chesapeake Bay Wide Averages with P Constraint Only}

Eagle Run

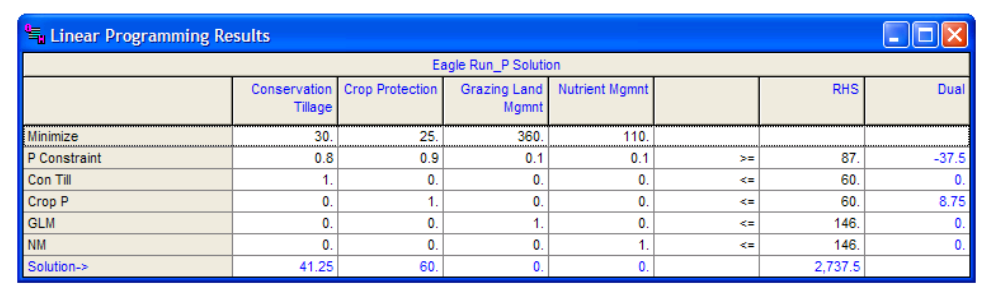

Hoke Run

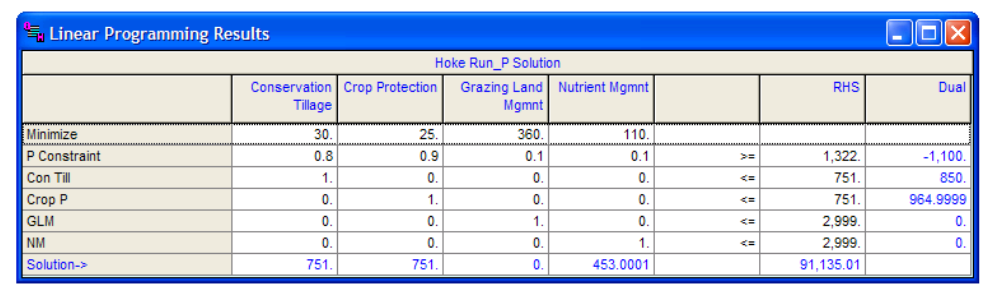

Mill Creek

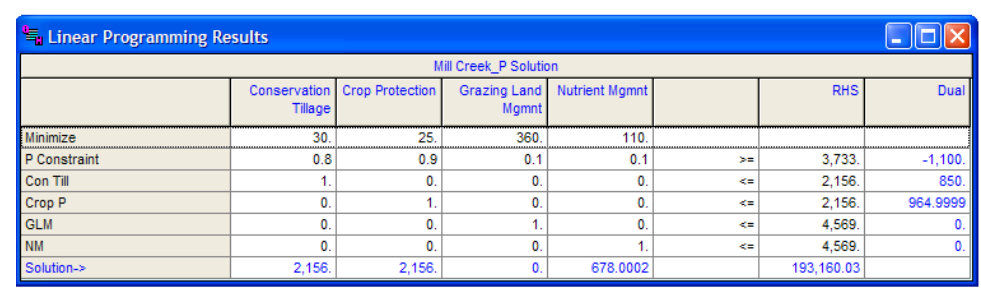


Redbud

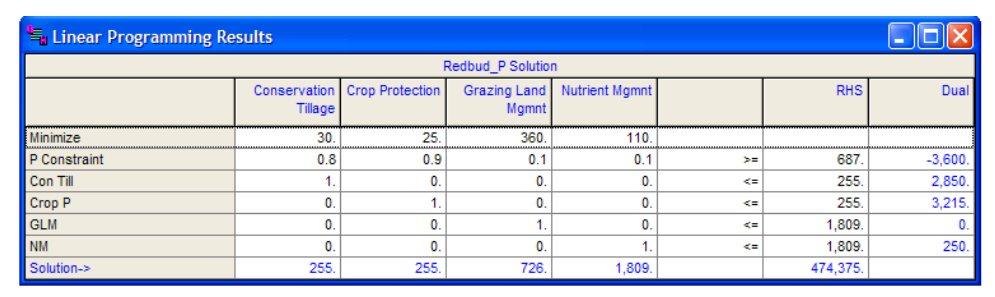

Three Run

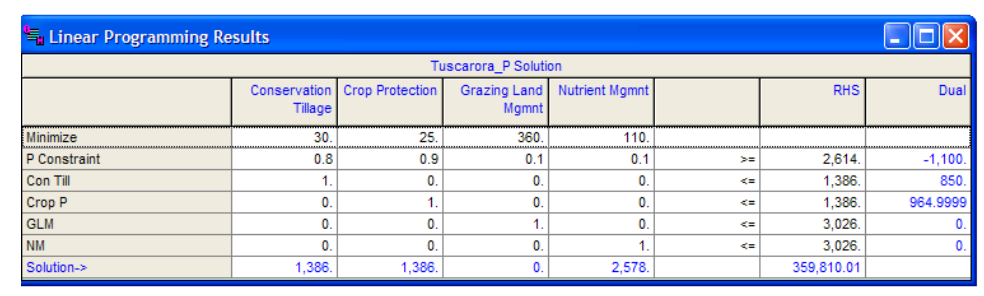

\section{SCENARIO I: SPECIFIC LAND USE CONTRIBUTIONS}

\section{Buzzard}

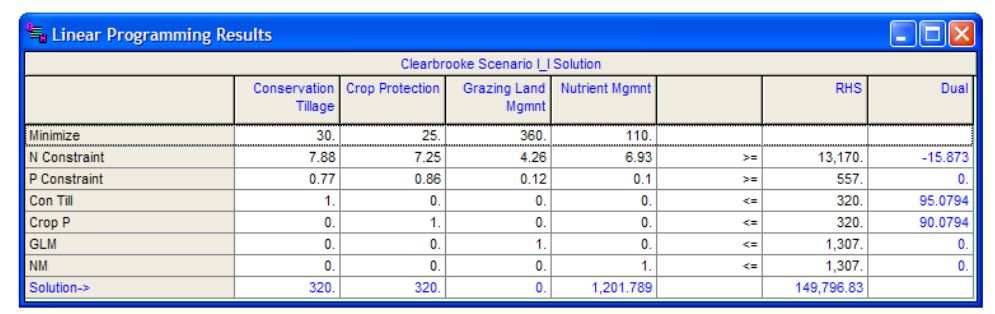

Clearbrooke

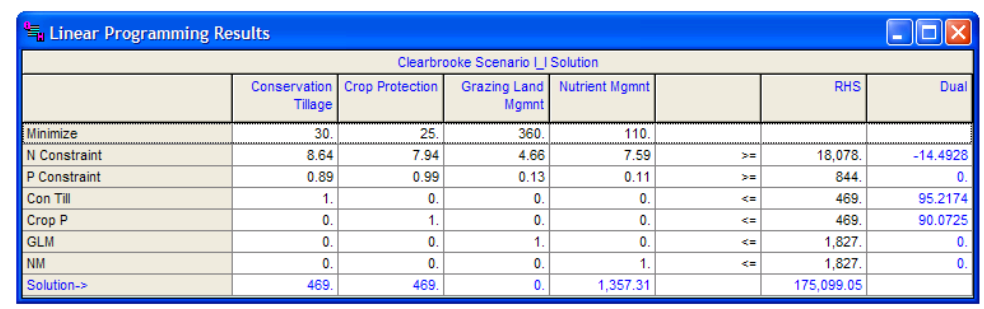

Dry Marsh

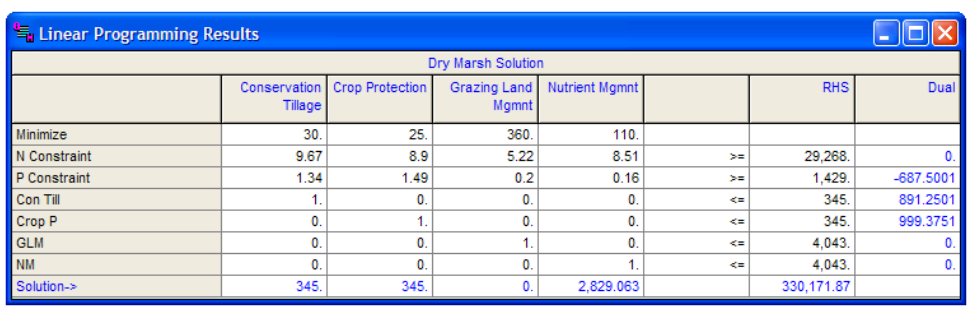




\section{Evans Run}

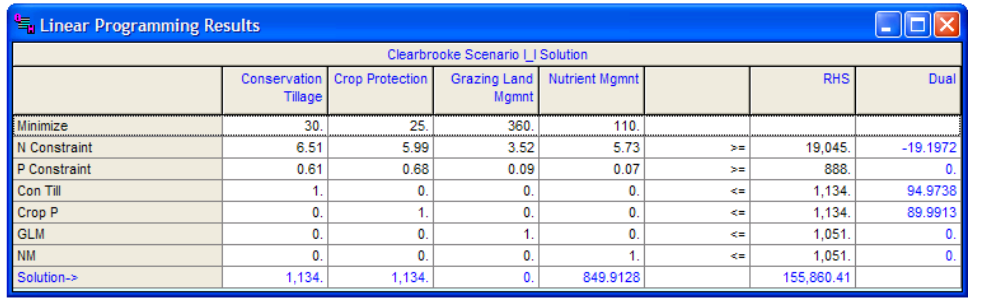

Hoke Run

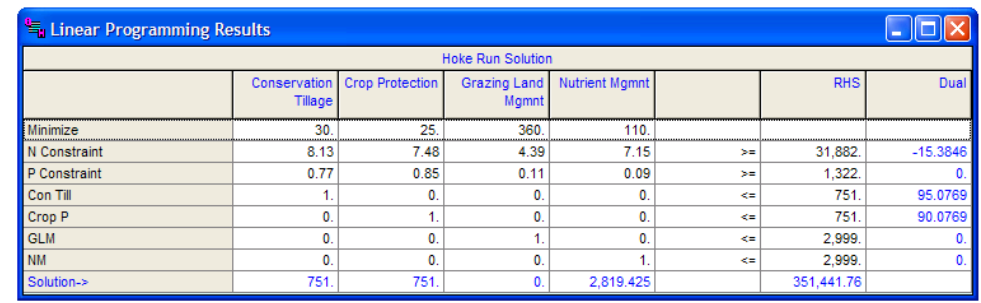

\section{Hopewell}

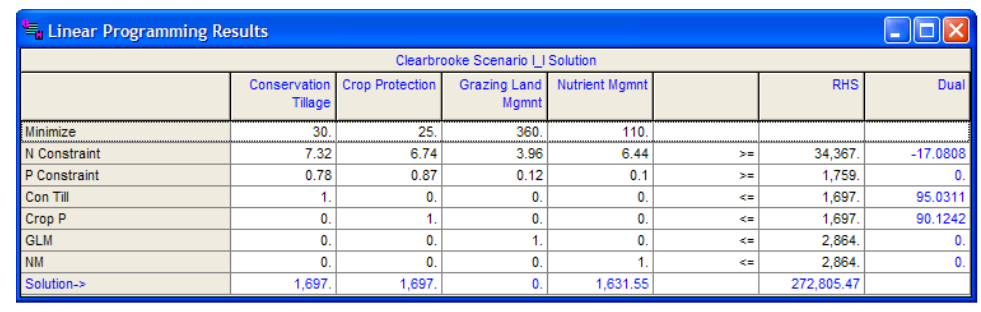

\section{Lick Run}

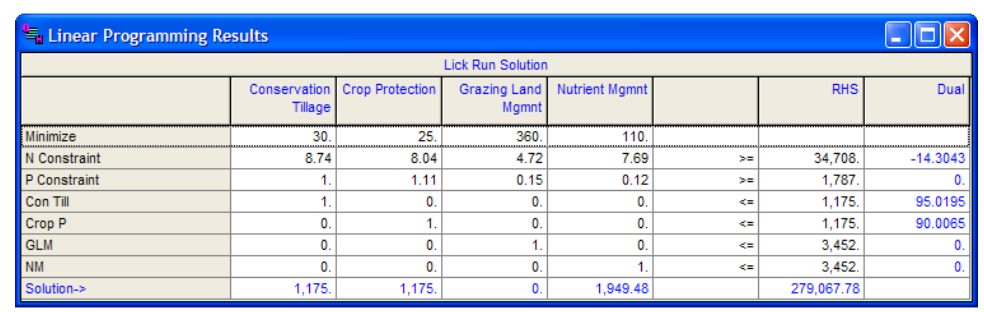

\section{Middle Creek}

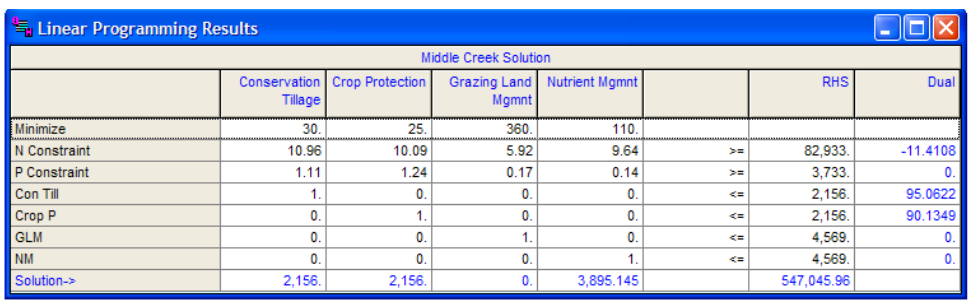




\section{Mill Creek}

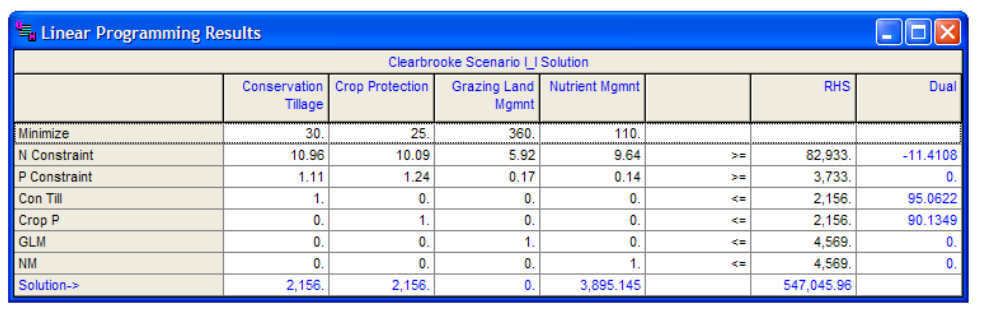

Redbud

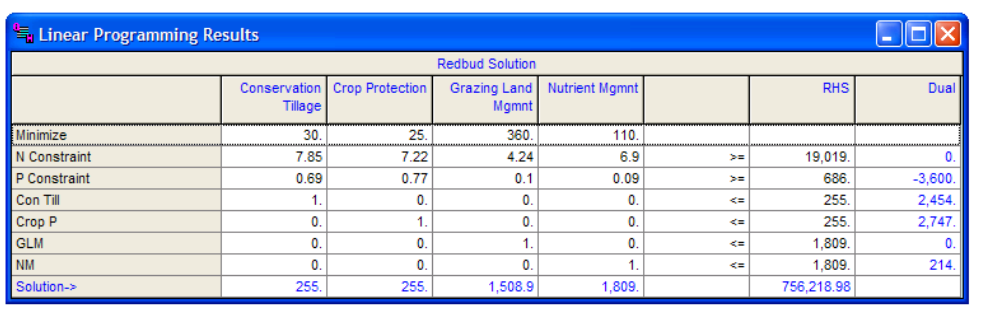

Shaw

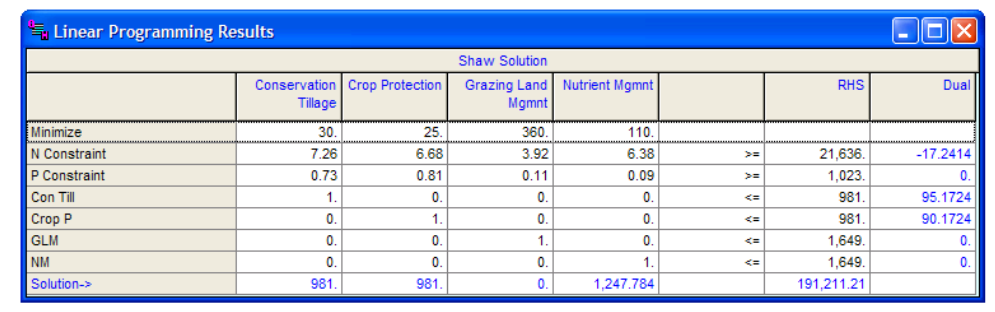

\section{Three Run}

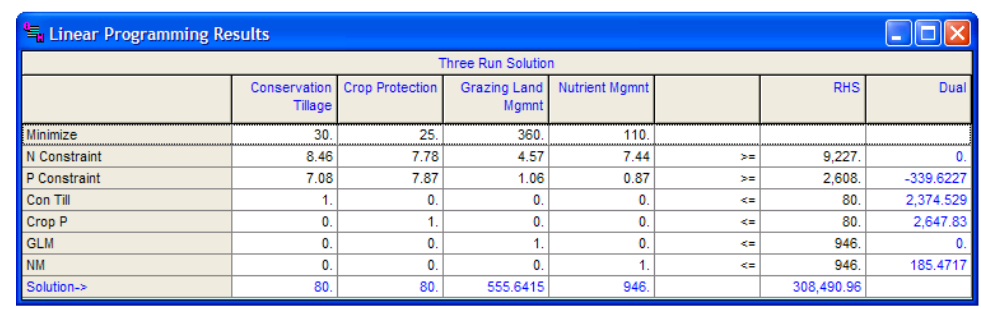

\section{Turkey Run}

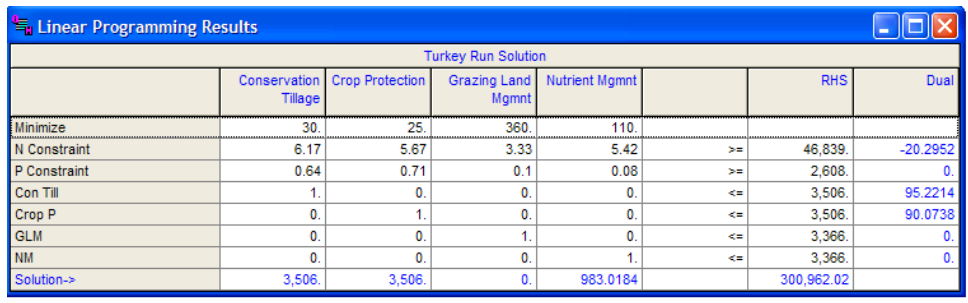


Tuscarora

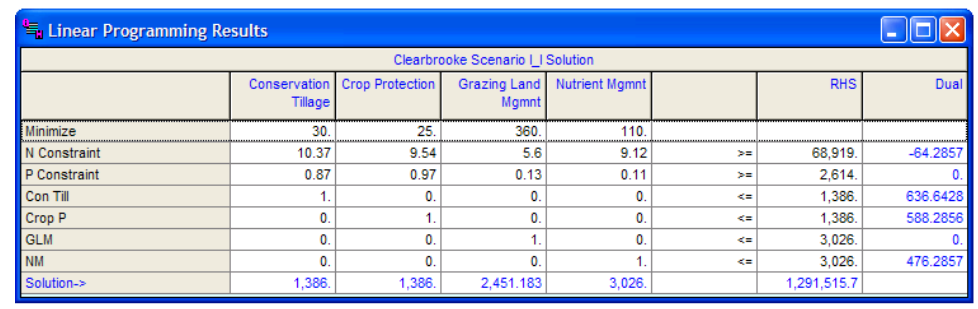

Specific Land Use Contributions with P Constraint Only

Goose Creek

\begin{tabular}{|c|c|c|c|c|c|c|c|}
\hline \multicolumn{7}{|c|}{ Linear Programming Results } & \multirow[t]{2}{*}{$\sqrt{\square x}$} \\
\hline & & Clearb & Doke Scenario —I & Solution & & & \\
\hline & $\begin{aligned} \begin{array}{c}\text { Conservation } \\
\text { Thlage }\end{array} & \end{aligned}$ & Crop Protection & $\begin{array}{c}\text { Grazing Land } \\
\text { Mgmnt }\end{array}$ & \begin{tabular}{|l|} 
Nutrient Mgmnt \\
\end{tabular} & & RHS & Dua \\
\hline Minimize & 30. & 25 & 360. & 110. & & & \\
\hline$P$ Constraint & 1.22 & 1.35 & 0.18 & 0.15 & $y=$ & 179. & $-2,000$ \\
\hline Con Till & 1. & 0 & 0 & 0. & $\Leftrightarrow$ & 60. & 2,410 \\
\hline Crop $\mathrm{P}$ & 0. & 1 & 0. & 0. & $\Leftrightarrow$ & 60. & 2,675 \\
\hline GLM & 0. & 0 & & 0. & $\Leftrightarrow$ & 146. & \\
\hline & 0. & 0 & 0. & 1. & $\Leftrightarrow$ & 146. & 190 \\
\hline Solution $\rightarrow x$ & 60. & 60 & 16.11111 & 146 . & & $25,159.99$ & \\
\hline
\end{tabular}




\section{Scenario II - Holistic Model Cost Minimization Results}

\begin{tabular}{|c|c|c|c|c|c|c|}
\hline & $\begin{array}{r}\text { Cons } \\
\text { Tillage }\end{array}$ & $\begin{array}{r}\text { Crop } \\
\text { Protection }\end{array}$ & $\begin{array}{c}\text { Grazing Land } \\
\text { Management }\end{array}$ & $\begin{array}{r}\text { Nutrient } \\
\text { Management }\end{array}$ & USED & RHS \\
\hline BMP Costs & 30 & 25 & 360 & 110 & $\$ 19,281,628.5$ & \\
\hline & & & & $\mathbf{N}$ & 428331.9 & 944022.0 \\
\hline & & & & $\mathbf{P}$ & 24012.6 & 42147.1 \\
\hline Decis var_Abrams & 508.7 & 508.7 & 2996.3 & 2996.3 & & \\
\hline Abrams N & 2.03 & 1.87 & 1.10 & 1.79 & 10618.7 & 58703.6 \\
\hline Abrams P & 0.10 & 0.11 & 0.01 & 0.01 & 189.9 & 1530.8 \\
\hline ACT_Const & 1 & & & & 508.7 & 508.7 \\
\hline ACP_Const & & 1 & & & 508.7 & 508.7 \\
\hline AGLM_Const & & & 1 & & 2996.3 & 2996.3 \\
\hline ANM_Cons & & & & 1 & 2996.3 & 2996.3 \\
\hline Decis var_DMarsh & 345.9 & 345.9 & 4043.4 & 4043.4 & & \\
\hline DMarsh N & 2.80 & 2.58 & 1.52 & 2.47 & 17963.0 & 29268.1 \\
\hline DMarsh P & 0.33 & 0.37 & 0.05 & 0.04 & 612.3 & 1429.0 \\
\hline DCT_Const & 1 & & & & 345.9 & 345.9 \\
\hline DCP_Const & & 1 & & & 345.9 & 345.9 \\
\hline DGLM_Const & & & 1 & & 4043.4 & 4043.4 \\
\hline DNM_Cons & & & & 1 & 4043.4 & 4043.4 \\
\hline Decis var_Redbud & 255.2 & 255.2 & 1809.1 & 1809.1 & & \\
\hline Rdbud N & 1.96 & 1.80 & 1.06 & 1.72 & 5998.0 & 19018.8 \\
\hline Rdbud P & 0.15 & 0.17 & 0.02 & 0.02 & 157.2 & 686.5 \\
\hline RCT_Const & 1 & & & & 255.2 & 255.2 \\
\hline RCP_Const & & 1 & & & 255.2 & 255.2 \\
\hline RGLM_Const & & & 1 & & 1809.1 & 1809.1 \\
\hline RNM_Cons & & & & 1 & 1809.1 & 1809.1 \\
\hline Decis var_LickR & 1174.6 & 1174.6 & 3451.8 & 3451.8 & & \\
\hline LickR N & 2.89 & 2.65 & 1.56 & 2.54 & 20648.6 & 34707.7 \\
\hline LickR P & 0.30 & 0.33 & 0.04 & 0.04 & 1021.7 & 1787.3 \\
\hline LCT_Const & 1 & & & & 1174.6 & 1174.6 \\
\hline LCP_Const & & 1 & & & 1174.6 & 1174.6 \\
\hline LGLM_Const & & & 1 & & 3451.8 & 3451.8 \\
\hline LNM_Cons & & & & 1 & 3451.8 & 3451.8 \\
\hline Decis var_Clearbrook & 469.1 & 469.1 & 1827.7 & 1827.7 & & \\
\hline Clbrk N & 3.02 & 2.78 & 1.63 & 2.66 & 10563.9 & 18078.6 \\
\hline Clbrk P & 0.29 & 0.32 & 0.04 & 0.04 & 424.9 & 844.4 \\
\hline CCT_Const & 1 & & & & 469.1 & 469.1 \\
\hline CCP_Const & & 1 & & & 469.1 & 469.1 \\
\hline CGLM_Const & & & 1 & & 1827.7 & 1827.7 \\
\hline
\end{tabular}




\begin{tabular}{|c|c|c|c|c|c|c|c|}
\hline & CNM_Cons & & & & 1 & 1827.7 & 1827.7 \\
\hline \multicolumn{2}{|c|}{ Decis var_Turkey } & 3506.3 & 3506.3 & 3366.4 & 3366.4 & & \\
\hline & Turkey N & 3.08 & 2.84 & 1.67 & 2.71 & 35498.6 & 46839.2 \\
\hline & Turkey P & 0.32 & 0.36 & 0.05 & 0.04 & 2672.8 & 2608.4 \\
\hline & ACT_Const & 1 & & & & 3506.3 & 3506.3 \\
\hline & ACP_Const & & 1 & & & 3506.3 & 3506.3 \\
\hline & AGLM_Const & & & 1 & & 3366.4 & 3366.4 \\
\hline & ANM_Cons & & & & 1 & 3366.4 & 3366.4 \\
\hline \multicolumn{2}{|c|}{ Decis var_Mill } & 2155.5 & 2155.5 & 4568.8 & 4568.8 & & \\
\hline & Mill N & 6.69 & 6.15 & 3.61 & 5.88 & 71064.0 & 82932.7 \\
\hline & Mill P & 0.68 & 0.75 & 0.10 & 0.08 & 3930.6 & 3733.2 \\
\hline & DCT_Const & 1 & & & & 2155.5 & 2155.5 \\
\hline & DCP_Const & & 1 & & & 2155.5 & 2155.5 \\
\hline & DGLM_Const & & & 1 & & 4568.8 & 4568.8 \\
\hline & DNM_Cons & & & & 1 & 4568.8 & 4568.8 \\
\hline \multicolumn{2}{|c|}{ Decis var_Three } & 80.2 & 80.2 & 945.9 & 945.9 & & \\
\hline & Three N & 5.33 & 4.90 & 2.88 & 4.68 & 7973.4 & 9226.7 \\
\hline & Three P & 4.46 & 4.96 & 0.67 & 0.55 & 1903.0 & 337.6 \\
\hline & RCT_Const & 1 & & & & 80.2 & 80.2 \\
\hline & RCP_Const & & 1 & & & 80.2 & 80.2 \\
\hline & RGLM_Const & & & 1 & & 945.9 & 945.9 \\
\hline & RNM_Cons & & & & 1 & 945.9 & 945.9 \\
\hline \multicolumn{2}{|c|}{ Decis var_Goose } & 46.5 & 46.5 & 487.2 & 487.2 & & \\
\hline & Goose N & 5.79 & 5.32 & 3.13 & 5.09 & 4519.2 & 4143.9 \\
\hline & Goose P & 0.77 & 0.85 & 0.11 & 0.09 & 177.1 & 178.5 \\
\hline & LCT_Const & 1 & & & & 46.5 & 46.5 \\
\hline & LCP_Const & & 1 & & & 46.5 & 46.5 \\
\hline & LGLM_Const & & & 1 & & 487.2 & 487.2 \\
\hline & LNM_Cons & & & & 1 & 487.2 & 487.2 \\
\hline \multicolumn{2}{|c|}{ Decis var_Middle } & 1954.8 & 1954.8 & 2517.7 & 2517.7 & & \\
\hline & Middle N & 4.88 & 4.49 & 2.64 & 4.30 & 35789.1 & 38027.3 \\
\hline & Middle P & 0.47 & 0.52 & 0.07 & 0.06 & 2255.3 & 1869.0 \\
\hline & CCT_Const & 1 & & & & 1954.8 & 1954.8 \\
\hline & CCP_Const & & 1 & & & 1954.8 & 1954.8 \\
\hline & CGLM_Const & & & 1 & & 2517.7 & 2517.7 \\
\hline & CNM_Cons & & & & 1 & 2517.7 & 2517.7 \\
\hline \multicolumn{2}{|c|}{ Decis var_Hopewell } & 1696.9 & 1696.9 & 2863.5 & 2863.5 & & \\
\hline & Hopewell N & 5.27 & 4.85 & 2.85 & 4.64 & 38613.9 & 34367.2 \\
\hline & Hopewell P & 0.57 & 0.64 & 0.09 & 0.07 & 2496.9 & 1759.0 \\
\hline & RCT_Const & 1 & & & & 1696.9 & 1696.9 \\
\hline & RCP_Const & & 1 & & & 1696.9 & 1696.9 \\
\hline
\end{tabular}




\begin{tabular}{|c|c|c|c|c|c|c|c|}
\hline & RGLM_Const & & & 1 & & 2863.5 & 2863.5 \\
\hline & RNM_Cons & & & & 1 & 2863.5 & 2863.5 \\
\hline \multicolumn{2}{|c|}{ Decis var_Buzzard } & 320.2 & 320.2 & 1307.2 & 1307.2 & & \\
\hline & Buzzard N & 5.83 & 5.37 & 3.15 & 5.13 & 14408.8 & 13170.2 \\
\hline & Buzzard P & 0.58 & 0.64 & 0.09 & 0.07 & 598.4 & 556.6 \\
\hline & LCT_Const & 1 & & & & 320.2 & 320.2 \\
\hline & LCP_Const & & 1 & & & 320.2 & 320.2 \\
\hline & LGLM_Const & & & 1 & & 1307.2 & 1307.2 \\
\hline & LNM_Cons & & & & 1 & 1307.2 & 1307.2 \\
\hline \multicolumn{2}{|c|}{ Decis var_Shaw } & 980.7 & 980.7 & 1648.7 & 1648.7 & & \\
\hline & Shaw N & 5.59 & 5.14 & 3.02 & 4.91 & 23603.0 & 21636.0 \\
\hline & Shaw P & 0.57 & 0.63 & 0.09 & 0.07 & 1439.0 & 1022.8 \\
\hline & CCT_Const & 1 & & & & 980.7 & 980.7 \\
\hline & CCP_Const & & 1 & & & 980.7 & 980.7 \\
\hline & CGLM_Const & & & 1 & & 1648.7 & 1648.7 \\
\hline & CNM_Cons & & & & 1 & 1648.7 & 1648.7 \\
\hline \multicolumn{2}{|c|}{ Decis var_Evans } & 1134 & 1134 & 1051.6 & 1051.6 & & \\
\hline & Evans N & 5.27 & 4.85 & 2.85 & 4.64 & 19356.0 & 19045.0 \\
\hline & Evans P & 0.50 & 0.56 & 0.07 & 0.06 & 1341.9 & 888.8 \\
\hline & RCT_Const & 1 & & & & 1134.0 & 1134.0 \\
\hline & RCP_Const & & 1 & & & 1134.0 & 1134.0 \\
\hline & RGLM_Const & & & 1 & & 1051.6 & 1051.6 \\
\hline & RNM_Cons & & & & 1 & 1051.6 & 1051.6 \\
\hline \multicolumn{2}{|c|}{ Decis var_Tuscarora } & 1385.7 & 1385.7 & 3025.6 & 3025.6 & & \\
\hline & Tuscarora $\mathrm{N}$ & 9.23 & 8.49 & 4.99 & 8.12 & 64222.5 & 68919.3 \\
\hline & Tuscarora P & 0.78 & 0.86 & 0.12 & 0.10 & 2917.0 & 2613.8 \\
\hline & LCT_Const & 1 & & & & 1385.7 & 1385.7 \\
\hline & LCP_Const & & 1 & & & 1385.7 & 1385.7 \\
\hline & LGLM_Const & & & 1 & & 3025.6 & 3025.6 \\
\hline & LNM_Cons & & & & 1 & 3025.6 & 3025.6 \\
\hline \multicolumn{2}{|c|}{ Decis var_Eagle } & 59.9 & 59.9 & 145.6 & 145.6 & & \\
\hline & Eagle $\mathrm{N}$ & 6.52 & 6.00 & 3.52 & 5.73 & 2097.1 & 3290.5 \\
\hline & Eagle $\mathrm{P}$ & 0.39 & 0.43 & 0.06 & 0.05 & 64.9 & 87.5 \\
\hline & CCT_Const & 1 & & & & 59.9 & 59.9 \\
\hline & CCP_Const & & 1 & & & 59.9 & 59.9 \\
\hline & CGLM_Const & & & 1 & & 145.6 & 145.6 \\
\hline & CNM_Cons & & & & 1 & 145.6 & 145.6 \\
\hline \multicolumn{2}{|c|}{ Decis var_Hoke } & 751.3 & 751.3 & 2999.3 & 2999.3 & & \\
\hline & Hoke N & 7.96 & 7.33 & 4.30 & 7.00 & 45394.1 & 31882.0 \\
\hline & Hoke P & 0.75 & 0.84 & 0.11 & 0.09 & 1809.7 & 1322.3 \\
\hline & CCT_Const & 1 & & & & 751.3 & 751.3 \\
\hline
\end{tabular}




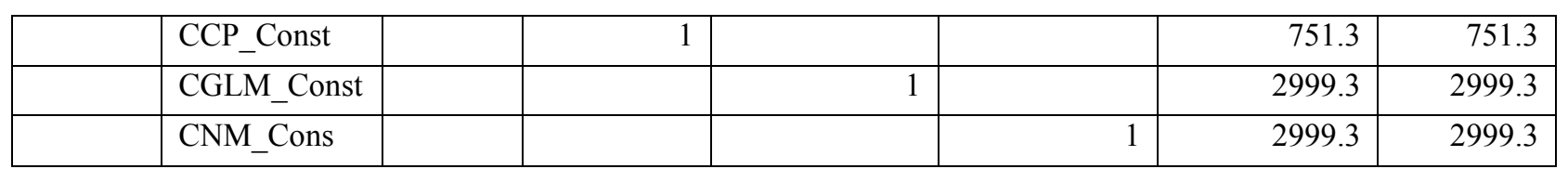




\section{Scenario II - Holistic Model with Constraint Only}

\begin{tabular}{|c|c|c|c|c|c|c|c|}
\hline & & $\begin{array}{r}\text { Cons } \\
\text { Tillage }\end{array}$ & $\begin{array}{r}\text { Crop } \\
\text { Prt } \\
\end{array}$ & $\begin{array}{r}\text { Graz } \\
\text { LM } \\
\end{array}$ & Nut Mgt & USED & RHS \\
\hline & & & & & & $\$ 07004720$ & \\
\hline & BMP Costs & 30 & 25 & 360 & 110 & $\$ 9,709,472.9$ & \\
\hline & & & & & & 11845.4 & 42147.1 \\
\hline \multicolumn{2}{|c|}{ Decis var_Abrams } & 261.3 & 262.1 & 1499.2 & 1499.0 & & \\
\hline & Abrams P & 0.10 & 0.11 & 0.01 & 0.01 & 96.6 & 1530.8 \\
\hline & ACT_Const & 1 & & & & 261.3 & 508.7 \\
\hline & \multicolumn{2}{|l|}{ ACP_Const } & 1 & & & 262.1 & 508.7 \\
\hline & \multicolumn{2}{|l|}{ AGLM_Const } & & 1 & & 1499.2 & 2996.3 \\
\hline & \multicolumn{2}{|l|}{ ANM_Cons } & & & 1 & 1499.0 & 2996.3 \\
\hline \multicolumn{2}{|c|}{ Decis var_Dmarsh } & 196.2 & 198.8 & 2025.2 & 2024.6 & & \\
\hline & DMarsh P & 0.33 & 0.37 & 0.05 & 0.04 & 323.8 & 1429.0 \\
\hline & DCT_Const & 1 & & & & 196.2 & 345.9 \\
\hline & \multicolumn{2}{|l|}{ DCP_Const } & 1 & & & 198.8 & 345.9 \\
\hline & \multicolumn{2}{|l|}{ DGLM_Const } & & 1 & & 2025.2 & 4043.4 \\
\hline & \multicolumn{2}{|l|}{ DNM_Cons } & & & 1 & 2024.6 & 4043.4 \\
\hline \multicolumn{2}{|c|}{ Decis var_Redbud } & 138.2 & 139.4 & 906.1 & 905.9 & & \\
\hline & Rdbud P & 0.15 & 0.17 & 0.02 & 0.02 & 82.3 & 686.5 \\
\hline & RCT_Const & 1 & & & & 138.2 & 255.2 \\
\hline & \multicolumn{2}{|l|}{ RCP_Const } & 1 & & & 139.4 & 255.2 \\
\hline & \multicolumn{2}{|l|}{ RGLM_Const } & & 1 & & 906.1 & 1809.1 \\
\hline & \multicolumn{2}{|l|}{ RNM_Cons } & & & 1 & 905.9 & 1809.1 \\
\hline \multicolumn{2}{|c|}{ Decis var_LickR } & 608.1 & 610.4 & 1729.0 & 1728.4 & & \\
\hline & LickR P & 0.30 & 0.33 & 0.04 & 0.04 & 524.9 & 1787.3 \\
\hline & LCT_Const & 1 & & & & 608.1 & 1174.6 \\
\hline & \multicolumn{2}{|l|}{ LCP_Const } & 1 & & & 610.4 & 1174.6 \\
\hline & \multicolumn{2}{|l|}{ LGLM_Const } & & 1 & & 1729.0 & 3451.8 \\
\hline & \multicolumn{2}{|l|}{ LNM_Cons } & & & 1 & 1728.4 & 3451.8 \\
\hline \multicolumn{2}{|c|}{ Decis var_Clearbrook } & 254.4 & 256.6 & 916.8 & 916.3 & & \\
\hline & Clbrk P & 0.29 & 0.32 & 0.04 & 0.04 & 225.4 & 844.4 \\
\hline & CCT_Const & 1 & & & & 254.4 & 469.1 \\
\hline & \multicolumn{2}{|l|}{ CCP_Const } & 1 & & & 256.6 & 469.1 \\
\hline & \multicolumn{2}{|l|}{ CGLM_Const } & & 1 & & 916.8 & 1827.7 \\
\hline & \multicolumn{2}{|l|}{ CNM_Cons } & & & 1 & 916.3 & 1827.7 \\
\hline \multicolumn{2}{|c|}{ Decis var_Turkey } & 1775.5 & 1777.9 & 1686.5 & 1685.9 & & \\
\hline & Turkey P & 0.32 & 0.36 & 0.05 & 0.04 & 1352.7 & 2608.4 \\
\hline & ACT_Const & 1 & & & & 1775.5 & 3506.3 \\
\hline & \multicolumn{2}{|l|}{ ACP_Const } & 1 & & & 1777.9 & 3506.3 \\
\hline
\end{tabular}




\begin{tabular}{|c|c|c|c|c|c|c|c|}
\hline & \multicolumn{2}{|l|}{ AGLM_Const } & & 1 & & 1686.5 & 3366.4 \\
\hline & \multicolumn{2}{|l|}{ ANM_Cons } & & & 1 & 1685.9 & 3366.4 \\
\hline \multicolumn{2}{|c|}{ Decis var_Mill } & 1124.9 & 1130.1 & 2291.4 & 2290.2 & & \\
\hline & Mill P & 0.68 & 0.75 & 0.10 & 0.08 & 2038.0 & 3733.2 \\
\hline & DCT_Const & 1 & & & & 1124.9 & 2155.5 \\
\hline & \multicolumn{2}{|l|}{ DCP_Const } & 1 & & & 1130.1 & 2155.5 \\
\hline & \multicolumn{2}{|l|}{ DGLM_Const } & & 1 & & 2291.4 & 4568.8 \\
\hline & \multicolumn{2}{|l|}{ DNM_Cons } & & & 1 & 2290.2 & 4568.8 \\
\hline \multicolumn{2}{|c|}{ Decis var_Three } & 80.2 & 80.2 & 478.9 & 477.9 & & \\
\hline & Three P & 0.58 & 0.64 & 0.09 & 0.07 & 172.9 & 337.6 \\
\hline & RCT_Const & 1 & & & & 80.2 & 80.2 \\
\hline & \multicolumn{2}{|l|}{ RCP_Const } & 1 & & & 80.2 & 80.2 \\
\hline & \multicolumn{2}{|l|}{ RGLM_Const } & & 1 & & 478.9 & 945.9 \\
\hline & \multicolumn{2}{|l|}{ RNM_Cons } & & & 1 & 477.9 & 945.9 \\
\hline \multicolumn{2}{|c|}{ Decis var_Goose } & 46.5 & 46.5 & 251.5 & 250.1 & & \\
\hline & Goose P & 0.77 & 0.85 & 0.11 & 0.09 & 127.7 & 178.5 \\
\hline & LCT_Const & 1 & & & & 46.5 & 46.5 \\
\hline & \multicolumn{2}{|l|}{ LCP_Const } & 1 & & & 46.5 & 46.5 \\
\hline & \multicolumn{2}{|l|}{ LGLM_Const } & & 1 & & 251.5 & 487.2 \\
\hline & \multicolumn{2}{|l|}{ LNM_Cons } & & & 1 & 250.1 & 487.2 \\
\hline \multicolumn{2}{|c|}{ Decis var_Middle } & 1009.9 & 1013.6 & 1263.7 & 1262.8 & & \\
\hline & Middle P & 0.47 & 0.52 & 0.07 & 0.06 & 1162.3 & 1869.0 \\
\hline & CCT_Const & 1 & & & & 1009.9 & 1954.8 \\
\hline & \multicolumn{2}{|l|}{ CCP_Const } & 1 & & & 1013.6 & 1954.8 \\
\hline & \multicolumn{2}{|l|}{ CGLM_Const } & & 1 & & 1263.7 & 2517.7 \\
\hline & \multicolumn{2}{|l|}{ CNM_Cons } & & & 1 & 1262.8 & 2517.7 \\
\hline \multicolumn{2}{|c|}{ Decis var_Hopewell } & 888.2 & 892.6 & 1437.7 & 1436.6 & & \\
\hline & Hopewell P & 0.57 & 0.64 & 0.09 & 0.07 & 1300.1 & 1759.0 \\
\hline & RCT_Const & 1 & & & & 888.2 & 1696.9 \\
\hline & \multicolumn{2}{|l|}{ RCP_Const } & 1 & & & 892.6 & 1696.9 \\
\hline & \multicolumn{2}{|l|}{ RGLM_Const } & & 1 & & 1437.7 & 2863.5 \\
\hline & \multicolumn{2}{|l|}{ RNM_Cons } & & & 1 & 1436.6 & 2863.5 \\
\hline \multicolumn{2}{|c|}{ Decis var_Buzzard } & 200.4 & 204.9 & 659.6 & 658.5 & & \\
\hline & Buzzard P & 0.58 & 0.64 & 0.09 & 0.07 & 352.3 & 556.6 \\
\hline & LCT_Const & 1 & & & & 200.4 & 320.2 \\
\hline & \multicolumn{2}{|l|}{ LCP_Const } & 1 & & & 204.9 & 320.2 \\
\hline & \multicolumn{2}{|l|}{ LGLM_Const } & & 1 & & 659.6 & 1307.2 \\
\hline & LNM_Cons & & & & 1 & 658.5 & 1307.2 \\
\hline Decis var & Shaw & 530.0 & 534.4 & 830.3 & 829.2 & & \\
\hline & Shaw P & 0.57 & 0.63 & 0.09 & 0.07 & 771.0 & 1022.8 \\
\hline & CCT_Const & 1 & & & & 530.0 & 980.7 \\
\hline
\end{tabular}




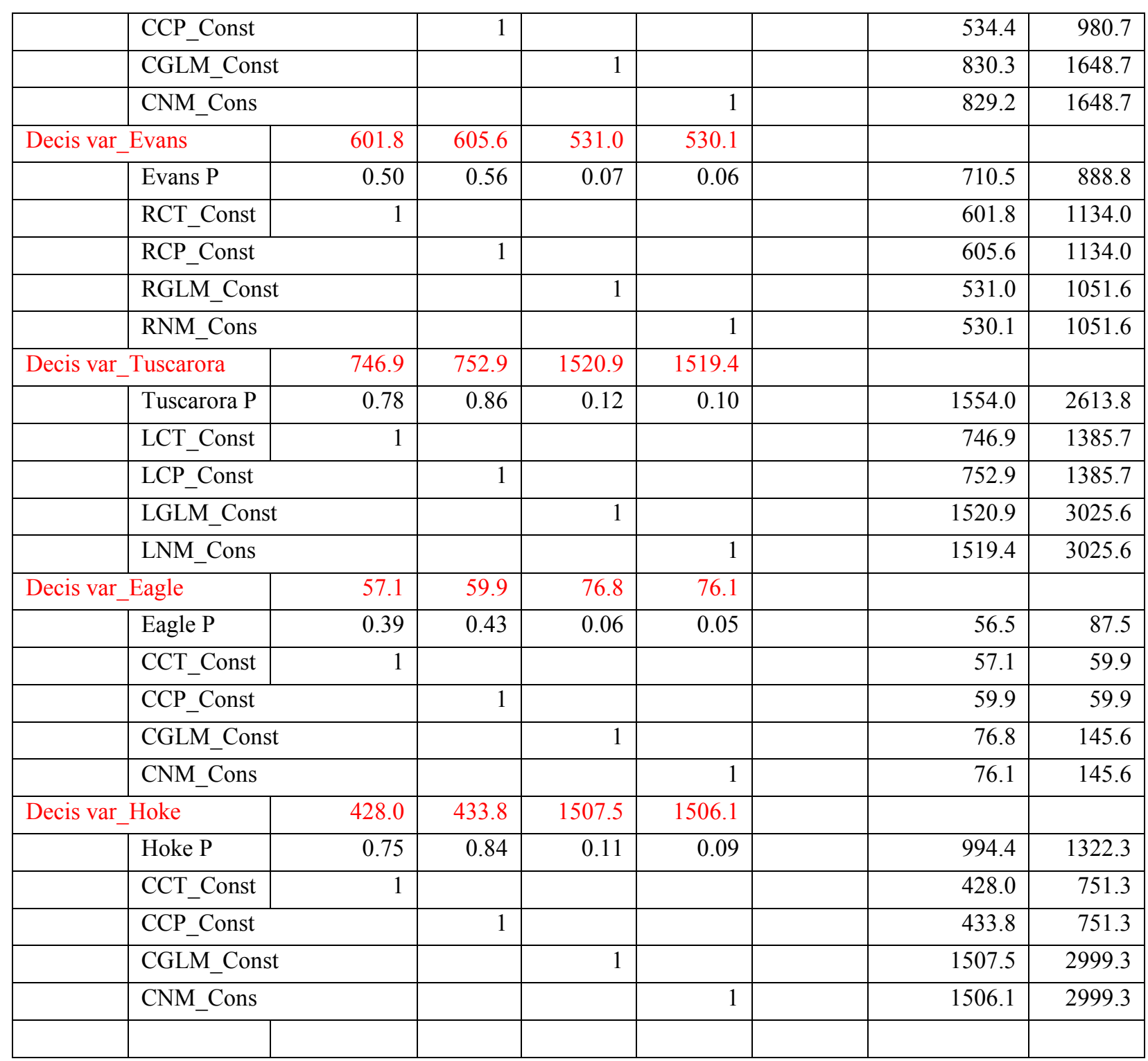




\section{Scenario IV - Targeted Approach: VA Cost Minimization Model Results}

\begin{tabular}{|c|c|c|c|c|c|c|}
\hline & Cons Tillage & Crop Prt & Graz LM & Nut Mgt & USED & RHS \\
\hline Costs of Reduction & 30 & 25 & 360 & 110 & $\$ 6,791,743.5$ & \\
\hline & & & & & 144,599 & 210,983 \\
\hline & & & & & 5,513 & 8,726 \\
\hline Decis var_Abrams & 508.7 & 508.7 & 2996.3 & 2996.3 & & \\
\hline Abrams N & 4.50 & 4.14 & 2.43 & 3.96 & 23545.9 & 74569.5 \\
\hline Abrams P & 0.23 & 0.26 & 0.03 & 0.03 & 436.9 & 2668.0 \\
\hline ACT_Const & 1 & & & & 508.7 & 508.7 \\
\hline ACP_Const & & 1 & & & 508.7 & 508.7 \\
\hline AGLM_Const & & & 1 & & 2996.3 & 2996.3 \\
\hline ANM_Cons & & & & 1 & 2996.3 & 2996.3 \\
\hline Decis var_Dmarsh & 345.9 & 345.9 & 4043.4 & 4043.4 & & \\
\hline DMarsh N & 6.09 & 5.61 & 3.29 & 5.36 & 39023.1 & 37178.4 \\
\hline DMarsh P & 0.78 & 0.86 & 0.12 & 0.10 & 1420.5 & 1592.3 \\
\hline DCT_Const & 1 & & & & 345.9 & 345.9 \\
\hline DCP_Const & & 1 & & & 345.9 & 345.9 \\
\hline DGLM_Const & & & 1 & & 4043.4 & 4043.4 \\
\hline DNM_Cons & & & & 1 & 4043.4 & 4043.4 \\
\hline Decis var_Redbud & 255.2 & 255.2 & 1809.1 & 1809.1 & & \\
\hline Rdbud N & 4.39 & 4.04 & 2.37 & 3.86 & 13435.6 & 24159.0 \\
\hline Rdbud P & 0.35 & 0.39 & 0.05 & 0.04 & 357.3 & 764.9 \\
\hline RCT_Const & 1 & & & & 255.2 & 255.2 \\
\hline RCP_Const & & 1 & & & 255.2 & 255.2 \\
\hline RGLM_Const & & & 1 & & 1809.1 & 1809.1 \\
\hline RNM_Cons & & & & 1 & 1809.1 & 1809.1 \\
\hline Decis var_Lick & 1174.6 & 1174.6 & 3451.8 & 3451.8 & & \\
\hline LickR N & 6.30 & 5.79 & 3.40 & 5.54 & 45051.6 & 44088.1 \\
\hline LickR P & 0.68 & 0.75 & 0.10 & 0.08 & 2315.9 & 1991.6 \\
\hline LCT_Const & 1 & & & & 1174.6 & 1174.6 \\
\hline LCP_Const & & 1 & & & 1174.6 & 1174.6 \\
\hline LGLM_Const & & & 1 & & 3451.8 & 3451.8 \\
\hline LNM_Cons & & & & 1 & 3451.8 & 3451.8 \\
\hline Decis var Clbrk & 469.1 & 469.1 & 1827.7 & 1827.7 & & \\
\hline Clbrk N & 6.74 & 6.20 & 3.64 & 5.92 & 23542.3 & 22964.7 \\
\hline Clbrk P & 0.66 & 0.73 & 0.10 & 0.08 & 982.7 & 940.9 \\
\hline CCT_Const & 1 & & & & 469.1 & 469.1 \\
\hline CCP_Const & & 1 & & & 469.1 & 469.1 \\
\hline CGLM_Const & & & 1 & & 1827.7 & 1827.7 \\
\hline CNM_Cons & & & & 1 & 1827.7 & 1827.7 \\
\hline
\end{tabular}




\section{Scenario IV - Targeted Approach: WV Cost Minimization Model Results}

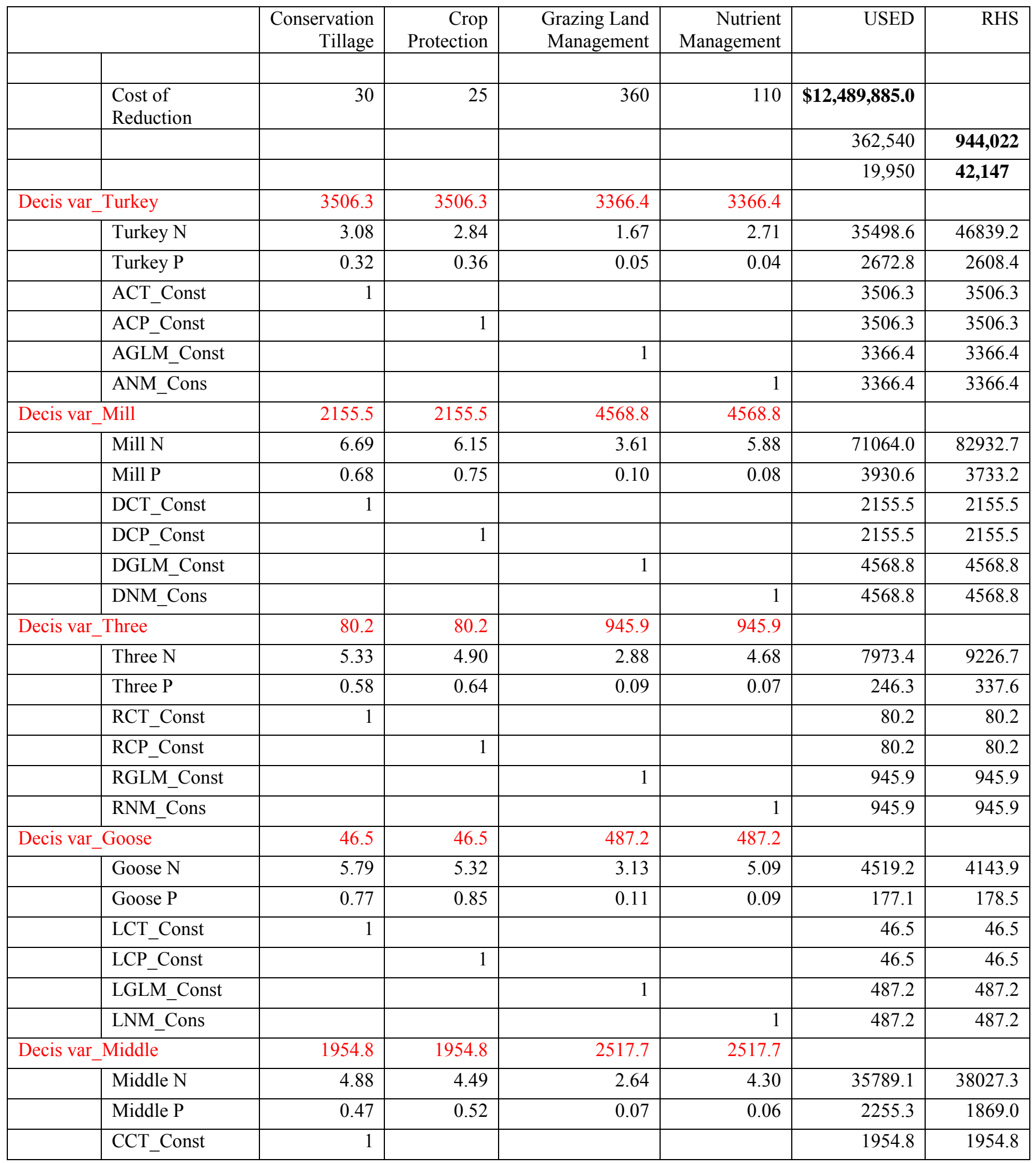




\begin{tabular}{|c|c|c|c|c|c|c|c|}
\hline & CCP_Const & & 1 & & & 1954.8 & 1954.8 \\
\hline & CGLM_Const & & & 1 & & 2517.7 & 2517.7 \\
\hline & CNM_Cons & & & & 1 & 2517.7 & 2517.7 \\
\hline \multicolumn{2}{|c|}{ Decis var_Hopewell } & 1696.9 & 1696.9 & 2863.5 & 2863.5 & & \\
\hline & Hopewell N & 5.27 & 4.85 & 2.85 & 4.64 & 38613.9 & 34367.2 \\
\hline & Hopewell P & 0.57 & 0.64 & 0.09 & 0.07 & 2496.9 & 1759.0 \\
\hline & RCT_Const & 1 & & & & 1696.9 & 1696.9 \\
\hline & RCP_Const & & 1 & & & 1696.9 & 1696.9 \\
\hline & RGLM_Const & & & 1 & & 2863.5 & 2863.5 \\
\hline & RNM_Cons & & & & 1 & 2863.5 & 2863.5 \\
\hline \multicolumn{2}{|c|}{ Decis var_Buzzard } & 320.2 & 320.2 & 1307.2 & 1307.2 & & \\
\hline & Buzzard N & 5.83 & 5.37 & 3.15 & 5.13 & 14408.8 & 13170.2 \\
\hline & Buzzard P & 0.58 & 0.64 & 0.09 & 0.07 & 598.4 & 556.6 \\
\hline & LCT_Const & 1 & & & & 320.2 & 320.2 \\
\hline & LCP_Const & & 1 & & & 320.2 & 320.2 \\
\hline & LGLM_Const & & & 1 & & 1307.2 & 1307.2 \\
\hline & LNM_Cons & & & & 1 & 1307.2 & 1307.2 \\
\hline \multicolumn{2}{|c|}{ Decis var_Shaw } & 980.7 & 980.7 & 1648.7 & 1648.7 & & \\
\hline & Shaw N & 5.59 & 5.14 & 3.02 & 4.91 & 23603.0 & 21636.0 \\
\hline & Shaw P & 0.57 & 0.63 & 0.09 & 0.07 & 1439.0 & 1022.8 \\
\hline & CCT_Const & 1 & & & & 980.7 & 980.7 \\
\hline & CCP_Const & & 1 & & & 980.7 & 980.7 \\
\hline & CGLM_Const & & & 1 & & 1648.7 & 1648.7 \\
\hline & CNM_Cons & & & & 1 & 1648.7 & 1648.7 \\
\hline \multicolumn{2}{|c|}{ Decis var_Evans } & 1134 & 1134 & 1051.6 & 1051.6 & & \\
\hline & Evans $\mathrm{N}$ & 5.27 & 4.85 & 2.85 & 4.64 & 19356.0 & 19045.0 \\
\hline & Evans P & 0.50 & 0.56 & 0.07 & 0.06 & 1341.9 & 888.8 \\
\hline & RCT_Const & 1 & & & & 1134.0 & 1134.0 \\
\hline & RCP_Const & & 1 & & & 1134.0 & 1134.0 \\
\hline & RGLM_Const & & & 1 & & 1051.6 & 1051.6 \\
\hline & RNM_Cons & & & & 1 & 1051.6 & 1051.6 \\
\hline \multicolumn{2}{|c|}{ Decis var_Tuscarora } & 1385.7 & 1385.7 & 3025.6 & 3025.6 & & \\
\hline & Tuscarora $\mathrm{N}$ & 9.23 & 8.49 & 4.99 & 8.12 & 64222.5 & 68919.3 \\
\hline & Tuscarora P & 0.78 & 0.86 & 0.12 & 0.10 & 2917.0 & 2613.8 \\
\hline & LCT_Const & 1 & & & & 1385.7 & 1385.7 \\
\hline & LCP_Const & & 1 & & & 1385.7 & 1385.7 \\
\hline & LGLM_Const & & & 1 & & 3025.6 & 3025.6 \\
\hline & LNM_Cons & & & & 1 & 3025.6 & 3025.6 \\
\hline \multicolumn{2}{|c|}{ Decis var_Eagle } & 59.9 & 59.9 & 145.6 & 145.6 & & \\
\hline & Eagle N & 6.52 & 6.00 & 3.52 & 5.73 & 2097.1 & 3290.5 \\
\hline & Eagle P & 0.39 & 0.43 & 0.06 & 0.05 & 64.9 & 87.5 \\
\hline
\end{tabular}




\begin{tabular}{|c|c|c|c|c|c|c|c|}
\hline & CCT_Const & 1 & & & & 59.9 & 59.9 \\
\hline & CCP_Const & & 1 & & & 59.9 & 59.9 \\
\hline & CGLM Const & & & 1 & & 145.6 & 145.6 \\
\hline & CNM_Cons & & & & 1 & 145.6 & 145.6 \\
\hline \multicolumn{2}{|c|}{ Decis var_Hoke } & 751.3 & 751.3 & 2999.3 & 2999.3 & & \\
\hline & Hoke $\mathrm{N}$ & 7.96 & 7.33 & 4.30 & 7.00 & 45394.1 & 31882.0 \\
\hline & Hoke P & 0.75 & 0.84 & 0.11 & 0.09 & 1809.7 & 1322.3 \\
\hline & CCT_Const & 1 & & & & 751.3 & 751.3 \\
\hline & CCP_Const & & 1 & & & 751.3 & 751.3 \\
\hline & CGLM Const & & & 1 & & 2999.3 & 2999.3 \\
\hline & CNM_Cons & & & & 1 & 2999.3 & 2999.3 \\
\hline
\end{tabular}

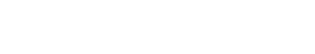

